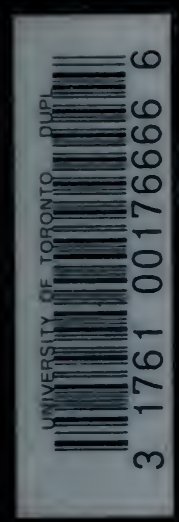




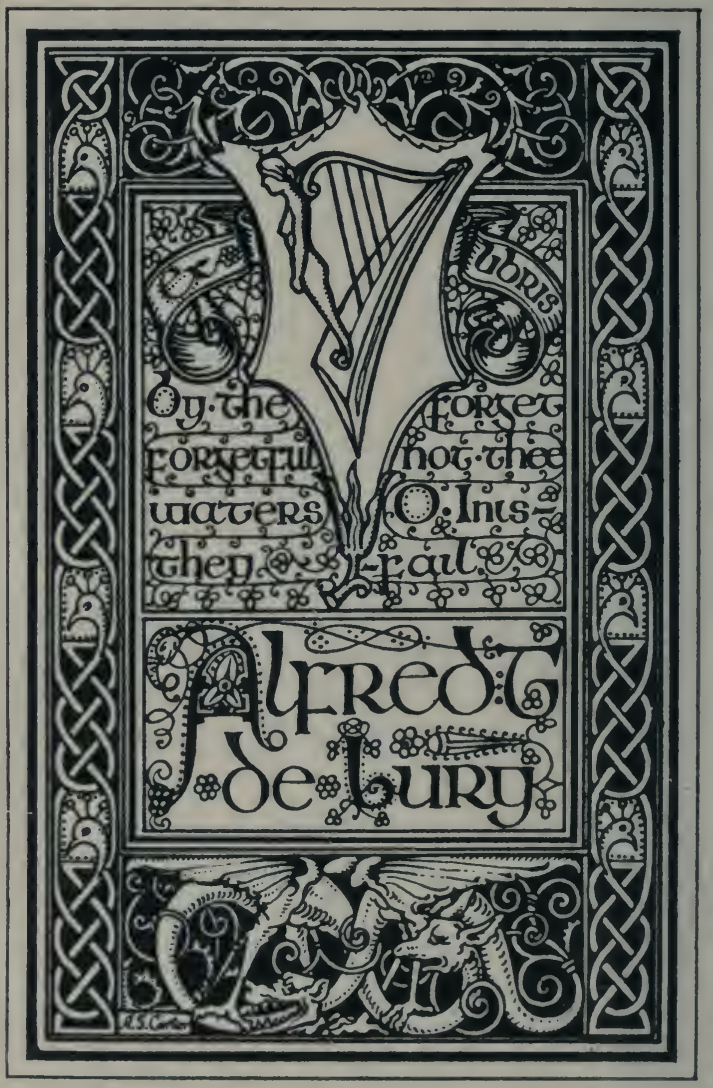


(1)

$1-1$ 
$+3=$ 

LES FEMMES

\section{DANS LA SCIENCE}


DU M ÊME A UTEUH

A LA MÊME LIBRAIRIE

\section{MATHÉMATIQUES ET MATHÉMATICLENS}

PE.SÉES ET CURIOSITÉS

$2^{\mathrm{C}}$ ÉDITION

Un vol. in-8 de $\$ 66$ pages. 


\title{
LES FEMMES
}

\section{DANS LA SCIENCE}

\section{NOTES RECUEILLIES}

PAlK

\author{
A. REBIERE
}

\section{DEUXIEME EDITION}

\section{TRÈS AUGMENTÉE}

ET ORXÉE DE PORTRATS ET D'AUTOGRAPHES

Si l'on roulait rassembler tout ce qui pourrait faire connaitre les femmes qui ont touché aux sciences... on en ferait une histoire assez longue et qui ne serait pas peu interessante.

GougeT.

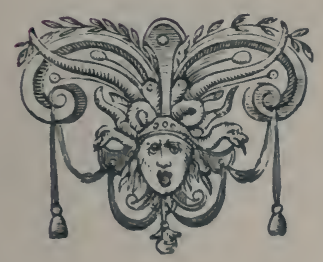

P A R IS

L I BRA IRIE NONY \& Cie

17. RUE DES ÉCOLES, 17 


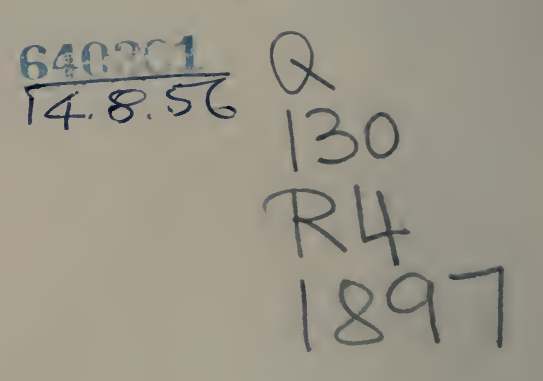


A MA PETITE FILLE

\section{MARGUERITE GOURSAT}

Tu n'as pas encore quatre ans, mon enfant, et tu commences à peine à lire. Je désire que tu ne saches jamais autant de mathématiques que ton papa Édouard 



\section{AVANT-PROPOS}

C'est en 1728 que Gouget a écrit les lignes que nous avons prises pour épigraphe. Depuis la mort de l'érudit chanoine, les seiences proprement dites, mathématiques, phỵsique, histoire naturelle et philosophie, ont beaucoup progressé. Lapport des femmes rà pas été une quantité négligeable:

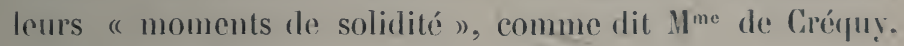
ont étó assez nombreux et pourtant persomme lia encore réalisé le vou de Gouget.

Depuis plus de quinze siècles, nous honorons Hypatic, cette greeque d'Alexandrie, si belle et si savante, lapidée par une populace stupide. Les travaux d'astronomic et de mécanique de la marquise dı Châtelet défendent sa mémoire. Marie Agnesi, après avoir enseigné le calcul infinitésimal à l'Italie, est morte comme une sainte. A l'oceasion d'un problème posé par Napoléon, Sophie Germain a créé, une des premières, la physique mathématique. Mary somerville a composé, après Laplace, une mécanique céleste. Une russe. IYme Kowalevski, couromuée par notre Académie des Sciences, a été enlevée, il y a queløues années, en pleine floraison de son génic.

Nous avons réuni, pour la première fois, ces belles et 
nobles figures. Nous avons tracé, de ces femmes hors pair et de quelques autres, des notices à grands traits, sans détails techniques. Le groupe d'élite a été encarlré dlaus un tableau assez complet des autres savantes: l'armée en marche avec son état-major.

Nous avons surtout étudié les savantes professionnelles, qui ont consacré aux études scientitiques la plus grande partie de leur vie, mathématiciennes, plụsiciennes, naturalistes et philosophes. Puis sont venues les simples curieuses qui, à l'occasion, ont dit leur mot sur les sciences; les collaboratrices qui ont aidé les savants, actirement et discrètement; les professeurs, les vulgarisatrices, modestes et utiles; enfin les protectrices, princesses ou riches bourgeoises, qui ont fondé des prix dans les académies ou répandu leurs bienfaits sous d'autres formes. Les unes et les autres, par des noyens divers. ont exercé unc heureuse influence sur le progrès des sciences.

Ces femmes savantes, (jui ne craignent pas Molière, auraient pu être classées chronologiquement, par genre d'étude. par nationalité, ou d'après leur rỏle. Nous nous sommes lonrué à un rangement alphabétique, mais il sera facile de grouper les noms autrement. Notre longue liste est pen homogime. elle présente de la sécheresse et elle dégénère ça et là en statistique. Nous avons surtout voulu réunir des faits nombreux, exacts et probauts.

Pour égayer um peu notre dictionnaire, nous l'avons orné de quelques autographes et de deux douzaines de portraits, curieux et peu comnus. Fontenelle a dit qưil faut avoir raison avec quelque agrément.

Deux notes, provenant d'une collahoration variće et yuil sera intéressant de parcourir, terminent le livre. Dans la premìre, nous avous rémi des opinions varićes sur celte question : Si la femme est capable de science. La seconde note est forméc de Menus propos sur les femmes ef les sciences, apergus divers, cilations, ancedotes. pensées, elc.

Nous avons fait, lo 2' février 189'1, an Cercle Saint-Simon, 
une conférence sur Les femmes dans la science. Cette conférence, imprimée en une brochure de 87 pp., a été patiemment développée depuis et sa seconde édition est devenue le livre actuel qui semblera peut-être trop long. Nous conseillons aux gens pressés de se borner aux notices principales, atux images et aux notes amusantes de la fin.

Il nous est doux de remercier ici les Revues et les personnes qui nous ont aidé dans notre travail, en particulier l'Intermédiaire des mathématiciens, la Bibliotheca mathematica (Notes bibliographiques de MII. Valentin et Eneström) et Ciel et Terre (Note de M. Lagrange sur les femmes astronomes).

En terminant, nous prions lectrices et lecteurs de signaler à notre éditeur les inexactitudes et les omissions, pour nous permettre d'améliorer une étude sincère, mais bien imparfaite.

Paris, le 150 décembre 1896.

A. R. 



\section{LES FEMMES DANS LA SCIENCE}

\section{AARON}

La Revue scientifique, dite la Revue rose, signale dans ses livraisons du 18 octobre 1890 et du 23 novembre 1890 , cette observation de Madame Aaron : "Lne mince couche d'huile ou de pétrole à la surface de l'eau où se trouvent des larves de moustiques détruit celles-ci, en les empêchant de venir respirer à la surface. "

\section{D'ABBADIE}

D'après une donation entre vifs, Hadame d'Abbadie et son mari, membre de l’Académie des Sciences, laisseront à leur mort leur fortune à cette compagnie, un chàteau et $\mathbf{4} 0.000$ livres de rente, à condition (qu'on confectionnera en 50 ans un catalogue de כ̋00.000 étoiles.

A la séance de l'Académie des Sciences du 27 janvier 1896 , le Président, M. Cornu, s’exprime ainsi : “L’Académie reillera à l'exécution scrupuleuse des travaux préparés dans votre Observatoire d'Abbadia, en particulier de ce grand catalogue d’étoiles commencé par vos soins et des études sur la direction et l'intensité de la gravité locale... »

\section{ACHAH MOUNT-ELY}

Cette dame est professeur de mathématiques an collige Vassar, U. S. A.

\section{ACKERMANN}

Madame Ackermann (1810-1890) est connue par ses poúsies philosophiques, empreintes de panthéisme et de pessimisme. 
“ Depuis Lucrèce, la négation ne s'est jamais traduite en ver's aussi hardis, aussi beaux. »

" Je déteste, écrit Madame A. à un neveu, le pur matérialisme. Le philosophe que je te recommande, puisque tu fais tes études philosophiques, est Spinosa. J'y mêle un peu d'Hegel et j'en compose un ragoût philosophique très sain et très fortifiant. "

OEurres de Louse Ackermann : Ma vie; Premières poésies; Poésies philosophiques. 188 .

Consulter dans la Revue des Deux-Mondes, les études sur Madame A., par Caro (187'4), et par d'Haussonville (1891).

\section{$A D A M$}

Notre contemporaine, Madame Edmond Adam, a écrit d'abord sous le pseudonyme de Juliette Lamber. Elle a répondu aux brutales théories de Proudhon sur la femme par ses Idées anti-proudhoniennes. Ses auvres ultérieures ne rentrent pas dans notre cadre. Nous citerons pourtant encore : Un rêve sur le Divin.

\section{AGAMÈDE}

D'après Homère (livre II de l'Iliade), la belle Agamède connaissait toutes les plantes et tous les simples que la terre produit et leurs différents usages.

\section{AGANICE}

Cette fille d’un Sésostris, roi d’Égypte, prédisait l'avenir à l'aide des constellations et des globes célestes. (Toir Plutarque Procep. conjug. fine, 1. II, p. I'ï. Ed. Wechel.)

\section{AGASSIZ (ELIZABETH)}

On connait la vie scientifique du naturaliste Louis Agassiz, en Suisse et en Amérique. 11 a dirigé les fenmes vers l'étude de la nature. Sa propre femme l’a suivi dans ses voyages et a 
collaboré à ses travaux. Devenue reuve, Madame Afrassiz dirige le collinge de filles de New-Cambridge, U. S. A.

I. Lne première leçon d'Histoire naturelle; Boston, 1859 et 1879. - II. Recherches géologiques; 1866. - III. Voyjaye au Brésil de Monsieur et de Madame Agassiz, traduit de l'anglais par Vogeli; Paris, 1869, in-8. - IV. Louis A gassiz, sa vie et sa correspondance, par Madame Agassiz, traduit par A. Mayor, avec portrait; Neufchâtel, 1887, gr. in-8.

\title{
AGLAONICE
}

D’après Plutarque (Voir Préceptes sur le mariage, vers la tin), cette grecque de Thessalie prédisait les éclipses. C'est la première femme notée comme astronome. Le peuple la prenait pour une sorcière. Elle se moquait de ses contemporains, en les assurant qu’elle pouvait à volonté faire disparaitre le soleil et la lune.

\section{AGLASIE}

Saint Jéròme vante sa sagesse et sa science. Cette théologienne de Cahors mourut le $\mathbf{2 9}$ férrier 368.

\section{MARIE AGNESI}

\begin{abstract}
Si les lois de l'Académie avaient permis d'y admettro des dames, c'eủt ćté un triomphe pour Irademoiselle Agnesi.
\end{abstract}

\section{FONTENELLe (?)}

Ex famille. - Dans le dix-huitième siècle, qu'elle a parcouru presqu'en entier, a vécu une savante et pieuse fille, nommée Agnesi. Elle est néc à Milan, en 1718, d'une famille noble et elle a reçu les prénoms de Marguerite, Gaétane, Angiola, Marie.

Son père, riche et d'esprit élevé, avait le goùt des sciences. Il s'est marié trois fois et il a eu vingt-trois enfants dont une autre fille Marie-Thérèse, musicienne et auteur de trois opéras.

Marie s'est fait remarquer, dìs l'enfance, par sa soumission 
complète à son père et par son dévouement à ses nombreux frères et sœurs.

Les laNgues et la philosophie. - On a surnommé Marie Agnesi l'oracle des sept langues. Elle savait, en effet, le latin, l'hébreu, l'allemand, l'espagnol. Elle avait aussi appris le grec, pour mieux savoir le latin, et elle a dit, chaque soir de sa vie, l'office de la Vierge en grec. Enfin, elle parlait encor'e le français et la nobile fanciulla recevait, à peine âgée de cincf ans, ce compliment: "Une nymphe ne parle pas sur les bords de la Seine d'une manière plus douce.... Que dois-je (roire de ce que je vois ou de ce que j'entends? »

A dix-neuf ans, Maric avait sontenu dans son salon cent quatre-ringt-onze thèses philosophiques, pas une de moins. Elle se demandait dans l'une, comme plusieurs de nos contemporains: “ Si l'étude des arts libéraux convient aux femmes. »Le recueil a été imprimé à Milan chez Malatesta et réimprimé à Parloue. Il s'agit, bien entendu, d'une philosophie superficielle où, après avoir énoncé les principales opinions, on discute le pour et le contre.

In pamphlet contre les femmes de sciences avait paru sous le voile de l'anonyme. C'est le comte Robbio de SaintRaphaël qui arait publié cette Disgrâce d'Uranie, mais il y avait adressé une apostrophe admirative à Agnesi, considérée comme une exception. Proudhon dira plus tard, à son tour : Hypatie et Agnesi, ce sont des contradictions!

Vous lirez avec plaisir cette citation des Lettres d'Italie, par de Brosses : "Je veux vous faire part, mon cher Président, d'une espèce de phénomène littéraire dont je viens d'ètre témoin et qui ma a paru una cosa più stupenda que le dome de Milan, et en mêne temps j’ai manqué d’ètre pris sans vert. Je reviens de chez la signora Agnesi, ou je rous arais dit hier que je devais aller. On m’a fait entrer dans un grand et bel appartement. où jai trouré trente persomnes de toutes les nations de l'Europe, rangées en cercle. et mademoiselle Agrnesi assise seule avee sa petite seurr, sur un canapú. C'est 


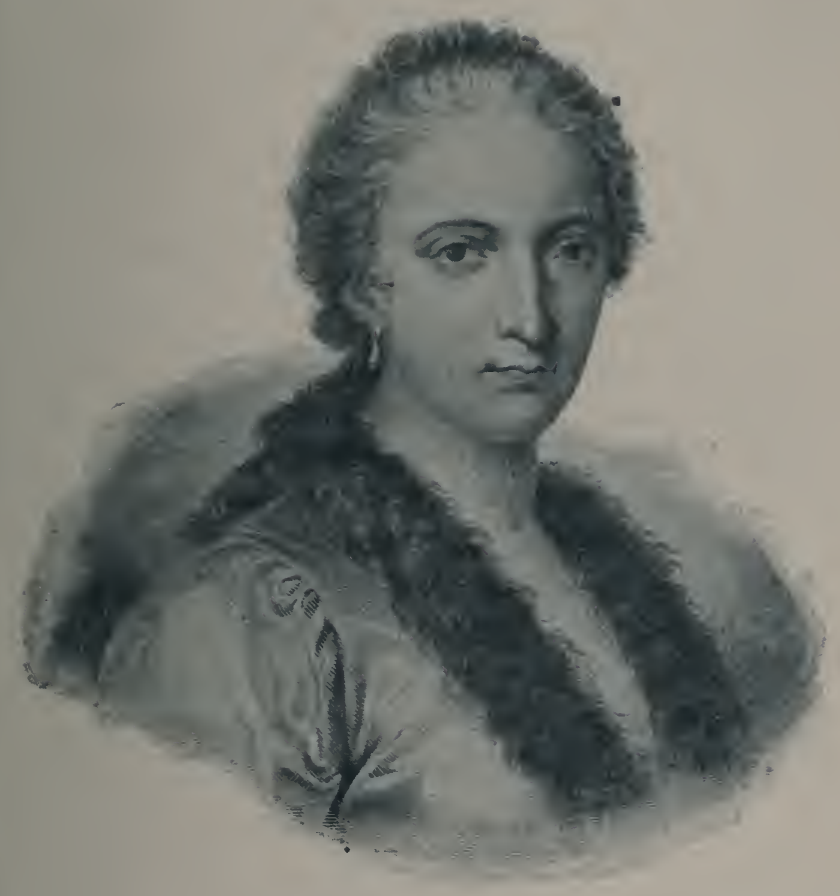

IA RIE AGNESI 

une fille de dix-huit à vingt ans, ni laide ni jolie, qui a l'air fort simple et fort doux. On a d'abord apporté foree eau glacée, ce qui m’a paru de bon augure. Je m’attendais, allant là, que ce n'était que pour converser tout ordinairement avec cette demoiselle; au lieu de cela, le comte Belloni, qui m’y amenait, a voulu faire une espèce d'action publique; il a débuté par adresser à cette jeune fille une belle harangue en latin, pour être compris par tout le monde. Elle lui a répondu fort bien; après quoi, ils se sont mis à disputer dans la même langue sur l'origine des fontaines et sur les causes du flux et reflux que quelques-unes ont comme la mer. Elle a parlé comme un ange sur cette matière; je n'ai rien ouï là-dessus qui m’ait plus satisfait. Cela fait, le comte Belloni m’a prić de disserter de mème avec elle sur quelque sujet qui me plairait, pourvu que ce fût sur un sujet philosophique ou mathématique. J'ai été fort stupéfait de voir qu’il me fallait haranguer impromptu et parler dans une langue dont j'ai si peu usage. Cependant, vaille que vaille, je lui ai fait un beau compliment ; puis nous avons d'abord disputé sur la manière dont l'àme peut être frappée des objets corporels et les communiquer aux organes du cerveau; et ensuite sur l'émanation de la lumière et sur les couleurs primitives. Loppin a disserté avec elle sur la transparence des corps et sur les propriétés de certaines courbes géométriques, où je n’ai rien entendu... »

Les Institutioss axalfitiques. - Pour obéir à son père, Marie Agnesi passe de la philologic et de la philosophie aux sciences proprement dites, pour lesquelles elle se passionne bientòt. " L’algèbre et la géométric, dit-elle, sont les seules provinces de la pensée où règne la paix. »

II y a une courbe intéressante qui s'appelle la Boucle d'Agnesi. Demandez à un de nos étudiants : “ Agnesi, qui est-ce? » Il ne vous répondra pas que c'est une femme. Pourtant M. Fouillée veut qu'on dise quelques mots d'Agnesi et de Sophie Germain, dans nos lycées des deux sexes.

En 17'18, Marie Agnesi a publié ses Institutions Analytiques 
qui ont vite remplacé les traités de l'Hòpital et du P. Reyneau. Les institutions comprennent deux volumes, le premier - dont nous reproduisons ci-contre la première page traite de l'algèbre et de ses applications à la géométrie (quantités finies), et le second des calculs différentiel et intégral (infiniment petits et infiniment grands). On y remarque l'équation de Riccati, publiée pour la première fois. Le livre, dédié à l'impératrice Marie-Thérèse, a coûté dix ans de travail et a été imprimé dans la maison même d'Agnesi, où l'imprimeur avait transporté ses presses. Il a été fait une traduction anglaise par Colson et une traduction française du second volume par d'Anthelmi, avec des notes de Bossut. Voici comment s'exprime le rapporteur de l'Académie des sciences de Paris : “ L’ordre, la clarté, la précision règnent dans toutes les parties de l'ourrage. On n'a point encore vu paraître dans aucune langue des Institutions analytiques qui puissent mener aussi vite et conduire aussi loin..... Nous le regardons comme le traité le plus complet et le mieux fait qu'on ait en ce genre.... ) Dans la préface, Marie dit modestement: «J'avais commencé le livre pour mon amusement particulier et pour l'instruction d'un frère qui arait des dispositions pour les mathématiques. » Nous n'avons pas besoin de faire remarquer que, lorsqu'il s'agit d'une science nouvelle et difficile, comme le Calcul infinitésimal, les premiers ourrages d'enseignement prennent une importance capitale.

Les papes et les sayantes. - Le pape Benoit XIY félicita la mathématicienne et lui fit don d'une couronne de pierres précieuses et d'une médaille en or. "Nous entreprimes dans la fleur de notre jeunesse, dit-il, l'étude de l'Analỵse mais nous dûmes malheureusement l'abandonner. Yous ne savons plus de l'Analyse que ce qu'il faut pour comprendre son importance et pour sentir combien il est glorieux à notre Italie d'en posséder des professeurs. Autant que nous arons pu en juger, en parcourant la table de l'ourrage et en lisant 


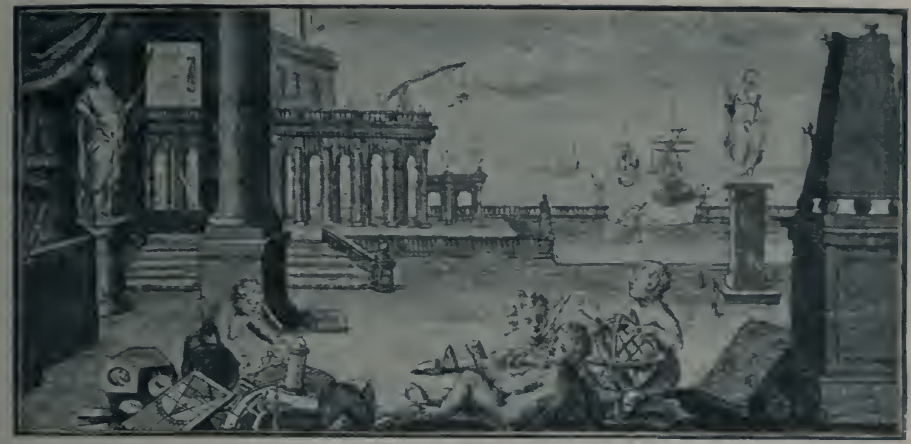

\section{NST I T UZ I O N I A N A L I T I C H E LIBRO PRIMO}

Dell Analisi delle Quantità finite.

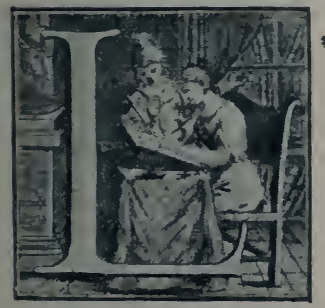

'Analifi delle quantità fínite, che comunemente chiamafi Algebra. Cartefiana, è un metodo, con cui trattando quantita finite fi fciolgono i Problemi ; cioè da certe quantità, e condizioni date e cognite, fi viene in cognizione d'altre incognite, $c$ che fi cercano, per mezzo di alcune operazioni, e metodi, che parte a parte mi propongo di ĺpiegare ne' feguenti Capi. 

quelques chapitres des quantités finies, nous croyons sincèrement que votre livre honorera l'Italie. »)

In peu plus tard, le même pape nomma Agnesi lectrice en mathématiques à l'Université de Bologne. Il faut entendre ici lecteur dans le sens de professeur, mais Marie n'a pas enseigné en chaire, malgré l’invitation du pape : " Ce n’est pas vous yui devez nous remercier, c'est au contraire nous qui vous devons tous nos remerciements. Dès les temps les plus reculés, Bologne a entendu des personnes de votre sexe dans ses chaires publiques. Il rous appartient de continuer dignement la tradition. ) Le diplòme était joliment relié en parchemin et muni du sceau attaché avec un cordon de soie et d'or.

Célébrité ét modestie. - Agnesi était aussi modeste qu’elle rtait célèbre. Elle était simple, bonne, presque timide. Elle était d'une beauté touchante, avec sa physionomie douce et candide. Sa taille était élancée. Ses yeux noirs et ses cheveux noirs faisaient ressortir l'éblouissante blancheur de son teint. Elle avait un doux sourire. On admirait sa noblesse et sa wràce.

Fontenelle (ou Fontanieu ?) faisait, à l'occasion de notre héroïne, cette intéressante déclaration : “Les Institutions dédommagent les Sciences de la perte qu'elles viennent de faire en la personne de la marquise du Chàtelet. Si les lois de l'Académie avaient permis d'y admettre des dames, c'en̂t été un triomphe pour Mademoiselle Agnesi. "

LA Maladie. - Agnesi a eu deux graves maladies, qui sont comme la rançon de son génie. Une première fois, elle a été atteinte d'une anémie profonde, causée par la vie sédentaire et le travail : les médecins lui ont ordonné le cheval et le bal. Marie a-t-elle abusé d’un remède qui lui plaisait? Quoi qu'il en soit, à la première maladie a succédé une maladie nerveuse : la jeune fille est devenue somnambule et s'est sentie excitée à sauter en l'air, plusieurs fois par jour. Elle guérit pourtant à la longue, gràce à son patron, Saint Gaëtan, affirme un biographe. 
A la suite de sa double maladic, Agnesi devint mélancolique et elle changea de voie, comme le grand Pascal. Le vulgaire attribua le changement à un amour contrarié, et Pallavicini, l'Intendant de la province, en parla au père d'Agnesi. Ce dernier fut tellement indigné de cette hypothèse, qu’il eut une attaque qui abrégea sa vie.

Une servante des pauvres. - Dès l'âge de vingt ans, en plein succès, Marie avait demandé à entrer en religion et son père n'avait pu la retenir qu'en lui accordant trois faveurs : porter un habit humble, être dispensée du bal et du théâtre, enfin aller à l'église à volonté. Dans quelques chambres éloignées qu’on lui avait cédées, Marie soignait plusieurs femmes infirmes et instruisait une fille presque stupide. Elle édifiait déjà tout le monde, mais elle n'osait refuser à son pìre quelques-uns de ces excrcices publics qu'il aimait tant.

A la mort de son père, Marie entra dans l'ordre assez rigonreux des religieuses appelées Célestes ou Turquines, d'aprìs la couleur de leur robe. Elle renonça complètement à la sciençe humaine et elle devint la supérieure de l’hòpital Trivulzi. Après avoir abandonné tous ses biens aux malades, on la vit mendier pour eux. Elle avait vendu à un Anglais le cadeau de l'Impératrice, une boite de cristal de roche ornée de brillants et un anneau de diamants.

Agnesi avait retrouvé une certaine gaité. Le fils dı roi de Suède lui ayant demandé un mot sur son album, clle écrivit : "Il vaut mieux croire beaucoup que peu. ) Le prince était protestant. - Le sculpteur Conqui, voulant faire le buste d'Agnesi à son insu, vint la voir plusieurs fois sous différents prétextes. Elle surprit le manège, se borna à sourire et consentit à poser.

- Sa maxime favorite était : "Une àme dévouée au service de Dieu doit être saintement libre et ne pas plus s'embarrasser des blàmes que des éloges. "

Agnesi étudiait avec ardeur les Pères de l’Église, et elle a laissé quelques écrits religieux, en particulier une consulta- 
tion de vingt-quatre pages que l'archevêque de Milan lui avait demandée sur un ouvrage de Gorini. Cet ourrage intitulé Politique, droit et religion avait été condamné par l’Index, après avoir été approuvé par les Facultés ecclésiastiques. "Lauteur a bien eu l'intention de convaincre les hérétiques, mais, dans l'exécution de son dessein, il n'a pas rempli le but qu'il se proposait... Il avance quelques points qui pourraient être préjudiciables aux àmes, surtout parce que son livre, étant écrit en langue vulgaire, pourrait troubler la piété des esprits faibles et des femmes. "

IIarie Agnesi, la servante des pauvres, est morte dans son cher hòpital, d'une hydropisie de poitrine, à 81 ans, en 1799 .

Socrexir. - Frisi a composé sur Agnesi une notice assez détaillée, mais un peu confuse, qui a été traduite en français par Boulard.

Le cardinal Dumini avait placé le buste de la savante dans sil galerie des plus illustres Lombards.

On a inscrit ces mots sur la pierre tombale : "Fille remarquable par sa piété, sa science et sa bienfaisance. 》 Ne pourrait-on pas aller plus loin et canoniser notre Agnesi ? J'estime, moi profane, que ce serait une sainte qui en vaudrait bien d'autres!

$$
\text { BIBLIOGRAPIIE }
$$

OEurres d'd gnesi.

1. Oratio (jua ostenditur: Artium liberalium studia a femineo sexu neutiquan? abhorrere. Vlilan, 18 août 1727 , in-40.

2. Oratio habita a Maria de Agnesis ; Pro studiis mulierum (Réimpression du précédent). Padoue, 1729, in- ${ }^{\circ}$.

3. Propositiones philosophicue. Milan, 1738, in-4º.

4. Instituzioni analitiche ad uso della gioventu' italiana di $D^{\text {na }}$ Maria Gatana Agnesi milanese. Milan, 1748, nella regia Ducal Corte, 2 vol. in-4º, 16 planches gravées. - Traduction française du $2^{\mathrm{e}}$ vol. par Anthelmi, arec des notes de Bossut. Lyon, 17i5, in-80. - Traduction anclaise par Colson, profess. ì Cambridge, 1801.

5. Lettres latines et italiennes, dans l'cloge, par Frisi.

Sources pour Agnesi.

Frisi. Éloge historique. Milan, 1799 (arec portrait d'après Franchi). 
- Traduction française par Boulard,1808, in- $8^{\circ}$ (D'abord 1807, à la suite des Bienfaits de la religion chrétienne).

Bianca Milesi-Mojon. Vita. Milan, 1836 (Portrait). (Tiré à peu d'exemplaires non mis dans le commerce).

C. Grosi. Documenti et note. Bologne, 18 3.

Lalande. Voyage en Italie. 1796, T. IV, p. 457.

Disgrazie di donna Urania orero degli studi feminili. Parme, 1793, gr. in- $8^{\circ}$ (Contient une apostrophe à Agnesi).

Lombardi. Storia della litteratura italiana nel Secolo XVIII. Modène, 1827 (t. I, p. 379).

De Brosses. Lettres sur l'Italie (vol. I, p. 94 et 105-7).

Camerini. Donne illustri. Nilan, 1872, in-12.

Chiappetti-Mestica. Vita di M. G. A. Imola, 1872, in-80.

Caraza. Le scuole del antico studio Bolognese. Milan, 1896 , in- $4^{\circ}$, p. 290.

Bettoni. Vite et vitratti d'illustri italiani. Milan, 1812 (44 biographie; portrait).

L'Intermédiaire des Mathématiciens. 1894, p. 226, et 1895, p. 83.

\section{Pontraits}

Buste par Franchi (Milan, 1781). - Buste par Bisi, Longhi del. line de plomb jar E. Conquy, 1836 (Dans Les hommes utiles : c'est ce portrait que nous arons reproduit). - Redenti, sc.

\section{Autographes}

Aux manuscrits de la bibliothèque ambrosienne de Milan :

Diplomi e patenti, 0. 202. Sup.

Fisica e Matematica, 0. 199. Sup. Sup.

Manoscritti autografi sopra oggetti Sicri, 0. 203. Sup.

Metafisica e fisica, fisica, fisica, e Matematica, 0. 185-193. Sup.

Opuscoli appartenenti a letteratura, 0. 183-18\}. Sup.

Riscontro di un opuscolo del Sig. Bertucei, 0. 204. Sup.

Studi di Cosmografia, 0. 194. Sup.

Studi e corrispondenze Sopra rarii punti del Trattato analitico, 0. 200. Sup.

Diversi manoscritti in 2.5 volumi. 0. 180.204. Suए.

Nous donnons ci-contre le fac-simile d'un autographe de cette collection. 
ई

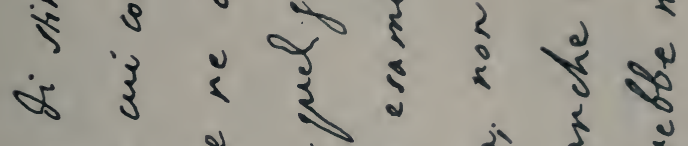

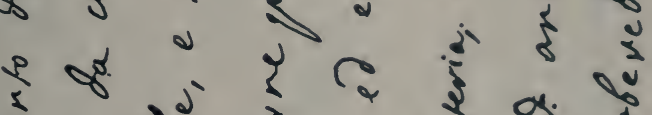

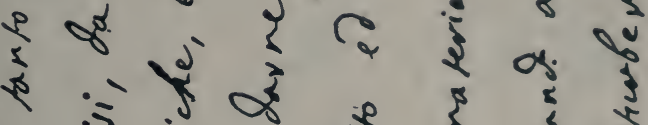

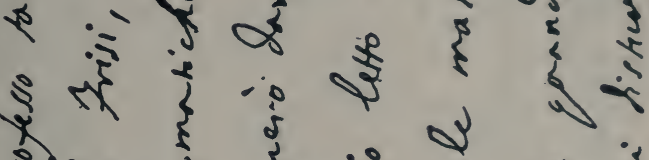

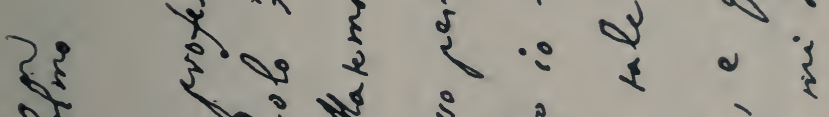

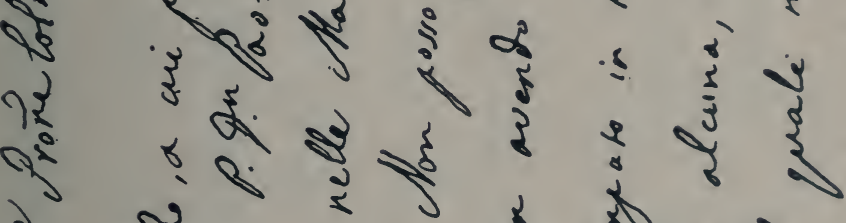

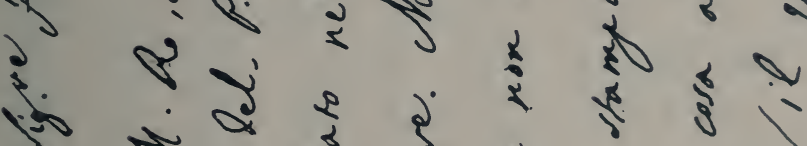

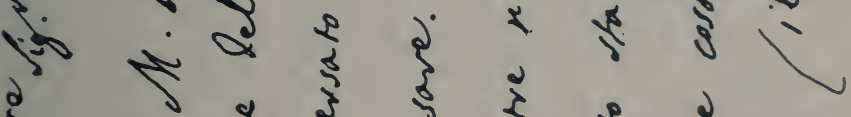

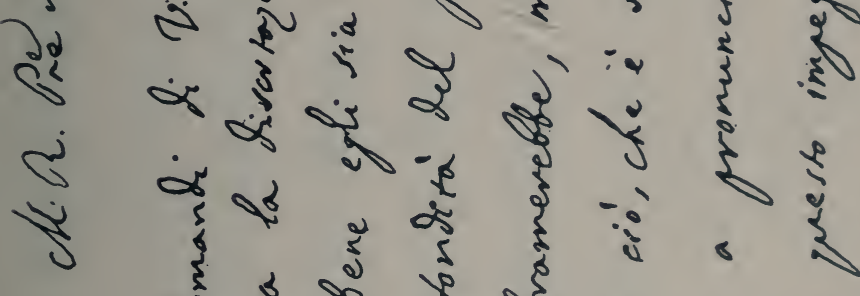

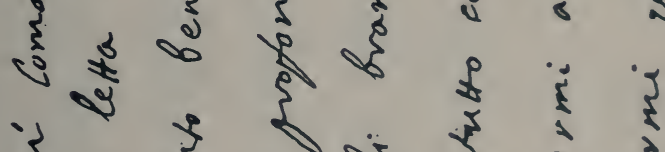

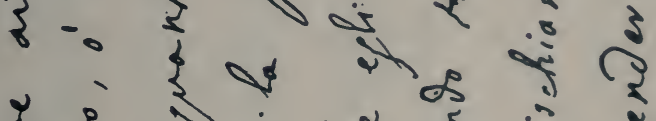

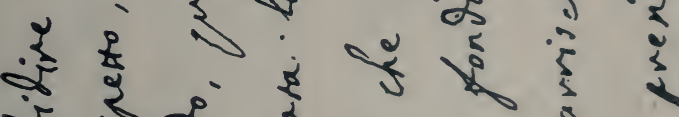

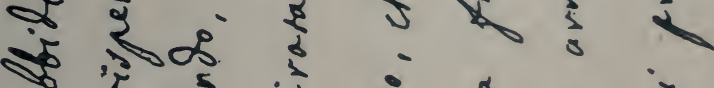

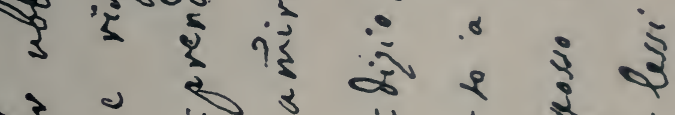

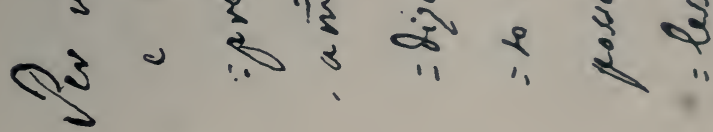




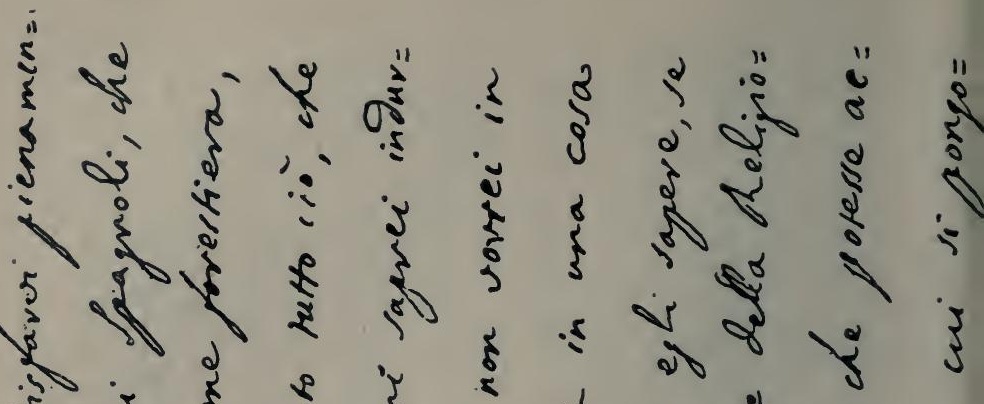

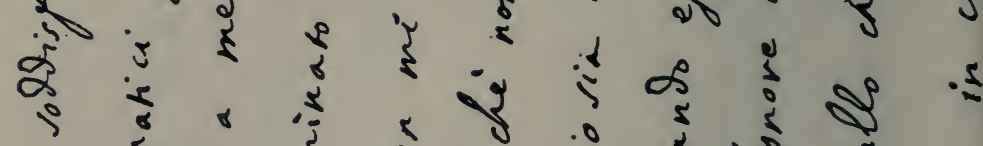

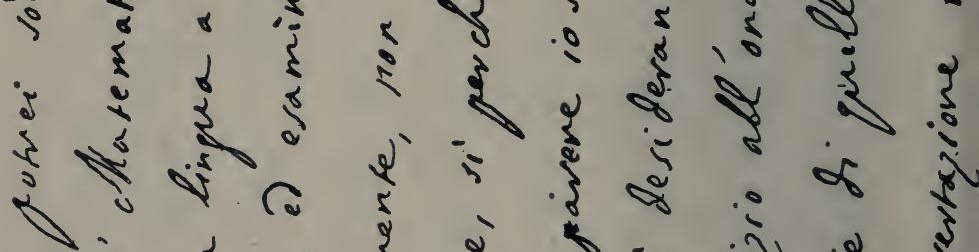

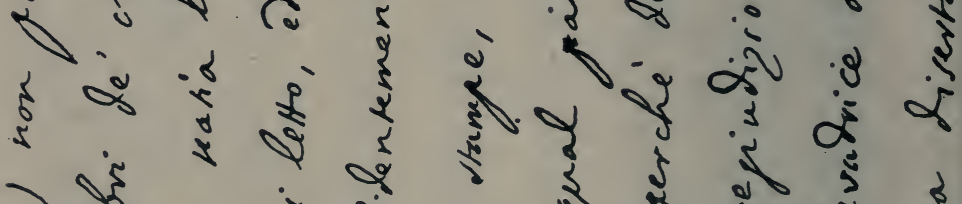

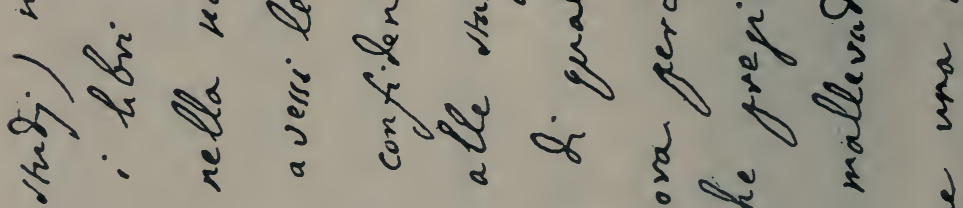

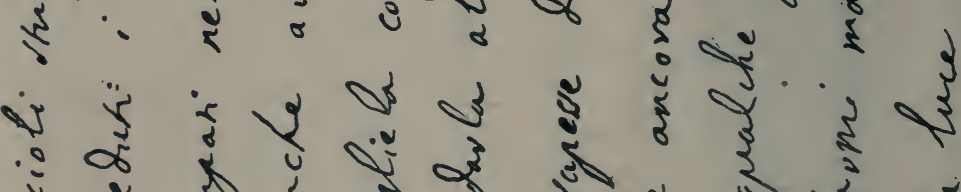

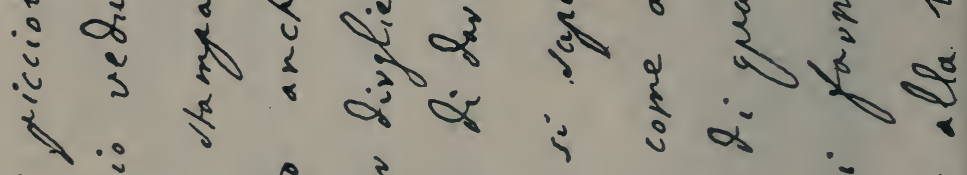

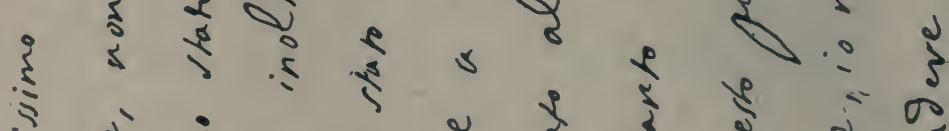

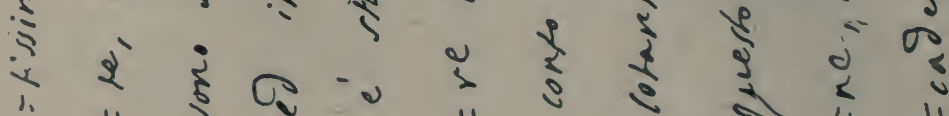

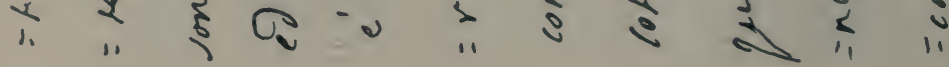




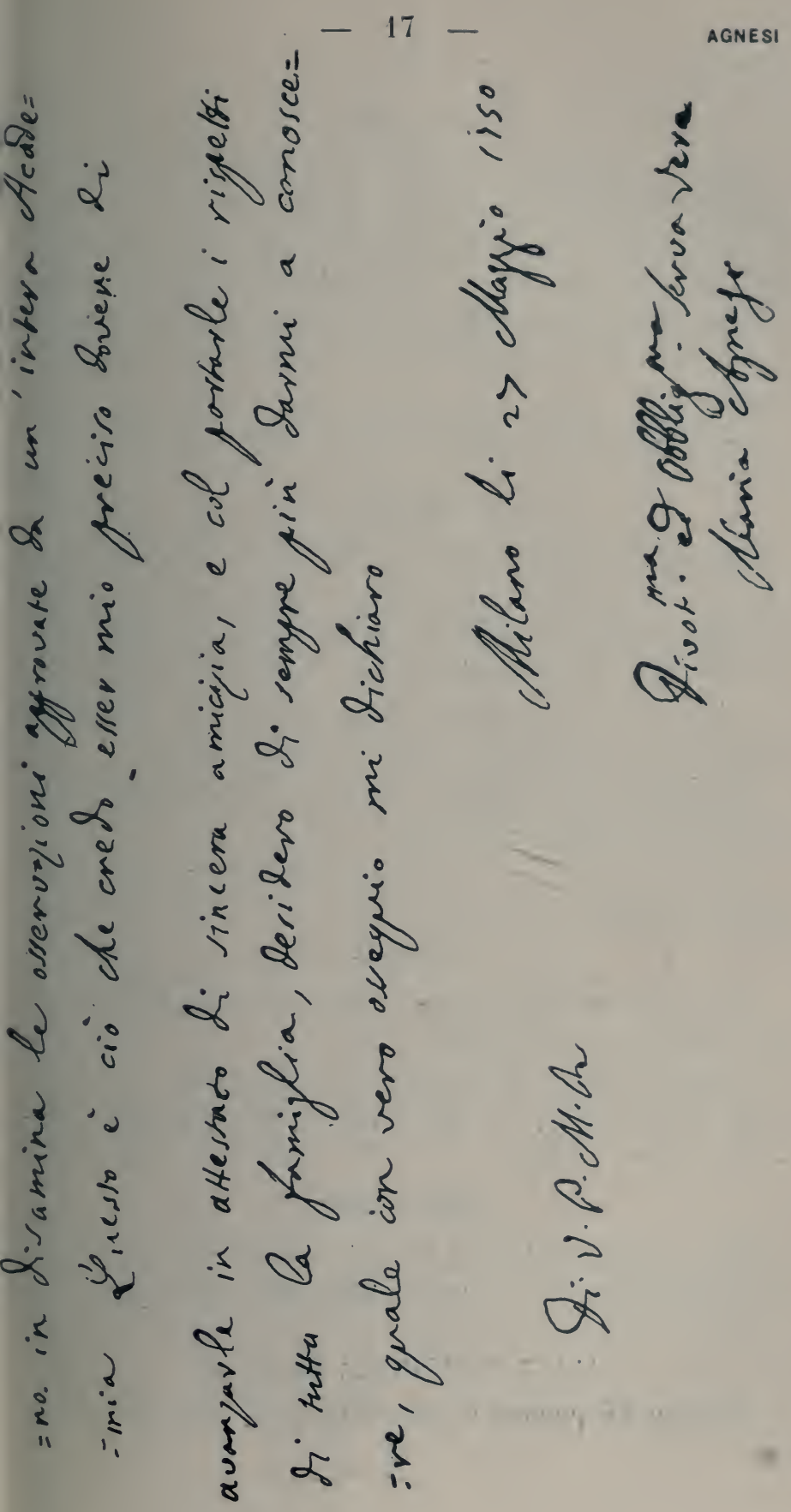




\section{AGNODICE}

Il était expressément défendu aux femmes grecques de pratiquer aucune partie de la médecine.

" Agnodice avait été bien instruite par le médecin Hérophile. Pour pouvoir exercer, elle s'était déguisée en homme. »

Manuel biographique de la Collection Roret.

"L'Athénienne Agnodice fut la première à exercer la médecine. »

A. Revaud. Histoire nouvelle des Arts el des Sciences, p. 2:\%.

\section{D'AGOULT}

La Comtesse d'Agoult, morte en 1876, a écrit sous le pseudonyme de Daniel Stern. Yoyageuse, moraliste, historienne, femme politique, romancière, nous ne citerons d'elle que l'Essai sur la liberté considérée comme principe et fin de l'Activité humaine et les Esquisses morales. L'auteur manifeste une foi inébranlable dans la perfectibilité humaine.

Il existe de $M^{\text {me }}$ d'Agoult un profil au crayon, par sa fille ainée, la Comtesse de Charnacé.

Yoir les études d'Armand Pommier (Dentu, 1867) et de L. de Ronchaud.

\section{D'AIGUILLON}

Une des principales fémmes de qualité auxquelles Maupertuis enseignait la géométrie.

Coloniey. Ruelles ct Cabarets, t. II, p. 12.

Voir aussi Collé et la duchesse d'Aiguillon, par BoxsextAVENANT, in- $8^{\circ} ; 1879$.

\section{A.-M. ALBERT}

Elle a adressé en 1891 à l'Académie des Sciences de Paris un mémoire sur la Construction des Tables numériques.

\section{ALLART DE MÉRITENS (HORTENSE)}

Historien de quclque valcur, auteur d'un Novum organum

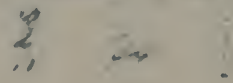


où il est question d'Herschel, de Phédon, de Kepler et des philosophes. On y lit à la page 100 :

"Ce que nous croirons, ce que nous verrons ressortir de l'ensemble des choses, sera moins extraordinaire que notre existence propre, que l'univers sous nos yeux, que le soleil qui nous éclaire, que la succession des jours, l'étendue des mers, la rapide course des sphères dans l'espace, les prodiges de ces mondes innombrables que l'insuffisance de nos yeux nous cache.

Et si l'on dit: Vivons doucement, laissons ces merveilles, imitons les fleurs et les oiseaux, qui vivent, brillent et meurent sans inquiétude, je répondrai : Faites-le. Mais il est des hommes qui ne peuvent se distraire de ces hautes questions... »

Novum organum ou Sainteté philosophique. (Garnier), 18:37; in-12.

1801-1879 ; amie de Chateaubriand dans sa vieillesse, Mme Allart est enterrée à Bourg-la-Reine.

\section{AMORETTI (MARIA-PELEGRINA)}

Née à Oneglia (Italie); 17ว̋6-1787. A soutenu très jeune des thèses philosophiques; dès 1777, l'université de Pavie lui a décerné il berretto dottorale (bonnet de docteur) et Parini l'a célébréc dans son ode : la Laurea.

OEuvres posthumes publiées à Milan, avec portrait, en $173 \% 8$. Mme Dora D’Istria. Des femmes, t. I, p. 263.

\section{AMORT (ANNA)}

Noureau traitement des puissances et des racines des expressions algébriques et des nombres décimaux. (En allemand). Jicin (Bohême); 1883.

\section{AMPÈRE (JULIE)}

Femme du grand Ampère, peu savante mais pleine de honté et de gràce. Consulter Journal et Correspondance de André-Llarie Amp̀̀re, publiés par Mme H. C. (Hortense Cheuvreux).

"Le début de ce livre, dit Mme Mathilde Bourdon, est d'une 
grâce sereine. Ampère est pauvre, mais il a foi dans l'avenir, il aime Julie; les moindres incidents, un beau jour passé à la campagne, une lecture, des vers qu'il destine à sa fiancée, une fable que Julie compose, ce sont autant de joies; elle devient sa femme, elle Jui donne un fils, leur bonheur serait à son apogée sans deux points noirs qui projettent leur ombre sur ces jours heureux : la nomination d'Ampère à Bourg et la santé chancelante de Julie. "

Après la lecture de ce livre touchant, on ne croira plus que la science dessèche le coeur.

\section{AMPHICHIE OU AMPHILIE}

Belle-fille de Jamblique, qui a écrit sur les femmes philosophes. C'était une platonicienne et Porphyre en fait l'éloge.

\section{AMPHICLÉE}

Plotin la cite comme philosophe.

\section{ANHALT-DESSAU}

Cette princesse, nièce du Roi de Prusse, a reçu d'Euler des leçons de physique (17.56-62) qui ont été publiées sous le titre de : Lettres à une princesse d'Allemagne sur divers points de physique et de philosophie; nombreuses éditions, avec notes.

\section{ANTHUSE}

Photius dit que cette femme faisait des prédictions d'après les nuées. On peut par suite supposer qu'elle avait des connaissances en météorologie.

\section{APFELFÄLTIN (ANNE-MARGUERITE)}

A travaillé l'histoire el les mathématiques.

Paulin, Gelehrte Frauen, p. 21.

\section{D'ARCONVILLE (GeneViève-Charlotte)}

Femme de lettres, amie de Gresset et de Lavoisier (17201803̈), mariée à M. Thiroux, conseiller au Parlement. Signe 
souvent, Thiroux d'Arconville, lorsqu'elle signe. Outre ses essais moraux, clle a publié : $1^{0}$ Leçons de chimie, traduites de l'anglais de Shaw, 17509, in-4 ${ }^{\circ}$, avec des corrections, des compléments et des notes historiques. (Dans le discours préliminaire de la traductrice, il est traité de la naissance et des progrès de la chimie : invention du feu et des métaux, fabrication du pain, le verre et la porcelaine, etc.); 20 Traité d'ostéologie, 1767, in-folio, avec des planches anatomiques; $3^{\circ}$ Essai pour servir à l'histoire de la putréfaction; Didot jeune; in-8 ${ }^{\circ}$, 1766; XXXVI-כ̆78 pp. (Épître dédicatoire à son ami, sans doute Fourcroy. Action de nombreuses substances sur les viandes à conserver. Conservation des œufs ; du poisson, etc. Expériences variées relatées avec précision. Un certain nombre de tableaux-résumés.)

V. Diderot, IX, 4 3ั3 et 450 ; XX, 99. - FourcroT. Système des connaissances chimiques, IX, 102 et Éléments d'histoire naturelle et de chimie, IV, 489. - Delaponte. $\boldsymbol{N}^{m e}$ Th. d'A. (indiqué par l'Intermédiaire des Chercheurs, de 1892).

\section{ARDINGHELI (MARIE-ANGÈLE)}

Physicienne et naturaliste, de Naples (1730-182:). Elle a publié une traduction importante des ouvres de Hales et de plusieurs mathématiciens français. L'Académie des sciences de Paris lui a adressé des félicitations.

Les cuvres d'Étienne Hales, traduites en italien, 3 vol. in-8 : Naples, 1730,1732 et 17306 ; la 3e édition est de 1776 . (Ier vol., la statique des animaux; e vol. expériences sur les calculs de la vessie et des reins; 3 e vol. statique des végrétaux et analyse de l'air. La traductrice a fait précéder chaque volume d'une préface raisonnée).

V. Abbé Nollet. Lettres sur l'électricité (177't, in-12, p. 1 et 2. La première lettre est adressée à Mlle Marie-Ange Ardingheli). - Mazucheld. Scriptori .... I, partie 3e.- Biogr. Hofer et Quérard. - Dora D'Istria. Des femmes, I, 26'. Éloge par le Maréchal de Villarosa. 


\section{ARÉTÉE OU OLIVÈTE}

Vivait à Cyrène, dans la deuxième moitié du rve siècle av. J.-C.; morte à 78 ans. Fille et élève d'Aristippe l'Ancien, continua son enseignement, écrivit, dit-on, un grand nombre de volumes perdus, forma clle-même une centaine d'ćlèves, dont son propre fils Aristippe le Jeune.

\section{ARGIE}

Clément d'Alexandrie et Saint Jéróme disent qu'instruite par son père, le philosophe Théodore, elle devint très savante. Elle avait trois sœurs qui avaient profité comme elle des leçons philosophiques de Diodore.

\section{ARIGNOTE}

De Samos. Fille de Pythagore et de Théano, la tradition lui attribue beaucoup d'écrits disparus.

\section{ARISTOCLÉE OU THEMISTOCLÉE}

Sour et collaboratrice de Pythagore, enseigna sa doctrine. Drogène de Laerce. Vie de Pythagore.

\section{ARRIE}

Platonicienne, vivant du temps d'Alexandre Sévère. Diogène de Lacrce lui a dédié son histoire de la philosophie; il la désigne sous le nom de Philoplalon, amie de Platon.

\section{ASCLÉPIGÉNIE}

Philosophe du re siècle aprìs J.-C., fille de Plutarque le Jeune, elle enseigna à Athènes comme lui et l'on croit qu' $\mathrm{Hy}_{y}$ patie a suivi ses lesons.

- La mère et la fille ont porté le nom d'Asclépigénic.

La première Asclépigénie était manifestement supérieure à son père, Plutarque, par l'intelligence. Il lui confia en mourant le dépòt de la doctrine secrète. Mais, quoiqu'elle eùt instruit Proclus lui-mème, elle ne put, ćtant femme, prendre 
la tète de l'École d'Athènes, ni son mari Archiadas non plus, parce qu’il était trop peu philosophe. On choisit Syrianos, d'Alexandrie.

La fille d'Archiadas, Asclépigénic la jeune, épousa Théigène.

"Plutarque fut le père de cette Asclépigénie qui, de son vivant, rivale d'Hypatie, eût peut-être partagé sa réputation dans la postérité, si elle avait obtenu, comme elle, le triste honneur d'une fin tragique. L'histoire est plein de ces privilèges dus au hasard de la mort. Synésius assista sans doute aux leçons de la philosophe mariée d'Athènes; mais, dans son enthousiaste admiration pour la jeune fille d'Alexandrie, vouée au seul culte des inuses, il ne veut pas même placer son nom à côté de celui d'Hỵpatie. Il y a, dans ce dédain, de l'exagération et de l'injustice. "

Drvox. Ėude sur la vie et les cuvres de Synésius, pp. 15 et 16.

\section{ASHLEY (MARY)}

Astronome anglaise, habite Bath, où elle étudie la surface lunaire avec persévérance et succès. (Voir le Selenographical Journal.) Son travail sur les taches de la lune est de $\mathbf{1 8 8 0 .}$

\section{ASPASIE}

C'est autour d'une jeune femme, Aspasic de Milet, épouse de Périclès, que se réunissaient les fondateurs de la philosophie et de la science grecques. Le P. Zahm vient de découvrir un bas-relief représentant ce groupe.

Aspasic n'a pas laissé d'écrits. Comme elle fut le maitre de Socrate, on la surnomma la Socratique. C'est en se jouant qu'elle aborda, avec Périclès et Socrate, les plus hautes questions de la philosophie.

M. Anatole France, le fin critique, met dans la bouche d'Aspasie cette déclaration: " Je n'ai eu de pouvoir sur les hommes que parce que j'étais musicienne et géomètre.... mon cour était nombreux et rythmé comme mon àme. Tout est nombre et il n’y a rien dans l'univers, hors la géométrie.») 
Ne pas confondre Aspasie de Milet avec une autre Aspasie dont les mœurs furent franchement mauvaises.

\section{ATHÉNAIS OU EUDOXIE}

Athénaïs (396-160 après J.-C.) était la fille du rhéteur Léonce l'athénien. D’une grande beauté. Elle se convertit au christianisme, changea de nom et épousa Théodose II le jeune, empereur d'Orient.

«Elle connaissait toutes les subtilités de la logique. Elle s'éleva plus haut qu'aucune autre femme en astronomic, en géométrie et dans l'étude des nombres. »

Mévage. Vie des femmes philosophes.

V. Thierry (Ам.). Saint Jean-Chrysostome et l'Impératrice Eudoxie.

Il y a une autre Eudoxie ou Eudocie, femme de Constant Paléologue, philosophe comme son homonyme et comparée par les savants qu’elle fréquentait, à Théano et à Hypatic.

\section{ATHYRTA}

Cette fille de Sésostris observait les signes du ciel et en concluait des prédictions favorables aux guerres du Roi, son père. C'était une astronome doublée d'une politique.

Dionore. I, p. 3't.

\section{D'AUMONT (LOUISE-CAROLINE)}

Née le 1 S̈ septembre 1827 à Hancourt (Marne); descendait de la famille de Coucy; morte à Toulon le 19 août 18533 . Naturaliste passionnée, Madame d'Aumont a étudié les insectes, les coquilles et les plantes. Les insectes suivants lui ont été dédiés: Chrisomela Ludovica, Staphylinus Ludovicre, Helix hortensis variété Ludoviciana.

"Il fallait la voir, accroupie au pied d'un arbre, pourchassant les insectes sous les écorces, dans le gazon, dans la mousse et autres lieux où ils aiment à se cacher; ou, pour fouiller le sable, employant, comme un rateau, ses doigts délicats réservés jusqu'alors aux plus gracieux ourrages de femme. Arec quel soin minutieux 
elle épluchait les plantes, feuille à feuille, brin à brin, pour saisir les Apions, les Altises et autres coléoptères de petite taille, fixés à ces matières végétales ou cherchant sous elles un abri!

I'n jour, sur les boulevards de la ville, un Taupin, d'une espèce qu'elle ne possédait pas encore (corymbites castaneus), vint se poser étourdiment sur l'épaulette de son époux. Elle ne l'eût pas plus tôt aperçu, que sa main s'était levée pour le saisir; mais, animé par les feux du soleil, l'insecte, plus agile, avait déployé ses ailes à son approche et avait cherché son salut dans la fuite. Notre chasseresse n'était pas femme à renoncer ainsi à la conquete qu'elle s'était promise. Sans s'inquiéter des spectateurs, elle suivit dans les airs, l'insecte d'un regard perspicace, et de poursuite en poursuite, finit par s'en emparer."

E. Iulsant. Notice sur Louise-Caroline d'Aumont (avec portrait); Lyon, 1856, in-8, 16 pp.

\section{AXIOTHÉE}

Trois cents ans avant J.-C., Axiothée d'Arcadie et Lasthénie de Mantinée se déguisaient en hommes pour suivre les leçons de Platon. Ce ne furent pas les seules, au dire de Clément d'Alexandrie.

“ Ne semble-t-il pas vous apparaitre, sous le manteau sévère du platonicien, vain déguisement auquel nul ne se trompait, l'image d'Axiothée, que le philosophe aimait à reconnaître parmi ses disciples, dans les jardins d'Académus? »)

\section{AYRES (HENRY)}

Mrs Ayres est l'auteur des deux ouvrages suivants en anglais :

Conversation sur l'arithmétique, Londres, 18'13.

L'arithméticien pratique des dames, 2 éd., Londres, 1816. - Clef, $18^{\prime} \mathbf{\prime} 6$.

\section{AYRTON}

IIme Ayrton. Recherches sur l'arc électrique et la question de la résistance négative. 


\section{BAILLY}

Dans la biographie de l'astronome Bailly, maire de Paris, mort sur l'échafaud révolutionnaire, Arago parle de sa veuve.

«Un incident étrange aggrava beaucoup la triste situation de madame Bailly. Dans un jour de trouble, du vivant de son mari, elle avait substitué à la ouate d'un de ses vêtements le produit, en assignats, de la vente de leur maison de Chaillot. C'était une trentaine de mille francs. La mémoire affaiblie de la veuve infortunée ne lui rappela pas l'existence de ce trésor, même dans les moments de la plus grande détresse. Lorsque la vétusté de l'étoffe qui les cachait eut ràmené les assignats au jour, ils n'avaient plus aucune valeur. »

Le géomètre Cousin parvint à faire inscrire la pauvre veuve au bureau de charité et il lui apportait lui-même les secours qui se distribuaient en nature.

Après le 18 brumaire, les crieurs publics annoncèrent partout que Bonaparte était consul et Laplace ministre de l'intérieur. Le soir mème, ce ministre demandait une pension de deux mille francs pour madame Bailly. Madame Laplace lui porta l'argent le lendemain de bonne heure; Madame Bailly était à la fenêtre et dit à la femme du ministre « Nadame, je vous attendais.

\section{BAKER (JosIE)}

Miss Baker, helléniste et mathématicienne, a été professeur au Simpson College d'Indianapolis. (Illinois, U. S. A.)

\section{BALICKA-IVANOWSKA}

Mad. G. Balicka-Ivanowska a publié dans les Annales des Sciences physiques et naturelles, Genève, (novembre 1892 , janvier et février 1893) :

Contributions à l'étude anatomique du genre Iris et des autres genres voisins.

\section{BARBAPICCOLA (GIUSEPPA)}

Cette italienne a traduit les Principes de philosophie de Descartes. Voici le titre du livre, devenu rare: 
Barbaplccula Gilseppa Eleonora, di Napoli. Principi de la Filosofia di Reriato des Cartes (Cartesius) tradotti. Torrino, Mairesse, 1722, in- ${ }^{\circ}$.

L'édition est ornée du portrait de la traductrice, gravé par Grado. Une préface érudite montre que les femmes italiennes se sont livrées non seulement aux études faciles, mais aussi aux sciences les plus sévères.

\section{BARDI}

La sảur Dea de Bardi, née à Florence, religieuse à Castel Fiorentino, cultiva les sciences dans sa retraite et mérita les éloges des savants de son temps.

\section{BARET (JEANNE)}

Le naturaliste Commerson accompagna Bougainville dans son grand royage. Son domestique, qui devint d'une force remarquable en botanique, était une femme, qui put longtemps dissimuler son sexe. Jeanne ferma les yeux de Commerson, à l'Ile-de-France.

Léopold Hugo a offert à l'Ac. des Sc. diverses pièces concernant Jeanne Baret, préposée aux herbiers de Commerson.

V. R. Cortanbert. Les illustres voyageuses. - BovgalNville. Voyage autour du Monde. - Comptes Rendus de l'Ac. des Sc. 1895 (p. 579).

\section{DE BARKOW}

A fondé quatre bourses de $1.000 \mathrm{fr}$. dans les établissements d’enseignement supérieur de Paris.

\section{BARRAS}

La femme du Membre du Directoire s'est occupée d'histoire naturelle.

\section{BARRÈRE (CHRISTINE)}

Cette demoiselle a donné dans Les Mondes (T. 19, 1869, 22) la solution d'un problème de F. Lucas. 


\section{BASSEPORTE (MAGDELEINE)}

Excelle à peindre les oiseaux, les plantes, les fleurs, les reptiles et presque tout ce qui appartient à l'histoire naturelle. Les ouvrages qui naissent sous son pinceau sont regardés par les connaisseurs comme des chefs-d'œuvre où l'art le dispute à la nature, pour la vérité de l'expression, la délicatesse et la précision du coloris. Quoique actucllement àgée de soixante-dix-huit ans (en 1779), on voit encore cette infatigable artiste exposée pendant des journées entières à l'ardeur du soleil, dans les attitudes les plus gênantes, copier pour le cabinet du Roi, tout ce que la nature offre de plus magnifique, de plus précieux et de plus rare dans les plantes que rassemble le Jardin du Roi (Ancien nom du Muséum d'histoire naturelle, à Paris).

Ribaldier. De l'éducation des femmes, pp. 1'43-4.

\section{BASSI (Laure-Marie-Catherine), dame Verati}

Une mère de famille, charitable el savante.

Bologne, de 1711 à 1778. - Apprend le latin et la philosophie, soutient à vingt et un ans, une dissertation publique. Encouragée par le cardinal Lambertini, qui deriendra pape sousle nom de Benoit XIT. Próclamée lauréate en philosophie, elle argumente avec le cardinal de Polignac. Apprend la géométrie, l'algèbre et le grec. Est attachée à l'Institut de Bologne, sans l'avoir demandé. Lílecteur de Bavière et l'empereur Joseph II assistent à ses exptériences de physique.

Épouse le médecin Terati, devient une excellente mère de famille et se montre pleine de charité pour les paurres.

Ouvre dans sa propre maison un cours de physique expérimentale et cultive cette science pendant vingt-huit ans. En 1776, le Sénat la nomme à la chaire de phụsique de l'Institut de Bologne, en remplacement de Balbi. 


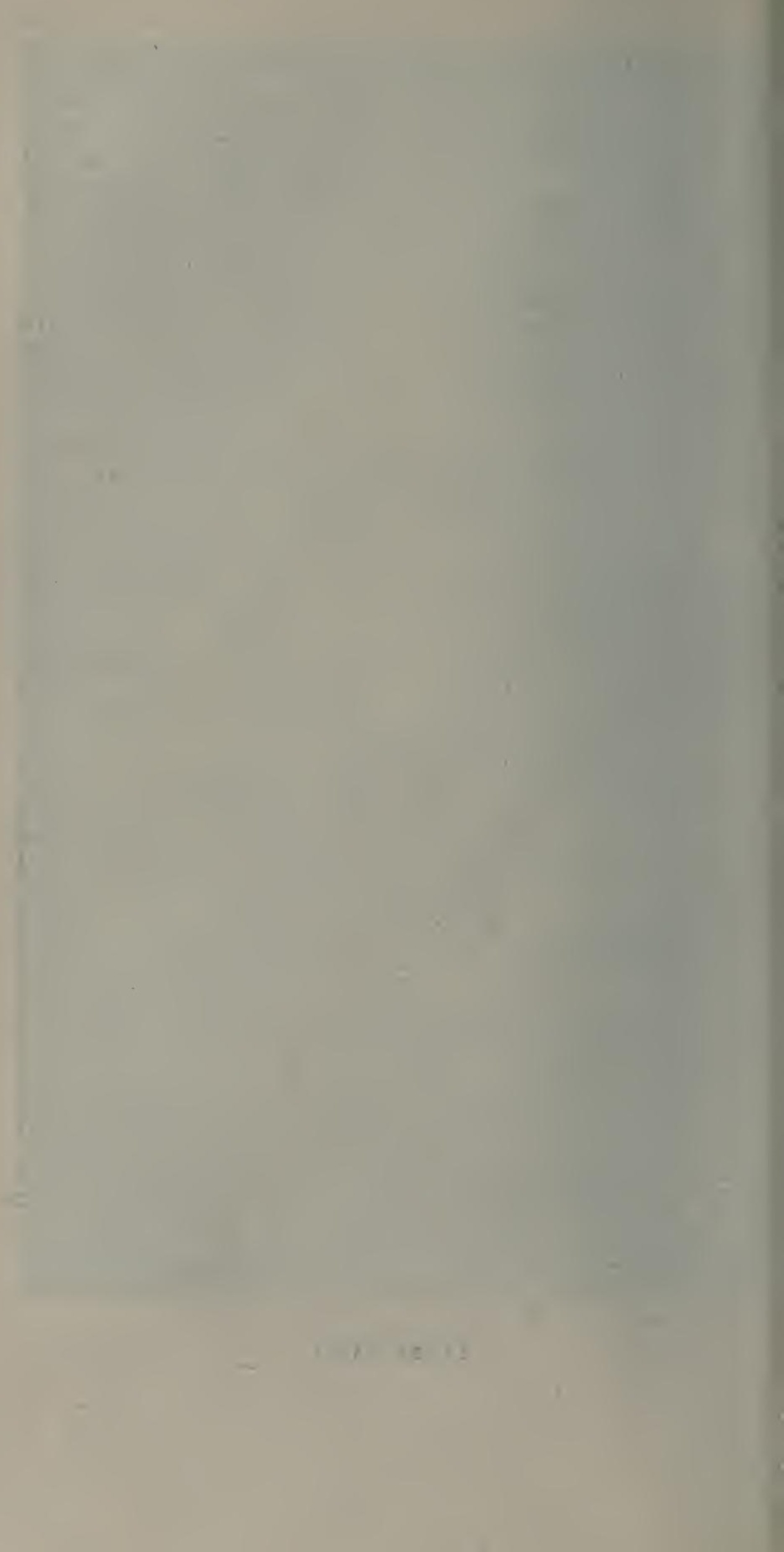


"Il ne faut pas oublier madame Laura Bassi, professeur de philosophie, laquelle a été reçue et a pris le bonnet de docteur en pleine université. Aussi en porte-t-elle la robe et l'hermine, quand elle va faire des leçons publiques; ce qui n'arrive que rarement et à certains jours solennels seulement, parce qu'on n'a pas jugé qu'il fût décent qu'une femme montrât ainsi chaque jour, à tout venant, les choses cachées de la nature. En récoinpense, on tient de temps en teinps chez elle des conférences philosophiques. Je m'y trouvai un soir, et il me fallut encore, comme à Milan, dérouiller mon vieux latin pour disserter sur l'aimant et sur l'attraction singulière qu'ont les corps électriques.

La signora Bassi a de l'esprit, de la politesse, de la doctrine; mais, a vec tout cela, je ne troquerais pas contre ma jeune fille de Milan (Agnesi.)" De Brosses. Lettres d'Italie, t. I, p. 222.

Le t. IV des Mémoires de l'Institut de Bologne contient deux dissertatîons de Bassi, l'une sur une question d'hydrométrie, l'autre sur un problème de mécanique.

Ses expériences sur la compression de l'air ont été exposées par Zanotti.

V. Mme Du BoccaGe. Lettres sur l'Italie. - Corer. Lettres d'Italie et de Hollande, t. 1, p. 96. - Bibl. ital., t. XVI. Brukfr. Biblioth. des écrivains célèbres de notre age. - Fastuzzı. Eloge de Laure Bassi, Bologne, 1778, in-4ㅇ. - Autre éloge, par Mag.Yaxi, Venise, 1806. - Ması. Laura Bassi et Voltaire (Studi et Ritratti, Bologne, 1881, in-16. - Noldet (Abbé). Lettres surl'électricité. Paris, in-12, $3^{\circ}$ partie, $2^{\circ}$ édition $(1770)$, p. 274. - Cavazza. Le Scuole dell' antico studio bolognese; Milan, 1896, in-4 (pp. 289 et 291. Reproduction d'une miniature du temps représentant la première leçon de $\mathrm{B}$. devant le Gonfalonnier et les Anciens :

Terminons par le détail des ceuvres de L. Bassi :

Rime. Venezzi, 1739, in-12.

Dialogo pastorale. Bologna, 1745.

De problemate quodam hydrometrico.

De problemate quodam mechanico.

Questi due opuscoli stanno alle page 61 e 74 del libro intitolato: De Bononiensi scientiarum et artium Institutio atque Academia commentarii. Tomus quartus. Bononiœ, 1757, in-4.

I.ettres inédites. Bologne, 1836, in-8 ${ }^{\circ}$. 


\section{BAYETTE (EUGÉNIE)}

Nièce du calculateur Fedor Thoman et professeur distinguée de mathématiques, à Paris.

\section{BÉATRIX}

L'héroïne de la Divine Comédie de Dante. Elle conduit le poète du purgatoire au paradis, l'initie de cercle en cercle, puis se perd et se fond au sein de l'éternelle beauté.

" Trois passages très courts marquent admirablement cette progression, d'après Nichelet. Dans le premier, Dante est encore si préoccupé de son aimable guide, qu'il a peine à regarder plus haut. - Elle me ramena à moi-même, en m'éclairant d'un doux sourire, et elle dit : Tourne-toi, écoute..... Ne crois pas que le paradis soit seulement dans mes yeux...!

Parvenu à un cercle plus élevé, Béatrix se transfigure ; le charme est mêlé de terreur. - Elle ne riait pas... Si je riais, dit-elle, il t'adviendrait comme à Sémélé qui tomba en cendres. Ma beauté éclate à mesure que nous montons les degrés du palais éternel ; mais je la tempère pour toi...

Enfin, lorsqu'il a franchi les derniers cercles et que l'initiation est achevée, elle lui dit : Eh bien ! il en est temps, ouvre les yeux ; regarde. Tu as vu maintenant de telles choses que tu es devenu assez fort pour affronter mon sourire!"

\section{DE BEAUFORT (V.)}

Cette demoiselle a publié : Leçons d'astronomie; Paris et Lyon, 18302,388 pp.

\section{BEAUSOLEIL (BARONNE DE)}

D’après le Magasin pittoresque, année 18'12, pp. $2,21,32$.

C'est à madame de Beausoleil que remonte la gloire d'avoir donné l'éveil sur l'importance de la richesse minérale de la France, et conçu d'un coup d'oil vraiment politique, l'augmentation du crédit à l'extérieur et de la prospérité intérieure, par l'exploitation de la nature souterraine.

Elle détaille elle-même les sciences qui sont nécessaires à un ingénieur : géométrie, mécanique, hỵdraulique, minéra- 
logie. chimie, auxquelles elle déclare sètre studieusement appliquéc pendant trente ans.

A la suite du titre Restitution de Pluton, madame de Bealusoleil avait ajouté " avec la réfutation de ceux qui eroient que les mines et choses souterraines ne se peuvent trouver sans magrie et sans l’aide des démons. ”

Un an apris l'envoi de son mémoire an cardinal de Richelieu. sans jugement, la baronne était enfermée dans la prison d'État de Vincennes et son mari dans celle de la Bastille. On ne sait à quelle époque madame de Beausoleil eut entin le bonheur de mourir. Le mari mourut en I6ł:̈.

Goвет (Anciens minéralogistes du royaume de France, 1779). in-8) publie dans le premier rol. à partir de la p. 259. les (éures du baron et de la baronne de Beausoleil. Il nous apprend que le mari était né en $10 ̈ 78$ dans le Brabant et que la femme, de mèmeàge, était française. Ils ont consacrá toute leur vie à l'étude et à l'exploitation des mines.

Pendant un rosage en Bretagne, La Touche-Grippé, préròt provincial, pensant qu'on ne pouvait découvrir des mines sans ètre magicien, profite d'une absence de Mme de Beausoleil pour saisir ses instruments, ses réactifs et ses écrits, afin de les examiner et de les dénoncer à la justice. La baromne est acquittée, elle accable de ses railleries celui qu' elle appelle Touche-Grippe-Minon et lutte en vain pendant douze ans pour obtenir la restitution de son bien.

Les deux livres de Mme de Beausoleil, la Véritable déclaration et la Restitution de Pluton sont des documents très curieux et très prícieux. On y voit qu’elle voulait traiter de la scienee et de la connaissance des mines, leurs différences, les flux propres pour leurs fontes, arec l'ordre de poids, de tin et d'ressai, ensemble l'économie des mines, l'ordre de leurs officines, etc. On lit dans un sonnet dédicatoire :

La France et les Francais rous demandent les Mines.

Lor, l'argent et l'azur, laymant, les calamines

Sont des Thrésors cachés de par l'esprit de Dieu. 
Ailleurs, à propos de la découverte, en 1629, de l'eau minérale de Château-Thierry, l'auteur déclare que " c'est une bénédiction de Dieu, de quoi je lui rends grâce... tant de cette eau médicinalle que des autres commodités par moi découvertes ». Elle promet les descriptions des principales fontaines de France, leurs vertus et facultés.

I. Vérilable déclaration de la découverte des mines et minières par le moyen desquelles Sa Majesté et sujets se peuvent passer des pays étrangers. Par Dame Martine DE Bertereau, baronne de Beausoleil, Paris, 1632, in-4; 12 pp. (Dédié à d'Effiat, surintendant des mines de France.)

II. La Restitution de Pluton, à Mgr. l'éminent card. de Richelieu, des mines et minières de France, cachées jusqu’à présent au ventre de la terre, par le moyen desquelles les finances de S. M. seront beaucoup plus grandes que celles de tous les princes chrestiens et ses sujets plus heureux de tous les peuples, par Nartine de Bertereau, dame et baronne de Beacsoleil et d'Auffembach ; 16't0, in-8, pl. d'armoiries en taille-douce, vél.

V. Bazıv. Histoire de Louis NIII.-Bulletin du bibliophile (Juillet 18'tö, pp. 310 et 311). - En. Founsien. Le vieux Paris (t. I, pp. '408 et '409). - Hénissavt. Bibliothèque physique de la France, 1771, p. 101. - LeLoxg. Bibliothèque historique, t.1.

\section{BECKER (MARTHA)}

Matérialisme et spiritualisme; Paris, chez Didier, 1 vol. in-8.

\section{BEHN (ALPHARA OU Astrea)}

Anglaise (16'10-1689), dramaturge, romancière, femme politique, mais aussi philosophe, théologienne et mathématicienne. A traduit la Pluralité des Mondes, de Fontenelle. Gibbon l'appelle l'incomparable Behn. Elle a été enterrée à Westminster, dans le tombeau des rois.

\section{BELĖZE (MARGUERITE)}

Une savante aussi douce que bonne et modeste. 
Plantes rares ou intéressantes des envirous de Montfortlimaury et de Rambouillet, par Mademoiselle Marguerite Belèze (Bull. de la Soc. botaniq. de France, t. XLII, p. '19'1). L'auteur, qui parcourt depuis plus de vingt ans la forêt des Ivelines, notamment aux environs de Montfort, de Saint-Léger et de Rambouillet, donne une très longue liste, véritable catalogue, avec indication d'un certain nombre de localités pour chaque espèce.

\section{BELOT}

Cette dame est la première traductrice en notre langue des œuvres du philosophe Hume.

\section{BENDER (EDWIGE)}

Elle continue aujourd'hui avec le plus grand talent la tradition métaphysique de Kant et de Hegel. Ellle s'est formée aux études philosophiques, à l'insu de sa famille, et son livre Essai pour la solution du problème métaphysique a produit une vive émotion dans le monde de la philosophie. Son système parait être une sorte de panthéisme fondé sur les théories Kantiennes de l'espace et les hypothèses de l'évolutionisme.

Revue bleue du 27 juin 1891.

\section{BÉRÉNICE}

Femme de Ptolémée III Evergète, roi d'Ĺgypte. L’astronome Conon plaça la chevelure de Bérénice parmi les astres. Ptolémée Philopator, son fils, la fit mourir en 216 avant J.-C.

“Vers l'an 2't6 avant notre ère, le roi d'Égypte, Ptolémée III Evergète, avait entrepris une expédition en Assyrie; sa jeune femme Bérénice, qu’il renait d'épouser récemment, s'engagea par un vœu à couper une boucle de ses cheveux et à la consacrer dans un temple, si les dieux ramenaient à Alexandrie son époux vainqueur; la guerre s'étant terminée d'une façon heureuse et Evergète étant rentré sain et sauf 
dans son royaume, Bérúnice s'acquitta envers les immortels. Au même moment, un astronome célìbre du Musée, Conon. signala une constellation qu'on n'avait pas encore observée; on s'écria que la boucle de cheveux de la reine avait été transportée au ciel et métamorphosée, par la volonté de Vénus; ce fut un grand érénement à la cour d’Alexandric ; Callimaque prêta le secours de ses vers à la fable inventée par Conon. son ami. C'est ce sujet que Catulle a repris... »

Georges Lafaye. Calulle et ses amis, p. 199.

Barrès a intitulé une de ses études : La Chevelure de Bérénice.

\section{BERGEN (FANNY)}

Collaboratrice du Popular Science Monthly. Malarle et ne quittant pas la chambre, elle a composé un lirre sur la théoric de l'érolution.

\section{BÉRONICE}

D’après Photius, une femme du nom de Bérénice, Béronice ou Phérénis a été la collaboratrice de Stobée, auteur de Maximes.

\section{BERTRAM (ROSA)}

A traduit en allemand la Théorie des déterminants de Brioschi (Préface de Schellbach). Berlin, 18:5.6.

A aidé son frère H. Bertram dans ses Solutions des Fxercices d'Algèbre de Meier Hirsch.

\section{BICKEL (M.)}

Friedn. Kraxcie. Arithmetic primer. A guide for elementary instruction in arithmetic., etc. Translated and prepared for english use. - Hanover 188.;.

\section{- BIELISCHEFF}

Cette dame russe, née Vargounin, après avoir terminé ses études à la Sorlonne, a ouvert à Saint-Pétersbourg des cours de mathématiques pour les jeunes gens. Elle a puhlié un travail sur les conditions déquilibre d'un fil flexible. 


\section{BIGNON (LOUISE-AUGUSTINE-FANNY)}

Naturaliste, née à Chàtillon-sur-Seine.

Le jeudi 21 novembre 1889, à 3 heures, Mademoiselle Bignon (Fanny), professeur à l'École Sophie-Germain, secrétaire de la Société zoologique de France, a soutenu, devant la Faculté des sciences de Paris, deux thèses ayant pour titre :

I re thèse. - Contributionà l'étude de pneumaticité chez les oiseaux. (Lille, 1889, in-8).

2e thèse. - Propositions données par la Faculté.

ylle Bignon a été déclarée digne d'obtenir le grade de docteur ìs sciences.

La mème a publié : De l'enseignement de l'histoire naturelle (Bulletin de la Société zoologique de France, 189:; t. XX, p. ̋̈I).

\section{BIHÉRON}

"Lorsque Gustave III de Suède, qui n’était encore que prince royal, visita à Paris l'Académie des Sciences, on tit devant lui des expériences d'anatomie. Le démonstrateur était une demoiselle Bihéron, atteinte pour l'anatomie et la chirurgie d'une véritable passion. Elle était parvenue à fabriquer des cadavres artificiels et inodores analogues à ceux auxquels plus tard le docteur Auzout a dù sa réputation. Gustave III nomma Mademoiselle Bihéron démonstrateur à Stokholm ou à Upsal. »

Maury. L'ancienne Académie des sciences, pp. 179-180.

Mademoiselle Bihéron s'engage à démontrer l'anatomie à vos jeunes demoiselles.

Lettre de Dinerot au général Betzky (15̈ juin 177' ). Voir aussi sur Bihéron, Diderot, II, 1'48; IX, 2'10; XX, 60.

" Madame de Genlis parle d'une demoiselle Bihéron qui faisait des pièces anatomiques si parfaitement imitées qu’on ne pourait distinguer les pièces artificielles des pièces naturelles. Un jour, le chevalier Ringle, examinant ruelques-unes 
de ces pièces s'écria : En vérité, c’est parfait, il n’y manque que la puanteur. ")

$$
\text { E. LoIRE. Anecdotes. }
$$

\section{BIOT}

Madame Biot a traduit de l'allemand un ouvrage scientifique et cette traduction a paru d'abord sous le nom de son mari, l'illustre physicien.

E. G. Fischer. Physique mécanique. Traduit de l'allemand (par $\mathrm{M}^{\mathrm{me}}$ Biot), avec des notes, etc., par I. B. Biot. Paris, 1806 (2e éd., 1813; 3e éd., 1819; ‘éd., 1829).

\section{BLACKWEELL (ANTOINETTE-BROWN)}

Auteur du livre récent publié à New-Vork : The philosophy of individuality, or The one and the Many.

Ne pas confondre avec la première femme qui a reçu le titre de docteur-médecin (18'9) et qui s'appelait Élisabeth Blackwell.

\section{BLACKWOOD (ÉLISABETH)}

Solutions de problèmes proposés dans " Educational times ").

Bibliotheca mathematica, 189:); G. VALENTIX.

\section{DE BLOCQUEVILLE (ADÉLÄ̈DE-LOUISE)}

Dernière fille du maréchal Davout; morte en 1892. L'astronomic intéresse cette grande dame, par ses mịstères et ses symboles.

"Astronomie, science des sciences, tu m'attires, tu n'épouvantes, et je t'adore; car tu détaches mon ârne des choses de la terre, car tu m'attires vers ces mondes inconnus qui arrachaient à Newton, alors qu'il contemplait les astres, ce mot triomphant: Cocli enarrant gloriam Dei!

Herschel, ébloui des éclatantes couleurs de la Croix du Sud, comparait ces joyaux qui enchantaient ses regards à un écrin de pierres précieuses répandues dans l'espace.

Verra-t-on dans le par-deli les étoiles de la Croix du Sud? 
Certes oui! on verra la Croix du Sud et bien d'autres choses! On saura s'il est vrai que les anneaux de Saturne ne réchauffent pas cette planète éloignée des soleils qui nous éclairent.

$\mathrm{Ab}$ ! vraiment, si ce monde immense, en dehors de ses anneaux, cent fois plus grand que notre pauvre petite terre, est privé de chaleur, pourquoi Saturne ne serait-il pas le lieu de chátiment des coupables et malheureux humains? Que de douloureux cette planète pourrait contenir!

Il y a de si frappants rapports entre les divers phénomènes de l'œuvre divine que l'on se demande, en songeant aux débris du monde disparu qui virent, pareils à une procession de fantòmes, autour de la patrie perdue, si la peine du dam ne consisterait pas en une éternelle promenade faite par les ames autour des lieux où elles ont vécu, aimé et où on les oublie?»

$\mathrm{I}^{\mathrm{m}} \mathrm{DE}$ Bloceueville. A travers l'invisible, p. 217.

\section{COMTESSE BOBINSKI (N.)}

Détermination de l'orbite de la $6^{\text {e }}$ comète de 1891, basée sur toutes les observations connues (une centaine environ) et déduite, d'après la méthode des moindres carrés.

Académie des Sciences de Saint-Pétersbourg, séance du 27 novembre 1893.

\section{DU BOCAGE (MARIE-ANNE)}

Vée en 1710 et morte à 92 ans. Fontenelle dont elle a soignć la vieillesse l'appelait sa fille, Clairaut la comparait à

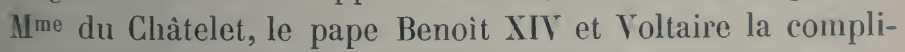
mentaient. A publić des voyages, un poème sur Les sciences . et les lettres, une ode à l'astronome Bailly, etc. Il a paru sur elle à Rouen, 1807, une notice signée GuLbert.

Dans sa Colombiade elle fait parler Colomb à un vieillard du nouveau monde. " Je doute, dit l'abbé de Laporte, que les détails astronomiques et l'exposition des différents systèmes de l'Univers soient à leur place. On parle à ce vieillard de l'éther, des pỏles, des zones, du sud, de l’Ourse, du zénith, des atomes, d'Épicure, etc. »

\section{BOIVIN}

Ime Boivin a publić, en collaboration avec Dugès, un im- 
portant travail sur les maladies des femmes. En 1827, l’Université de Marbourg lui octroya le titre de docteur en médecine "Honoris Causa ».

\section{BOMMER (E.)}

Madame Bommer, de Bruxelles, est connue par ses études sur les champignons. Elle a eu pour collaboratrice Nadame Rousseau.

\section{BON-BRENZONI (CATERINA)}

Auteur d’un poème sur l’Astronomie intitulé «Les Cieux », publié à Milan, 183̈3, par Vallardi.

Elle a adressé des vers à Madame Somerville.

\section{BOODWITCH}

Le vulgarisateur de Laplace en Amérique a dédié son astronomie à sa femme. Le portrait de Mrs Boodwitch est placé au commencement du premier volume.

\section{BOOSER}

La citoyenne de ce nom a publié le livre intitulé Triomphe de la saine philosophie, Debrai, an $\mathrm{V}$, in-8.

\section{BORGHINI (MARIA-SELVAGgIA}

Poète et mathématicienne italienne (163̈'t-1731).

Sur elle : Axgunlesi. Discorso... Pisa, 1828, in-8. - SmoNell. Elogio... Pisa, 1731, in-8. - Banboni L. Selvaggia Borghini. Pisa, 1873, in-8 (non mis dans le commerce).

\section{BOROMEO 'CLELIA)}

Cette marquise a fondé, cu Italie, l’académie de Vigilanti, pour les sciences naturelles.

V. Intermidiaire des mathématiciens. 189't, p. 23:3.

\section{BORTNIKER}

Mademoiselle Bortuiker ne s'est pas contentée de l'agrégation des jemes filles, elle a étí resue seconde, en 188.), à l'agrré- 
¿ration ìs sciences mathématiques. Ses principaux travaux portent sur les cyclides; on lit dans le Bulletin de Darboux de mai 1890 :

"Étant donnés une sphère et un point, l'auteur appelle distance moyenne du point à la sphère la puissance de ce point par rapport à la sphère, divisée par le rayon. Le moment du point par rapport à la sphère est le produit de la masse de ce point par le carré de sa distance moyenne à la sphère.

Cela posé, un système de points matériels de masses $m$, $m^{\prime}$... étant donné, quelle estl'enveloppe des sphères pour lesquelles le moment du système est constant et qui coupent orthogonalement une sphère fixe? On trouve, en considérant la valeur du moment comme un paramètre, un système de cyclides homofocales générales.

On peut disposer de la sphère directrice de façon qu'on ait des cyclides à plans de symétrie. Pour une valeur donnée du rayon, le centre aura sept positions possibles. Quand le rạon variera, le centre décrira une cubique gauche.

linfin, si l'on cherche le lieu des points d'où l'on peut mener trois sphères orthogonales entre elles et à la sphère directrice, et doublement tangentes à trois cyclides homofocales données, on trouve une cyclide."

Déjà dans les comptes rendus de l'Ac. des Sc.1887,771-773. sur un genre de transformation homographique. - Idem, 1888, 82't-29, Sur la theorie des cyclides.

\section{BORTOLOTTI EMMA)}

sulle frazioni continue algebriche periodiche. Palermo, Circolo matem., Rendiconti 9, 189בั, 136-1'49.

Bibliot. malem., 189:; G. VALENTIN.

\section{BOURGEOIS (LOUISE)}

"Ce temps si fécond pour la médecine, dit le Dr Valdeyer parlant de la fin du xvi $^{\mathrm{e}}$ siècle, a été surtout marqué par l'œuvre durable et presque parfaite de Louise Bourgeois. Femme d'un aide chirurgien barbier, clle apprit la médecine dans les ouvrages de Paré. Sa réputation alla si loin et si hant qu’elle fut nommée sage-femme de Marie de Médicis, la 
femme de Henri IV. Elle publia un livre caractérisé par un esprit d'observation pénétrant et par une lucidité merveilleuse. Cette œuvre fut traduite en Allemand d'abord, en Hollandais ensuite. Siebold, parlant de Louise Bourgeois, dit qu'elle était la digne élève d'un maître tel qu'Ambroise Paré; les faits qu'elle a décrits, sont encore aujourd'hui des modèles d'observation rigoureuse. )

Maladies des femmes (Observations diverses sur les) et enfants nouveaux naiz, amplement traictées et heureusement praticquées par Lovyse Bourgeois, dite Boursier, sage-femme de la Roine, 1609 , in-8, beau titre gravé, portrait de Marie de Médicis et de Louise Bourgeois.

V. Cimevreau. Esquisse historique sur Louise Bourgeois, médecin de Marie de Médicis. 18ă2, in-8; portrait.

\section{BOURIGNON (ANTOINETTE)}

Née à Lille en 1616, cette mystique rêva une réforme du Christianisme. Ses œurres en français et en allemand, comprennent 19 vol. (Amsterdam). Chasséc de ville en ville, comme sorcière. Morte en 1679.

Il y a sur elle un article violent dans le Dictionnaire de Bayle et une étude assez sympathique de Salomon Reinach, dans la Revue des Deux-Mondes dı Iö octobre 189'ł. Voir aussi Le Siècle de Louis XIV de Voltaire.

Swammerdam, l'anatomiste hollandais, avait adopté les idées de Mademoiselle Bourignon.

Née en 1811.

BOUVIER (ANNAH-M.)

Auteur de traités scientifiques, en particulier de Familiar Astronomy, Phila. 185̈7, in-8, $199 \mathrm{pp}$.

V. A critical Dictionary of english litterature.

\section{BOUWMEESTER (S.)}

Problème de géométrie. Mathesis ; 1887, 260. - Propriétés de certaines hyperboles équilatères, 1b. 2928-239. - Questions de géométrie du triangle, Ib. 9, 1889, 226-298. 
BOWEN (SUzANE), PUIS MRS JORDAN

Professeur de zoologie à Mount Hyloke, U. S. A., morte en 1886, remplacée par Cornélia M. Clapp.

\section{BRAHÉ (SOPHIE)}

A la fin du xvie siècle, la plus jeune sweur de Tycho-Brahé devint habile en astronomie. (Voir Les Fondateur's de l'astronomie moderne, par J. Bentraxd, p. 68.)

\section{BRANDBOURG-ANSPACH}

Ine princesse d'Allemagne, Caroline de Brandbourg-Anspach, qui cultivait les sciences arec fruit, accourut chez Newton, le lendemain de son arrivée à Londres. «J'abrège, lui dit-elle, l'étiquette d'une première entrevue, pour jouir du bonheur de (vous voir. ) Elle ajouta en le quittant: ( Je $\overline{r e n} d s$ gràce au ciel d'être née dans le siècle que votre génie immortalisera. )

\section{BROCA (C. V.)}

Miss Broca, de New-York, a envoyé au Directeur, Pickering, de l'observatoire de Harward College, 500.000 dollars pour la construction d'une lunette photographique. (Revue L'Astronomie, 1889 , p. 3oั'.)

\section{BROWN (ELISA)}

La Société astronomique de Liverpool a envoyé à Kineshma, près de Moscou, un docteur féminin, Mademoiselle Elisa Brown, pour observer l'éclipse totale de soleil du 19 août 1887.

Revue L'Astronomie, 1887, p. 36'.

E. Brown est directrice de la section solaire de British astronomical Association.

\section{BROWNING (ELISABETH)}

Voir sur sa philosophie une étude de J. Texte dans la Revue des Deux-Mondes, du 1 "̈ août 1892. "Son beau poème 
Aurora Leigh. Elle est le poète le plus philosophe de notre temps. Son poème est l'Évangile poétique de l'idéation (?) contemporaine. "

- Le droit et la justice vous sont aussi indifférents qu'un problème d'algèbre. " BruWrisg.

An collège Hall (Wellesley), il y a un salon dédié à la mémoire d'Élisabeth Browning.

V. Seldex. - Mrs Hexri Fawcett. Some eminent women of our time, pp. 111-116.

\section{BRUCE (C.-W.)}

L'américaine, Miss Bruce, a fait construire à ses frais une grande lunette photographique pour l'Ohservatoire de Harvard College, près de Boston ( 200000 fr.). Elle a aussi institué des prix d'astronomie.

Avis aux astronomes:

« M. Edward Pickering, directeur de l'Observatoire d'Harvard College (Massachusetts), fait savoir aux astronomes que Mlle C.-IV. Bruce vient d'offrir une somme de 30.000 francs, qui doit ètre dépensée en recherches scientifịues.

Cette somme sera partagée en douze parties égales, destinées chacune à un objet unique. »)

Quatre-vingt-quatre astronomes ont adressé des demandes, à la suite de l'avis précédent. Quinze ont reçu de l'argent pour leurs travaux.

\section{BRUNNER}

D'après le rapport de II. Tisserand sur l'état de l'Observatoire de Paris en 1898̈, MHe Brumer a fait don à cet établissement de la lunette zénithale construite par M. Émile Brunner, son père, et d'une lunette de $108^{\mathrm{mm}}$ d'ouverture dont l'objectif est liceuve de M.'Léon Brumner.

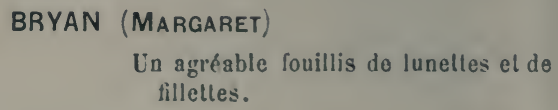

Cette maitressed'école, belle et instruite, fut, comme disent nos voisins, “ a natural philosopher ». Elle publia en 1797, 


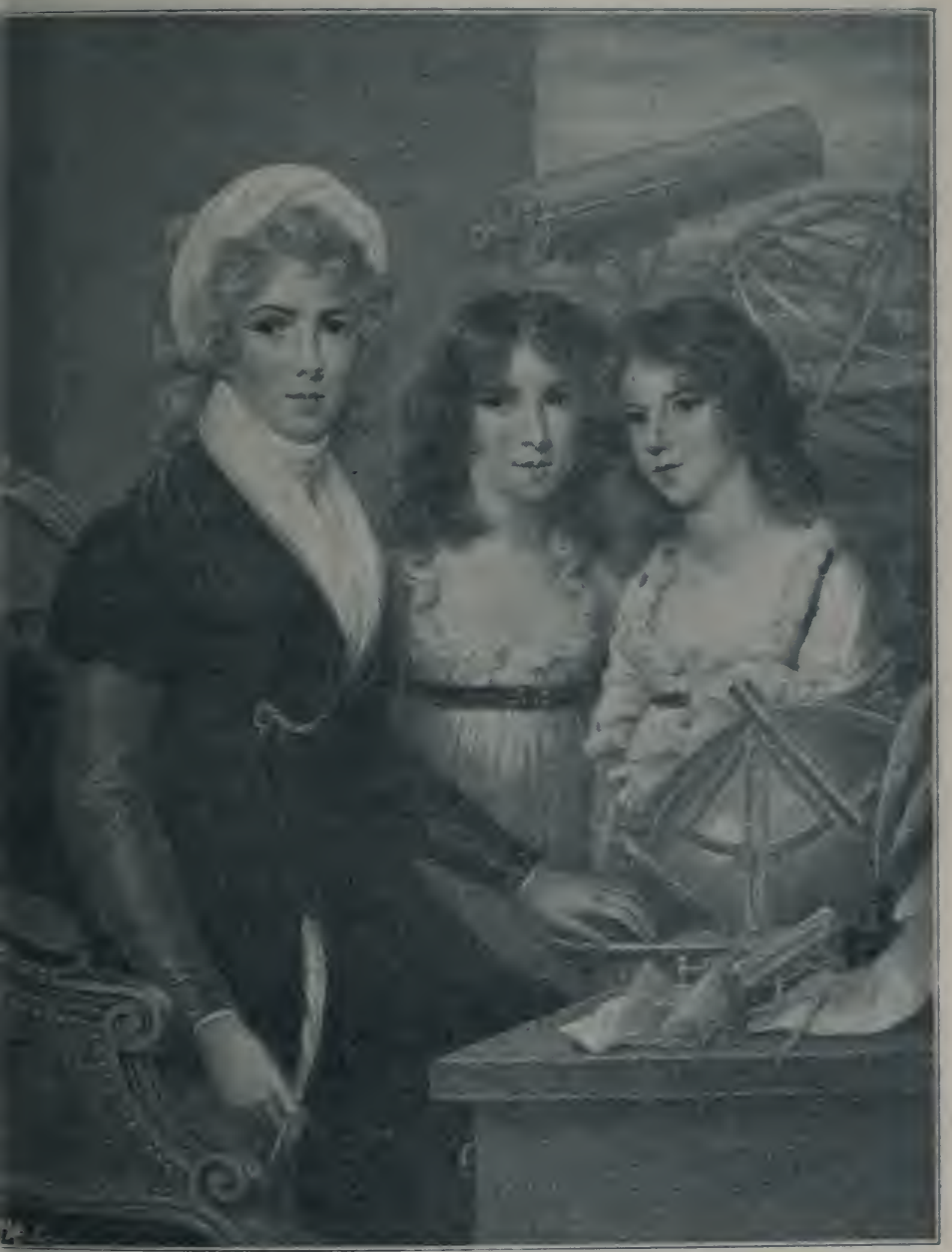

MRS BRYAN ET SES FILLES 
par souscription, A compedious system of astronomy, in-'t, avec portrait de l'auteur et de ses deux filles, gravé par Nutter, d'après une miniature de Samuel Schelley. Ce livre, vanté par Charles Hulton, a eu une deuxième édition, in-8.

En 1806, Mrs Bryan fit imprimer in-4 et encore par souscription Lectures on natural philosophy (hydrotastique, optique, pneumatique, acoustique) avec un nouveau portrait gravé par Ileath, d'après une peinture de T. Kearsley. Une note nous apprend que l'auteur donne des leçons aux demoiselles, ì Bryan House, Blackheath.

Un troisième ouvrage de la dame aux portraits parut en 18I0̈ : Astronomical and geographical Class-Book, in-8.

C'est à tort qu'on a attribué à Mrs Bryan un livre anonyme Conversations on Chimistry qui est dù à Mrs Marcet.

L'école, plusieurs fois déplacée, de IIme Bryan parait avoir joui d'une certaine réputation.

Y. Dictionary of national biograpliy. Londres.

\section{BRYANT (SOPHIE)}

Theory mathematic of probabilities. Philos. magaz. $17_{3}$, 188', ร10-ว̈18.

On the ideal geometrical form of natural cellestructure. London, Nathem. Soc. Proceed. 16, 188'-כ̃ ; 311-31\%.

An exemple in «Correlation of averages » for four variables. Philosoph. magaz., 36, 189'‘, 372-77.

\section{BUCCA (DOROTHÉE)}

Vée à Bologne d'un père philosophe et médecin, elle étudia les sciences dès son bas àge. Proclamée docteur en 1'136, elle fut chargée d'une chaire de philosophie.

\section{BUCKLAND}

Buchland (Miss) A.W. Ethnological hints afforded by the stimulants, in use among savages and among the ancicnts 1878). Antropol. Instit. Journ., 1879, pp. 239 à 2003. 
Notes of some comish and irish prehistoric monuments (1879! . Antrop. Instit. Journ. 1880, pp. 146 à 163̈.

\section{BUESCHING (JOHANA)}

Saranteallemande morte en 1783. Une notice sur elle a été publiée par son frère. Berlin, 178'.

\section{BUNBURY}

Daprès Mme Somerville (Mémoires p. 1:̈'t), ladỵ Bunhurỵ s'est livrée à l'étude des Coquilles et son fils s'est distingué dans la botanique fossile.

\section{BUSSARD ET DUBOIS}

Leçons élémentaires de Chimie, par Mlles B. Bussard et H. 1)ubois, 1893 , in- 12 .

$$
\text { BURTON (F. B.) }
$$

Astronomy familiarized. Londres, 1860, in-8.

Déjà de la même :

Distant glimpses, astronomical Slietches. Londres, 1837. in-12.

\section{BUCKLEY}

Voir Correspondance de Darwin, tome II, p. 579. Lettre à Mlle Buckley (plus tard Mme Fischer) auteur d'un lirre: A Short History of natural science.

\section{BYRD (MARY-EMMA)}

Directrice de l’Observatoire du collège Smith, Northampton, Mass.. U.S.A.

\section{CALDERINI (NOVELLE)}

Fille de Jean Audry, légiste à Bologne. Exposait la philosophie des lois, lorsque son père était malade. Elle était si belle, qu'on devait tendre un rideau entre la chaire et les auditeurs, pour éviter les distractions de ceux-ci. (Voir le tableau ébauché par Frangois Gérard en 18:31.)

Sa sour Bettina a été une légiste. 


\section{CALLCOTT}

Mrs Calleott a étudié, en 1829, arec précision, un terrible tremblement de terre à Valparaiso et le long de la cote. (Transactions of the geological society.)

\section{CARLyLe (ANNie), née WELSH}

"Ses études furent brillantes. Elle avait des dispositions si remarquables pour les sciences qu'on l'envova à la classe de mathématiques des garçons où elle prit la tête. »

Arvene Banise. La femme d'un grand homme. (Revue des Deux-Mondes du 1:5 octobre 188't.)

\section{CARPEGNA}

Comtesse romaine, savait six langues, très versée dans toute la philosophie.

Voir Ritschianus, 20 novembre 1670 (Romæ prescriptis.)

\section{CARPENTIER (ÉMILIE)}

La botanique d'Andrée, s. d. ; in-8 ; figures.

\section{CARTER (ÉLISABETH)}

A traduit de l'italien en anglais, à Londres, 1739 et $\mathbf{1 7} 12$, deux ouvrages de F. Algarotti :

$I^{\circ}$ La philosophie de Newton expliquée.

2. La théorie popularisée de Newton, sur la lumière et les couleurs.

V. Mémoires sur les vies de Mrs E. Carter, par M. PenvingTox, qe édition, 1808, 2 rol.

\section{CATANI GIOSEPpIna)}

Professeur de pathologie générale à la Faculté de médecine de Bologne. Elle avait été, jusque dans ces derniers temps, suppléantedu Professeur Tizzoni. Les étudiants étaient depuis longtemps habitués à l'entendre professer. La première leçon qui elle a faite a eu lieu devant un amphithéátre comble. La 
jeune doctoresse a fait preuve d'un véritable talent de parole et d'exposition, d'une grande clarté.

Des applaudissements frénétiques l’ont saluée à la fin de son cours.

\section{Catherine d'AleXandrie (Sainte)}

Lorsqu'au Ive siècle, le tyran Maximin ou Maxence, vint à Alexandrie faire adorer les.idoles, la jeune Catherine réfuta les rhéteurs par la force de ses syllogismes, et subit, dit-on, le supplice de la roue en l'an 311. On rapporte qu'elle avait déclaré à ses bourreaux : " Je me suis exercée dans toutes les parties de la rhétorique, de la philosophie, de la géométrie et des autres sciences. »)

Catherine, fètée chaque année le 20 novembre, est représentée avec une roue à demi rompue et teinte de sang, pour la distinguer des autres saintes de mème nom. Elle est à la fois la patronne des classes de philosophie et la patronne des vieilles filles.

Certains protestants ont contesté le supplice de Catherine d'Alexandrie et prétendu qu'il s'agissait du meurtre d'Hypatic.

Ine religieuse nommée Delachapelde a écrit la Vie de Sainte Catherine (Autum, 1663, in-8). - Consulter surtout le livre de Mielot, dans la belle édition illustrée qu’a donnée Sepet, in-4, 1881.

"Catharina, vierge et martyre à Alexandrie, $\mathrm{I}^{\mathrm{e}}$ siècle; culte introduit au $\mathrm{xII}^{\mathrm{e}}$ siècle dans la liturgie romaine ; fète, 2马 novembre. )

Grirs. Manuel de diplomatique.

\section{Catherine de CLERMONT}

Duchesse de Retz (15้'3-1603), avait étudié la philosophie et les mathématiques.

\section{Catherine de médicis}

Luca Gaureco, versé dans l'astronomie et les sciences naturelles, avait enseigné l'astronomie à Catherine. Les astrologues de la reine observaicut à liHòtel de Soissons. 


\section{Catherine de PORTUGaL}

Duchesse de Bragance, morte en 1อ̈82. Qualifiée de savante en lettres et en mathématiques.

\section{Catherine II de russie}

Blessée de certaines appréciations contenuesdans le Voyage en Sibérie, par Chape d'Anteroche, la grande Catherine essaya de les réfuter, dans son Antidote du voyage de l'abbé Chape. Elle organisa ensuite une autre expédition scientifique dont elle confia la direction au naturaliste Pallas.

L’auvergnat Chape était allé observer le passage de Vénus, à Tobolsk (Sibérie). Le pamphlet de Catherine II a été imprimé à la suite de l'édition d'Amsterdam dı Voyage en Sibérie, de l'académicien francais (1769-71), 6 rol. in-12. L’impératrice, laissant de côté l'astronomie de Chape, s'en prenait à ses observations statistiques, politiques et histori(ques. Le savant n’avait-il pas osé écrire que la Sibérie est presque dépourvue de végétation ! Elle envoya à Voltaire des noix de cèdre sibérien pour prouver le contraire. L'abondante réfutation, où la princesse Dachkof prêta main forte à sa soureraine, se trouve à notre Bibliothèque nationale, en exemplaires rares de la Ire et de la 2 e édition.

In trait assez piquant : la grande Catherine désigna comme directrice par intérim de l’Académie des Sciences de SaintPétersbourg, une dame du Palais déjà nommée, la princesse Dachkof.

On lit dans la vie de Catherine II (Paris, an VIII. t. II, p. 313̈) : En 1786, l’impératrice fit l’acquisition de la riche collection d'histoire naturelle forméc par le savant Pallas. Elle avait açuis quelques années auparavant la bibliothèque de d'Alembert.

V. Cistera. Histoire de Catherine II, impératrice de Russie. Paris, an VIII, 4 vol. in-12, avec portraits. - Surtout K. Wiliszewsit. Le roman d'une Impératrice, 189'; gr. in-8. (Nous avons fait des emprunts à ce dernier livre.) 


\section{CATLOW (AGNÈS)}

A publié, de 18 10 à $18 \%$ ğ, des traités scientifiques populaires: Botanique ; Entomologie ; Zoologie ; Conchyliologie ; Drops and water.

\section{CAUCHY}

Le grand géomètre fut d'abord commis en soieries à Lyon. Il recherchait en mariage la fille de son patron. Elle exigea qu'il entrât à l'École polýtechnique. Il quitta le magasin pour les hautes études et, pendant son absence, la jeune lyonnaise se maria avec le commis qui avait remplacé Cauchy dans la maison.

\section{CEDERCRENTZ (FANNY), NÉE LAGERBORG}

La baronne Cedercrentz habite maintenant Helsingfors (Finlande). On lui doit :

Étude sur la variation des indices de réfraction et de la densité du sel gemme sous l'influence de la température. Stockholm, 1888.

Sur le problème du mouvement d'un corps solide autour d'un point fixe. Paris, Bulletin de la Société mathématique, 1890, pp. 118 à 122 (Résolution complète de ce problème : Trouver une fonction de forces conduisant à des intégrales elliptiques, dans le cas générảl du mouvement d'un corps solide de révolution, fixé par un point de son axe.)

\section{CERETA-SERINA LAURE)}

I'après Napoléon Petrucci, Delle donne illustri di Padov'a $\left(18^{\prime} 10\right)$ :

"Appartenant à me illustre famille, Laura manifesta de bonme heure des talents exceptionmels. A dix-huit ans, elle soutenait des thìses publiques sur la métaphỵsipue; à vingt, elle professait à l'Universitć, où l'on armirait ses commaissances philosophiques et théologiques, ainsi que son savoir daus les mathématiques. Elle mourut avant l'àcre de trente ans, dans les eommencements du xve siècle. » 


\section{DE CHAMBRUN}

La comtesse de Chambrun est la fondatrice du Cours d'Histoire de l'Économie sociale, que M. Espinas fait à la Sorbonne.

\section{CHANTICLAIR (HENRI}

Auteur de L'herbier de Jeanne, in-18.

\section{CHANTRE}

M. Chantre, directeur du musée géologique de Lrion, a été chargé, par le Gouvernement, d’une mission scientifique en Arménie. Il a accompli sa mission, accompagné de sa fémme. M. et Mad. Chantre ont rapporté de belles collections génlogilyues et botaniques recueillies sur l'Ararat, à 3.:̈00 mètres d'altitude. Ils ont également réuni de nombreux documents anthropologiques et près de 200 vues photographiques.

\section{DE CHARRIÈRE}

Isabelle de Tuỵll, qui devait devenir Madame de Charrière, est née en 17130, près d’Utrecht. Hollandaise par sa naissance. suisse par son mariage, française par ses ielations et ses idées, elle est l'auteur d'un roman, Calixte, et des Lettres de Lausanne. "Elle s'occupe de science arec ardeur, dit M. P.Godet, elle a l'esprit géométrique, comme Mme de Staal-Delaunay, qu'elle admirait fort, par une sorte d'instinct de parenté. Sainte-Beuve ne l'a-t-il pas appelée " une mademoiselle Delaunay égarée à Harlem ») ?

Ci-joint un extrait de Mad. de Charrière, d'une belle allure.

" J'étudie avec la plus grande application toutes les propriétés des sections coniques... Une heure ou deux de mathématiques me rendent l'esprit libre et le cœur plus gai; il me semble que j'en dors et mange mieux, quand j'ai vu des vérités évidentes et indiscutables; cela me console des obscurités de la religion et de la métaphysique, ou plutôt cela me les fait oublier; je suis fort aise de ce qu'il y a quelque chose de sîr dans ce monde...

Je in’ennuie à la mécanique, et pourtant je l'apprends ; ne faut- 
il pas savoir pourquoi un levier est un levier, et comment l'on fait une balance, et -où Archimède eût pris son point d'appui pour soulever la terre...

A propos de philosophie, je commence dans huit jours un cours de physique spéculative et expérimentale. Il y a longtemps que j'en mourais d'envie...

On dit que je dédaigne toute conversation commune et que je crois mon esprit au-dessus de tout; on trouve mauvais que je veuille savoir plus que la plupart des femmes, et on ne sait pas que, très sujette à une noire mélancolie, je n'ai de santé, ni pour ainsi dire de vie, qu'au moyen d'une occupation d'esprit continuelle. Je suis bien éloignée de croire que beaucoup de science rende une femme plus estimable, mais je ne puis me passer d'apprendre; c'est une nécessité où m'ont mise mon éducation et ma façon de vivre...

Pour un trône je ne renoncerais pas à ce qui m'occupe dans ma chambre. Si je n'apprenais plus rien, je mourrais d'ennui... Songez que mes goûts ont tenu bon contre le préjugé, contre le ridicule dont on a voulu me couvrir mille fois, contre l'exemple de paresse et de stupidité que les trois quarts et demi de mes compatriotes me donnent, contre l'air pesant de ce pays. ")

La Revue des deux Mondes a publié sur: Madame de Charrière trois études, dont deux de SAIvTE-Beuve (18'1'4 et 18:̈̈), l'autre de M. P. Godet (juin 1891).

\section{ÉmILIE dU CHATELE'T}

Une femme qui a traduit et éclairci Newton; en un mot, un très grand homme.

Volt.iIRe.

Les Comancenents. - Au dix-huitiène sìcele, on remarque une savante moins vertueuse (ju’Hypatie. Je dirai les travaux de mathématiques et de phy̌sique qui défendent la mémoire de la marquise du Chàtelet.

Gabrielle-Émilie Le: 'Tonnelier de Breteuil, tille d'un introducteur des ambassadeurs, est née à Paris, en 1706.

Elle était prédestinée, si on en croit cette anecdote : " Un assez grand compas de bois, à grosse tête, imais dégarni de ses pointes, tomba sous la main de quelqu'un de la maison. 
On s'avisa d'habiller ce compas en poupée et de le faire servir de jouet pour la petite Émilie. L'enfant, l'ayant examiné pendant quelque temps, commença par le dépouiller, avec une sorte d'indignation ou d'impatience, des draperies importunes dont on l'avait affublé; et, après l'avoir retourné plusicurs fois entre ses mains débiles, elle vint à en découvrir l'usage. Alors, comme par instinet, on la vit tracer, avec cet instrument dégradé, une figure informe, mais dans latquelle cependant on n'eut pas de peine à reconnaitre un cerele, qui est, comme on sait, la figure la plus parfaite en géométrie. »)

La première instruction de Mademoiselle de Breteuil fut soignée. Elle apprit le français et en outre le latin, l'anglais et l'italien. Madame de Genlis raconte, dans ses mémoires, que son grand-père, M. de Mézières, donna à la jeune fille les premières leçons de Sciences.

Mademoiselle de Breteuil épouse, à dix-neuf ans, le Mar'puis rlu Chàtelet-Laumont, lieutenant-général des armées du Roi. Elle a un tabouret chez la reine et elle mène à la Cour une vie brillante et dissipée.

En 1733, Madame du Chàtelet devient pendant une quinzaine d'années, jusqu’à sa mort, l'amie de Voltaire.

Au chateau de Cirex. - Le chàteau de Cirey est voisin de Chaumont, dans le plat et monotone pays de Champagne, à deux pas de la frontière lorraine. M. du Châtelet y offrit IThospitalité à Voltaire, que la Marquise vint bientòt rejoindre.

La pièce principale de l'appartement était une longue galerie servant de laboratoire de physique. L’abbé Moussinot y recevait et y rangeait des ballots d'instruments, machines pneumatiques, télescopes, etc. Pendant ce temps, un jeune homme, nommé Cousin, faisait à Paris des expériences pour le compte de Cirey.

Quelques citations nous montreront quelle était la vie habituelle au chàteau. “ L’un fait des vers, dit Hénault, l'autre des triangles. ») Le valet de chambre, Longehamps, une ve- 
nimeuse commère, constate que « Madame du Chàtelet passait une grande partie de la matinée au milieu de ses livres et de ses écritures. » Madame Denis : “ Non seulement Émilie travaillait le jour, mais elle passait les nuits à son secrétaire et n'entrait dans son lit qu’à einq ou six heures du matin. » Enfin Madame de Graffigny : “ Elle toume la tête à Voltaire arec la géométrie, elle n’aime que cela. » Pourtant, la Marquise faisait quelquefois une longue course aux environs, sur l'Hirondelle, sa jument farorite.

Le soir était consacré à la conversation, comme nous l'apprennent les petits vers de Voltaire :

Mlais je vois venir, le soir,

Du plus haut de son aphélie, Notre astronomique Émilie, Avec un vieux tablier noir, Et la main d'encre encor salie;

Elle a laissé là son compas

Et ses calculs et sa lunette.

Maîtres et anis.- On peut dire que Voltaire était, pourles sciences, l'élève de Madame du Châtelet et, il faut l'avouer, un élève assez médiocre. Toujours en désaccord, sur la philosophie de Leibniz, sur la théorie du feu et sur la force vive, ils ne se réconcilìrent qu'en Newton, qu'ils ont ensemble popularisé en France. Quelque part. Voltaire s'étonne, à propos de la réfraction de la lumière, de ce que le sinus, qui est la mesure de l'angle (sic), ne lui soit pas proportionnel; ailleurs, il refuse d'admettre qu'on puisse mener d'autres lignes, entre une circonférence et le cercle tangent. Voilà l'homme qui voulait être, dit-on, Secrétaire perpétuel de l'Académie des sciences, malgré Clairaut lui disant : “Laissez les sciences à ceux qui ne peurent pas être poètes ! ”

Le Prince royal de Prusse envoyait un encrier d'ambre à Vénus-Yiewton, comme il disait, et lui promettait de lire la physique de Muschenbroeck, l'hiver suivant. Il préféra alors réfuter Machiavel, sans doute pour mieux s'en pénétrer. 


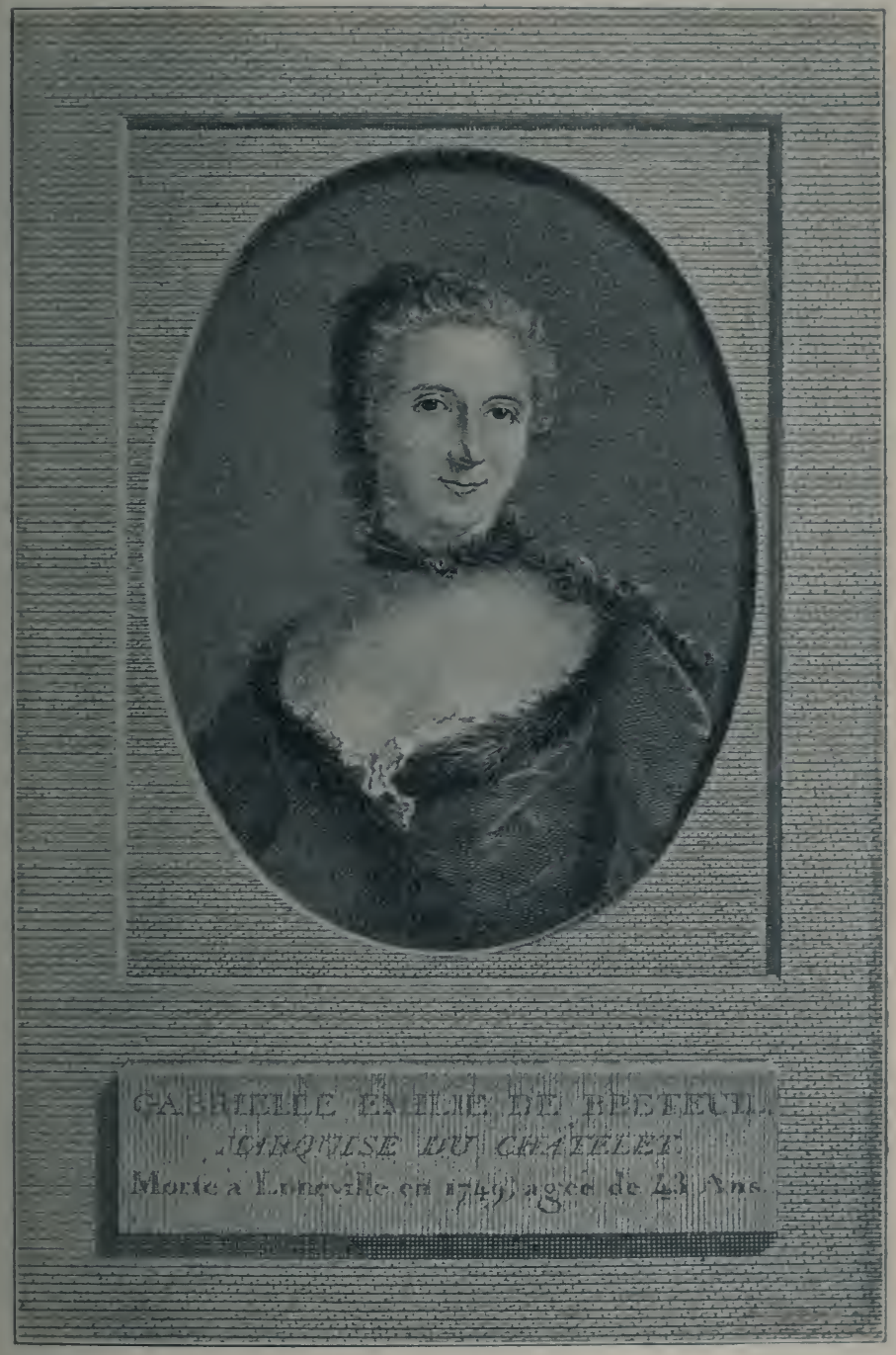



Litalien Algarotti, un des hòtes 'du Château, est l'auteur du Newtonisme pour les dames; il essaye en vain d'imiter l'élégant badinage de Fontenelle.

Les deux principaux maitres et correspondants de Madame du Châtelet sont Maupertuis et Clairaut, deux mathématiciens de valeur, dévoués aux doctrines de Newton. Citons atussi Jean Bernoulli, Konig et le père Jacquier.

La marquise appelait volontiers sa cour de sarants les Émiliens et elle se proposait d'écrire des mémoires qu’elle aurait intitulés Émiliana.

Le physigue et le moral. - Il y a aux Estampes de la Bibliothèque nationale une vingtaine de gravures et de dessins représentant Madame du Chàtelet. Ils sont faits, pour la plupart, d'après le pastel de Latour ou le portrait dû ả Marianne Loir; nous avons préféré ce dernier. Quant aux portraits écrits, vous connaissez celui si méchant où Madame du Deffand ne donne pas à notre physicienne le prix de physique. Madame de Graffigny, déjà nommée, ne flatte pas non plus le modèle : "C'était un colosse en toutes proportions; c'était une merveille de force ainsi qu'un prodige de gaucherie; elle avait des pieds terribles et des mains formidables; elle avait la peau comme une ràpe à muscade; enfin la belle Émilie n'était qu'un vilain cent-suisse. » Écoutons plutòt Madame Louise Colet: " Madame du Châtelet était grande, svelte et hrune. Nous avous vu un fort beau pastel qui la représente à vingt ans. Le jour où l'artiste a tracé pour la postérité cette virante image, la marquise portait une agaçante robe bleue, pomponnée de blanc; ses éclatants chereux légèrement poudrés faisaient paraître plus encore son grand oil noir qui raỵonnait sous un épais sourcil; sa bouche expressive souriait; sat taille souple et fine s'épanouissait dans un corsage de soie. Telle elle était alors, telle elle fut jusqu’à la fin de sa vie si courte, car sa beauté consistait surtout dans une vive physionomie, mélange de force et de gràce. »

La Nationale conserve la plupart des manuserits de la 
marquise. Elle a une grosse écriture qu'elle rature sans pitié: elle ne veut pas que l'expression trahisse sa pensée.

Au moral, Madame du Chàtelet était pleine de naturel, de simplicité et de franchise. Son caractère était résolı et logique. Elle aimait la vérité et la justice. Elle refusa de lire un libelle publié contre elle et ne voulut pas qu'on punit le coupable.

Elle avait conservé, malgré ses études, une certaine frivolité. Son goût pour la parure et les diamants était très vif. Et puis, elle riait de si bon cœur aux marionnettes !

Traracx scievtifoces.- A prìsees trop longs préliminaires, parlons enfin des travaux scientifiques de Madame du Chàtelet. Ils sont au nombre de quatre principaux.

L’Académie des Sciences avait proposé «Le feu », comme sujet d'un de ses concours. Voltaire avait composé un mémoire, mais la marquise n'en fut pas satisfaite et résolut d'étudier à son tour la question, secrètement. Aucun des deux mémoires n’obtint le prix, parce qu'il y avait un troisième concurrent qui s'appelait Euler. "Le numéro 6, dit le rapport, est d'une dame du plus haut rang, il est rempli de vues et de faits. » " Le travail d'Émilie, dit à son tour Arago, n’est pas seulement un élégant tableau de toutes les propriétés connues alors des physiciens ; on y remarquait encore divers projets d'expériences, une entre autres qu'Herschel a fécondée. " Le Mémoire sur le feu est imprimé dans les Collections de l'Académie : la marquise y soutient que la chaleur et la lumière ont la mème cause.

Le second ouvrage s'appelle Institutions de physigue. II faut prendre le mot dans son sens étymologique de fondements ou de principes. Le livre (dont nous reproduisons ciaprès la page de titre) est dédié par Madame du Chàtelet à son fils. "Jai toujours pensé que le deroir le plus sacré des hommes était de donner à leurs enfants une éducation qui les empêchât dans un âge plus avancé de regretter leur jeunesse, qui est le seul temps où l'on puisse véritablements instruire; 
vous ètes, mon cher fils, dans cet àge heureux où l'esprit commence à penser et dans lequel le ceur n'a pas encore des passions assez vives pour le troubler. ") (Nous donnons plus loin le fac-simile de ce passage du manuscrit.) La phỹsique positive n'était pas encore décourerte. La marquise exposait la philosophie de Leibniz et dissertait sur le temps, l'espace et la force.

Faut-il mesurer la force par le produit de la masse et ie la vitesse ou par le produit de la masse et du carré de lit vitesse ? Cette discussion entre la quantité de mouvement et la force vive divisait les bons esprits: d'un còté, Descartes, Newton et en sous-ordre Voltaire; de l'autre, toute l'École de Leibniz et Madame du Châtelet. Certains effets dépendent de la première expression, mais les plus importants dépendent de la seconde, en particulier le travail mécanique. L’avenir devait domner raison à la marquise : dans le monde physique, la quantité de matière et la quantité de force vive sont permanentes et ne font que se transformer.

On appelait philosophie naturelle au xvre et au xvir siècles, l'étude physique, mécanique et mathématique de la nature. Dans le livre de Newton, intitulé Principes de la philosophie nuturelle, resplendissent les deux plus grandes découvertes du génie humain : le principe de l’attraction universelle qui règle l'équilibre et le mourement des astres et des atomes, et le principe des fluxions ou du calcul des infiniment grands et des infiniment petits. Le livre des Principes, comme on dit pour abréger, n’a que cincl cents pages, d'une synthèse géométrique très serrée. Pour traduire ce livre du latin, comme l'a fait Madame du Chàtelet, il fallait le comprendre à fond pour le faire comprendre aux autres. Cette traduction n'a paru qu'en 17อั9, après la mort de la marquise. Elle y a joint un commentaire qui n’a pas été assez remarqué. Il est probable que Newton a établi d'abord sa théorie à l'aide du calcul infinitésimal dont il est l'inventeur avec Leibniz, puis qu’il l’a transposée pour la présenter 


\section{INSTITUTIONS}

\section{$D E$}

\section{$P H Y S I Q U E$.}

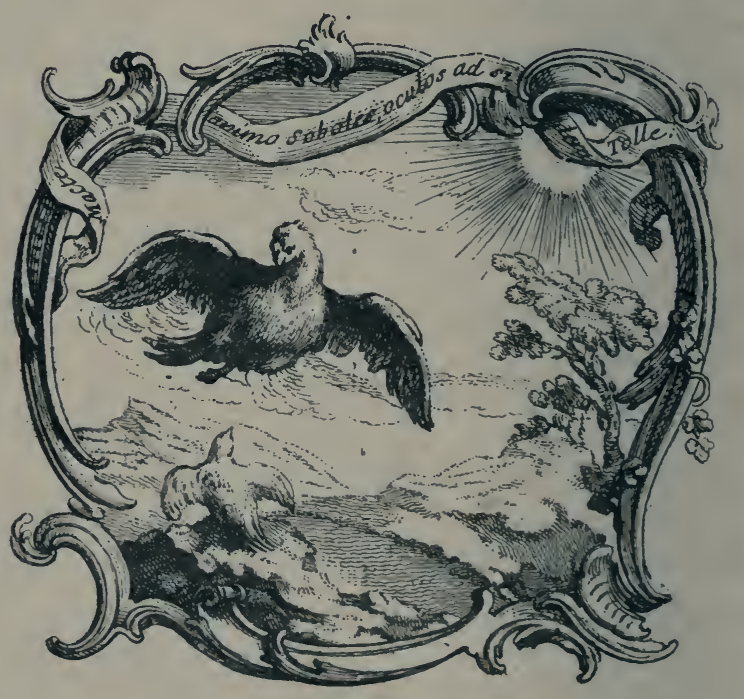

\section{A P A R I S,}

Chez PRAult fils, Quai de Conty, vis-à-vis la defcente du Pont-Neuf, à la Charite.

M. D C C. X L.

Avec Approkation of Privilége àn Roi. 
sous la forme consacrée par les Anciens. La marquise a reconstitué, d'après les idées de Clairaut, le travail primitif de Newton et l'a intitulé : Solutions analyliques des principaux problèmes du système du monde. Elle composait chaque chapitre, dont elle faisait tous les calculs, puis le soumettait à la revision de Clairaut.

Mademoiselle Delaunay, une scientifique aussi, comme nous disons dans notre jargon moderne, une scientifique spirituclle, raille dans ses mémoires la savante Émilie, alor's à la petite cour de Sceaux. "Elle fait actuellement la revue de ses Principes : c'est un excrcice qu'elle réitìre chaque année, sans quoi ils pourraient s'échapper et même s'en aller si loin qu'elle n'en retrourerait pas un seul. Je crois bien que sa tête est pour eux une maison de force et non pas le lieu de leur naissance."

Mexus Écirts. - Madame du Chàtelet a laissé quelques autres écrits et sa correspondance.

Le petit Traité du bonheur est sec et positif. Les conditions nécessaires et suffisantes sont énoncées d’abord, puis démontrées par ordre. Voici deux citations assez piquantes. "Nous n'avons rien à faire en ce monde qu à nous procurer" des sensations agréables. "Ailleurs : A l'égard des malades, des cacochrmes que tout incommode, ils ont d'autres espèces de bonheur : avoir bien chaud, bien digérer leur poulet, aller à la garde-robe est une jouissance pour eux. " Son ton s'élève pourtant, lorsqu'elle célibbre les bienfaits de l'étude, pour les femmes surtoat: "Guand, par hasard, il s'en trouve quelıu'une néc avec une àme assez álevée, il ne lui reste que l'étude pour la consoler de toutes les exclusions et de toutes les dépendances auxquelles elle se trouve condamnée par état."

Les Leltres de .Madame du Châtelel ont été publiées par U. Asse, avec une préface, des notes et un index. On y roit arec quelle passion la maryuise cherchait à sünstruire auprès de tous les savants compétents. Je rerrette que l'éditeur 
consciencieux se croie autorisé à sauter çà et là plusieurs passages, sous prétexte qu'ils sont scientifiques. Il faut alors consulter les manuscrits, à la Nationale.

Enfin le petit écrit intitulé Preuves de l'existence de I ieu est un exposé des preures classiques. La marquise est déiste, mais elle est aussi sensualiste et épicurienne.

LA MonT. - Nadame du Chàtelet mourut prématurément en 17'19, au Palais de Lunéville, après la naissance d'une fille. Ce fut une imprudence qui l'emporta : elle but un verre d'orgeat glacé, dans l'ardeur de la fièvre.

La pauvre marquise fut couchée sur un brancard de tleurs et enterrée dans la chapelle voisine.

Le pour et LE CoNtre. - Pour les gens superficiels, on peut résumer Madame du Chàtelet dans ce distique :

Ie l'esprit et des appas,

L'éventail et le compas,

le compas étant simplement une singularité.

Il faut avouer qu'il n'y a pas dans la vie de la marquise cette unité qui plait. D'autre part, un moraliste l'apostrophe "Femme sans foi, sans mœur's, sans pudeur! ) Nous devons reconnaitre en effet que Nadame du Châtelet a jeté quelquefois son compas par dessus les moulins. D'autre part, la savante, en tant que savante, mérite l'admiration do tous. Voltaire a dit : "Une femme qui a traduit et éclairci Newton, en un mot un trìs grand homme. " Ampère affirme à son tour que : “Madame du Châtelet est un génie en géométrie. "

\section{BIBLIOGRAPHIE}

\section{OEuvres de $M^{\text {me }} d u$ Châtelet.}

Institutions de physique. 1740, in-8, frontisp. gr.; 20 édition, Amsterdam, portr. - Traduction allemande par von Steinwehr, Halle et Leipzig, 1743, portr. - Traduction italienne, Venise, 1743.

Réponse à M. de Mairan sur les forces vires. Bruxelles, 1741, in-8. Traduction italienne par Giuliani, 1743: memorie sopra la fisica. - Traduction allemande par Mme Gottsched-Kulmus.

Dissertation sur la nature et la propagation du feu, 1744, in-8. (Aussi dans les prix de l'Académie des sciences, piéces de 1738.) 
Principes sur la philosophie naturelle, traduit de Newton.(Posthume.) 1759, 2 vol in-4. (Commentaire et planches.)

Lettres. L'édition la plus complète est celle de Asse, in-18.

Réflexions 'sur le bonheur (Dans : Opuscules philosophiques et littéraires, 1796)

De l'existence de Dieu (Imprimé à la suite de l'édition de 1806 des Lettres).

\section{Sources pour $M^{\mathrm{me}}$ du Châtelet.}

Le P. Paulian. Dictionnaire de phrsique.

La Place. Pièces intéressantes, t. V.

Grimm, Diderot. Correspondance littéraire, III, 87, 96, 104; VI, 158 ; IX, 321 .

Louise Collet. Revue des Deux-Mondes du 15 décembre 1845.

Voltaire. Epître à Uranie; vie de $I^{\mathrm{me}}$ du Chàtelet; correspondance. (Consult. la table générale des œurres compl.)

I'Nlbanès. Voltaire et $M^{\mathrm{mo}}$ du Châtelet, 1863, in-12.

De la Beaumelle. Vie de Maupertuis ; pp. 60-1.

Abbé Piot. t. VIl des Mémoires de la Société de Saint-Dizier. Mmo du Chàtelet (Il a été fait un tirage à part).

L'Intermédiaịre des chercheur's et des curieux, 1891, pp. 13, 178.

Sainte-Beuve. Lundis, t. XIII, pp. 13 et 178.

Saint-Marc-Girardin. Revue des Cours littéraires du 16 janvier 1869.

Histoire littéraire des dames françaises; $t$. IV.

L. Perrey. Le président Hénault et Mmo du Deffant. Chap. 7, p. 251.

Dubois-Reymond. Revue scientifique (rose) du 25 juillet 1868. Résumé d'un discours à Berlin sur Voltaire physicien. - Une traduction par Lépine, in-8, 1869.

Imo de Graffigny. Voltaire et $\mathrm{M}^{\mathrm{m} e}$ du Châtelot, 1820, pet. in- 8 (ou édition Asse des Lettres de Mmo de Graffigny, 1879).

Emile Saigey. Les Sciences au $x^{2} m^{e}$ siècle; La physique de Voltaire. 1873, in-8.

Delambre. Histoire de l'astronomie au $x^{\prime}$ III $^{\circ}$ siècle, pp. 3 à 31 . (La traduction des Principes y est résumée.)

Desnoirestierres. Voltaire et la Société au xvmº siècle. 1871-6;8 rol. in-12. t. 11 .

Chasles. Rapport sur les progrès de la géométrie, pp. 36-7.

Capefigue. La marquise du Chàtelet et les amies des philosophes; 1868.

De Lescure. Les femmes philosophes ; 1880 , in-18.

Sourry. Voltaire physicien, dans Portraits du xvmº siècle.

Marquise de Créquy. Souvenirs. (Passim. - I la p. 104 du t. I., il est question de la Baronne de Breteuil, mère de la Marq. du Chàtelet : " Elle était prodigieusement instruite, et les leux parties du savoir où ma tante excellait étaient surtout lit théologie et l'astronomie. ")

Les portraits de la marquise sont nombreux, les deux principaux sont dus à La tour (Musée de Saint-Quentin ?) et a Marianne Ioir(Musée de Bordeaux). Ils ont été souvent reproduits; nous avons préféré le second. - V. aussi l'image dans la Galerie française de Restout, Monnet del., Lempereur sc. - Dans ll Newtonianismo per le dane d'Algarotti, Naples, 1737, in-4, le frontispice de Battil Piazzetta, gravé par Pitteri, représente $\mathrm{I}^{\mathrm{m}} \mathrm{e}$ du Chatelet et l'auteur se promenant dans les jardins de Cirey. 
Autographes. Aux Manuscrits de la Bibliothèque nationale. Fonds français : 1226\%, Institutions de physique; 1266 et 7 , Principes, etc.; 1268, Commentaires des mèmes; 1269, Lettres à Maupertuis (de l'année 1734 à 1741).

\section{DE LA CHAUX}

Mtle de La Chaux, amie de Condillac, lui conseille a de commencer par le commencement, de rejeter, avec Hobbes, la distinction des deux substances dans l'homme. "

Voir dans Diderot : Mlle de La Chaux, auteur d'une traduction des Essais sur l'entendement humain de Hume, I, 396, 398, 410 , ete.

"A.-A. Barbier (Dictionnaire des anonymes) a supposé que Diderot en attribuant à Mlle de La Chaux la traduction des " premiers essais de la métaphysique de Hume » et des " Essais sur l'entendement humain » avait été trompé par sà mémoire. Il n'en est rien. Diderot a seulement, comme toujours, donné à l'ouvrage de Hume, traduit par Mlle de La Chaux un titre trop général. Il s'agit ici des Political discourses, formant la deuxième partie des Essays. La première traduction de cette partie (Essais sur le commerce, le luxe et largent, Amsterdam, 173̈2, 173̈3, in-12; Paris et Lyon, in-12) est bien de Mlle de La Chaux. Elle contient seulement sept des seize discours de Hume, avec des réflexions do traducteur... La traduction de Mlle de La Chaux des Essais économiques de Hume a pris place dans le tome XIV de la Colleclion des principaux économistes. Mlle de La Chaux mourut en 17วั. ")

(Note de Asséz.ıт, précédant Ceci n'est pas un conte, dans les curres complètes de Diderot.)

Ceci n'est pas un conte, par Diderot, concerne $M^{110}$ de La Chaux. Cette nouvelle littéralement vraie nous montre à la fois un exemple de la tendresse de la femme et de l'ingratitude de l'homme. NHle de La Chaux avait eu, outre l'ami indigne, pour amis d'Alembert et Condillac.

Dans la notice de Hume, tome XIV des grands économistes: 
La traduction des Essays est de $\mathbf{M}^{1{ }^{1}}$ de La Chaux, jeune personne de beaucoup de mérite. Faite en $17: 92$ ou 1733 , cette traduction dont on ne retrouve plus les exemplaires primitifs, portant une dédicace à $M^{m e}$ d'Arconville..., est bien écrite.

Essais sur le commerce, le luxe, l'argent, l'intérêt de l'aígent, les impôts, le crédit public et la balance du commerce, par D. Hume, traduction nouvelle avec des réflexions du traducteur (Mlle de La Chaux), et lettre d'un négociant de Londres, contenant des réflexions sur les impòts, auxquels sont assujetties les denrées de première nécessité; 1767 , in-12.

\section{CHELLIER (DOROTHÉE)}

Cette doctoresse de la Faculté de Paris, ancien aide d'anatomie, a été chargée, par le gouverneur général de l'Algćrie, d'une mission sur la situation sanitaire et médicale de l'Aurès. Le rapport envoyé à l'Académie de médecine a été jugé très remarquable. Ce rapport et le récit du voṣage ont été publiés.

Mère d'Épicure.

\section{CHERESTRATA}

\section{CHÉRET (ANNE-GeneviÈve)}

Mỵstique française du xrme siècle. Ses wuvres ont été publiées en deux vol. Paris. 1792.

\section{CHEUVREUX (HORTENSE)}

Cette dame, qui habitait Pau, a publié les deux livres signés H. C. sur les Ampère. Elle a donné l'hospitalité à J.-J. Ampère et elle a dirigé la publication des OEuvres complètes de Bastiat.

Correspondance de $\boldsymbol{M}^{\text {me }}$ Cheuvreux (1830̈-18:39). Paris, Quantin, 1889, 2 vol. petit in-8, avec portrait à l'eau forte. (Non mis dans le commerce.)

\section{CHEVALLIER, NÉE PEYTAL}

La femme de M. Cherallier, chimiste, est l'auteur des Fastes de la pharmacie française publiés en 1830. 
V. Statistique des lettres et des sciences en France... par Gurot dE Fère (vol. concernant Paris), 183', in-8, p. 138.

\section{CHISHOLM (Grace-EmiLy)}

Docteur en philosophie de la Faculté de Goettingue. Avait déjà inérité les honneurs de première classe pour les mathématiques, à Cambridge et à Oxford. Mariée maintenant à Mr Young, fellow de l'Université de Cambridge.

Algebraisch-gruppentheoritische Untersuchungen zur spharischen Trigonometrie, Götting, 1895̈, in-8, 68 pp., 3 pl.

\section{CHRISTINE DE SUĖDE}

Femınc étrange! Dans son zele pour la philosophie, elle tua Descartes.

" Cette princesse cartésienne est Christine de Suède. Reine bizarro plutòt que grande reine, la fille de Gustave-Adolphe, douće d'une infatigable activité, partageait son temps entre les études et les affaires; elle avait attiré un grand nombre de savants à sa cour, elle étudiait à la fóis plusieurs seiences et plusieurs langues. Ce qu'elle avait appris de la philosophie de Descartes par M. Chanut, ambassadeur de France en Suède, lui donna le vif désir de l'approfondir davantage et d'attirer Descartes à sa cour. Descartes, après avoir longrtemps hésité, cédant à ses vives sollicitations, alla à Stockholm lui enseigner sa philosophie. L'objection qu'elle arait faite à Descartes, par l'intermédiaire de M. Chanut, sur la difficulté de concilier avec le christianisme l'idée de l'inlinité du monde, semble prouver qu'elle n’était pas incapable des études métaphysiques. Mais au bout de trois mois, la mort lui enleva Descartes qui ne put résister au climat de la Suède, et au brusque changement de toutes ses liabitudes. Virant, elle lui avait prodigué les marques d'estime et d'admiration, mort, elle le pleura. Peu de temps après elle 
étonna l'Europe par son abdication et par sa conversion au catholicisme. )

Bocilliter.

Il y a dans les œurres de Pascal une lettre de dédicace de sa machine arithméticue à la reine de Suède.

V. Descartes, la princesse Élisabeth et la reine Christine, par Foccher de Careit, Paris, 1879, in-8. - Pensées de Christine de Suède, Paris, 182:̈, in-12. - Didenot. XIII, 328. - Valsox. Vie des Savants illustres; t. II, p. 99 et suiv.

Les ouvrages de Christine de Suède ont été recueillis, dans les mémoires publiés sur elle par Archenholtz. 17:̃1, '4 vol. in-'́.

\section{CIBo (CATHERINe)}

xvi $^{\mathrm{e}}$ siècle. Duchesse de Camerino. A cultivé les langues, la philosophie, les mathématiques et la théologie. D'une grande piété. Morte le 27 octobre $13 \% 3 \%$

\section{CICCOLINI (A.)}

Cette marquise est l'auteur de " L'Inspiration profonde incomnue en physiologie; 1890 » et de mémoires en allemand sur des questions médicales.

\section{CICERI (THÉRÈSE)}

Cette docte amie de Volta est morte vers 1820.

Dora d'Istria. Des Femmes, t. I, p. 26 '.

\section{CLÉA}

Plutarque lui a dédié son livre des Vertus des femmes: il lıi a adressé aussi des consolations philosophiques à loccasion de la mort de sa mìre Léontide.

\section{CLÉMENCE}

Questions de mathématiques proposées ct résolues dans le Cosmos (Nouv. sér., t. 10 à 18, passim).

Bibioth. mathematica, 1895 . G. VAlEatix. 


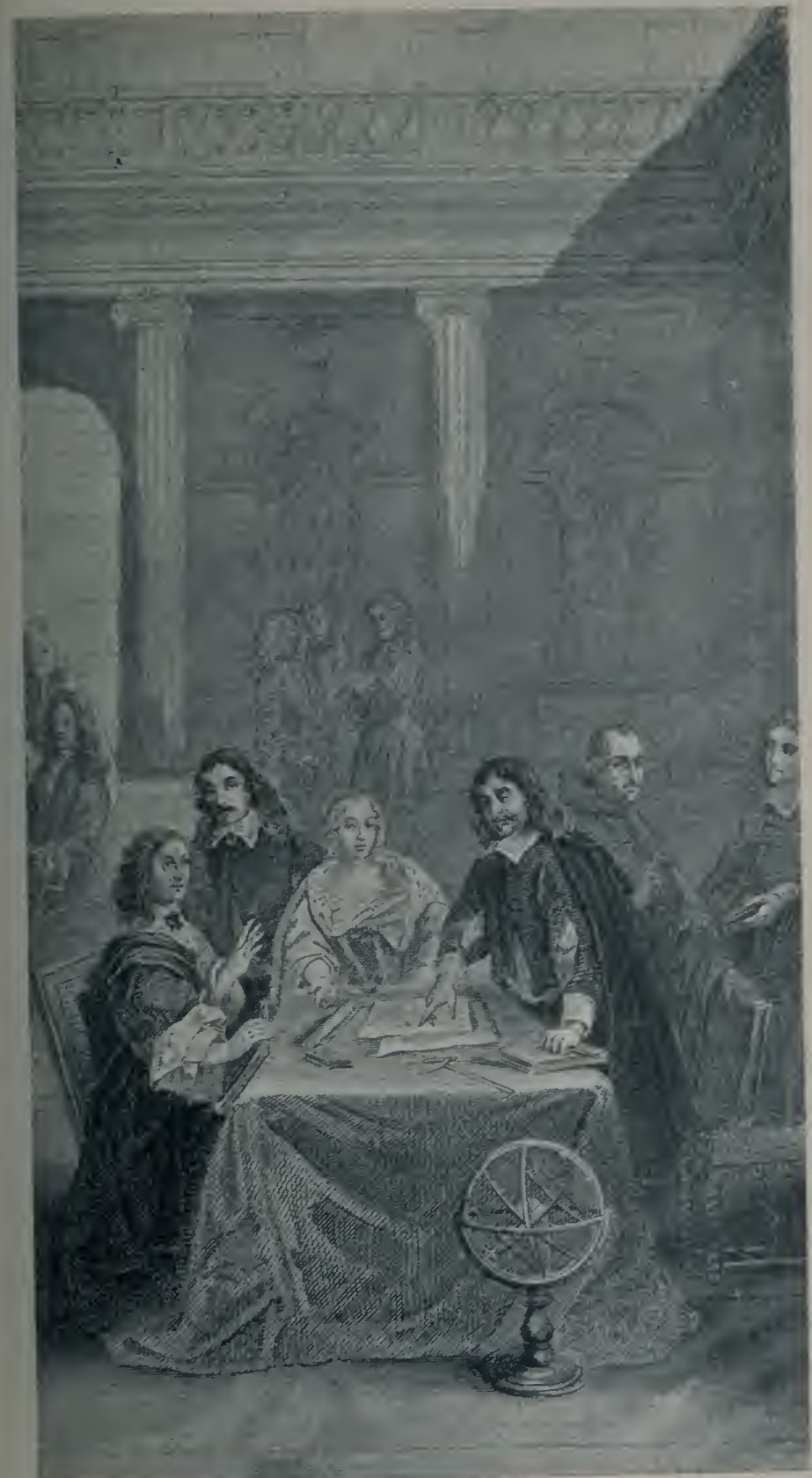

CHRISTINE DE SUEDE ET DESCARTES

Fragment d'un tableau de Dumesnil

(Musée de Versailles) 
s. 


\section{CLÉOBULINE}

Fille d'un des sept sages de la Grèce, Cléobule. Elle s'occupait de philosophie, puisque Thalès la qualifie de Sage. Aristote, Diogène de Laerte et Clément d'Alexandrie la citent.

\section{CLÉOECHMA}

Elle est au nombre des seize pythagoriciennes inscrites sur un manuscrit de la Bibliothèque du Roi.

\section{CLÉOpatre dite la SAVANTE}

Auteur d'un Traité des cosmétiques et d'un Traité des poids et mesures, elle vivait au premier siècle de l'ère chrétienne et elle est classéc parmi les écrivains alchimistes (Voir Berthelot. Origine de l'Alchimie, p. 111). Hoffer en cite des extraits dans le premier volume de son Histoire de la chimie.

Certaines biographies distinguent deux femmes ayant à la fois le même nom, Cléopâtre, et le même surnom de Savante.

\section{CLERKE (AGNĖS-MARY)}

Notre contemporaine, l'astronome liss Clerke, est née daus le sud de l'Irlande. Elle s'est instruite seule, dans sat jeunesse, en mathématiques et en physique. C'est de Florence qu’elle habitait avec sa famille qu'est daté son premier écrit "Copernic en Italie » publié dans Edinburgh Review. Elle est l'auteur de deux ouvrages importants: $1^{0}$ Histoire populaire de l'Astronomie pendant le 19 e siècle, dont la $I^{\text {re }}$ édition date de 1883̈; une 2 e édition a été pullicée dix-huit mois après et plusieurs autres depuis. En 1887, le Dr H. Maser a fait imprimer à Berlin une traduction allemande. 2o Le système des étoiles, étude détaillée des étoiles et des nébuleuses. Miss Clerke a en outre donné aux Revues scientifiques diverses notes astronomiques (Distance des Pléiades; Etoiles à compagnons sombres; La nébuleuse d'Andromìde, etc.).

Voici la fin d'un compte-rendu de la Revue scientifique du 
16 mai 1891, où l'on regrette qu'une traduction française de l'Histoire de l'Astronomie n'ait pas encore été faite :

" Le livre se termine par une table chronologique des principales découvertes et par une table alphabétique excellente. Le lecteur peut ouvrir au hasard: il est de suite intéressé, et les choses lui sont si simplement exposées qu il n'éprouve aucune difficulté à suivre l'auteur. Et d'autre part le savant se réjouira à la vue des notes qui, au bas de la page, renvoient aux travaux originaux importants : cela a bien l'allure d'une histoire faite d'après les documents, et reposant sur des renseignements précis. »)

Donnons, en terminant, les titres anglais des deux livres dont nous venons de parler et des autres du même auteur.

A popular History of astronomy during the ninetenth century. Edimbourg, Blacke, 1 vol. gr. in-8 de :00 pages.

The system of the stars. Londres, Green, 1 vol. gr. in-8 de 42't pages, avec de nombreuses gravures hors texte et dans le texte.

The suns motion in space. Nature (Londres), 1891.

The Herschels and modern astronomy. Londres, 189.;, in-8.

\section{CLERKE (ELLEN-M.)}

Sour de la précédente et astronome comme elle. Jupiter and his system. Lond'es, 1892, in-9.

The planet Venus. Londres, 1893, in-8.

\section{COCONATO-RUDIENTI (MARIANNA)}

Memoria sul Grano Carbone, che i Francesi chiamano Bled noir, e dai contadini Milanese si chiama yuado. Delle signora CMDC (comtesse Marianna di Coconato).

E inscrita negli Opuscoli scelti sulli scicnze et sulle arti, etc. t. XII, p. 9̈̈ et suiv. Milan, 1789.

\section{COERELIA}

Cicéron, dans ses lettres à Atticus (livre 12, lettre 引̈1), dit que Corelia fut une des plus fameuses philosophes, parmi 


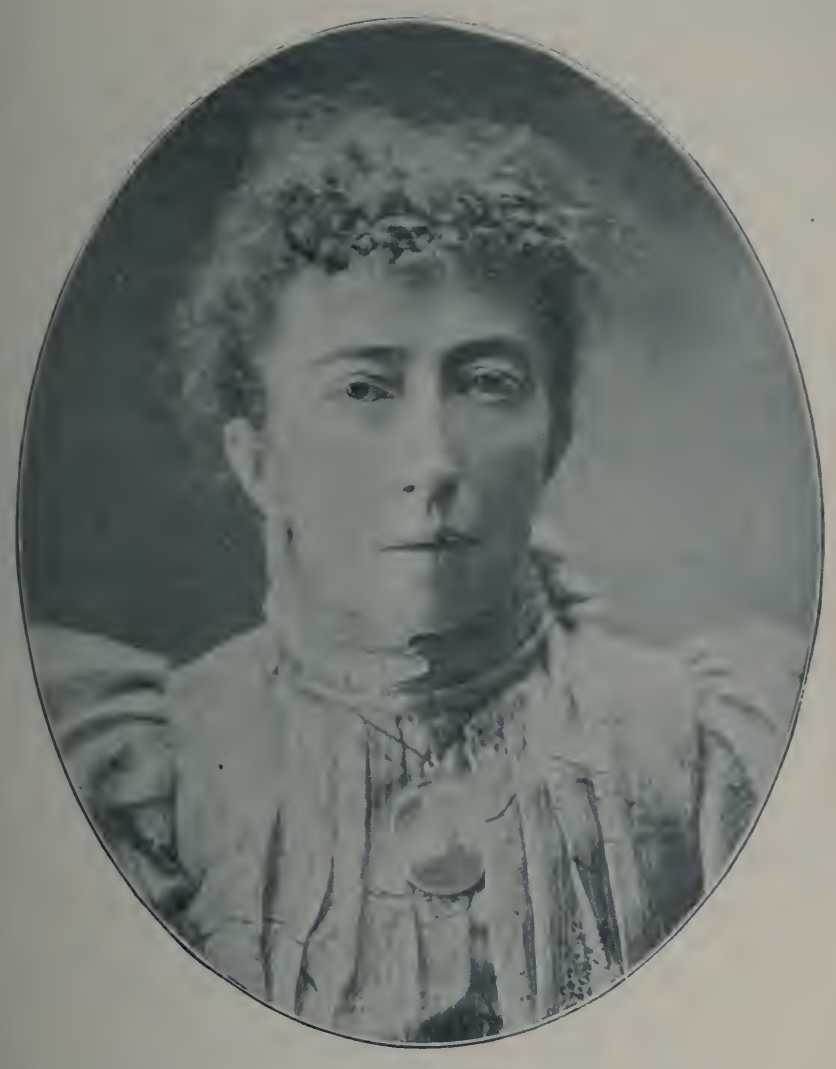

AgNES-MARY ĆLERKE 

les académiciennes. Martial lui adresse la 63e épigramme de son te livre.

\section{COIGNET (CLARISSE), NÉE GAUTHIER}

Voici un extrait de son livre, intitulé: Morale indépendante dans son principe et dans son droit ; Paris, 1869.

" Le principe de la mathématique est une conception abstraite donnée par la raison.

Le principe de la morale est un fait vivant donné par l'expérience.

Les axiomes mathématiques ne rencontrent pas d'obstacles dans la vie, parce qu'ils ne s'attaquent point à la vie. Leur sphère est l'idée pure dégagée de tout élément positif.

La morale, tout en ayant un principe subjectif qui est la liberté et un idéal qui est la justice, ne se manifeste réellement que dans l'application... L'objet de la morale n'est point un enchainement de théorèmes qui se développent sans résistance et sans obstacle en dehors de la vie, c'est une conquête qui a pour théatre la vic elle-même ; c'est la conquête de la liberté sur la fatalité, de la justice sur la force. "

Notre contemporaine, $\mathbf{M}^{\mathrm{me}}$ Coignet, a aussi publié : De l'éducation dans la Démocratie. - De l'affranchissement des

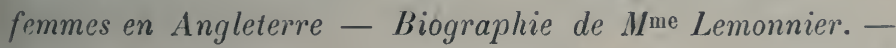
Victor Considérant. - Catherine de Médicis et François de Guise, etc.

\section{Colombière (Anne-Henriette de Briqueville, Marquise de)}

Auteur d'un ouvrage intitulé : Réflexions sur les Causes des Tremblements de Terre, avec les principes qu'on doit suivre pour dissiper les orages, tant sur terre que sur mer; 17506 , in-12.

Daus cet écrit de כ̋0 pages, l’auteur attribue à l'électricité la plupart des désordres physiques qui ont surgi dans le monde.

Lire un résumé et des extraits dans l'Histoire littéraire des femmes françaises, t. IV, pp. 260-273. 


\section{Columbrano (Princesse de)}

"Cette dispute sur les forces actives $(s i c)$, qui partage aujourd'hui l'Europe, n’a jamais exercé de plus illustres mains qu'aujourd'hui. La dame respectable dont je parle (Ime du Châtelet), et Mme la princesse de Columbrano, ont toutes deux suivi l'étendard de Leibnitz, non pas comme les femmes prennent d'ordinaire partie pour des théologiens, par faiblesse, par goût, et avec une opiniàtreté fondée sur leur ignorance, et souvent sur celle de leur maître ; elles ont écrit l'une et l'autre en mathématiciennes, et toutes deux avec des vues nouvelles. »

Voltaine. Exposition du livre des Institutions physiques.

\section{COMNÈNE (ANNE)}

1083-11'48. - Fille de l'empereur Alexis Jer, s’est appliquée à la philosophie et aux sciences, où elle a surpassé son mari Nycéphore Bryenne.

\section{COMTE (ACHILLE)}

Cette dame est l'auteur de cours élémentaires d'histoire naturelle.

Histoire naturelle des femmes et des jeunes personnes, par Madame Achille Comte ; Paris, Gosselin, 183̈', gr. in-18. Bibliothèque d'élite.

\section{CONDORCET}

La femme du philosophe-mathématicien, née Grouchy, a traduit en français la Théorie des sentiments moraux d'Idam Smith, Paris, Buisson, an VI, 2 vol. in-8 ${ }^{\circ}$. Elle complète et discute les théories de l'auteur.

On doit aussi à Madame Condoreet des Lettres sur la sympathie, adressées au médecin Cabanis, son beau-frère.

Elle engagea son mari, poursuivi par ses ennemis poli- 
tiques et refugié chez Madame Vernet, à écrire son Tableau historique des progrès de l'esprit humain.

I. A. Gullors. La Marquise de Condorcet; 1896.

\section{CONDUITT}

C'est Madame Conduitt, née Barton, nièce du grand Newton, yui a raconté l'anecdote de la pomme dont la chute a fait découvrir la loi de l'Attraction universelle. Cette dame et son mari entourèrent le savant de soins attentifs et lui tinrent lieu de famille.

\section{COOPER (SUZAN-FÉNIMORE)}

La fille du grand romancier, morte à 81 ans, est l'auteur des Souvenirs d'un naturaliste.

\section{CORNARO-PRISCOPIA (LUCRÈCE-HELLÈNE)}

Née à Venise en 16't6. S’adonna aux langues, à la philosophie et à la théologie. Reçut, presque malgré elle, le bonnet de docteur à Padoue, en 1678. Une fois maitresse ìs arts libéraux, l'Université de Padoue voulut la proclamer docteur en théologie, mais l'évêque s'y opposa. Elle portait l'habit de Saint-François sous son vêtement et avait fait vou d'observer les rìgles. Elle est morte à 38 ans.

(Kivres publiées à Parme, 1688, in-8, avec un portrait de l'auteur (Livre très rare).

\section{COSTE-BLANCHE (MARIE)}

Cette parisienne a cultivé les langues anciennes, la philosophic et les sciences. Elle a traduit de l'espagnol trois Dialogues de Pierre Messie, touchant la nature du soleil et de la terie et de toutes les choses qui se font et apparaissent dans l'air ; Paris, Morel, 15066 et $\mathbf{1 5 7} 79$, petit in-18. (Dédicace à Madame Marguerite de Saluces.)

Yoici les arguments des trois Dialogues :

Au premier dialogue : du Soleil, la preuve que le Soleil est plus grand que la Terreet la Terreplus grande que la Lune: et 
pour ce que la Terre est ronde, que les hommes se soutienment de toutes parts dessus icelle : et l'autorité d'aucuns anciens disputans s'il y a des antipodes ou non.

Au second: de la Terre, se démonstre avec merveilleux artifice, le lieu et situatiò des Eléments, et pour yuelle cause la 'Terre est descouverte de l'eau : il se preuve encore, que le lieu du Feu est voisin au Ciel de la Lune, combien qu'il ne se voye.

Au troisième : des Météores, briefvement est déclaré comme se sont et d'où procedêt les Nües, les Pluyes, les Neiges, la Grelle, la Rosée, la Brouée, les Brouillars, les Tonnerres, la Fouldre, les Esclairs, et les Comèttes qui apparoïssent en l'air, et comme se cause le tremblement de la Terre.

\section{COSTON (MARTHE-J.)}

Cette dame a combiné les diverses couleurs de façon à former un langage à distance. C'est le système des signaux de nuit, appliqué sur une grande échelle aux États-Unis et qui porte le nom de signaux Coston.

\section{CRAMERIA (ANNA-MARIA)}

Née en 1613 à Magdebourg (Litterarum studiis, præesertim Musicâ et Arithmeticâ, optime informata et exercitatissima.) Extrait de sa pierre tumulaire. - Morte en 1627.

\section{CROSFIELD (MARGARET)}

Miss Margaret Crosfield et Miss Ethel G. Skeat lisent un mémoire sur la géologie des environs de Camartheu...

Nature (de Londres); 7 mai 1896, p. 23.

\section{CROUS (MARIE)}

Abrégée-recherche de Marie Crous, pour tirer la solution de toutes propositions d'arithmétique dépendantes des règles y contenues, etc. A Paris, chez Jacques Auvray, 1641, in-8 1'y't pages (On n'en connaît qu'un seul exemplaire, il est à la bibliothèque Mazarine, $n^{\circ} 300$ ' 7 7). Commence par unc épître à Mme de Combalet. 
Ensuite : “Advis aux filles mes compagnes » où M. C. dit yu'elle a fait ce livre " pour essayer à soulager celles qui s'exercent en cette science, tant pour la nécessité de leurs affaires, que pour le contentement de leur esprit, d'un embarras de plusieurs lettres inutiles. »)

A ce premier ouvrage est joint le suivant :

Advis de Marie Crous aux filles exersants l'arithmélique sur les dixmes ou dixièmes du sieur Stévin. Dédié à Charlotte de Caumont, damoiselle de La Force.

L’auteur réclame le système métrique décimal.

Elle sépare la partie décimale des entiers par un point, et remplace par les zéros (qu’elle appelle des nuls) les unités décimales manquantes; elle a ainsi donné au calcul décimal Sa véritable forme, encore conservée.

Gérono ajoute : “ L'existence de M. C. a été sans contredit profitable aux savants, aux industriels, aux commerçants, à tout le monde : ne serait-il pas convenable, lorsqu'on a tant de noms à donner à de nouvelles rues, à d'anciennes rues, d'inserire quelque part le nom de Marie Crous? »)

D’après les Nouv. Annales de Mathém., 18こั3, p. 20 '.

\section{CULVER (HELEN)}

On lit dans la Revue scientifique (rose), du 11 janvier 1896 : Une américaine, Miss Helen Culver vient de donner la somme de cinq millions de francs à l'Université de Chicago, pour le développement des laboratoires biologiques.

\section{CUNITZ (MARIE)}

1610-166'. - Fille aînée d’un médecin silésien. Très instruite dans diverses directions, en relation avec les principaux savants, a publié en 1600 des T'ables astronomiques connues sous le nom de Urania propitia. Elle avait épousé en 1630, Elie de Liewen, médecin.

"Hypatia n'est pas la seule femme qui se soit fait un nom par son habileté dans celte science. Elle eut pour imitatrice dans le 
xvı ${ }^{\ominus}$ siècle, la célèbre Mairia Kunicia, Marie Cunitz, fille ainée de Henri Cunitz, médecin de Schweidnitz, et non de Pitschen, comme l'a dit Lalande, et femme d'Elie de Lœwen, astronome et médecin de Pitschen, dans le duché de Brieg, en Silésie. Elle naquit vers la fin $d u x \mathbf{x l}^{\circ}$ siècle, et dès ses plus tendres années elle s'appliqua à l'étude avec beaucoup de zèle. Elle possédait sept langnes qu'elle parlait avec une égale facilité : l'hébreu, le grec, le latin, l'italien, l'allemand, le français et le polonais. Elle se livra surtout aux mathématiques et à l'astronomie, et elle cultiva la médecine, la poésie, la musique et la peinture. Elle entreprit, à la sollicitation de son mari, de publier un abrégé des tables rudolphines, et elle y travailla en Pologne chez l'abbesse d'Oels, où elle s'était retirée pendant la guerre d'Allemagne. Elle retourna ensuite à Pitschen, où elle mourut le 22 août 1664, laissant à la postérilé ses tables astronomiques, intitulées Urania propilia, seu labulce astronomicce mirè faciles vim hypolesium physicarum Keplerii complexce, facillimo calculandi compendio absque logarithmis, prcemisso usu tabellarum, et vernaculo idiomate (16ว0). Quoique cet ouvrage ne réponde pas à ce qu'il promet, il est toujours étonnant qu'un travail aussi difficile ait $\mathrm{pu}$ faire l'occupation d'une femme; aussi ne songeait-elle guère à sa maison, comme c'est l'ordinaire des femınes savantes. Elle veillait la nuit pour observer le ciel; elle dormait le jour pour se reposer, mais elle ne vécut pas assez pour publier son livre; il fut mis au jour par son inari qui dit dans sa préface l'avoir beaucoup aidée.

Cunicia mérite ainsi plus que toute autre femme, la qualification de seconde IIypatie, qu'on donnait autrefois à celles qui se distinguaient par leurs lumières des personnes de leır sexe; mais aucune n’a jamais égalé llypatia pour la profundeur et l'étendue de ses connaissances. "

Commentaire de Théon d'Alexandrie, traduction de l'aвве́ Hal.мa, Paris, 1822. Discours préliminaire, page X.

V. Bibliothèque germanique, 1721, pp. 15̈7 à 183. Eitudes par Desiginotes.

\section{DACIER (ANNE-LEFĖVRE, DAME)}

163't-1720. - Nous ne citons ici celte helléniste, cette érudite, que parce que Ménage lui a dédić sal Vie des femmes philosophes dans l'untiquité (Lyon, in-16, 1690, en latin). "Aimant comme vous le faites, l'histoire de la Philosophie, 
comme le prouvent vos savantes notes sur les livres de l'Empereur Marc-Aurèle, j’espère, Madame, que ce petit ouvrage vous sera agréable. »

\section{DALLE-DONNE (MARIA)}

Cette dottoressa, morte en 18'12, était née en 1777 dans la montagne bolonaise, d'une famille de pauvres paysans. Envoyée jeune à Bologne par sa famille, qui avait été frappée de sa vive intelligence, elle y étudia le latin, la philosophie, les mathématiques et la médecine... Le savant Caterzani la proposa (1802) pour la chaire de physique générale à l’Ennirersité.

Dori d'Istria. Des Femmes, par une femme, t. I, p. 260.

\section{DAMO}

Pythagore, qui prétendait avoir été femme dans une vie antérieure, avait une très haute idée de l'excellence de la fenme et avait rêvé l'incarnation de sa vieille sagesse dans un beau tỵpe féminin. Ce tỵpe, il le trouva dans sa propre famille. Damo, sa fille, devint son disciple le plus ardent, il la voua aux dieux par un voeu de virginité perpétuelle, lui confia tous les secrets de sa psychologie et lui laissa, dit-on, ses ćcrits, en lui faisant promettre qu'elle ne les publierait jamais. Damo, l'étonnement et l'admiration de la Grèce, eut le courage de l'obéissance. Elle mourut avec les secrets du divin vieillard.

Lot is Figcier. Vie des Savants illustres, t. I, p. Iö't.

\section{DAMOISEAU}

La baronne Damoiseau a fondé, le 9 mars 1863, un prix d'astronomie que décerne chaque année l'Académie des siciences de Paris.

\section{DANTI (THEODORA)}

D'après Vermiglioli, Scrittori perugini, Perugia, 1828, 2 vol. in-'t, t. I, p. 366, Theodora Danti a commenté Euclide. 
Elle était de la famille du dominicain Ignace Danti, qui a contribué à la réforme grégorienne du calendrier.

LiBnI. Histoire des mathématiques en Italie, t. III, note de la page 37 .

\section{DANVILLE OU DENVILLE}

Cette duchesse, protectrice des philosophes et des économistes, les recevait dans son chàteau de la Roche-Guyon, près Mantes (S.-et-0.).

\section{DARNET}

"La femme d'un chirurgien de Saint-Yrieix, Mme Darnet, s'étant servie un jour d'une certaine argile, à défaut de saron, pour enlever quelques taches de graisse, se trouva fort bien de cet expédient, et eut l'idée de remplacer le savon par cette matière onctueuse dans le blanchissage du linge. C'était le kaolin des chinois! Le mari en offrit la vente au Contròleur général Bertin. "

G. D’Hugues. Essai sur l'Administration de Turgot. 185ั9, in-8, pp. 190-1.

\section{DARU (PAULINE)}

Devenue plus tard Marquise d'Oraison, en épousant le général de ce nom, elle a été dame d'honneur de la duchesse de Nemours. Son salon a été remarqué. Elle est morte en 1890.

Dans sa jeunesse, cette fille de l'ancien ministre de Napoléon Ier, a aidé son père dans la composition du poème L'A stronomie. Elle suivait assidûment les cours d'Arago.

\section{DAUBENTON (MARGUERITE)}

Femme d'un grand esprit, auteur de plusieur's romans, notamment de celui de Zélie dans le désert (1787, 2 vol. in-8) qui eut du succès, elle survécut à son mari, le célìbre naturaliste. Elle fut autorisée à continuer d'habiter la maison du Muséum jusqu’à sa mort. On put la voir gravir, chaque matin, les allées de la grande butte et s'arrêter près de la colonne élevée sur la tombe de Daubenton. Elle mourut presque centenaire, le 2 août 1818. 
M. Mante. Histoire des sciences mathématiques. t. VIII, p. 171.

\section{DAUDIN}

François-llarie Daudin, privé dès son enfance de l'usage de ses jambes, s'adonna à l'histoire naturelle. Aidé de sa femme, il publia un grand nombre d'ourrages: Traité d'ornithologie, 1799, 2 vol.; Histoire des reptiles, 1802, 8 vol., etc.

\section{DEAN (ÉLISABETH)}

I. Dea Dean a construit un bateau de sauvetage insubmersible qui a servi plusieurs fois avec succès et a mérité des médailles d'honneur aux expositions maritimes.

\section{DEFLANDRE (C.)}

A la Société de Biologie (séance du 15 février 1896) M. P. Carnot et Mile Deflandre font une communication sur les greffes pigmentées. Une greffe noire, transplantée sur de la peau blanche, grandit et s'étale peu à peu; un lambeau blane, greffé sur un épiderme noir, finit au contraire par être résorbé. Les cellules pigmentées semblent donc plus actives que les autres.

Revue générale des sciences, du 150 avril 1896.

\section{DÉJARDIN (M.)}

A abservé à Cannes un superbe halo lunaire, intérieurement bordé de rouge.

\section{DÉJERINE-KLUMPKE}

Mlle KLumphe. Contribution à l'étude des paralysies radiculaires du plexus brachial.

Déserixe (J.), professeur à la Faculté de médecine, et Déjerise-KLcmpke ( $\left(\mathrm{M}^{\mathrm{me}}\right)$, docteur en médecine. A natomie des centres nerveux. Ler $^{\mathrm{e}}$ vol. grand in-8, de $816 \mathrm{p}$. avec $401 \mathrm{fig}$., dont 4 s̈ en couleurs. Paris, 1893. Voir Revue générale des sciences, 30 décembre $1893 ̈$; p. 1103. 
Des mêmes : Sur la connexion du noyjau rouge avec la corticalité cérébrale. (C. R. de la Sociétéde Biologie, 30 mars 189̋̈.)

Mlle Klumpke, søur de l'astronome, a été la première femme interne des hòpitaux de Paris.

\section{DELALANDE-GUÉRINEAU}

Par testament du 17 aoùt 1872, Mme Vre Delalande-Guérineau a légué à l'Académie des Sciences, le capital pour la fondation d'un prix à décerner, tous les deux ans, " au voyageur français ou au savant qui, l'un ou l'autre, aura rendu le plus de services à la science $)$.

\section{DELAUNAY (MARGUERITE) OU STAAL}

Une des premières scientifiques, celle finc nouche!

168'1-17500. - Très curieuse de science, comme on le constate souvent dans ses intéressants Mémoires, dont nous donnons ces cours extraits :

« Je lus ensuite La Recherche de la vérité et je me passionnai du système de l'auteur (Malebranche). Pour vérifier si j'y comprenais quelque chose, je m'attachais à prévoir les conséquences de ses principes, que je ne manquais guère de retrouver. "

"Le meilleur moyen de calmer les troubles de l'esprit n'est pas de combattre l'objet qui les cause, mais de lui en présenter d'autres qui le détournent et l'éloignent insensiblement de celuilà. J'avais remarqué dans mes premières études l'inconvénient de ne pas savoir un peu de géométrie et je conservai l'envie d'en prendre quelque teinture. Je m'y déterminai alors par la nécessité d'occuper mon esprit d'idées qui le rempliraient entièrement. "

"La connaissance d'une vérité vaut bien la perte d'un plaisir."

Nous empruntons à un éminent critique la page suivante :

"Tout le monde a lu les Mémoires de $\mathrm{M}^{\text {mo }}$ de Staal-Delaunay et personne, je pense, ne les a oubliés.

Dirai-je qu'elle est l'une des premières qui ait reçu de ses 


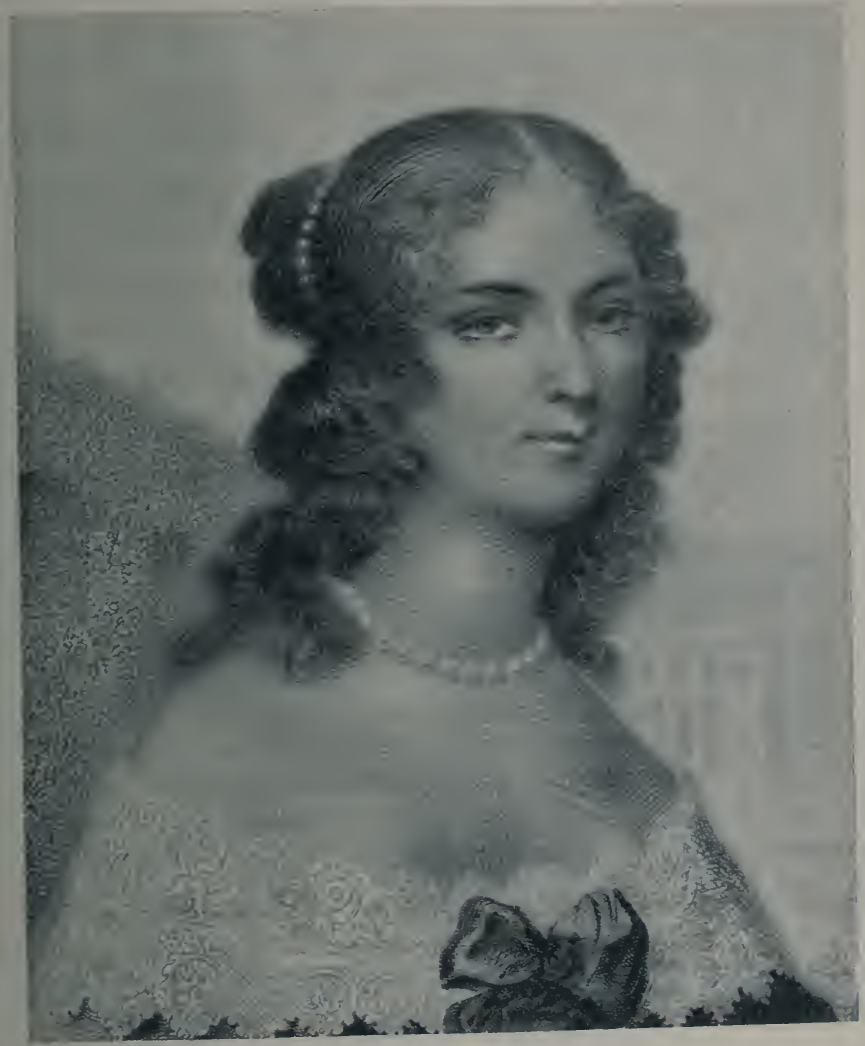

MARGUERITE DE STAAL-DELAUNAY 
maitres ou de la mode une éducation scientifique? Non, sans doute, puisque Molière et Boileau se sont assez moqués des femmes savantes.

Qui s'offrira d'abord? Bon! C'est cette savante

Qu'estime Roberval et que Saureur fréquente...

Mais, comme on l'a remarqué plus d'une fois, elle est l'une des premières dont le style emprunte à la physique ou à la géométrie quelques-unes de ses plus agréables trouvailles. C'est le chevalier d'Herb...y qu'elle dispute à M${ }^{\text {tho }}$ de Silly. "La conquête était des plus minces, dit-elle, mais dans la solitude les objets se boursouflent, comme ce que l'on met dans la machine du vide. " ("est M. de Rey, un autre galant, dans les sentiments duquel elle découvre quelque diminution. " 11 me donnait la main pour me conduire jusque chez moi. 11 y avait une grande place à passer, et dans les commencements de notre connaissance il prenait son chemin par les côtés de cette place. Je vis alors qu'il la traversait par le milieu : d'où je jugeai que son amour était au moins diminué de la différence de la diagonale aux deux côtés du carré. " C'est M. Le Blanc qui l'interroge, à l'occasion de la conspiration de Cellamare, et elle se tire adroitement de l'interrogatoire. « Je fus, dit-elle, assez contente de moi... ne m'étant pas presque écartée du vrai, dans lequel il me semble que l'esprit forcé à quelque détour rentre aussi naturellement que le corps qui circule rattrape la ligne droite. " Fontenelle a passé par là. Ce qui, du temps de Molière, était encore chez une femme une espèce de ridicule, est devenu maintenant une élégance, - nous dirions, de nos jours, un sport. Mieux encore que cela : l'astronomie, la géométrie, la physique ne suffisent déjà plus; l'anatomie s'y joint; et le naif du Verney, van' tant à la duchesse du Maine les mérites de M110 Delaunay, la loue singulièrement d'être " la fille de France, dit-il, qui connait le mieux le corps humain."

F. Brunetiére. La formation de l'idée de Progrés. (Revue des Deux-Mondes, 1ว̆ octobre 189\%.)

\section{DELAVIGNE (ANNE)}

Signalée comme cartésienne.

\section{DELESSE}

La veuve du géologue a fondé un prix à l'Académie des Sciences, pour récompenser, tous les deux ans, un travail 
sur les sciences géologiques ou, à défaut, sur les sciences minéralogiques.

\section{DEMOULIN (GUSTAVE)}

Cette dame est une vulgarisatrice scientifique. Ses principaux livres sont: Philippe de Girard; La pluie et le beau temps; L'eau liquide et l'eau solide; Les cinq sens. Les bêtes de nos maisons, etc.

\section{DENSMORE (ANNA)}

Un des professeurs distingués du Collège médical de NewYork; elle est venue à Londres assister à une séance de The Ladies medical College. (Journal The American, du 9 octobre 1867.)

\section{DESCARTES (CATHERINE)}

Mademoiselle Descartes, morte en 1706, soutint dignement. par son esprit et son savoir, la gloire de son oncle, le grand Descartes. Elle était fort instruite et écrivait d'une façon distinguée en vers et en prose. On a d'elle la Relation de la mort de Descartes et L'Ombre de Descartes, pièces pleines de naturel, de vivacité et de délicatesse. Un bel esprit a prétendu que ( l'esprit de René Descartes était tombé en quenouille ».

V. Éloge de Catherine Descartes, dans le Parnasse francois, 1732, p. 500ั, et dans l'Histoire litterr. de l'abbé Lambert, t. III, partie 2, p. 63.

Consulter aussi Madame de Sévigné (Tables Monmerqué).

\section{DESLOGES (NÉE MARIE BRUneau)}

Cette dame, si cólébrée en prose et en vers, connaissait plusieurs langues, les mathématíques et la philosophie. Elle est inorte en 16'1.

\section{DHUODA}

La femme de Bernard, duc de Septimanie, a composé pour son fils aîné, en 8'13, un livre où elle fait de la philosophie à la manière pythagoricienne et de la théologie comme un père de l’Église.

Ed. Bondurand. Ise Manuel de Dhuoda. 1887. 


\section{DIEULAFOY (JEANNE)}

Les observations métallurgiques abondent dans les réeits de cette vovageuse. La Perse, la Susiane et la Chaldée, 1886 ; A Suse, 1887.

V. SÉblLLot. Les travaux publics et les mines dans les tradttions... 1896, in-8.

\section{DILLON}

Cette demoiselle a fait le buste en bronze du géomètre Lobatchefsky. Ce buste a été érigé à Kasan (Russie), en septembre 1896.

\section{DIODORE (LES FILLES DE)}

Elles s'appelaient Argie, Théognide, Artémise et Pantaclée. Elles étaient dialecticiennes, comme leur père. Philon a écrit leur histoire.

\section{DIOTIME}

Savante athénienne. Daprès Platon et Lucien, elle donna comme Aspasie des leçons à Socrate.

Les actes de Diotime sont une fiction antique de M. Heuzey.

\section{DODEL-PORT (CAROLINE)}

de Zurich ; étudie l’iconographie botanique.

\section{DOMNA (JULIE)}

Femme de l'empereur Sévère. Dion Cassius dit qu’elle sappliquait à la philosophie et qu'elle aimait à discuter arec les logiciens et les géomètres.

Il y a une autre Domna, femme du philosophe Isidore.

\section{DONGLAS-STAIR}

A publié à Londres, 1881, in-8, La Vie et la Correspondance choisie de $W$. Whewell, le mathématicien-philosophe.

\section{DRAPER (HENRY)}

La femme du physsicien américain de ce nom passe pour avoir participé à ses travaux. 


\section{DROHOJOWSKA}

Vulgarisatrice. Auteur de : 10 Les grands inventeurs modernes; 20 Les grandes industries de la France (Le sucre; l'éclairage; la teinture et l'impression des tissus).

\section{DU BUISSON}

Mlle de Scudéry appelle Sapho, la bonne savante, et Damophile, la mauvaise. Sapho, c'était Mme du Buisson et, dit Somaize, " elle savait bien les mécaniques».

\section{DUDLEY (BLANDINE)}

A Albany New-York, en face de la porte d'entrée de l’Observatoire Dudley, se trouve un beau buste en marbre, avec cette inscription :

Charles E. Dudley

by Blandina, his Wife, dedicated to Astronomy.

L'Astronomie pratique et les Observatoires; t. III, par C. Avdré et A. Angot, pp. 138 et 139.

\section{DUGUESCLIN, NÉE TIPHAINE RAGUENEL}

Cette première femme du connétable

Du sens d'astronomie était bien escolée

Et de philosophie estait sage esprouvée.

Cuvellier. Chronique de Bertrand Duguesclin. 2331e et 2332 e vers.

La demoiselle de Dinan avait fait, dit-on, une prédiction astrologique de victoire à Duguesclin, qui l'arait alors épousće.

La belle-sœur du connétable, Julienne Raguenel, fut une femme guerrière.

\section{DUHAMEL}

Cette demoiselle, qui récut au xvire siècle, fut, d'après Ménage, une cartésienne distinguée. 


\section{DUjaRdin (Suzanne), dame Habert}

S'occupa de mathématiques, de philosophie et de théologie, d'après La Croix du Maine. Morte en 1633.

Lucas Tremblay lui a dédié ses Appendices ou Commentaires sur l'arithmétique de Gemme Phrison, 1583 (avec dédicace en vers et anagramme).

\section{DUMÉE (JEANNE)}

Bourgeoise parisienne. Veuve à 17 ans, elle s'adonna à l'étude des Sciences. On a conservé le manuscrit de ses Entretiens sur le système de Copernic. Elle est morte en 1706.

L'important manuscrit dont nous parlons, porte au Fonds français de la Bibliothèque nationale le $\mathrm{n}^{0}$ 199'1. C'est un in-'́t en maroquin rouge, portant sur le plat un écusson doré où une poule couronnée lève la patte. Ex-libris de B.-H. de Fourcy. Titre complet : Entretiens sur l'opinion de Copernic, touchant la mobilité de la terre. Dédicace au Chancelier de France de Boucherat, avec son portrait.

Voici quelques citations :

" On dira peut-être que c'est un ouvrage trop délicat aux personnes de mon sexe, je demeure d'accord que je me suis laissée toucher à l'ambition de travailler sur des matières auxquelles les dames de mon temps n'ont encore point pensé et même afin de leur faire connoistre qu'elles ne sont pas incapables de l'estude, si elles s'en vouloient donner la peine, puisqu'entre le cerveau d'une femme et celui d'un homme il n'y a aucune différence. Je souhaiterais que mon livre leur peust donner quelque émulation.

Ce que je prétens dire icy de l'opinion de Copernic n'est pas à dessein de l'établir, encore moins de la vouloir soutenir, mais seulement pour faire voir les raisons avec lesquelles les Coperniciens se deffendent et encore pour satisfaire à quelques personnes scauantes qui, m'ayant fait l'honneur de me visiter, virent une sphère que j'auais dressée suivant cette opinion. Ils (sic) 
m'obligèrent de les entretenir des raisons de cette opinion et m'engagèrent de les meltre par escrit.

La première hypothèse, etc. "

A la fin : Joanna Dumée Parisis fecit.

Le Journal des savants, 1680, p. 269, parle du livre comme s'il avait été imprimé, mais personne n'en a vu d'exemplaire.

V. aussi LaLANDE. Bibliographie astronomique.

\section{DUPIERRY}

Lalande, qui a dédié à cette savante son Astronomie des dames, dit qu'elle est la première qui ait professé l'astronomie à Paris. On lui doit beaucoup de calculs d'éclipses pour préciser le mouvement de la lune, ainsi que différents mémoires imprimés dans les ouvrages de Lalande. Elle a composé les Tables des dix tomes des connaissances chimiques de Fourcroy, Paris, Beaudoin, an $\mathbf{X}$, in-8. - Tables de la durée du jour et de la nuit, calculée par Mme du Pierry, Paris, 1742, in-4. - Tables de l'effet des réfractions en ascension droite et en déclinaison, pour la latitude de Paris, 1791.

Cette astronome s'appelait d'abord Louise-Élisabeth-Félicité Pourra de la Madeleine et elle était née à La Ferté-Bernard, dans le Maine, le 1er aoùt 1746.

\section{DUPLESSy (Jeanne-Marie-Françoise), née de Chazot}

Ce fut une de ces studieuses qui ne trouvent jamais de journée trop longue. A l'avidité de tout connaitre, elle joignait la faculté de tout embrasser. Mais la pente de son esprit l'entrainait vers les sciences exactes. Lhistoire naturelle surtout la captivait : son cabinet, le premier qu'on vit à Bordeaux, passait pour l'un des plus beaux de l'Europe... Poussons la porte du "sanctuaire ", et, à la suite d'un contemporain qui veut bien nous servir de guide, visitons-en les curiosités...

Deux vastes pièces ordonnées avec méthode, sont affectées 
aux collections. La première, garnie d'armoires, de tablettes, de vitrines, contient toutes les richesses de la "conchyliologie, la seconde rappelle les boutiques d'antiquaires, telles que certains romans se plaisent à les dépeindre, avec un appareil de réchauds, de cornues, d'instruments mystérieux, et toute une série d'animaux suspendus aux solives : chiens de mer, poissons volants, crocorliles, chaures-souris aux ailes déployées... Spectacle troublant pour les âmes délicates ! Heureusement le regard ne tarde pas à se porter vers les parois de la muraille où apparaissent, rangés avec sỵmétrie, les plumages multicolores des oiseaux des iles : un chatoiement de couleurs gaies allant du jaune de chrome au bleu d'azur, en passant par toutes les nuances de l'are-en-ciel...

Du temple de fl'ornithologie, on accède à la bibliothèque, dont les mathématiques, la physique, l'astronomie se disputent les hauts rayons.

A. Grellet-Dumazeau. La société bordelaise sous Louis XV et le salon de $\boldsymbol{I}^{\text {me }}$ Duplessy. Bordeaux, 1897, in-8 (Portr.), pp. 22-3.

「. aussi Dézallier D’Argenville. Conchyliologie. $150 \% 7$. t. I. p. 138.

\section{DUPRÉ (MARIE)}

Morte en 1675; clle avait reçu les leçons de philosophie de Desmarets et mérité le surnom de «la cartésienne ».

\section{DUPUY (Laurence)}

I. H. D. B. Depcx. Le franc-arithme ou le calcul affranchi de l'embarras des retenues, des emprunts et des restes, ete. Revu et augmenté d'un supplément par Mlle Laurence Dupuy.- Blois, 1862.

\section{DUTILLEU}

IIme Dutilleu a pris, en 1823, le premier brevet d'invention pour le marbre artificiel, lequel fut, plus tard, perfectionné par une autre femme, Mme Marchal. 


\section{ÉDESSE OU ÉDÉSIE}

d'Alexandrie, ve siècle. Femme du philosophe Hermias, fut une stö̈cienne.

\section{EDWARDS}

La veuve du savant anglais de ce nom, a travaillé au Nautical almanach de Londres.

\section{EIMMART-MULLER (MARIE-CLAIRE)}

Ratisbonne et Altdorf (Suisse), 1676-1717. Fille du peintre, astronome et médecin Eimmart, qu'elle aida dans ses travaux . Devint aussi la collaboratrice de son mari, le physicien astronome Henri Muller qui dirigea l'observatoire de Nuremberg, après le célèbre Jean Muller dit Regiomontanus.

Iconographia nova contemplationum de Sole... Nuremberg, 1701.

V. Marie, Lalande, Madler, etc.

\section{ELARA}

Il nous reste un fragment d'une étude sur la nature humaine, par cette pythagoricienne.

\section{ELIOT (GミORGE) OU EVANS (MARIE)}

1819-1880. - Nous lisons, sur la célèbre romancière anglaise, cette réflexion de M. Mouret (Revue philosophique du Ier août 1892) :

George Eliot, dans l'esprit de laquelle des tendances au mysticisme n'ont pas eu d'influence fâcheuse sur le còté positif et intellectuel, a fait remarquer par une intensité d'abstraction rare chez une femme, que « des choses qui ont une relation constante avec la même chose, ont une relation constante entre elles ».

L'auteur d'Adam Bìde s'appelait Evans de son rrai nom. Elle a appris la chimie, la géométrie, l’entomologie, 
traduit la vie de Jésus de Strauss et aussi l'Éthique de Spinoza.

V. Anvède Barine. Portraits de femmes.

\section{Élisabeth de bohême (Princesse palatine)}

Elle gottait également, chose rare, la métaphysique et l'algèbre.

"Mettons au premier rang des élèves de Descartes la princesse lilisabeth, l'ainée des filles de l'infortuné Frédéric $V$, électeur palatin du Rhin, élu roi de Bohème au commencement de la guerre de Trente ans. Elle vivait à La Ilaye chez sa mère qui $\therefore$ ýtait réfugiée, et elle avait refusé de hautes alliances pour se livrer librement à son goût de l'étude et de la philosophie. Descartes était venu résider dans les environs de La Haye, la princesse l'appelait souvent auprès d'elle pour l'entretenir de sa philosophie. Il lui dédia ses Principes et fit d'elle ce grand éloge que jamais il n'avait rencontré personne qui l'eût mieux compris. Mais un tragique évènement interrompit ces conférences philosophiques. Obligée de quitter la Hollande, la princesse Élisabeth s'en va successivement résider dans les cours de divers princes d'Allemagne ses parents, d'où elle entretient un commerce de lettresavec Descartes. Les lettres de Descartes à la princesse Élisabeth offrent un intérèt tout particulier, parce qu'elles se rapportent à la morale, dont il ne traite nulle part ailleurs. Il y montre cette connaissance profonde des passions et du cœur humain que déjà nous avons admirée dans le Traité des Passions, il développe une pure et douce morale toute pénétrée du sentiment de la béatitude de la vertu et par la vertu, il cherche à agir sur le cœur en même temps que sur l'esprit de la princesse.

Nommée plus tard, quoique calviniste, abbesse de la riche abbaye luthérienne d'Hervorden en Westphalie, la princesse Élisabeth fit de son abbaye une école cartésienne. Catholiques, calvinistes, luthériens, sociniens, déistes, tous y étaient bien accueillis, à la seule condition de s'occuper de philosophie. Elle ne mourut que longtemps après Descartes, en 1680, après avoir eu des relations arec quelques-uns de ses principaux disciples. Elle entretint une correspondance malheureusement perdue avec Malebranche. Elle échangea aussi quelques lettres avec Poiret qui de cartésien devint inystique. A en juger par le ton de quelques-unes des lettres qu'elle lui adresse, il semble que la noble abbesse sur la fin 
de sa vie ait aussi elle-même incliné à un certain mysticisme. Elle eut pour nièce et pour élève la fameuse princesse SophieCharlotte, reine de Prusse, dont le nom s'associe glorieusement à celui de Leibniz comme le sien à celui de Descartes. "

Boulluer. Histoire de la philosophie cartésienne.

On a remarqué deux des lettres de Descartes à la princesse; elles ne sont pas datées, mais elles se rapportent sans doute à $16 \% 3$.

" A Ilme la Princesse Élisabeth, etc., sur le problème : trois cercles étant donnés, trouver le quatrième touchant les trois.

Madame, ayant su de M. de Pollot que votre Altesse a pris la peine de chercher la question des trois cercles et qu'elle a trouvé le moyen de la résoudre, en ne supposant qu'une quantité inconnue, j'ai pensé que mon devoir m’obligeait de mettre ici la raison pourquoi j'en avais proposé plusieurs, et de quelle façon je les démêle

" Mladame, la question qu'il a plu à votre Altesse de me faire l'honneur de m'envoyer est si juste, qu'il ne s'y peut rien désirer davantage ; et je n'ai pas seulement été surpris d'étonnement en la voyant, mais je ne peux m'abstenir d'ajouter que j'ai été aussi ravi de joie

A propos des lettres de la princesse, on doit consulter l'inventaire des papiers de Descartes, du 14 février $\mathbf{1 6} 0$. 0 .

L'article $\mathrm{V}$ mentionne les ininutes des lettres à la princesse Élisabeth. Ainsi Descartes les avait soigneusement mises à part, ce qui facilita singulièrement la tàche de Clerselier lorsqu'il voulut les publier. Aussi les a-t-il imprimées, avec les deux épîtres à Christine de Suède, au commencement du premier volume des Lettres, en 163̈7 : il regardait sans doute, et le public avec lui, comme un honneur pour le philosophe d'avoir été en correspondance arec une princesse et une reine. Parmi ces lettres à Élisabeth, il en est deux, la vingt-neuvième et la trentième de Clerselier, dont on retroure des copies manuscrites à Leyde, bibliothèque de l'Université, d’abord parmi quelques papiers de Descartes laissés en Hol- 


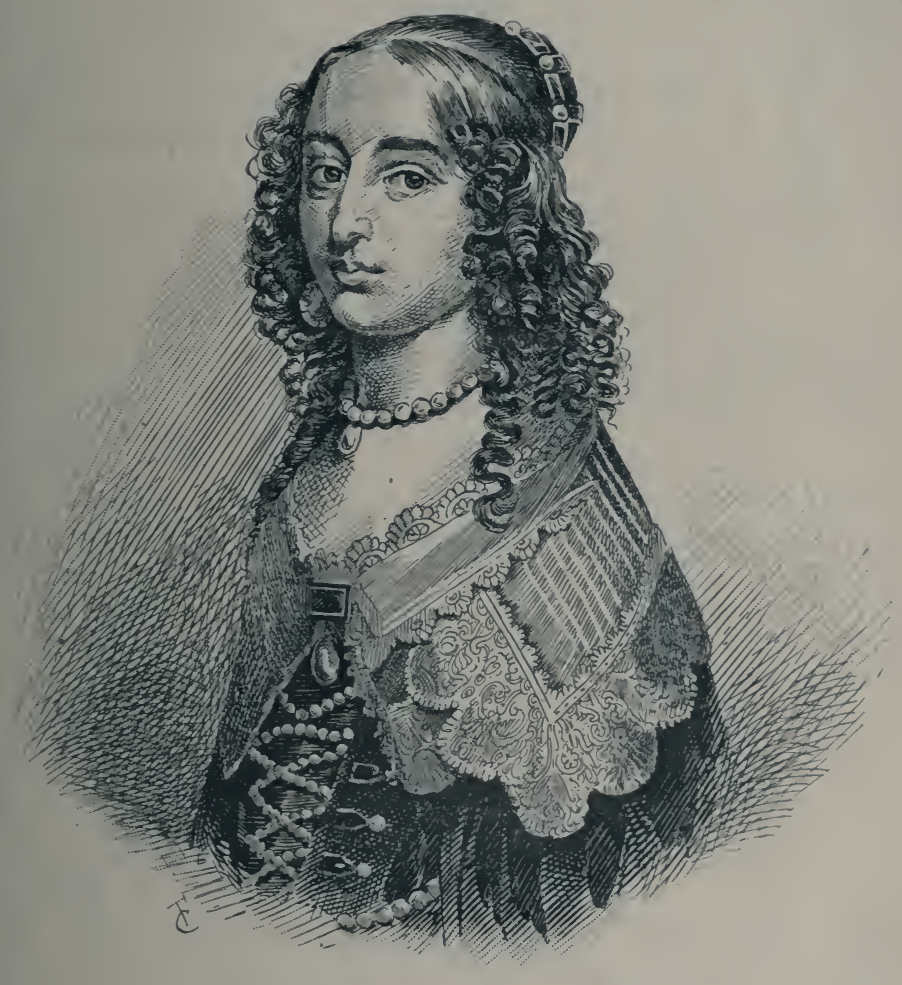

ÉLISABETII DE BOU ÊME

Princesse palatine 
$\Rightarrow$ 
lande (ils contieunent ume copie de la première, et jusq̧u’à deux copies de la seconde), puis dans un cahier de lettres provenant de la collection Perizonius. Mais déjà en $16 \Xi 33$ Pierre Borel, dans son Compendium vite Cartesii, avait publié une tradluction latine dę ces deux mêmes lettres, sur l'union de l'âme et du corps, nouvelle preuve de l'importance qu'elles avaient pour les contemporains comme pour I)escartes Iui-même. - Enfin une copie de toutes les lettres d'Élisabeth à Descartes est conservée au château de Rosendael, près d'Arnhem : le baron de Pallandt, qui en est possesseur, en a gracieusement donné de nouveau communication, et on a pu rérifier le texte publié en 1879 par Foucher de Careil. Ces lettres d'Élisabeth sont datées, ce qui permet de retrouver aussi la date pour les réponses de Descartes ; plusieurs fois, d'ailleur's, elle se trouve rappelée dans les lettres d'Élisabeth elle-même.

V. Brвcr. Histoire des ouvrages des savants; juin 1739. BLAzE de Bunr. Memoirs of the princess palatine. Londres, 183̈3, in-8. - Guirader. Elisabeth Pfalzgräfin..., Leipzig, 1800 - J. Bertrand. Une amie de Descartes. (Revue des

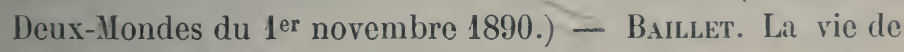
Descartes. 1691, 2 vol. in-4.

\section{ERMANSKA (OLGA)}

On trouve d'elle dans les Nouvelles annales de mathémaiiques, t. VIII, p. '432, cet énoncé :

"Étant données une parabole et une circonférence passant par son foyer et coupant la parabole en quatre points, trouver le lieu des points de rencontre des tangentes communes. " Il faut une donnée de plus pour déterminer le problème, par exemple la longueur du rayon.

Mlle Ermanska, de Strasbourg, avait déjà publié dans le mème recueil (1869, pp. 321 et 322) un travail sur l'enveloppe des ellipses concentriques d'aire constante, dont les axes ont même direction. 


\section{ERXLEBEN (ARISTINA)}

$\mathrm{Au}$ xvm $^{\mathrm{e}}$ siècle; à l'Université de Halle. Anfangsgrunde Naturlehre, Götting, 178'.

\section{EURYDICE}

Plutarque signale deux femmes de ce nom, élevées dans l'étude de la philosophie. L'une, femme de Pollian, à laquelle il a dédié ses Préceptes sur le mariage; l'autre, qu'il qualifie de très étrangère, parce qu'elle était illyrienne.

\section{EVERETT (ALICE)}

Astronome. A étudié les mathématiques à l'Université de Cambridge. Degré of M. A. (master of arts), with honours. Attachée au département astrographique de l'Observatoire de Greenwich, secrétaire pendant deux ans du British Astronomical Association, actuellement à l'Observatoire de Potsdam. A étudié les orbites des étoiles binaires, travaille à la carte du ciel.

\section{EYREINOV (JOHANNA)}

Mathématicienne russe; docteur en mathématiques en 1787.

\section{FABRI (CORNELIA)}

Fille de Ruggero Fabri, physicien et mathématicien, Cornelia est née à Ravenne en 1869, elle a fait ses études à l'Université de Pise, où elle a été proclamée docteur, en mathématiques en 1891. L’abbé Ravaglia a été l'un de ses professeurs.

Sopra alcune proprieta generali delle funzioni che dipendono di altere funzioni et da linee. Torino, Accad. d. sc., Atti 25, 1889-9c, 654674.

I moti vorticosi nei fluidi perfelti. Bologna, 1892, 4.

Supra le funzioni di iperspazzi. Venezia, Instituto Veneto. Atti 4,1892$1893,283-295$.

Sulla teorica dei moti vorticosi nei fluidi incompressibili. Nuov. cimento $31_{3}, 1892,135-14$.

I moti vorticosi di ordine superiore al primo, in relazione alle equazioni pel movimento dei fluidi viscosi. 1h. $363,1874,8 i-91$.

Brevi considerazioni intorno alle nuove discipline per la chiusa sul fume montone. Ravenna, 1892, $16 \mathrm{\mu}$. 
On voit que MHe Fabri, qui s'est exercée dans les parties les plus abstraites de la science, n’a pas dédaigné les applications.

\section{FAIRBANKS (CHARLOTTE)}

A publié, en collaboration avec Mr Gooch, dans The chemical Neu's (Londres) du 20 octobre 1895̈: Estimation des halogènes dans les sels d'argent mélangés.

\section{FAVRE (Jules), NÉE VELten}

La veuve du célèbre avocat et homme politique, directrice de l'École normale supérieure de Sèvres, est morte en 1896. On lui doit plusieurs livres de philosophie: La morale de Socrate; La morale d'Aristote; La morale des Stoïciens; La morale de Cicéron; Montaigne, moraliste et pédagogue, etc.

\section{FAWCETT}

Ime Fawcett est l'auteur de: Économie politique. - Contes sur l'économie politique. - Quelques femmes éminentes de notre temps, vingt-quatre esquisses biographiques; Londres, 1889.

Miss Philippa Fawcett, fille de la précédente, a remporté le premier prix de mathématiques, en 1890, à l'Université de Cambridge.Elle a publié dans The quarterly Journal of Mathematics, 1893, pp. 231-57: Notes sur le mouvement des solides dans un liquide. V. Bulletin Darboux, 189气̆, p. 67.

\section{DE FAY (FÉLICIE)}

Au xviII siècle, à l’Université de Montpellier.

\section{FEDCHENKO}

Naturaliste russe.

\section{FERRAND}

Amie et collaboratrice de Condillac. Grimm dit dans sa Correspondance littéraire (lettre du $1^{\text {er }}$ décembre 175’'): 
"Cette personne d'un mérite rare, philosophe et géomètre, est morte il y a deux ou trois ans, fort regrettée de Condillac et de tous ceux qui l'ont connue. »)

Voici ce qu'écrit Condillac lui-même sur M[1/e Ferrand :

Traité des sensations. - Dédicace de cet ouvrage (à Madame de Vassé) p. 48 et suiv.

Vous savez, Madame, à qui je dois les lumières qui ont enfin dissipé mes préjugés : vous savez la part qu'a eue à cet ouvrage une personne qui vous étoit si chère, et qui étoit si digne de votre estime et de votre amitié. C'est à sa mémoire que je le consacre....

les vues les plus fines qu'il renferme sont dues à la justesse de son esprit et à la vivacité de son imagination; qualités qu'elle réunissoit dans un point, où elles paroissent presque incompatibles. Elle sentit la nécessité de considérer séparément nos sens, de distinguer avec précision les idées que nous devons à chacun d'eux, et d'observer avec quel progrès ils s'instruisent, et comment ils se prêtent des secours mutuels.

Pour remplir cet objet, nous imaginâmes une statue organisée intérieurement comme nous, et animée d'un esprit privé de toute espèce d'idées. Nous supposâmes encore....

Mademoiselle Ferrand m'a éclairé sur les principes, sur le plan et sur les moindres détails, et j'en suis d'autant plus reconnoissant que son projet n'étoit ni. de m'instruire ni de faire un livre. Elle ne s'aperçevoit pas qu'elle devenoit auteur, et elle n'avoit d'autre dessein que de s'entretenir avec moi des choses auxquelles je prenois quelque intérêt. Aussi ne se prévenoit-elle jamais pour sessentiments; et si je les ai presque toujours préférés à ceux que j'avois d'abord,j'ai eu le plaisir de ne me rendre qu'à la Iumière. Je l'estimois trop, pour les adopter par tout autre motif ; et elle-mème elle en eut été offensée. Cependant il m'arrivoit si souvent de reconnoltre la supériorité de ses vues, que mon aveu ne pouvoit éviter d'être soupçonné de trop de complaisance. Elle m'en faisoit quelquefois des reproches ; elle craignoit, disoit-elle, de gater mon ouvrage; et examinant avec scrupule les opinions que j'abandonnois, elle eût voulu se convaincre que ses critiques n'étoient pas fondées. 
Si elle avoit pris elle-mème la plume, cet ouvrage prouveroit mieux quels étoient ses talents. Mais elle avoit une délicatesse qui ne lui permettoit seulement pas d'y penser. Contraint d'y applaudir, quand je considérois les motifs qui en étoient le principe ; je l'en blaınois aussi, parce que je voyois dans ses conseils ce qu'elle auroit voulu faire elle-même. Ce traité n'est donc malheureusement que le résultat des conversations, que j'ai eues avec elle, et je crains bien de n'avoir pas toujours su présenter ses pensées dans leur vrai jour. Il est fácheux qu'elle n'ait pas pu m'éclairer jusqu'au moment de l'impression ; je regrette surtout qu'il y ait deux ou trois questions sur lesquelles nous n'avons pas été entièrement d'accord.

La justice que je rends à Mlademoiselle Ferrand, je n'oserois la lui rendre, si elle vivoit encore. Uniquement jalouse de la gloire de ses amis, et regardant comme à eux tout ce qui pouvoit en elle y contribuer, elle n'auroit point reconnu la part qu'elle a à cet ouvrage, et m'auroit défendu en faire l'aveu, et je lui aurois ohéi. Mais aujourd'hui puis-je me refuser au plaisir de lui rendre cette justice? C'est tout ce qui me reste dans la perte que j'ai faite d'un conseil sage, d'un critique éclairé, d'un ami sûr.

\section{A. FICHTENHOLTZ}

Cette demoiselle a traduit du russe l'Éloge hislorique de Lobatchefsky, par Vassilief.

\section{FIDÈLE (CASSANDRE)}

Cassandre Fidèle, née à Venise 1460̈, morte à un àge très avancé.

" On dit que dans la dialectique, vous savez compliquer des noruds que personne ne peut dénouer, et trourer la solution de ce qui avait été jugé et paraissait devoir être insoluble. Dans les combats philosophiques, voussavez également soutenir vos propositions et attaquer celles des autres.... ) Lettres de Politien, liv. III, ép. 17.

L'élogieux Thomas renchérit encore : « Elle possédait toute la philosophie de son siècle et des siècles précédents; elle 
embellissait de ses grâces la théologie elle-même ; clle soutint des thèses avec éclat et elle donna plusieurs fois à Padoue des leçons publiques....

A composé un livre De ordine scientiaruin. V. Рівкнегмer.

\section{DE FITZ-JAMES (DUCHESSE)}

A publié dans la Revue des Deux-Mondes et daus le Correspondant des études sur le phylloxera et les vignes américaines et un livre La Pratıque de la viticulture, 189'́, in-12.

\section{flamel (Pernelle)}

Vers la fin du $x^{\circ}$ siècle, Nicolas Flamel faisait ses recherches d'alchimie près de la tour Saint-Jacques-la-Boucherie. Il était devenu très riche, par la science ou autrement. Sa belle et bonne femme, Pernelle, secourait avec ardeur les lépreux et les malandrins. Elle fit construire quatorze hospices et vingt-sept chapelles.

Quelques-uns prétendent que Flamel et Pernelle se sont retirés aux Indes où ils vivent encore, gràce à un certain élixir de longue vie (?).

Voir le testament de Pernelle dans l'Histoire critique publiée, sans nom d'auteur, par l'abbé Yillais, 1761, in-12.

La légende exagère : Flamel était simplement un riche bourgeois écrivain enlumineur, et lorsqu’il épousa la charitable et pieuse Pernelle, celle-ci était deux fois veuve.

\section{FLAMMARION (CAMILLE)}

On nous assure que la femme de l'astronome Flammarion a le goût des sciences. On trouve une note d'elle dans la revue L'Astronomie, sur le tremblement de terre du 30 mai 1889. Lire aussi: Histoire anecdotique de l'Observatoire de Juvisy (Revue des Revues, ter janvier 1896.)

\section{FLEMMING (MARGARET)}

Historien et astronome. 
Astronomy and Astro-Physics (Chicago); octobre 1893. Mrs Flemming : Les travaux des femmes en Astronomie.

On lit dans la Revue scientifique (rose) du 25 janvier 18900 :

La nouvelle variable du Centaure. - Une nouvelle étoile de grandeur variable a été découverte par Mrs Flemming, de l'Observatoire de Cambridge (États-Unis), dans les Constellations du Centaure, en examinant les photographies du memorial Draper. La position approchéc pour 1900 a les coordonnées suivantes: $\quad \mathrm{AR}=13^{\mathrm{h}} 3^{\prime} \mathrm{t}^{\mathrm{m}}, 3 ; \quad \mathrm{D}=121^{\circ} 8^{\prime}$.

L'attention a été appelée sur cette étoile en raison de la singularité de son spectre sur une plaque photographique prise à Aréquipa le 18 juillet $189 \%$, avec le télescope Bache, après une exposition de 22 minutes. Ce spectre ressemble à colui de la nébuleuse qui entoure 30 Dorade, ainsi qu’à celui de l'étoile 20937 du catalogue de Gould, mais diffère complètement des nébuleuses ordinaires et des nouvelles étoiles du Cocher, de la Norma et de la Carène.

\section{FLEUR D'ÉPINE}

Cette princesse sarrasine, dont les aventures sont racontées dans Gaufrey, chanson de geste publiée en 18599, avait, parait-il, une instruction variée. Non seulement elle savait à l'àge de quatorze ans et demi, parler latin et entendre roman, jouer aux dés et aux échecs, mais elle se connaissait mieux que fermme du monde au cours des étoiles et de la lune:

Et du cours des étoiles et de la lune luisant

Savoit moult plus que fame de chest siècle vivant.

\section{FOEHR}

Cette demoiselle a fondé le prix Bellion destiné à la personne qui aura écrit des ouvrages ou fait des découvertes profitables à la santé humaine ou à l'amélioration de notre espìce. (Testament du 23 novembre 1881.) 


\section{de FONCECA (Eleonore Pimentel)}

La marquise de ce nom s'est livrée à l'étude de l'histoire naturelle et spécialement de la botanique. Spallanzani l'a associée à ses recherches. C'était aussi un écrivain politique. Elle fut pendue à Naples en 1799, à l'àge de trente et un ans, dans la sanglante réaction dirigée par l'agent anglais Acton contre le parti français, sous la reine Marie-Caroline.

V. Magasin pittoresque. 18'10, p. 366. - Busticm. FoncecaPimentel. Venise, 1871. - Croce, id., Rome, 1887.

Pas de portrait authentique.

\section{FORE}

Mme Fore. Éducation de lophomores faites à Montrevel (Revue des Sciences naturelles appliquées; avril 1892).

\section{FOUCAULT}

Foucallt (LÉon), membre de l'Institut. Recueil de ses travaux scientifiques, publié par $\mathbb{M}^{\mathrm{me}}$ Vre Foucault, sa mère, 1878, in-4.

\section{FRANCOEUR}

Un décret du 18 janvier 1883 autorise l'Académie des Sciences à accepter la donation qui lui est faite par Mme Veure Francour, pour un prix qui sera décerné à l'auteur de découvertes ou de travaux utiles aux progrès des sciences mathématiques pures ou appliøuées.

\section{FRANKLAND}

Madame Frankland est collaboratrice de la revue scientifique anglaise Nalure.

\section{GACON-DUFOUR}

Cette dame a publié des romans et des essais historiques. Elle a remporté un prix à propos des abeilles, composé un dictionnaire rural (1808), travaillé pour la bibliothèque physico-économique, etc. 
Dans ses Jugements listoriques et littéraires, 1810, de Feletz dit : "Madame Gacon-Dufour a des secrets armirables; elle fait du vin sans raisin, des confitures sans sucre, et des livres sans jugement, sans esprit, sans style et sans raison. ")

\section{GAIO (OLIMPIA)}

La théorie des équations appliquée à la résolution d'une ŕquation du 7 e degré. (En italien.) Florence, 188̋̈, in-8, $.36 \mathrm{p}$.

\section{GALEAZZI (LUCIA)}

Voir dans Poggendorf (traduction de la Quesnerie) son sonnet au physsicien Galvani.

\section{GALILÉE (VIRGINIE)}

En religion, sueur Maric-Céleste, la fille du grand Galilée (1600-163' $)$.

On a écrit l'histoire du savant d'après les lettres de sa fille :

F.rano. Galileo Galilei e suor Maria Céleste. Florence, 1891 , in-12.

Madame Arvède BariNe a analysé ce livre dans la Revue de Paris du 100 mars 189.̈ :

"Galilée a eu pour confidente, et pour consolatrice dans ses épreuves, une humble religieuse, sa fille ånée qui passa sa vie dans un couvent très pauvre... "Les lettres de sœur MarieCéleste ont été retrouvées. Elle " avait une âme noble et elle devait à son père de nobles échappées sur la science et sur le monde. " " Les lettres de Marie-Céleste prouvent une parfaite communion d'idée avec son illustre père. 》 Le 21 novembre 1623, elle écrit : "Je vous prie de me faire la grace de m'envoyer votre livre, celui qu'on vient d'imprimer, afin que je le lise, car j'ai grand désir de le connaltre. "

Voici encore la lettre familière et touchante du $\mathbf{1 6}$ décemhre 1625 :

“ Des citrons que vous m'avez chargé de confire, j'ai arrangé 
le peu que je vous envoie maintenant, parce que je me doutais qu’étant aussi avancés, on ne devait pas les réussir avec la perfection désirée, et, de fait, ils ne sont pas réussis. Je vous adresse en même temps des poires cuites pour ces jours de Vigile; mais afin de vous faire un plus beau présent, j’y ai joint une rose qui, comme chose extraordinaire en cette saison, devra vous ètre très agréable, et d'autant plus qu'avec la rose vous pourrez accepter les épines, image de la cruelle passion de Notre Seigneur, et ses vertes feuilles, emblème de l'espérance que (grâce à cette sainte passion) nous pourrons avoir de parvenir, après la brièveté et l'obscurité de l'hiver de la vie présente, à la splendeur et à la félicité de l'éternel printemps du ciel, lequel nous est concédé par la miséricorde du Dieu béni. "

\section{. GALITZINE (EudoXIE), NÉE ISMAiloffF}

On a de cette princesse :

De l'analyse de la force. 18'46. 3 parties.

\section{dE GASPARIN (VALÉRIE BoISSIER, Comtesse)}

Née en 1813. Auteur de mélanges philosophiques : Les Horizons Célestes; Les horizons prochains; Vesper, etc.

Mad. de Gasparin a été étudiée par MM. Ph. Godet (un vol. in-8, 1887), Mazade, Pommier, etc.

« Une femme de lettres d'un talent fort original qui était devenue française par son mariage, Mme Agénor de Gasparin, vient de mourir à Genève, sa ville natale, à l'àge de quatre-vingt-un ans. " (189' $)$.

\section{GATES (FANNY)}

Quelques considérations sur le cercle des neuf points et su réciproque (Anglais). - Annales de mathématiques; 189', pp. 18 à 188.

\section{GATTI DE GAMOND (ZOÉ)}

Madame Gatti ide Gamond, belge, née en 1812, est l'auteur d'un livre intitulé : Fourier el son système; 18'10, in-16.

M. Sarrut a écrit, en 1839, l'histoire de cette dame. In-S. 


\section{GAY-LUSSAC}

C'est dans un magasin de lingerie, refuge ordinaire des femmes de toutes les conditions et de tous les àges, dont les révolutions ont ébranlé l'existence, où Joséphine s'était placée, que Gay-Lussac fit sa connaissance. Il vit avec curiosité une jeune personne de dix-sept ans, assise derrière le comptoir et tenant à la main un petit livre qui paraissait lixer vivement son attention. « Que lisez-vous, Mademoiselle? fit notre ami. - Un ouvrage peut-être au-dessus de ma portée; en tout cas, il m’intéresse beaucoup : un traité de chimie. »)

Le mariage fut des plus heureux. Ils finirent par avoir la même écriture, et un amateur d'autographes put croire qu’un mémoire copié par Madame Gay-Lussac avait été écrit par le mari.

Trois jours avant sa mort, touché des soins infinis dont il était l'objet, Gay-Lussac disait à sa compagne : "Aimonsnous jusqu'au dernier moment; la sincérité des attachements est le seul bouheur. »)

D’après Arago, Biographie de Gay-Lussac.

\section{GEMINE}

Gemine et sa mère étaient disciples de Plotin, le plus célìbre platonicien de son temps; en son absence, elles donnaient, l'une ou l'autre, des leçons au reste de l'Académie.

Porphyr J.. Vie de Plotin.

\section{GENDRE (B.) (PSEUDONYME) OU NIKITINE}

Cronstadt, 18'12; Paris, 188'.

Études sociales, philosophiques et morales ; 1886, in-19.

Notice biographique, par le Dr Letocrneau.

\section{DE GENLIS}

17'16-1830. - Cette dame, pédagogue prolixe, a écrit, entre autres sujets, sur l'économie rurale, la technologie, la bota- 
nique, etc. Dans sa Maison rustique (3 vol., 1810), elle adjoint à la maison qu'elle imagine un laboratoire, un cabinet d'histoire naturelle, un jardin des plantes, etc. Madame de Genlis a aussi publié La botanique historique et littéraire (1810, in-8); La découverte du quinquina (1817, in-12), etc., etc.

\section{GENTRY (RUTH)}

Instructor en Mathématiques au Vassar College, U. S. A.

\section{DE GÉRANDO}

En 1798, un jeune soldat en garnison à Colmar méditait cette question proposée par l'Académie des Sciences morales et politiques : “Quelle a été l'influence des signes sur les idées? „ Le prix consistait en cinq hectogrammes d'or. Le philosophe de Gérando pria sa tiancée Annette de Rathsamhausen de copier son mémoire pour l'Académie.

Mme de Gérando fut la compagne intellectuelle de son mari. Elle connaissait et discutait les philosophes.

\section{GERMAIN (SOPHIE)}

J'apprécie autant qu'il le mérite un écrit aussi remarquable, que bien peu d'hommes peuvent lire et qu'une seule femme pouvait faire.

Nivien

Ex pleine Terreur. - Dans la seconde moitié du siècle dernier, uı orfèvre, nommé Germain. vendait à l'enseigne du Cabat d'or, rue Saint-l)enis. Il n'était pas parent de ses homonymes, les orfèvres du Roi. Notre Germain fut membre de la Constituante et y prononga un discours contre les faiseurs d'affiaires. Il fut plus tard un des Directeurs de la Banque de France.

Une fille, nommée Sophie, lui naquit en 1776. En grandissant, elle se passionna, comme tous les siens, pour les idées 


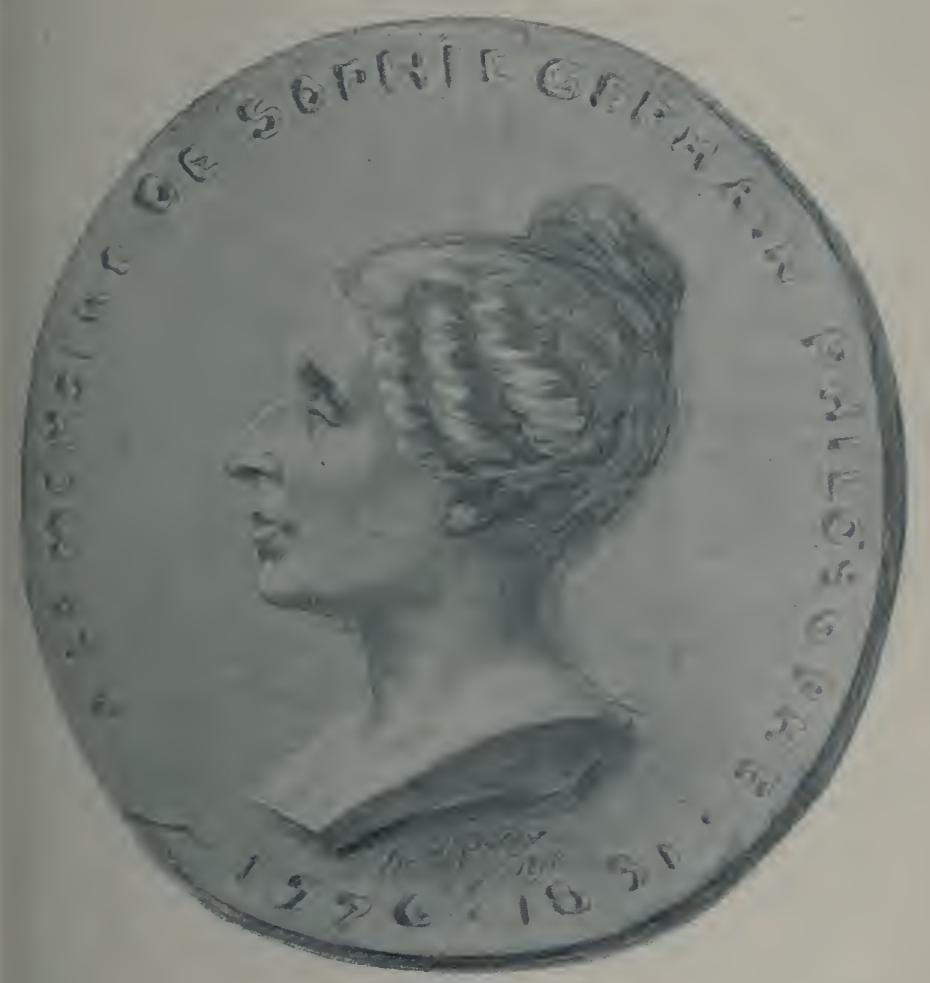



de 89. Mais lorsque vint la Terreur, l'enfant, qui n’avait que treize ans, fut indignée et épouvantée. Elle ne voulut plus sortir et se plongea dans l'Histoire des mathématiques de Montucla. Le récit de la mort d'Archimède l'avait frappée et elle se sentait plcine d'admiration pour une science qui, absorbant l'homme tout entier, peut le consoler des plus grandes douleurs. Plus tard, pendant la révolution de juillet 1830 , Sophie Germain composera un mémoire de mathématiques, mais n'anticipons pas. La jeune Sophie prit la ferme résolution de comprendre ces sciences si attirantes et, malgré l'opposition de sa famille, elle lut Bezout la nuit, enveloppée dans ses couvertures, pendant que l'encre gelait dans l'encrier. Voilà certes une rocation.

A cette époque, on créait notre grande École polytechnique. Lagrange surtout y était vivement goûté, il distribuait ses leçons autographiées et excitait les élèves à lui demander par écrit des explications. Sophie devint alors un des correspondants anonymes du célèbre géomètre.

LA PHXSiQue мathéMatique. - Une science nouvelle allait naitre, la phỵsique mathématique, dont Sophie Germain devait être un des créateurs.

Les expériences de Chladni occupaient les esprits. Vous savez que si une plaque métallique mince est placée horizontalement, saupoudréc de sable fin, saisie en un point de son contour par un étau et attaquée en un autre point avec un archet qui la fait vibrer, on voit le sable se disposer en courbes régulières. Sur l'ordre de l'Empereur, l'Académie des Sciences avait mis au concours ce sujet : “ Donner la théorie de la vibration des plaques élastiques et comparer les résultats à l'expérience. " Lagrange disait qu’il faudrait imaginer une nouvelle analỵse, pour résoudre la question.

Une fenme osa seule concourir sur le sujet posé et elle tit preuve d'une intelligence vive et tenace. Son équation est d’abord défectueuse, puis Sophie Germain mérite une men- 
tion honorable et enfin, en 1815, le grand prix lui est décerné. Dans la commission, Poisson, qui a été aussi un des promoteurs de la physique mathématique, se montra seul peu bienveillant.

A la suite, la mathématicienne développa et précisa sa théorie dans quatre mémoires successifs qui sont trop techniques pour être analyssés ici. Dans un cinquième mémoire, Sophie Germain calculait l'influence d'une épaisseur variant tout le long de la plaque. Ce mémoire est resté égaré longtemps; c'est M. G. de Courcel qui l'a découvert récemment, à la Bibliothèque des Ponts et Chaussées dans les papiers de de Prony, et qui l'a publié. Du reste, on avait aussi perdu la trace d'une note de Sophie sur une expérience de Wheatstone relative encore à l'élasticité et on l'a retrouvée à Londres, au British Museum.

Les personnes curieuses de plus de détails pourront consulter l'Histoire de l'élasticité par Todhunter, où se trouvent résumés avec soin tous les mémoires de Mademoiselle Germain.

LES MathéMatiques PUREs. - Les mathématiques pures ont aussi attiré Sophie Germain qui s'est surtout exercée sur l'arithmétique supérieure c'est-à-dire la théorie profonde des nombres. Elle n’a pas trouvé, elle non plus, la démonstration du Théorème de Fermat qui résiste encore à tous les efforts, mais elle a rencontré en chemin de jolies propositions, telle que celle-ci : “ Tout nombre entier $x^{4}+4$ est le produit de deux nombres entiers. »

La correspondance de Gauss et de la jeune Française contient aussi d'intéressantes études. Dans la Théorie des nombres de Legendre, il y a un mémoire d'elle, dans le second supplément. Le Journal de mathématiques de Crelle a publié aussi plusieurs de ses travaux.

Ux mystène. - Auguste Comte a été un admirable examinateur d'entrée à l'École polytechnique, au moins pendant 
les premières années. On raconte qu'une dame, curieuse de ses examens, s'était déguisée en homme pour y assister. Elle résumait ainsi ses impressions : “ Il semble à chaque instant inventer les mathématiques.' »)

La sage Sophie Germain allait, elle aussi, jusqu’à sacrifier son sexe à la science. Lorsqu'elle correspondait avec Lagrange, Legendre ou Gauss, elle signait « un élève de l'École polytechnique », ou plus simplement : "Le Blanc. »

L. guerre de Prusse. - Pendant la campagne d'Téna, contre la Prusse, Sophie, dont le coeur n'avait pas été desséché par les mathématiques, pensa à la fin tragique d'Archimède et trembla pour Gauss qui habitait Brunswick. Elle écrivit une lettre pressante à un ami de sa famille, le général Pernetti qui assiégeait alors Breslau. Le général s'empressa de détacher un de ses officiers vers Gauss, de la part de Sophie Germain, pour le rassurer. Le géomètre déclara qu’il ne connaissait qu'une Française s'occupant de science, Мadame Lefrançais de Lalande. Une explication était inćvitable et voici un extrait de la lettre que reçut Gauss : “ .... je ne vous suis pas aussi parfaitement inconnue que vous le croyez. Craignant le ridicule attaché au titre de femme savante, j’ai autrefois emprunté le nom de M. Le Blane pour vous écrire et vous communiquer des notes qui, sans doute, ne méritaient pas l'indulgence avec laquelle vous avez bien voulu y répondre.

J'espère que la singularité dont je vous fais aujourd'hui l'aveu ne me privera pas de l'honneur que vous m'avez accordé sous un nom emprunté.....

Votre très humble servante,

Sophit Germain.

Nous reproduisons l'autographe de cette lettre historique. 

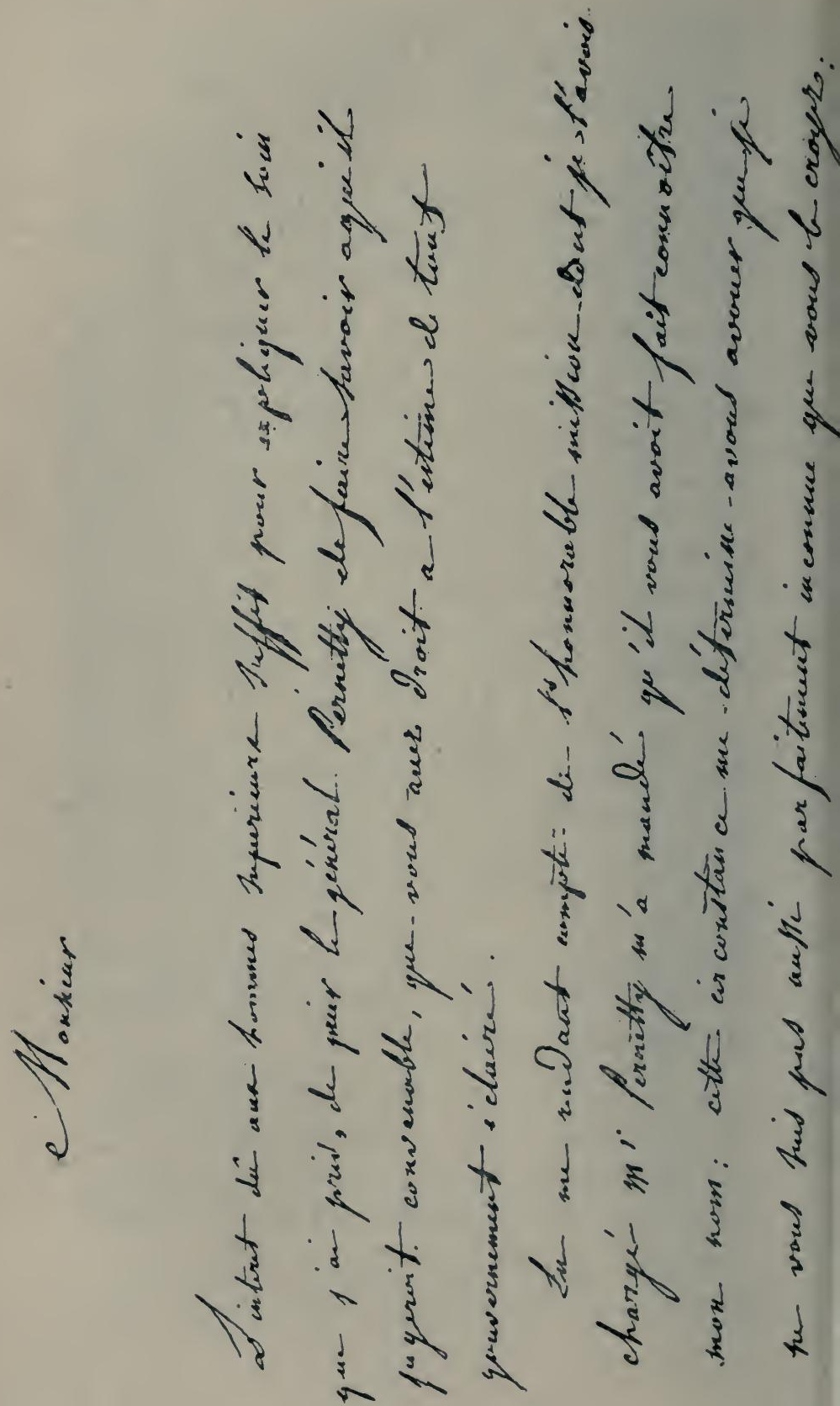


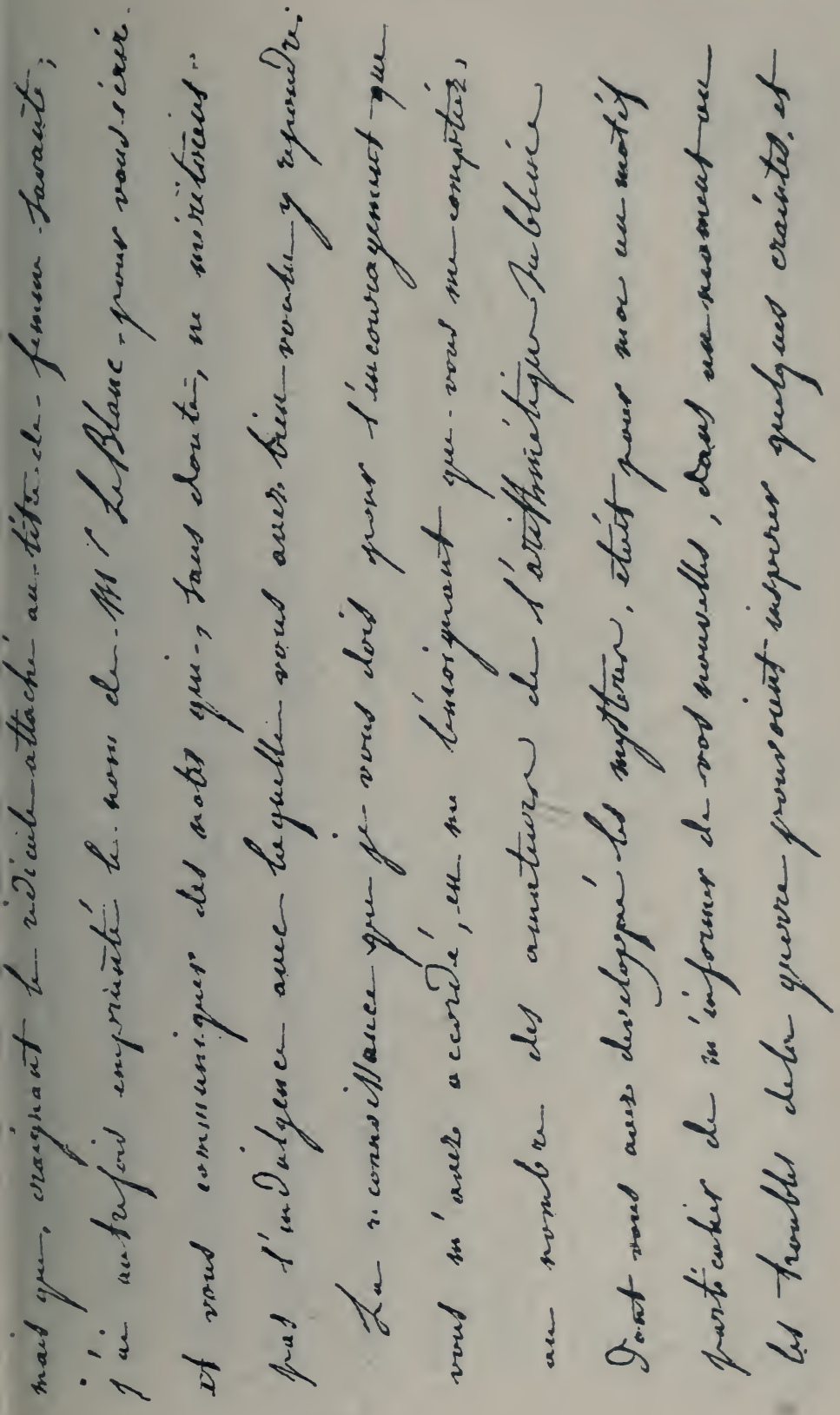


为

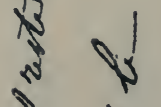

\$

$3+\sqrt[3]{3}$

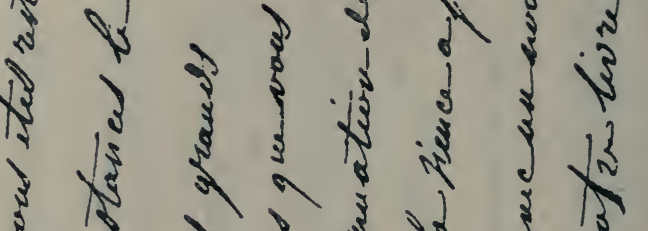

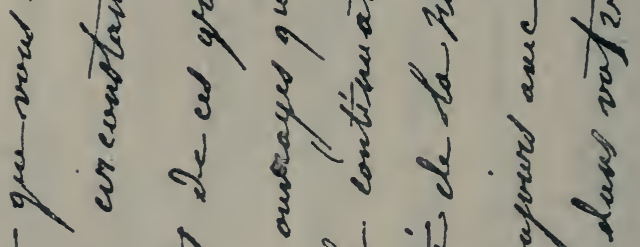

स कर

4
4 और

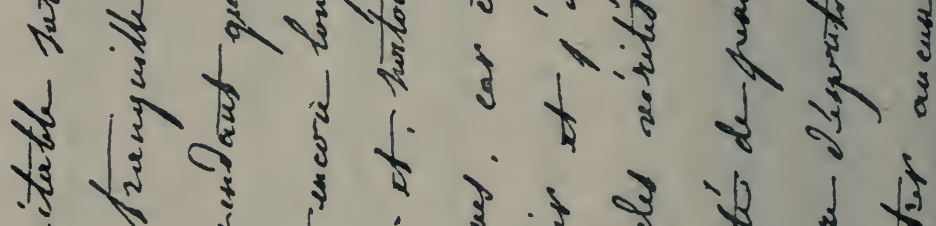

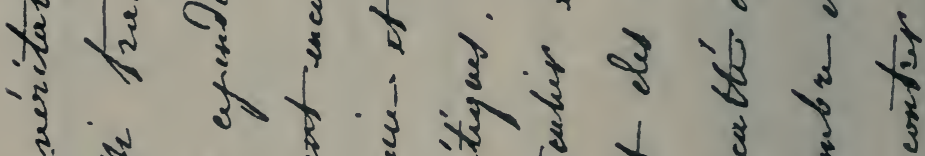

3
3
2

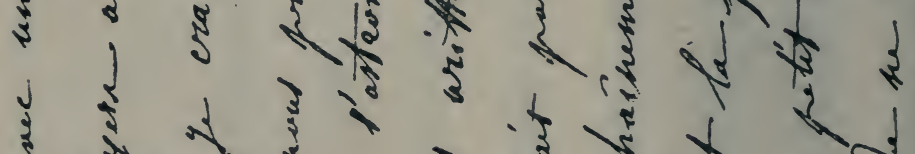

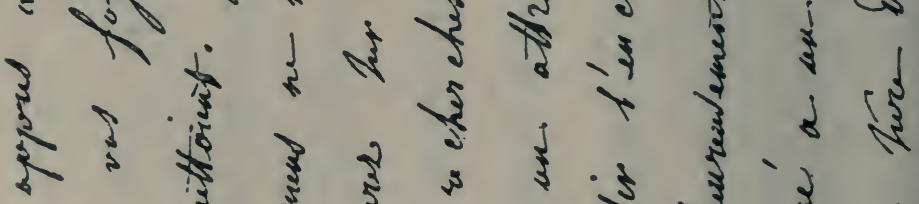

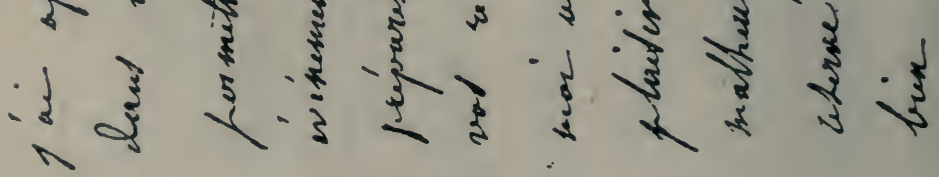


. i.

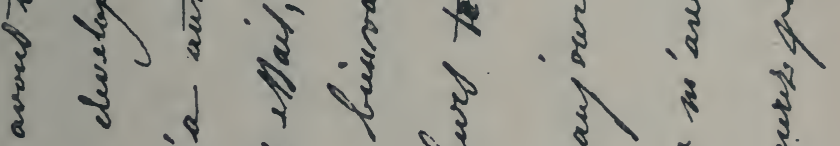

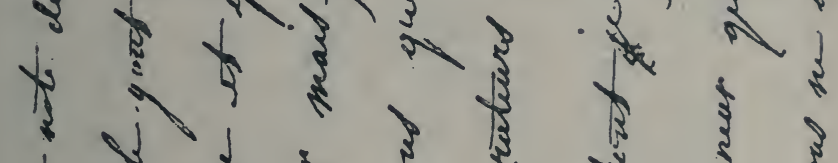
3.

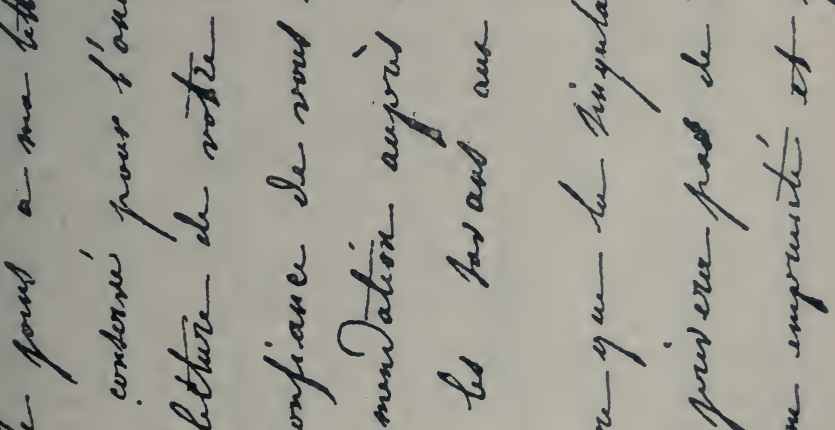

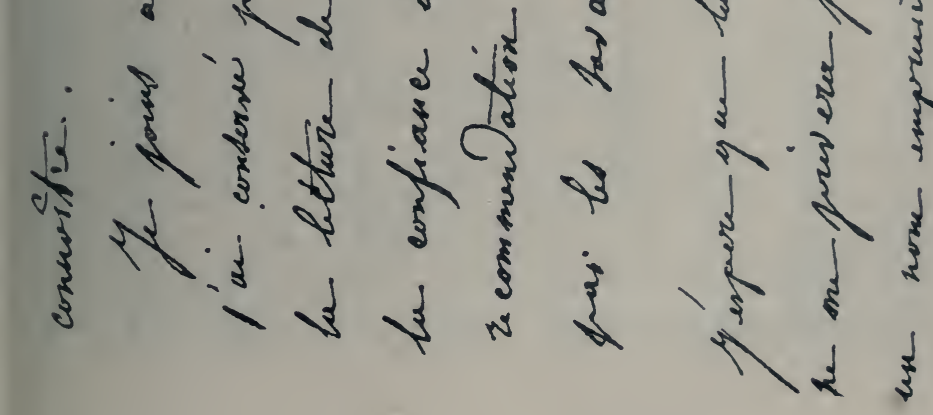




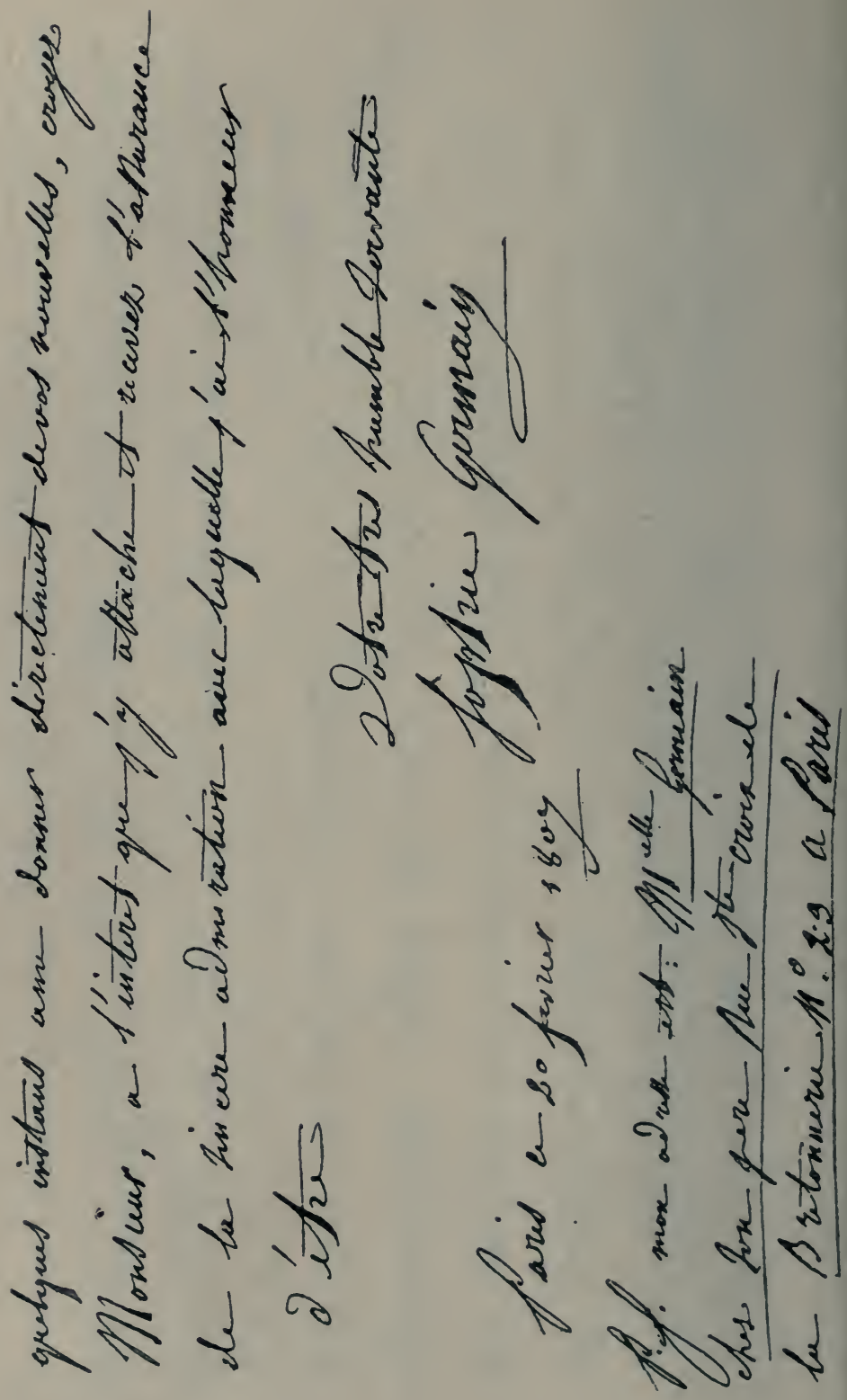


Vues phulosophoces. - Notre héroïne s'est révélée comme un philosophe des plus distingués dans son écrit posthume: Considérations sur l'état des lettres et des sciences aux différentes époques de leur culture. Une première édition, asse\% défectueuse, a été publiée par un parent, le député Lherbette et une autre par M. Stupuy. La troisième édition, due aussi à ce dernier, est précédée d'une intéressante préface et suivie d'un choix de lettres et de pensées.

Sophie Germain soutient la thèse de l'unité dans les manifestations de la pensée humaine. "Pour qui comprend ce livre, dit M. Liard, il est une synthèse à larges traits des doctrines qui allaient bientòt se disputer la prééminence. Par certains còtés, il prépare la philosophie positive et, par d'autres, il se rattache à cette philosophie rationnelle... qui prétend trouver dans l'homme la mesure de la vérité. ») Dans son Cours de philosophie positive, Comte revendique Sophie Germain comme un précurseur de cette philosophie. Voici ce que M. Ravaisson dit à son tour :

“De nos jours, une femme a eu un sentiment profond de cette doctrine qu'il y a, au fond de toute connaissance, un absolu. «Il existe en nous, dit Sophie Germain, un sentiment profond d'unité, d'ordre et de proportion qui sert de guide à nos jugements. Nous y trouvons : dans les choses morales, la riggle du bien; dans les choses intellectuelles, la connaissance du vrai; dans les choses de pur agrément, le caractère du beau. ) Et après avoir indiqué ce qu'il y a de contradictoire dans les théories d'aprìs lesquelles il n'y aurait que des rérités relatives, elle fait voir qu’il y a nécessairement un type d'après lequel nous jugeons, nous comparons, nous mesurons, et que ce type nous le trouvons dans la conscience que nous avons de notre propre ètre. “Doutera-t-on que le type de l'être ait une réalité absolue lorsqu'on voit la langue des calculs faire jaillir d'une réalité qu'elle a suivie toutes les réalités liées à la première par une essence commune ? „ Le progrès de la Science, c'est de tout ramener par 
l'observation et le calcul à l'unité de ce type, « qui a son modèle dans le sentiment de notre propre existence. L'ètre nous appartient, il pénètre notre intelligence et l'éclaire du flambeau de la vérité. Les idées du beau, du bon sont plus compliquées: nous les devons à la comparaison entre les connaissances acquises et notre modèle intérieur. ) Et encore: “ C'est à l'uniformité des conditions de l'être qu’il faut rạ)porter le sentiment d'analogie qui dirige toutes les opérations de notre entendement. Aujourd'hui que différentes branches de la physique sont entrées dans le domaine des sciences mathématiques, on voit arec admiration les mêmes intégrales, à l'aide des constantes fournies par plusieurs genres de phénomènes, représenter des faits entre lesquels on n'aurait jamais soupçonné la moindre analogie. Leur ressemblance est alors sensible, elle est intellectuelle, elle dérive des lois de l'être; et ce qui fut autrefois le rêve d'une imagination hardie, incertaine encore des formes qu'elle osait revêtir, l'identité des rapports de l'ordre et des proportions dans les existences les plus diverses, apparaît aux yeux en même temps qu’à la pensée, avec l'évidence qui appartient aux sciences exactes. »)

Sophie Germain a laissé des Pensées. Citons-en deux seulement. « L’algèbre n’est qu’une géométrie écrite, liı géométrie n'est qu'une algèbre figurée. » Ailleurs : "La langue mathématique est celle de la raison dans toute sa pureté; clle interdit la divagation, elle signale l'erreur involontaire; il faudrait ne pas la connaitre pour la faire servir à l'imposture. )

Il y a enfin la Correspondance entre la mathématicienne et ses divers collìgues, pleins de déférence pour elle. On trouve là des détails intéressants sur l'histoire des sciences, au commencement de ce siècle.

Au concours dagrégation des jeunes filles, en 1891 (Ordre des sciences), on demandait d'étudier cette opinion de Sophie Germain: Que l'esprit humain, dans sa marche vers le vrai, ne connaît qu'une seule voie, et que la séparation qu'on pré- 
tend faire entre les facultés de l'esprit n’a rien de réel. “Dirigéés vers le même but (la vérité), nos recherches dans les différents genres d'études emploient des procédés qui sont les mêmes. Les oracles du goût ressemblent aux arrêts de la raison. )

Une stö̈̈rense. - Insensible à la louange, Sophie Germain n’a jamais aimé la vérité que pour clle-même. Il parait qu’un érudit, Ansse de Villoison, l’a réellement peinée en la poursuivant de ses vers grees.

Une terrible maladie, un cancer au sein, attaqua la géomitre qui se montra stö̈cienne. Elle se savait perdue et travaillait toujours; elle recevait ses amis dans son modeste salon et leur souriait encore. Lherbette va cependant trop loin, lorsqu'il affirme que c'est pour tromper ses douleurs qu'clle a écrit hàtivement son livre philosophique. Le manuscrit, corrigé plusieurs fois, est en effet déposé à la Nationale.

Sophic Germain est morte le 17 juillet 1831, à une heure du matin, rue de Savoie, numéro 13, à đ̌ă ans. L'employé de l'état civil n'a pas voulu inscrire la profession de mathématicienne, sur l'acte mortuaire; celle de rentière lui a paru à la fois plus claire et plus digne.

How.Mages RÉCEnTs. - Terminons en citant quelques opinions compétentes sur Sophie Germain. Biot : “Mademoiselle Germain est probablement la personne de son sexe qui a pénétré le plus profondément dans les mathématiques, carr ici il n'y a point de Clairaut. » Chasles : "Elle fut plus profonde mathématicienne que la marquise du Chàtelet et que Mademoiselle Agnesi; elle avait l'esprit philosophique de cette dernière. » Navier : “ J'apprécie autant qu’il le mérite un mémoire aussi remarquable que peu d'hommes peuvent lire et qu'une seule femme pouvait écrire. " De Prony l'appelle l'Hypatie du dix-neuvième siècle. Un livre d'analyse de Poinsot a pour épigraphe : (Sophiæ germana mathesis. » Il y a peut-être là un calembour laudatif? 
Au cimetière du Pìre Lachaise, on a réparé et fleuri le tombeau. Une plaque commémorative a été fixée à la maison mortuaire. Une école supérieure de filles porte le nom de Sophie Germain et une rue s'appelle de mème.

On n'avait pas de portrait de la savante mais on avait son masque phrénologique, dans la collection du Muséum. Nous devons au crayon de Mme Chegaray, directrice de l'école Sophie Germain, le portrait que nous reproduisons et qui a été exécuté d'après ce moulage. Zacharie Astruc avait déjà fait un buste, d'après le même moulage. Sophie a un grand front, des sourcils accentués, le nez long est un peu courbé, le haut du visage large: elle est grave, pensive, presque sévère.

Pour construire la tour Eiffel, les ingénieurs ont utilisé l'élasticité des métaux. On a inscrit sur la tour les noms de 72 savants; on a oublié celui d'une fille de génie, la théoricienne de l'élasticité.

\section{Bibloghaphine.}

OEuvres de Sophie Germain.

Tables générales de nutation. Connaissance des temps, 1807, p. 484. Recherches sur la théorie des surfaces élastiques, 1821, in-4, $36 \mathrm{pp}$. et $1 \mathrm{pl}$.

Remarques sur la nature, les bornes et l'étendue de la question des surfaces élastiques et équation générale de ces surfaces, 1826.

Examen des principes qui peurent conduire à la connaissance des lois de l'équilibre et du mouvement des solides élastiques. 1828. (Dans les Annales de physique et de chimie.)

Mémoire sur la courbure des surfaces (Dans le Journal de Crelle, 1831, pp. 1 à $29 .-11$ y a eu un tirage à part, in- $4^{\circ}$ arec 1 pl.)

Note sur la manière dont se composent les valeur's de $y$ et de z dans l'équation $\frac{4\left(x^{p}-1\right)}{x-1}=y^{2}+p z^{2}$, etc. (Idem., pp. 201 à 20

Considérations générales sur l'état des Sciences et des Lettres aux différentes époques de leur culture. A la suite, des pensées et des lettres. (1 $1^{\mathrm{re}}$ édition postlume due à Lherbette, $18: 33 ; 2^{\circ}$ et $3^{\circ}$ éditions dues à Stupuy, 1879 et 1895 , précédées d'une étude sur S. G.; 3॰ édition arec portrait et masque phrénologique).

Mémoire sur l'emploi de l'épaisseur dans la théorie des surfares élastiques (retrouvé et publié par M. G. de Courcel, dans le Journal de Liouville, 1880, suppl., pp. 1 iे 66).

\section{Sources pour Sophie Germain.}

Chasles. Rapport sur les progrès de la Géométrie, p. 3วั.

G. Libri. Journal des Débats, du 18 mai 1832. 
Terquem. Bulletin de bibliographie, d'histoire et de biographie mathématiques, 1860, pp. 9 à 12.

Biographie universelle des contemporains; suppl. 1834, in-8.

Bulletin Darboux. 1879. Etude de Ch. Henry.

Bolletino di bibliografia e di storia delle scienze matematiche de Boncompagni. 1884. Note de Genocchi.

Bulletin de l'Association française pour l'avancement des sciences, 1880 .

lavaisson. Rapport sur la Philosophie au xux siècle.

Rerue positiviste, 1879 .

Aug Comte. Cours de philosophie positive.

Journal des Savants, mars 1817 (Article de Biot). ld. , mai 1879 (Article de J. Bertrand).

Revue philosophicque d'octobre 1879 (Article de Liard).

Hugo-Guering. Sophie Germain et Clodilde de Vaux. Zurich, 1889 (en allemand) Du mème, plusieurs autres travaux sur S. G.

Le Collaborateur des Érudits et des Curieux du 12 décembre 1896. (S. G. aurait indiqué le principe du téléphone).

Masque phrénologique au Muséum, seul document primitif. - Portrait dû à Mmo Chegaray, que nous reproduisons. -Buste par Zacharie Istruc, à l'école Sophie Germain.

Autographes. Aux Manuscrits de la Biblioth. Nation. Fonds français. De 9114 à 9116 , Papiers de S. G., mémoire de physique. 9117. Considérations générales, etc .

Cinq̣ lettres à Gauss, fac-similés par Boncumpagni. Berlin, 1880 .

Dans un des premiers rolumes du Journal de Crelle, fac-similé d'un autographe.

\section{GERNET (MARIE)}

Reduktion hyperelliptischer Integrale durch rationelle Substitutionen. Heidelberg, 189 sั.

\section{GERVAIS}

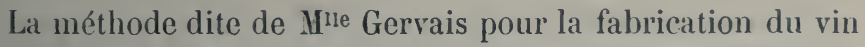
serait due à Casbois, physicien de la fin du xvme siècle.

Bibliothèque portative.

V. Académie de Bordeaux, 1822. Rapport de M. Gutard.

\section{GIBERNE (AGNĖS)}

Sun, Moon and Stars (préface C. Pritchard). Londres, 1880 , 302 pp.; nouv. édition, 318 pp.

\section{GIGLIANI (ALEXANDRA)}

Xvi siècle; anatomiste à Bologne. 


\section{GINOT-DESROIS}

On lit dans les catalogues de la librairie GauthierVillars :

M $^{110}$ Ginot-Desrois. Planisphère mobile au moyen duquel on peut apprendre l'astronomie seul et sans mathématiques, 7 e édition, 1847; sur carton.

De la même. - Calendrier astronomique et perpétuel, donnant le quantième du mois, les jours de la semaine, les phases de la lune, la place du soleil dans l'écliptique pour un jour donné, le lever, le passage au méridien, le coucher de ces astres et des étoiles, ainsi que les principales éclipses visibles à Paris, dans l'ordre de leur grandeur et dimensions; $2^{e}$ édition, 1861, sur carton, avec une brochure in-8.

\section{GODIN DES ODONAIS}

On sait que l'astronome Godin avait été désigné, en 17'11, par l'Académie des Sciences, pour faire avec La Condamine des observations au Pérou. Là, il dut quitter sa femme qui l'avait accompagné, pour faire un voyage de 19 ans. Mme Godin, le crovant perdu, alla à sa recherche. Elle se retira plus tard à Saint-Amand, dans le Berry et mourut en 1792.

V. Les grandes voyageuses, par Marie Dronsart.

\section{GOLDE}

Cette demoiselle a traité de L'incinération au point de vue historique et hygiénique. 1896, in-8, 92 p.

\section{DE GONZAGUE (BARBE)}

Fonda, en 1'47, l’Université de Tubingue; mourut en $1500 \%$.

\section{gotha (Louise de SAXE)}

Cette duchesse a fait une quantité de calculs, mais elle ne veut pas être citée. Elle observe et elle calcule d'une façon surprenante.

Laldide. Astronomie des dames; p. 11. 
C'est l'astronome de Zach qui a engagé, en 1786, à Hières, cette dame à s'occuper d'astronoinie.

\section{GOTTSCHED (LOUISE-ALDEGONDE-VICTOIRE), NÉE KULMUS}

Née à Dantzig. A publié plusieurs ouvrages de mathématiques. Morte en 1762 et enterrée dans l'église de l'Université de Leipsig.

Jeux écrits de la marquise du Châtelet et de Mairan sur la force vive. Traduit du français. Leipzig, 1741.

\section{DE GOURNAY}

Mlle de Goirnay avoue qu'elle s'est beaucoup occupée et qu'elle s'occupe encore de l'alchymie, qu'elle y a despensé, la première année « quelque somme non mesprisable, quoique non excessive provenant de mes inventions et labeurs, non de mon patrimoine. Pendant les sept années suivantes, j’ai fait diverses opérations qui m’ont cousté chacune cent ou six vingt escus environ. Depuis lequel temps, deux escus d'ordinaire et le troisième d'extraordinaire, me deffrayent par an pour' ce regard, d'autant que j’ai trouvé moyen d'espargner le surplus à l'aide d'un feu qui m'est presté gratis par la courtoisie des maistres de la verrerie, feu jadis ma plus pesante charge.... Quelques-uns rient de ma longue patience en ce labeur; à tort, certes, puisqu'on attend bien toute une année un espy; outre que si mesmes je n'espérois nul succez en l'œuvre (comme je puis désormais faire après ce long temps escoulé sans fruit), je ne lairrois de travailler, pour voir soubs les degrés d'une très belle décoction, ce que deviendra la matière que je tiens sur le feu : curiosité naturelle et saine. »)

A pologie pour celle qui escrit, publiée dans l'Ombre.

V. P. DE Musset. Extravagants et originaux du xvü siècle. 186't, in-12. - L. Feugène. Mademoiselle de Gournay, sa vie et ses æeuvres. $18: 33$, in-8. 


\section{GRANCHAMP (SOPHIE)}

Cette amie intime de Mme Roland a fait des cours publies d'astronomie.

\section{DE GRIGNAN (COMTESSE)}

16'18-170כ. - M. Janet dit que la grand'mère fut une sainte, la mère une adorable payenne et la fille un philosophe. $M^{\text {me }}$ de Grignan, dont les lettres sont malheureusement perdues, était une cartésienne militante. Ime de Sévigné, quoique cartésienne aussi, raille sa fille sur son Père Descartes, l'indéfectibilité de la matière, la mécanique des animaux, la grandeur de la lune, les négations non conversibles, etc. Il ne nous reste de Mme de Grignan qu'un petit traité sur L'Amour de Dieu, traitant du quiétisme et de la querelle entre Fénelon et Bossuet (Lettres de Mme de Sévigné, tome $\mathrm{X}$, p. ร̌18, édition Monmerqué).

\section{GRILLIA OU BOROMEO (CLELIA)}

La comtesse de Grillia, morte le 23 aoùt 1777, a consacré toute sa vie à l'étude des sciences. Elle avait établi dans son palais à Milan une académie de phỵsique.

\section{GRUNBACHIA (ARGULA)}

Auteur de thèses théologiques, d'après la religion luthérienne.

\section{GUENARD (BARONNE DE MÉRÉ)}

Les Enfants voyageurs ou les petits botanistes. 1818, ' t rol. pet. format.

\section{GUILLAUME (JACQUETTE)}

Morte le 21 juin 1700.

Les Dames illustres anciennes et modernes, où, par bonnes et fortes raisons, il se prouve que le sexe féminin surpasse en toute sorte de genres le sexe masculin: par damoiselle Jac-

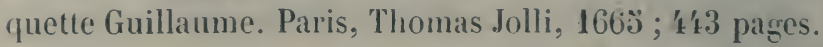

C'est un résumé curieux de connaissances scientifiques et 
philosophiques. Il y a une étude historique des travaux des femmes dans les sciences. Lire surtout, vers la fin, les propos attribués à deux savantes qui ne sont pas nommées.

\section{guizot (Élisabeth-Charlotte-Pauline), née de meulan}

1773-1827. - Auteur Des idées de droit et de devoir. - En collaboration avec M. Guizot, Héloïse et Abailard.

\section{GUYON}

Jeanne Bouvier de la Mothe, devenue $\mathrm{M}^{\mathrm{m}} \mathrm{e}$ Guyon (16'81717), est une mystique, liée avec Fénelon (querelle du quićtisme), auteur des Torrents spirituels, etc. Ses œuvres forment 39 vol.

( Si Madame Guyon avait lu le conte de la bonne vieille qui apportait un réchaud pour brûler le paradis et une cruche d'eau pour éteindre l'enfer, afin qu'on aimât Dieu pour luimème, elle n'aurait peut être pas tant écrit. »

V. L. Guerrier. $M^{\mathrm{m} \mathrm{c}} G$., sa vie, sa doctrine, et son influence, 1881 , in-8.

\section{GUYTON DE MORVEAU}

Mme Guyton de Morveau, la femme du grand chimiste, a traduit du suédois les llémoires de chymie de Scheele, Paris, 178.;, 2 vol. in-12.

Elle a aussi traduit de l'allemand le Traité des caractères exiérieur's des fossilles de Werner. Paris, 1790, in-8.

\section{GUZMAN}

On lit dans le testament de $\mathbb{L}^{\mathrm{m} e}$ Guzman, morte à Pau, à 92 ans, en juin 1891 :

Cn prix de $\mathbf{1 0 0 . 0 0 0}$ franes est léguć à l'Institut de France (section des sciences) pour la persomne qui trouvera le moven de communiquer arec un astre, Mars par exemple, et d'en recevoir la ríponse. 


\section{DE HAAS (CAROLINE)}

Collaboratrice de Mathesis, revue belge de mathématiques. Solutions de problèmes, de 1891 à 189'.

\section{HALL (ASAPH)}

A suivi les travaux de l'astronome, son mari, et l'a encouragé lorsqu'il allait abandonner les recherches qui l'ont conduit à la décourerte des satellites de Mars.

\section{HALLER}

La femme et les enfants de ce naturaliste l'aidaient continuellement, consultaient les auteurs, réunissaient des plantes, coloriaient et dessinaient.

Curiosités de la littérature, traduit de l'anglais par BEnTIN, 1809, t. I, p. 316.

\section{HALLOWELL (SUZAN)}

Professeur de botanique à Welleslay College, U. S. A.

\section{HANNEMANN}

Compte rendu du procès de Mime Hannemann, docteur en homéopathie, prévenue d'exercice illégal de la médecine, 1847 .

\section{HARDCASTLE (FRANCES)}

A traduit en anglais (Cambridge, Mac Millan et Bowes, 1893) : Sur la théorie de Riemann des fonctions algébriques et de leurs intégrales, par Félux Ku.eIx.

Cette demoiselle est probablement américaine.

\section{HAWS (CHARLOTTE)}

Étudie les algues à Boston.

\section{HAYES (ELLEN)}

Maitresse de mathématiques au Collège de Welleslay (U. S. A.), Miss Hayes a déterminé l'orbite d'une petite pla- 
nète à l'Observatoire de l'Université de Virginie. (Revue internationale de l'Enseignement du 15 janvier 1892: Un collìge de filles aux États-Unis.)

\section{HEIBERG}

D'aprìs le journal Les Débats du 16 août 1893 , les Mémoires de cette danoise ont un caractère philosophique très accentué.

\section{HÉLOİSE}

Née à Paris en 1101, élève d'Abailard qui l'épousa secrètement. Ils eurent un fils appelé Astrolabe. Héloïse devint religieuse au couvent d'Argenteuil, puis fonda l'Abbaye du Paraclet, où elle mourut en 116'. Elle savait le latin, la philosophie, la théologie et les mathématiques.

Dans une première traduction des Lettres, M. Oddoul écrit assez dròlement : « De sa sphère virginale, elle descend vers lui, comme sur un plan incliné. » Ce sont là géométrie et mécanique bien intentionnées.

V. M. ет $\mathbb{N}^{\mathrm{me}}$ Guzot. Abailard et Héložse; 180̈3, in-8.

HELVIA

Mère du philosophe Sénèque.

V. Diderot. III, 17, 327, 331.

\section{HERPYLIS}

Épouse d'Aristote; était versée dans l'histoire naturelle, d'après Deвay. Les nuits Corinthiennes; 18 9̈9.

\section{HERRADE}

\section{Une abbesse encyclopédique, artiste} et savante.

"Herrade de Landsberg qui gouvernait quarante-six religieuses nobles au Mont Saint-0dile, en Alsace, composa sous le titre de Hortus deliciarum, une sorte de cosmologie qui est regardée comme la première tentative d'une encyelopédie 
scientifique. " Movtalembert. Des moines d'occident, tome VI, p. 190.

Le manuscrit, mi prose mi vers, orné de miniatures d'une merveilleuse délicatesse (1167) était conservé à la Bibliothèque de Strasbourg (Bibliothèque de l'École des Chartes, série Ire, t. I, p. 239 et suiv.). Il a été détruit en août 1870, pendant le bombardement de la ville par les Badois.

Herrade de Landsberg, par C. Schnid ; Strasbourg, impr. Heitz, 1892 (Tiré à 5̋0 exemplaires, non mis dans le commerce).

Engelihardt. Vie de Herrade. Stuttgard, 1818, in-12, portr.

Lasternie (Comte Robert de). Miniatures inédites de l'Hortus deliciarum. 188̈, in-' 4,37 pp., כ̋ héliogravures.

Annales de la philosophie chrétienne, XIXe vol. Reproduction d'une gravure de l'Hortus deliciarum où l'Arithmétique est représentée par une femme comptant les grains d'un chapelet.

\section{HERSCHEL (CAROLINE-LUCRĖCE)}

Une centenaire qui a modestement découvert sept comèles.

Soeur de l'astronome William Herschel et astronome ellemême, Caroline Herschel est née et morte à Hanovre (16 mars $1730-9$ janvier 18'18). Le frère et la sueur vinrent à Bath (Angleterre) en 1772 et furent d'abord musiciens.

Nous n'arons pas à raconter ici comment W. Herschel devint un grand astronome; Caroline fut son aide passionné, physiquement et intellectuellement. Elle passa bien des nuits à observer les astres, elle polit des miroirs, elle nota et elle calcula ses propres observations et celles des autres.

Elle a découvert personnellement sept comètes, de 1786 à 1797. Elle a publié d'abord, en 1798, Le Catalogue des étoiles observées par Flamsteed et omises dans les catalogues anglais et ensuite, en 1828, le Catalogue des étoiles doubles et des nébuleuses observées par son frère. A la suite de la 


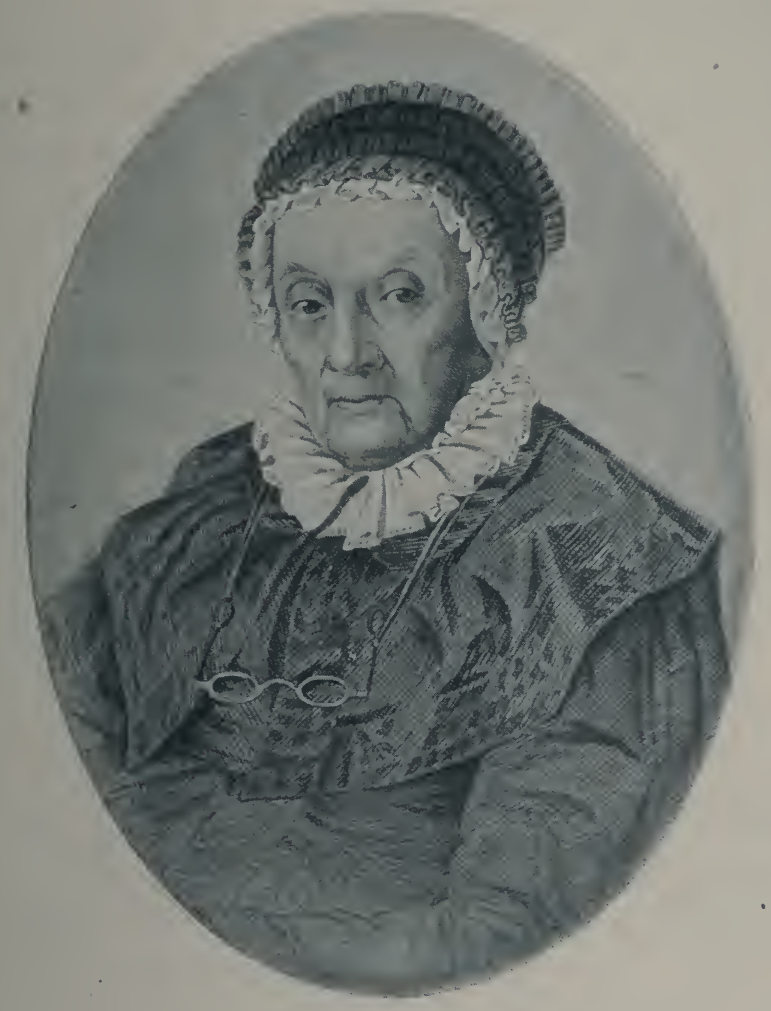

CAROLINE HERSCHEI 

seconde publication, Caroline a reçu la médaille d'or de la Société astronomique de Londres. Elle a donné en outre plusieurs Mémoires au Recueil de la Société royale. Le roi Georges III lui a accordé une pension.

Après la mort de son frère chéri, Caroline Herschel est revenue dans son pays natal où Alexandre de Humboldt lui a annoncé le 2כ septembre $18 \not 6$ que le Roi de Prusse lui envoyait une grande médaille pour honorer sa science et sa vieillesse. " La vieille petite dame " s'est éteinte presque centenaire, à 98 ans. Elle a fait mettre dans son cercueil une mèche de cheveux de son frère.

Catalogue of Stars taken from Flamsteed's observations, etc. With an index to point out every observation, etc. London, 1789, in-fol.

V. DezanBRE. Rapport sur les progrès des Sciences (où C. H. est citée trois fois).

Arago. Biographie de $W$. Herschel.

PARIsot. Article dans la Biographie Michaud.

Mrs Johv Henschel. Memoirs and Correspondence of Caroline Herschel. London, in-8, 1876. (Arec portrait.)

Revue britannique. (Janvier 1848; février et juin 1876.)

Ciel et Terre du 1 ja janvier 1885 ; p. 250 et suiv.

LODGE. Pionneers of Science, p. 27 s et suiv.

\section{HÉVÉLIUS (ÉLISABETH), NÉE KOOPMANN}

La deuxième femme de l'Astronome, a observé avec lui.

V. Westphal. Vie d'Hévélius. Königsberg, 1820. - DeideM...x. Mème titre. Zittau, 186'ł. - Loeschis. Geschichte Dantzigs, 1823, t. II, p. 87.

\section{HILDEGARDE (SAINTE)}

Les physiciens invoquent ta protection.

1100-1180. - Fondatrice du monastère du Mont-SaintRuppert, près de Bingen, sur les bords du Rhin.

Tr'̀s curicuse des productions et des phénomènes terrestres, son ouvrage de Physica contient beaucoup d'observations et de réflexions personnelles; il comprend quatre livres : le pre- 
mier traite des Éléments, des fleures de la Germanie, de la nature et des propriétés des métaux; le deuxième, des légumes, des fruits et des herbes; le troisième, des arbres; le quatrième, des poissons, des oiseaux et des quadrupìdes.

Le livre dont nous avons résumé la table a été imprimé avec d'autres: Argentorati, 1533 ; Collection des médecins,

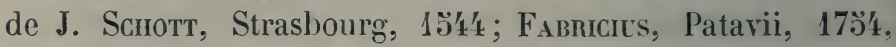
in-', t. III, p. 260 ; OEuvres réunies, Cologne, 1206.

Reuss F.-A. Commentatio de libris physicis S. Hildegardis, Wirceb, 1833̈, in-8.

Moxtalembert. Moines d'occident.

Revue des questions historiques, arril 1883. Ste Hildegarde et ses œuvres par A. Batta.idier.

Dans son livre des Subtilités des natures et dans l'autre de la médecine, Hildegarde nous donne tout le contingent scientifique de son temps. Le Dr Daremberg a édité le livre des Subtilités.

La Métallothérapie du Dr Burcq est tout entière dans la savante.

Influence réciproque de l'homme sur la terre et de la terre sur l'homme.

Au chapitre du Soleil, Hildegarde nous montre cet astre au milieu du firmament et retenant par sa force les étoiles qui gravitent autour de lui, les nuages qui flottent dans l'air, comme la terre soutient toutes les créatures qui l'habitent.

Puis Hildegarde arrive à l'inégalité des saisons et nous dit que, pendant l'hiver, s'il fait froid sur la partie de la terre que nous habitons, la partie de la terre qui est au-dessous de nous est chaude, afin que la température céleste soit ainsi équilibrée. (Au xir siècle !!)

Les étoiles (chap. De stellis) n’ont ni même éclat, ni même grandeur. Elles ne sont pas immobiles mais elles traversent le firmament dans son entier : de même que le sang se meut dans les veines, qu'il les agite et qu'il les fait bondir, ainsi les étoiles se trouvent dans le firmament et envoient des 


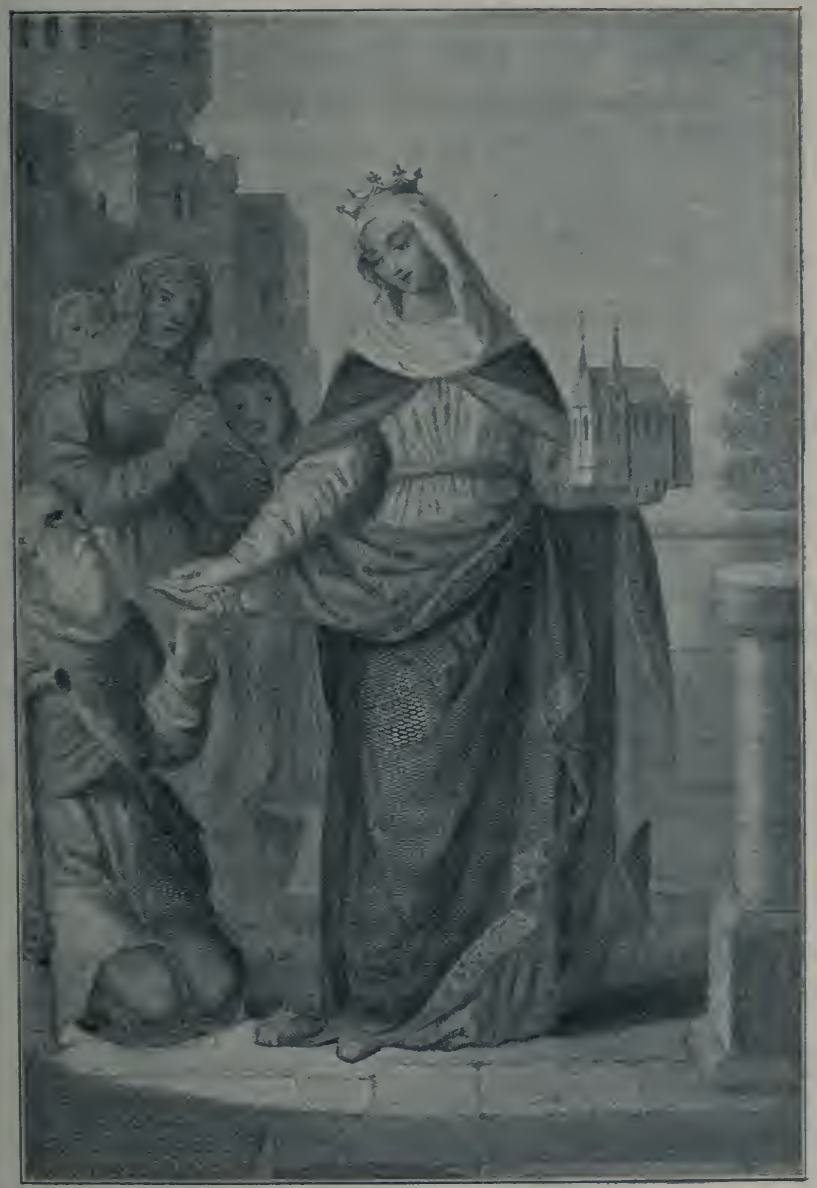

SAINTE HILDEGARDE 
$-$ 
étincelles comme des bonds de lumière (phénomène du scintillement). (Déjà circulation du sang! à cette époque.)

Décrivant le phénomène physique des vagues, Hildegarde a mis le doigt sur sa cause, en l'attribuant au peu de profondeur de la mer vers le rivage, donnée acceptée aujourd'hui par la science.

Le naturaliste trouvera dans Hildegarde le germe de plusieurs autres décourertes modernes. (D’après Battandier.)

V. Hildegardis. Opera omnia. Édition Daremberg et de Reuss. Chez Migne, 1882. Un vol. in-8.

\section{HIPPARCHIE}

Philosophe cỷnique, dont Diogène de Laerce a écrit la vie. Quoique bossue et fort pauvre, épouse Cratès. D’après Suidas, elle aurait écrit des ouvrages intitulés Hypothèses philosophiques et Épichérèmes. On trouve sur elle cette épigramme lans l'Anthologie grecque:

" Je n’ai point imité les mours délicates des femmes, j’ai suivi la vie dure et austère des Cyniques. Je n'aime point à avoir des agraffes au manteau, ni à mettre des ornements aux pieds, ni à m'oindre le front. Je marche avec un bâton, je rais nu-pieds, je porte un habit doublé, et la terre me sert de lit.... )

On a dit qu'Hipparchie était savante en physique et en astronomie.

V. Diderot. XIII, 26' . - Wieland. Cratès el Hipparchia, roman, suivi des Pythagoriciennes.

DE HIRSCH

Au commencement de cette année (1897), M ${ }^{\text {me }}$ la Baronne Maurice de Hirsch a fait don de deux millions à l'Institut Pasteur.

\section{HITCHCOCK}

Cette demoiselle s'occupe des fougères à Missouri, U. S. A. 
HOHEKER (ÉLÉONORE)

Entomologiste, née en 1761.

\section{HOMMAIRE DE HELL}

Née en Artois en 1819, voyageuse, collaborateur et secrćtaire de son mari (ingénieur et géologue) dans ses travaux scientifiques. A publié chez Hachette ses Voyages dans les steppes de la mer Caspienne.

V. A. Chevalier. Les Voyageuses au XIX $\mathrm{X}^{\mathrm{e}}$ siècle. Marie Dronsart. Les Grandes Voyageuses.

\section{HONORAT-BASTIDE}

M. et Madame Honorat-Bastide, de Digne, ont publié :

$1^{\circ}$ Le trias et ses couches bajociennes, 1891.

-20 Sur l'oxfordien de Courbons (Basses-Alpes). (Fenille des jeunes naturalistes, du der octobre 1890.)

En dessous du petit village de Courbons, 'sur le bord du torrent de Saint-Véran, se trouvent des Marnes noires avec Ammonites et Bélemnites qui ne laissent aucun doute sur l'origine oxfordienne de ces couches. Ces marnes noires et les rochers (oxfordiens aussi) qui les dominent navaient pas encore été signalés.

\section{DE L'HOPITAL}

( Il (le marquis de L’Hòpital) avait épousé Marie-Charlotte de Romilly de la Chesnelaye, demoiselle d'une ancienne noblesse de Bretagne, et dont il a eu de grands biens. Leur union a été jusqu’au point qu’il lui a fait part de son génie pour les mathématiques. ») (Fovtevelue, Éloges).

Elle présida à l'impression de l'Analyse des infiniment petits de son mari, pendant un long voyage de ce dernier.

Dans le Journal des Savconts, année 1691, p. 283, on troure un travail de La Montre sur le carré de l'hỵpoténuse; puis page 5020 du même recueil : Réponse de Me la M. de L“.” sur la prétendue démonstration de U. La Montre. Lat Marquise prouve que le raisonnement du successeur de Ramus revient à conclure que $\mathrm{A}=\mathrm{B}$ de ce que $\mathrm{A}+\mathrm{B}=\mathrm{A}+\mathrm{B}$. 


\section{HOSKELL}

Miss Hoskell, professeur de botanique, à Wassar College, U.S. A., a étudié spécialement les fougères.

\section{HUBER, NÉE LULLIN}

Cette génevoise a contribué aux remarquables découveittes de son mari, sur les abeilles. Elle lui donna des preures de dérouement lorsque, devenu aveugle, il ne vit plus qu'arec les yeux de sa chère collaboratrice de tous les instants.

"Il est probable que Flora Tristan connaissait les curieux travaux de $\mathrm{H}$. et de $\mathrm{M}^{\mathrm{me}} \mathrm{Huber}$, et que l'autorité de cette reine des abeilles qui commande ordinairement à 20.000 ouvrières et à 16.000 màles, lui paraissait l'idéal d’un bon gouvernement. ")

Dora is'Istria. Des femimes, t. I, p. 76.

\section{HUBER (MARIE)}

Philosophe, moraliste et surtout théologienne protestante; Genève et Lyon, 169't-17ö3. Elle a publié sans nom d'auteur :

Le monde fou préféré au monde sage; Amsterdam, 1731. Lettres sur l'état des àmes après la mort; Londres, 1731.

Lettres sur la religion essentielle; Amsterdam, 1738.

secondes lettres sur l'état des ames; Londres, 1739.

“Demandons à la bienveillance de nous donner le calme de l'àme et l'affection de ceux qui nous entourent, non la fortune; demandons celle-ci à l'activité unie à la prudence; et ne crions ni à l'absence d'ordre ni au manque de justice, parce que notre voisin actif et prudent, qui est devenu millionnaire, se trouve ètre en mème temps un fils ingrat ou un cœur sans pitié. II n'aura avec sa fortune ni des amis vrais ni le calıne du cœur, parce qu'il n'a pas ce qui engendre naturellement les amis et le calme du cœur; et, sil a des enfants, ses enfants lui feront probablement subir un jour les conséquences de l'inévitable façon dont il les aura élevés, comme ceux d'Harpagon le font à leur père. Mais il aura fait fortune parce qu'il avait ce qui doit 
naturellement engendrer la fortune. A chaque fin son moyen propre. Exigeriez-vous que de deux coureurs ce fût le plus vertueux qui arrivât le premier, et non pas le plus agile? »

V. Une aïeule du protestantisme libéral, par V. CourdavEAUX; Saint-Denis, 1884.

\section{HUDSON (HULDA)}

Simple proof of Euclid II, 9 and 10. Nature, 1891-92, p. 189 .

\section{HUGGINS}

Mrs Huggins, née à Dublin, aide et collaboratrice de son mari, Directeur de l'observatoire de Tulse Hill, près de Londres, a étudié les spectres des étoiles. (Notes de voyage de M. Perrotin).

M. ex Mme Hugans. Sur l'étoile nouvelle du Cocher (Bulletin astronomique de $\mathrm{M}$. Tisserand.t. 9, juillet-décembre 1892).

\section{HUMAN}

Soeur du ministre de Louis-Philippe, mère spirituelle de Gratry (Souvenirs de jeunesse, p. 1'łö et suiv.) et de Beautain (La chrétienne de nos jours, lettre 10̈).

\section{HÜRNISCH (JOHANNA-DOROTTEA)}

Chirurgienne allemande du $\mathrm{xIx}^{\mathrm{e}}$ siècle. On a écrit deux histoires de sa vie.

\section{HYPATIE}

Ma bienfaitrice, mon maitre, ma saur, ma mère.

L'ÊÊQQE SrXésIUS.

L'ÉCole D’Alexaxdrie. - La plus ancienne mathématicienne, sur laquelle nous ayons quelques renseignements positifs, est Hypatie d'Alexandrie.

L'antique Égypte est le bercenu des sciences. Les premiers philosophes grees sont venus s'y initier secrètement à la géométrie et à l'astronomie. Plus tard, la Grèce a payé largạe- 
ment sa dette à l'Égypte. Alexandric, la ville d'Alexandre, a été pendant de longs siècles un foyer intellectucl incomparable. La grande École d'Alexandrie a été double. On a écrit l'histoire, en plusieurs volumes, de l’École philosophique; je n'en ai guère retenu que ce trait : Un certain sage, à l'âme délicate, y rougissait d'avoir un corps. Quant à l'École scientifique où brillèrent Euclide, Apollonius, Diophante, Ptolémée et à laquelle se rattache Archimède luimême, cette école attend encore son historien.

Jeunesse d’Hrpatie. - Au Ive siècle après J.-C., Théon, un mathématicien connu, qui était aussi un naturaliste, enseignait à l'École d'Alexandrie. On lui attribue, peut-être à tort, un écrit sur les présages et la voix des corbeaux.

Théon eut une fille, Hypatie. Elle naquit vers l'an 370 ap. J.-C. Cette jeune grecque, qui devait grandement surpasser son père, reçut, de lui et de ses collègues, les premières leçons.

Il parait - quoique le fait ait été contesté, - qu'Hypatic fit dans sa jeunesse le voyage d'Athènes pour s'y perfectionner. Elle dut y suivre les cours de Plutarque le Jeune et de sa fille Asclépigénie, qui dirigeaient ensemble l'École philosophique.

Double exseignenest. - A son retour d'Athènes, Hypatie fut invitée, par les magistrats d'Alexandrie, à professer publiquement.

Son enseignement comprenait deux parties successives.

Platon avait jadis écrit sur son école de philosophie : "Que nul n'entre ici, s'il n'est géomètre. „ En conséquence, Hypatie enseignait d'abord les mathématiques, puis la philosophie proprement dite.

Nous ne dirons qu'un mot de la philosophie d'Hypatie. Elle était néo-platonicienne, tandis que Théon tenait pour la doctrine d'Aristote. Elle était éclectique et il semble, comme on l'a fait souvent remarquer, que la position d'Alexandrie, aux confins de trois continents, devait y produire le mélange des opinions. Cette philosophie était aussi un peu mystique, 
d'après les tendances de Platon et par suite de l'influence chrétienne. Nous devons constater qu'Hypatie a toujours repoussé la théurgie qui dominait alors, c'est-à-dire les génies, les enchantements et les prodiges. Nous arons encore, hélas, les mêmes chimères, sous d'autres noms.

Hypatie était, avant tout, une mathématicienne. Flle a enseigné ex cathedra la géométrie, l’algèbre et l'astronomie. Les mathématiques, déjà constituées par les Grees, ne devaient plus faire de progrès notables avant douze siècles, avant Descartes, Newton et Leibniz.

On attribue à Hypatie plusieurs inventions, d'abord celle de l'aréomètre ou pèse-liqueurs, d'après cette lettre : " Je suis malade. J'ai besoin d'essayer les eaux. Faites-moi faire un instrument de la forme et de longueur d'une flûte, etc. " Mais la lettre n'est pas écrite, comme on l'a dit, par Hypatie à Sýnésius. On a interverti les ròles, et du reste une conséquence aussi simple du principe des corps flottants devait être connue depuis Archimède. - D’après des lettres de Ș̣nésius à des tiers, il est certain qu'Hỵpatie a imaginé un planisphère et un astrolabe; pour le premier, on projetait la région équatoriale de la terre sur le cylindre circonscrit et le second était un cercle graduć pour mesurer les distances angulaires des astres. - On a parlé aussi de deux autres instruments, un niveau d'eau et un appareil à distiller, mais nous croyons que c'est à tort.

Livres perdus. - Les historiens signalent trois livres d'Hypatie, probablement perdus pour toujours.

Le premier livre était un commentaire du Traité des coniques d'A pollonius. - Le second livre était un commentaire des Arithmétiques de Diophante, qui sont le premier ouvrage connu d'algèbre; Diophante, qui était perdu, a été seulement découvert à la fin du quinzième siècle. - La troisième ouvre était un Canon astronomique, éest-ì-dire des Tables des mouvements des astres; s'agit-il là d'une ceuvre originale, comme on le croit généralement, ou d'un simple commen- 
taire des tables de Ptolémée, comme quelques-uns le prétendent? Dans ce dernier cas, le travail d'Hỵpatie subsisterait peut-être encore, mêlé à celui de son pìre Théon, sur le même sujet.

Triomphe d'une fenme. - Aucune femme, peut-être, n’a réuni autant de gloire, de beauté et de sagesse qu'Hỵpatie.

On vantait son éloquence. Sa roix était qualifiée de divine. Sa beauté était célébrée partout, mais on ne peut la préciser: il ne nous reste aucune statuette, aucune médaille. On accourait de toutes les parties du monde à ses leçons. Jl suffisait de lui écrire “à la Philosophe » ou "à la Muse, à Alexandrie ». Elle était respectée et lıonorée, autant qu’admirée. Elle portait arec modestie et assurance son manteau de philosophe.

M. Weil a traduit pour nous ces vers de l'Anthologie : "Quand je te rois et que j'entends tes discours, j’adore : c'est l'éthérée constellation de la Vierge que je contemple; car au ciel est rouée ta vie tout entière, auguste Hypatie, idéal d'éloquence, astre immaculé de la sagesse.»

On a cru lire, dans la vie d'Isidore par Damascius, qu'Hypatie avait été la femme de ce philosophe, mais il faut entendre unie dans le sens d'une communauté d'idées. L'historien prétend du reste que cet Isidore surpassait Hypatie, comme tout homme surpasse naturellement une femme et comme un philosophe surpasse une simple géomètre.

Il parait qu'un étudiant d'alors s'étant épris d'amour pour Hỵpatic, qui aimait seulement la vérité abstraite, fut guéri par elle. Une première version est donnée dans un grec intraduisible; d'après la seconde, le jeune homme aurait été apaisé par la musique.

On a produit une prétendue lettre d'Hỵpatie à l'évêque Cryille où elle demande à se convertir au christianisme. Elle y parle de la condamnation de Nestorius; or Nestorius est né seize ans après la mort de la Sarante.

Srvésics. - On ne connait que les noms de quelques-uns des disciples d'Hypatie. L'un d'eux, dont les aurres nous 
restent, Synésius, devint chrétien et évèque de Ptolémaïs. Il a composé des hymnes qui en font le précurseur du Lamartine des Méditations. Ses lettres sont la source principale sur Hypatie: sept sont adressées à cette dernière et dans quatre autres il parle d'elle. On y lit: "Nous avons vu, nous avons entendu celle qui préside aux mystères sacrés de la philosophie. » Ailleurs: “ Elle est sainte et chère à la divinité. » Et cette apostrophe : « Ma bienfaitrice, mon maître, ma sœur, ma mère ! » Heureusement pour lui, Synésius devait mourir avant Hypatie.

LE crine. - Alexandrie était une ville profondément troublée. On y professait trois religions rivales, le judaïsme, le paganisme et le christianisme qui triomphait. Il s'élevait entre l'évêque et le préfet de redoutables conflits d'attributions. L'érêque était Cyrille, fougueux et dominateur; le préfet, qui s'appelait Oreste, était chrétien, mais il voulait maintenir les droits de l'État.

Un maître d'école, Hierax, s'étant mal tenu devant le gouvorneur, promulguant ses décisions au théâtre, fut frappé de verges. Des moines ayant osé attaquer à coups de bàton Oreste et sa suite, l'un d'eux, Amonius, fut mis à mort.

Sur ces entrefaites, en mars $4 \mathbf{1}$, pendant le carême, le lecteur Pierre, suivi d'une foule furieuse, arracha Hypatie de son char. Elle fut traînée dans la Césarée, l'église de César, et là, dépouillée de ses vêtements, elle fut tuée à coups de pierres. Ses membres sanglants, portés au Cinaron, furent ensuite brûlés, dans ce lieu des supplices. Le crime était consommé!

L'historien Socrate, un chrétien pur et qui n'aimait guère Cyrille, ne va pas jusqu’à l'accuser. Il flétrit la populace du port et les parabolans, des garde-malades turbulents. Faut-il se borner à dire, avec un sceptique : " La faute en est au temps, à tous et à personne ? ) Nous croyons qu'Hypatie a été une martyre de la Science, qu'elle a été prise par la foule stupide pour une magicienne, empêchant par. ses maléfices 
astronomiques la réconciliation des deux chefs d'Alexandrie.

Quelques années plus tard, une autre savante, plus heureuse, Athénaïs-Eudoxie, devenait impératrice d'Orient.

On ne peut s'empêcher de penser, à propos d'Hypatie, à Archimède, qui fut une victime encore plus glorieuse de la Science. Yous savez qu'à la prise de Syracuse, Archimède, le plus grand mathématicien de l'antiquité, fut tué par un soldat romain qui le trouva absorbé dans un problème de géométrie et traçant des figures sur le sable : le soldat le prit pour un sorcier malfaisant.

LA postérité. - La mort tragique d'Hypatie n'a tenté ni le drame au théâtre, ni la musique, ni la peinture. La savante n'est représentée dans aucun de ces trois tableaux : l'Hémicycle de l'École des beaux-arts, l'École d'Athènes, l'Apothéose d'Homère. Presque seul, le peintre contemporain anglais, C. W. Mitchell, a peint Hypatie, nue dans la Césarée, implorant le grand Christ impassible aux bras tendus.

Nous arons trois romans historiques sur H. Dans le sien, l'anglais Kingsley attaque le christianisme naissant et dirait volontiers que les livres d'Hypatie ont été brûlés par l'Inquisition d'alors. De son côté, Drouhaut, dans un pastiche des Martyrs de Chateaubriand, raconte qu'Hypatie, devenue chrétienne, a été tuée par les Cyniques. C'est ainsi qu'on joue avec l'histoire. Enfin M. Barrès a écrit Sous l'œil des Barbares; Athénée, - lisez Hypatie, - c'est le moi, et les Barbares, sont le non-moi. Yous comprenez!

Les études allemandes sur Hypatie sont assez nombreuses. L'un des érudits avoue que la plus heureuse année de sa vie est celle qu'il a passée avec Hypatie. Un préfet français, M. Ligier, a fait une thèse de doctorat sur le sujet.

Voici, pour bien finir, quelques vers de Leconte de Lisle :

Dors, ô blanche victime, en notre âme profonde,

Dans ton linceul de vierge et ceinte de lotos;

Dors! l'impure laideur est la reine du monde, Et nous avons perdu le chemin de Paros. 
Les Dieux sont en poussière et la terre est muelte:

Rien ne parlera plus dans ton ciel déserté.

Dors! mais vivante en lui, chante au cœur du poète

L'hymne mélodieux de la sainte Beauté.

Elle seule survit, immuable, éternelle :

La mort peut disperser les univers tremblants,

Yais la Beauté flamboie, et tout renatt en elle,

Et les mondes encor roulent sous ses pieds blancs!

\section{Bibliograpile .}

\section{Sources pour Hypatie.}

Tolland. Tétradymus, III. Londres, 1720.

Lewis. The history of Hypatia, etc., 1721.

Wernsdorf. Diss. acad. I.IV, De Hypatia. Vitemberg, 1747-8.

Andr. Schmidt. Variorum philosophorum decas. P. I ; Iéna, 1689.

Ph. Hoche. Hypatia. (Philologus. 1860, pp. 437 à 474).

B. Ligier. De Hypatia, etc., Thèse de doctorat. Dijon 1879.

P. Tannery. Hypatia d'après Suidas, dans les Annales de la Faculté de

Bordenux, 1881, pp. 197 ì 201.1

St-Wolf. Hypatia, etc. Vienne, 1879.

W.-A. Meyer. Hypatia, etc. Heidelberg, 1886.

Bigoni. lpazia Alexandrina. Venise, 1887.

Scheer. Hypatia. etc. Leipzig, 1875.

Journal des Débats du 7 mars 1896. Article de H. Blaze de Bury.

M . Marie. Histoire des Sciences Mathématiques.

Abbé Y. Halma. Traduction de Ptolémée et de ses commentateurs.

Encyclopédie du xvure siècle.

Libes. Histoire philosophique des progrès de la physique.

C.-P. de Lasteyrie. Sentences des Sextius (suivies de la vie d'Hypatie), 1843 .

L. Mesnard. Etudes sur les Origines du Christianisme, 1893.

L'intermédiaire des Chercheur's et des Curieux, 1883, pp. 614, 669, 749.

Kingsley. Hypatia (roman), 185:3.

Drouault. id (id.).

Anonyme. Hypatia or the history, etc. Londres, $172 n$.

Druon. Etude sur la vie et les ceuvres de Synésius (Thèse de doctorat.) 1878 ; pp. 9 à 13.

Dictionnaire historique de Moréri.

J. Palmella. Aristocratia do genio et da belleza feminil, ete. Coimbre, 1881 , in $\cdot 8$.

Tillemont. Histoire ecclésiastique. t. XIV; voir Saint Cyrille.

F. Lapatz. Lettres de Srnésius, traduites. 1870, in-8.

Poggendorf. Histoire de la physique.

Cantor. Histoire dés Mathématiques (en allemand). t. I, pp. 421-2.

Montucla. Histoire des Mathématiques. t. I., p. 332.

Bossut. id. id.

Suidas. Lexicon (Iı mot Ifypatia.)

Delambre Astronomie: t. I, p 307.

Chateaubriand. Etudes historicques, pp. 289 et 290. 
E. Fage. (Bulletin de la Société des lettres de la Corrèze; $2^{\circ}$ livraison de 1S94). Tulle.

Leconte de Lisle. Poëmes antiques.

Gibbon. Histoire de la Décadence et de l'Empire romain.

J. Barny. Martyrs de la libre pensée.

Fleury. Histoire ecclésiastique. t. V, p. 420.

Barrès. Sous l'neil des Barbares.

Portrait. Ni buste, ni médaille authentiques. V. Narlet a exposé un buste, ver's 1882. - Il y a une statue de F.-J. Williamson, Londres. Encore une représentation à la sculpture de l'Exposition de 1878 (?). - Ine image médiocre dans les Savants illustres de Figuier. - On a affirmé à tort qu'Hypatie se trouvait sur Ihémicycle de Paul Delaroche à l'Ecole des Beaux-Arts. Elle n'est pas dans l'Ecole d'Athènes de Raphaël, ni dans l'Apothéose d'Homère de Ingres. - Un tableau peint par G.-IV. Mitchell représente le meurtre d'Hypatie, il appartient à II. Charles Lucas, anglais.

\section{HYPO OU HIPPO}

D’après Clément d'Alexandrie et Gyrille, cette fille du centaure Chiron, instruisit Éole dans l'étude de la nature. Euripide la cite comme versée dans l'astrologie.

\section{IRÈNE}

Sous le rìgne d'Andronie, Ir'ène, fille de Théodoros, s'est occupée de poésie, de métaphysique et de philosophie. Nicephore Gregoros la compare à Platon et à Pythagore.

\section{JAELL (MARIE)}

La musique et la psychophysiologie, 1883.

\section{JANSSEN}

A accompagné son mari dans ses royages astronomiques, lui sert de secrétaire. (Voir Ciel et Terre du 15 janvier 189\%, p. ‡ั26).

\section{JAUNESSE-SPONVILLE (LINA)}

Cours de perspective, 18'tŏ, in-fol.

$$
\text { JULIEN (LOUISE-ANGÉLIQUE), NÉE LEMIRE }
$$

Le chevalier de Caussans avait déposé une somme pour la personne qui prouverait la fausseté de sa quadrature du cercle. 
Mad. Julien la réclama en vain, le Châtelet ayant jugé que la fortune d'un homme ne devait pas souffrir des erreurs de son esprit, lorsqu'elles ne sont pas nuisibles à la société.

Le quadricide ou paralogisme prouvé géométriquement dans la quadrature de M. de Caussans; 175\%, in-4.

\section{JUNCKERIN (CATHERINE)}

Vivait en $15 \% 2$; théologienne.

\section{JURINE}

La découverte importante, capitale, pour la connaissance des insectes supérieurs, appartient à une demoiselle, la fille d'un savant naturaliste de la Suisse française, Mlle Jurine. Elle a trouvé que les ourrières des abeilles qu'on crovait neutres (n'ayant ni l'un ni l'autre sexe) étaient des femelles, atrophiées par leurs berceaux plus étroits et leur nourriture inférieure. Or comme ces ouvrières forment à peu près tout le peuple (moins cinq ou six élevées pour devenir mères, et quelques centaines de mâles), il en résulte que la ruche de vingt ou trente mille abeilles est femelle.

Michelet. L'insecte; pp. 393-'.'.

\section{KARSAKOFF (N.)}

Dans le Journal de botanique du $\mathcal{1}^{\text {er }}$ décembre 1892. Quelques remarques sur le genre Myriotrichia.

\section{KÉPLER}

La vieille Catherine, sa mère, fut accusée de magie. Sa femme Barbara le soutint par sa gaité.

T. J. Bentrand. Les fondateurs de l'Astronomie moderne.

DE KERBEDZ

Cette dame a écrit dans les Rendi conti Mathématiques de Palerme. 


\section{KERR-JOHNSTON}

Nommée par l'Université royale d'Irlande examinatrice de physique.

\section{KIRCH (MARIE-MARGUERITE)}

Née Winkelmann, à Panitz (Haute-Saxe). 1660-1720. L'astronome Godefroid Kirch l'a épousée et, comme les trois søur's de Kirch, elle est devenue son élève.

Amie de Leibniz qui l'a présentée à la Cour de Prusse, elle a publié des ouvrages d'astronomie, mais aussi des almanachs pour vivre. Elle a découvert une Comète en 1702.

"Après la mort de son mari, Marguerite Kirch ne cessa point cependant de se livrer tout entière à la science astronomique et nous possédons un ouvrage assez considérable qu'elle écrivit en 1712, comme préparation à la conjonction de Jupiter et de Saturne qui devait avoir lieu en 1713. Les conjonctions des planètes n'excitent plus aujourd'hui qu'une pure curiosité, et ne sont plus d'aucun intérêt particulier pour nos astronomes. Mais à l'époque où l'astronomie était fortement mélangée d'astrologie, il n'en était pas de même, et l'on attribuait à ces positions spéciales des astres dans le ciel, une influence occulte très capricieuse sur les destinées de la Terre.

Le livre de Marguerite Kirch ne contient que des calculs astronomiques et rien de plus, à I'honneur, dit Zach, de cette dame et de son siècle.

Les filles de Marguerite Kirch, longtemps encore après la mort de leur mère, s'occupèrent d'astronomie, et calculèrent pour l'Académie des Sciences de Berlin les éphémérides et l'almanach qui étaient une des sources du revenu de cette compagnie savante.

A cette même époque,plusieurs astronomes français ou italiens trouvaient dans leur propre famille des collaborateurs féminins. Celsius, le célèbre professeur d'Upsal, et élève de Kirch le fils, avait été fort bien accueilli, en passant par Paris pour se rendre à Bologne, par de l'Isle, qui avait une sœur adonnée à l'astronomie. En arrivant en Italie, il se trouva également que son nouveau maitre, Manfredi, avait deux sœurs fort savantes et qui s'étaient comme leur frère adonnées à la science du ciel; ceci fit dire à Celsius, dans une lettre à Kirch : " Je commence à 
croire qu'il est un destin que tous les astronomes que j'ai l'honneur de connaitre dans mon voyage, ont leurs sœurs savantes; j'ai aussi une sœur, moi, mais peu savante ; il faut donc la faire astronome, pour conserver l'harmonie."

E. Lagrange. Les femmes-astronomes. (Ciel et Terre, du 1ə̈ janvier 1883.)

Vorbereitung zur grossen Opposition; 1712 (Acta eruditorum Leipzig, 1712, pp. 77-78).

V. Biblioth. germanique, t. III.

\title{
KLUMPKE (DOROTHÉE)
}

\begin{abstract}
Votre thèse de mathématiques est la première qu'une femme ait soutenue de. vant notre Faculté.
\end{abstract}

DARBOUX.

Cette astronome est née à San-Francisco, qu’elle a quitté jeune, ainsi que ses sœur's, bien douées aussi, dont l'une est devenue $\mathbb{I}^{\mathrm{me}}$ Déjerine-Klumpke et a fait d'importants travaux de physiologie.

Mlle Dorothée a passé une partie de sa jeunesse à Grettingue, et à Lausanne, puis elle est venue à Paris. Elle a étudić d’abord les langues, ce qui lui a permis de suivre plus tard le mouvement scientifique partout. Après avoir passé les exalmens de l'Hỏtel de Ville, le baccalauréat ìs sciences et la licence, elle a été admise comme élève libre à l’Observatoire.

Lorsqu'en avril 1887, le premier congrès astro-photographique s'est réuni pour la carte du ciel, Mlle Klumpke a traduit les documents étrangers.

Elle s'est livrée ensuite à de nombreuses observations de planètes et de comètes nouvelles, à l'équatorial de la tour de l'est, dont l'usage est peu commode. Les résultats ont été présentés à l'Académie des Sciences par l'amiral Mouchez et consignés dans les comptes rendus (Planètes Millosewich, Charlois, Borelli, Wolf, ete.; comète Tempel-Swift, ete.).

Le 23 décembre 1893, Allle Klumpke a soutenu à la Sorbonno 


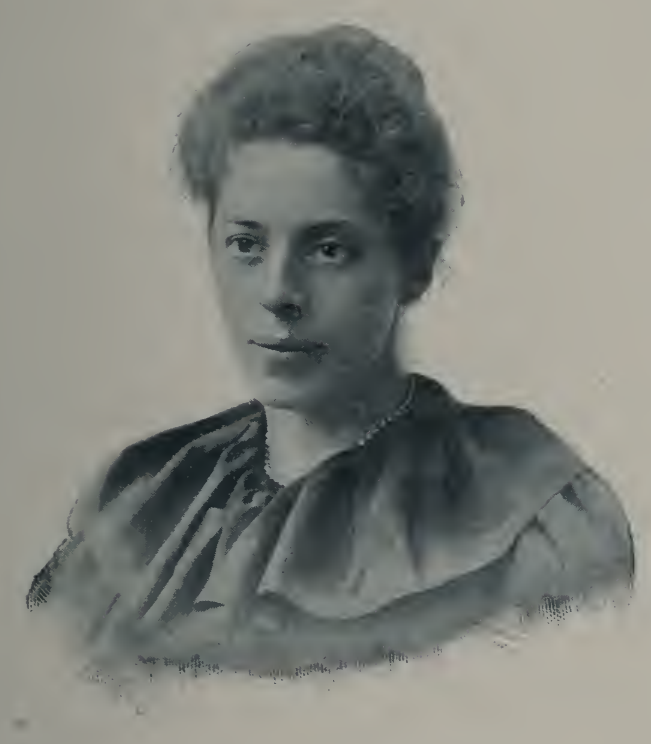

DOROTIIEE KLUMPKE 

ses thèses pour le doctorat ès sciences mathématiques, devant MII. Darboux, Tisserand et Andoyer. Le sujet portait Contribution à l'étude des anneaux de Saturne. C'est de la théorie pure. En effet, la science admet actuellement que les anneaux sont constitués par des particules solides très espacées et agissant les unes sur les autres par leurs attractions réciproques, très faibles par rapport à celle de la planète. Le cas considéré dans la thèse, purement hypothétique, n'est pas conforme à cette donnée; il avait déjà été traité par Laplace, puis par Inue Kowalerski, et sa solution vient d'être complétée. IIIle Klumpke a cherché les positions d'équilibre des anneaux, en négligeant complètement la masse de Saturne, etellea donné les inconnues avec une approximation du troisième ordre.

La doctoresse a été admise par le jury à l'unanimité des boules blanches. Le président a conclu ainsi :

" Les grands noms de Galilée, de Huygens, de Cassini, de Laplace, sans parler de ceux de mes illustres collègues et amis, sont attachés à l'histoire de chacun des progrès sérieux dans cette théorie aussi attrayante que difficile des anneaux de Saturne. Votre travail vient encore apporter une contribution qui n'est pas à dédaigner et vous place dans un rang honorable à côté des femmes qui se sont consacrées à l'étude des inathématiques. Au siècle dernier, Mlle Marie Agnesi nous avait donné un Traité de calcul différentiel et intégral. Depuis, Sophie Germain, aussi remarquable par son talent littéraire et philosophique que par ses facultés mathématiques, s'est attiré l'estime des grands géomètres qui honoraient notre pays au commencement de ce siècle. Il y a quelques années à peine, l'Académie des Sciences décernait un de ses plus beaux prix qui placera le nom de $\mathbf{M}^{\mathrm{m} \theta}$ Kowalevski à cóté de ceux d'Euler et de Lagrange, dans l'histoire des découvertes relatives à la théorie du mouvement d'un corps solide autour d'un point fixe... » Et M. Darboux ajoutait : “Et vous, Mademoiselle, votre thèse est la première qu'une femme ait présentée et soutenue avec succès devant notre Faculté pour 
obtenir le grade de docteur ès sciences mathématiques. Yous ouvrez dignement la voie et la Faculté s'empresse de vous déclarer digne d'obtenir le grade de docteur avec toutes boules blanches. )

Mlle Klumpke est actuellement à la tête du Bureau des mesures des clichés pour le catalogue photographique des étoiles. Il s'agit de joindre de trìs nombreuses plaques individuelles. Le travail s'opère dans un pavillon isolé, où, à l'aide de deux machines, les pointés de la carte sont faits par Mmes Schott, Marquette, Coniel, Dauphin et Lampdon.

L'hiver dernier, Mlle Klumpke a fait, à la rue de Toqueville, quelques conférences intitulées : Notions sur les mondes célestes et les systèmes d'étoiles. (1. Les généralités et le ciel des anciens. 2. Le soleil. 3. Les étoiles. 4. Le ciel moderne.)

Mlle Klumpke, qui est protestante libre, donne, aux missions protestantes, quelques indications pour l'usage des instruments astronomiques.

Lorsque nous avons eu l'honneur de voir la jeune astronome de l'Observatoire de Paris, elle allait partir pour observer en Norvège l'éclipse de soleil du 9 août 1896.

\section{Bibliograpile}

OEuvres de MHe D. Klumpke.

Les Catalogues stellaires, 1895. (Bulletin de la Société astronomique de France) [gravures.]

Recherches sur les spectres des mítéorites, d'après N. Lockyer.

Dans le Bulletin astronomique de $\mathbf{F}$. Tisserand : 1889.

Sur l'étude de Ḱreutz, Untersuchungen neber das Cometesystem.

Spectres stellaires. 1890.

Sur l'Observatoire de Pékin, d’après Russel. 1891.

Tycho-Brahé. 1891.

Eléments définitifs de la Comète 1883, III.

Dans le Bulletin de la Société astronomique de France ; janvier 1896 : Arcs crépusculaires de la planète Mars.

Contribution à l'étude des anneaux de Saturne. Paris, 1894, in-4º, io $\mathrm{pp}$.

The Observatory. Londres; décembre 1896. Notice nécrologique sur Félix Tisserand. 


\section{Sources pour $M^{110} h$.}

New York Herald (seconde quinzaine de décembre 1893).

Astronomy and Astro-Pliysics. Londres, novembre 1893.

Comptes rendus annuels de l'Ubservatoire de Paris.

Ein Weiblicher Astron. Berlin, 1893-9'. (Portrait.)

Journal : Le XIX` Siècle du 17 décembre 1893.

Id. Le Figaro du 16 décembre 1893.

La Nature du 29 juillet 1893.

\section{KODIS}

Cette dame a soutenu une thèse de philosophie en Suisse : L.e Sens de l'aperception.

Revue intern. de l'Enseignement, 15 oct. 1895.

\section{SOPHIE KOWALEVSKI}

L'histoire des mathématiques parlera certainement d'elle comme d'une des plus rares investigatrices.

KRONECKER.

Atavisue. - Sophie-Corvin-Krukowski est née à Moscou, en 1830 (et non en 18ว̈3, comme on l'a imprimé par erreur). C'est un heureux exemple d'atarisme. Son grand ancètre, Mathias Corvin, le roi de Hongrie, fut un guerrier protecteur des Lettres et des Sciences. Son père était génćral d'artillerie, commandant l'Ar'senal. Sa mère, d'origine allemande, était fille du général Schubert, mathématicien et topographe, et petite-fille de l'astronome connu qui porte le même noın.

Sophie a vécu jusqu’à quinze ans dans la propriété patrimoniale de Palibino (Russie occidentale) où le général Corrinhrukowski avait pris sa retraite, encore jeune. Il paraît que l'cnfant aimait peu la soupe et qu'elle était taxée à douze cuillerées par jour. Elle a appris à lire seule : elle demandait les dircrses lettres, marquées sur le journal de son père, tantòt à l'un, tantòt à l'autre; elle en essarait les combinaisons et, un beau jour, l’imprimé n'eut plus de secrets pour elle. On l'amena entendre l'opéra de Don Juan dont elle ne comprit pas toute la portée amoureuse, puisque quelque temps après, 
elle disait à son père : «Tu sais, le petit Paul, quel Don Juan d'enfant! On lui a donné une tartine beurrée, il a mangé le beurre et laissé le pain. »

C'est à quatorze ans que Sophie Krukowski a commencé les mathématiques, avec un certain Malewitch. Un jour, elle lui a proposé une méthode à elle pour calculer le rapport de la circonférence au diamètre et le professeur lui ayant dit que c'était un peu indirect, l'enfant a fondu en larmes. En étudiant seule un livre contenant quelques formules trigonométriques, elle a deviné la trigonométrie, sans être aidée.

Le château de Palibino fut une fois tapissé à neuf presque en entier, mais il manqua du papier de tenture pour la chambre des enfants. On y suppléa à l'aide des cahiers autographiés d'analyse du général, alors qu'il était étudiant. Sophie aimait à regarder ces hiéroglyphes, malgré sa gouvernante anglaise. "Il est assez étrange, dit-elle dans ses mémoires, que, lorsqu'à seize ans je commençai l'étude du Calcul différentiel, mon professeur fut étonné de la rapidité avec laquelle je le compris, comme si j’avais une réminiscence de ce qu'il me disait. La continuelle lecture des papiers collés sur les murs avait certainement laissé des traces inconscientes dans mon esprit d'enfant. »)

LEs thèses. - En 1868, Sophie Krukowski épousa Kowalevski, parce qu'il n'était permis qu'aux dames de suivre les Cours des Universités. Ces jeunes mariés étaient bien sérieux : ils convinrent de vivre comme frère et sœur jusquà la fin de leurs études; il serait temps plus tard de devenir vraiment mari et femme. Ils commencèrent par aller étudier ensemble à Heidelberg. Ils continuèrent à Berlin où l'éminent géoınètre Weierstrass consentit à donner, pendant trois ou quatre ans, des leçons particulières à Sophie Kowalevski, qu'il ne savait pas mariée.

Dans le temps, l’Université de Gœttingue avait déclaré Dorothea Schlœezer, docteur en philosophie et maitresse is arts libéraux. Elle s'empressa de recevoir à son tour Sophie Ko- 


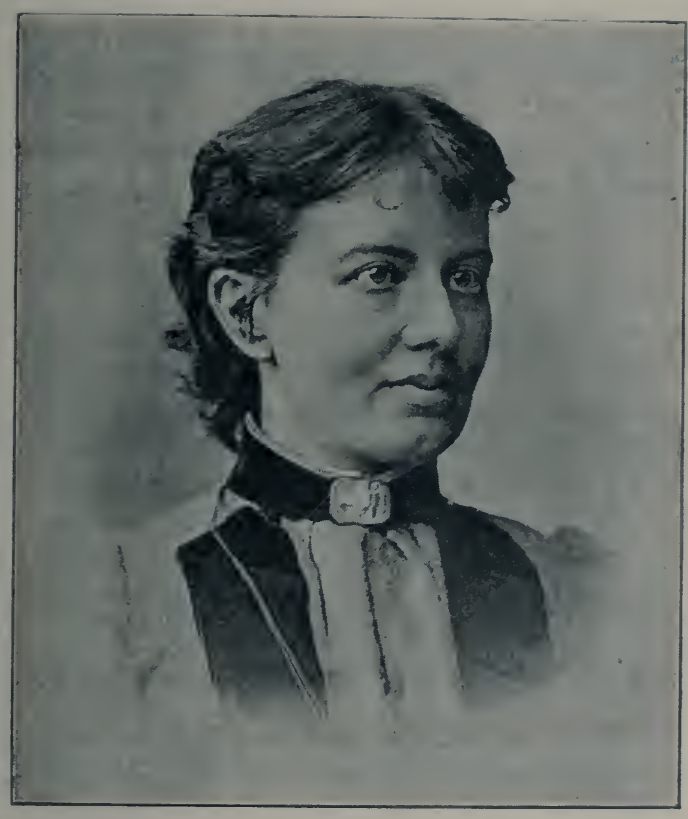

SOPHIE KUWALEVSKI 
, 
walevski, sans oral, et sur la production de trois thèses originales très remarquables, dont nous parlerons plus loin.

A Sтоскноц. - Monsieur Kowalevski était devenu de son cóté un paléontologue distingué. Malheureusement il avait engagé toute sa fortune dans l'affaire des naphtes du Caucase. Complètement ruiné, il fut acculé au suicide, en 1883. Il laissait dans le dénùment sa femme et une enfant qui s'appelait aussi Sophie.

Le professeur Mittag-Leffler parvint alors à obtenir pour Sophic Kowalerski une chaire de mathématiques supérieures, à l'Université de Stockholm.

Travaux Mathématiques. - Nous allons énumérer les mémoires de Madame Kowalevski. Les trois premiers sont ses thèses inaugurales.

Sur les systèmes d'équations aux différentielles partielles est un travail important, inséré dans un livre de M. Mansion.

Vient ensuite la Réduction d'une classe de fonctions elliptiques en fonctions abéliennes.

La troisième thèse est relative aux Anneaux de Saturne. Elle est reproduite dans la Mécanique céleste de M. Tisserand, ce beau livre qui, remplaçant celui de Laplace, fait honneur à la fin de notre siècle.

Un quatrième mémoire de Mme Kowalevski traite De la propagatıon de la lumière dans un milieu cristallin.

Le cinquic̀me mémoire est le plus remarquable de tous; M. Darboux en a fait l'éloge. En 1888, le sujet du prix Bordin à l'Académie des Sciences était: Perfectionner sur un point important la théorie du mouvement d'un corps solide. Un des mémoires présentés au concours portait cette devise : "Dis ce que sais, fais ce que dois, advienne que pourra ". II était de Sophie Kowalerski qui mérita le prix, à l'unanimité, en découvrant « un cas nouveau dans lequel on peut intégrer les équations différenticlles d'un corps pesant, mobile autour d'un point fixe. » C'est là une découverte théorique de première importance. 
Essais littérarres. - Sophic Kowalevski est aussi une littéraire. Elle a écrit en plusieurs langues et tourné même quelques vers français.

Elle nous a donné des Souvenirs sur George Eliot, la romancière anglaise.

$V_{i x}$ victis symbolise le combat de la vie, c'est l'hiver ou le printemps. L'auteur préfère l'hiver, c'est-à-dire le repos, le sommeil et l'oubli.

Les Souvenirs d'enfance ont paru dans la revue russe Le Messager d'Europe. C'est une belle analyse psychologique, digne de Bourget et de Tolstoï.

La famille des Vorontsoff, dont le premier chapitre a seul paru, est complète en manuscrit. On espère un grand succès. pour cette ouvre.

La lutte pour le bonheur est un drame qui a échoué au théâtre.

Il y a entin des Voyages, par exemple à l'Université de Zurich et à l'hòpital de la Salpêtrière.

Une romancière russe, $\mathrm{H}^{\mathrm{m}}$ Choubleski, s'étonnant qu'on puisse se livrer à la fois aux mathématiques et aux lettres, a reçu de Mme Kowalevski la réponse suivante :

" Je comprends que vous soyez très surprise de me voir cultiver à la fois les lettres et les mathématiques. Souvent, les personnes qui n'ont pas eu l'occasion de faire ample connaissance avec les mathématiques les confondent avec l'arithmétique et les considèrent comme une science sèche et aride. En réalité les mathématiques exigent beaucoup d'imagination, et l'un des plus grands mathématiciens de notre siècle a pu dire avec raison qu'il est impossible d'être bon mathématicien, si en même temps l'on n'est pas un peu poète.

" Il est vrai que pour comprendre la justesse de cette affirmation, il faut renoncer au vi euxỹpréjugé qui voit dans l'imagination et la fiction une seule et même chose, et qui veut que le poète ne chante que ce qui n'existe pas. Il me semble que le poète doil seulement voir ce que les auires ne discernent pas, son regard doit pénétrer plus profondément, et il en est de mèmepour le mathématicien... 
" En ce qui me concerne personnellement, je ne saurais dire ce que j'aime le plus des mathématiques ou des lettres. Dès que ma tète est fatiguée des spéculations abstraites, je me sens attirée vers l'observation de la vie el disposée à prendre la plume. A dautres moments, tout dans la vie me semble mesquin, insignifiant, et je me réfugie dans la contemplation des lois immuables et éternelles de la science. Peut-être aurais-je pu faire mieux dans chacune de ces deux sphères, si je m'étais adonnée exclusivement à l'une ou à l'autre? Mais que voulez-vous, je n'ai jamais eu le courage de choisir entre les mathématiques et les Jettres. "

Les Derners jours. - $\mathbf{M}^{\mathrm{m}_{\mathrm{o}}}$ Kowalevski ayant passé l'hiver 1890-91 dans le midi de la France, rendit visite, en traversant Paris, à M. Joseph Bertrand. Elle lui dit qu'elle comptait enseigner la théorie des nombres dans son prochain cours et elle lui demanda quelques conseils.

Le 6 février 1891, après avoir fait à Stockholm sa première leçon de l'année classique, Sophie Kowalevski, frappée d'une attaque de pleurésie foudroyante, se couche pour ne plus se relever. "Quelques heures après, on courait en toute hâte éveiller Foufi (la petite Sophie) profondément endormie après une soirée d'enfants où sa mère avait absolument tenu à l'enroyer... Les regards de la mourante se fixìrent un instant sur l'enfant puis s'éteignirent. )

Ine messe des morts fut dite suivant le rite orthodoxe et on enterra la mathématicienne au nouveau cimetière.

M $^{\text {me }}$ Kowalevski avait « une belle tête intelligente au front richement bossué, à la bouche expressive, aux yeux changeants, allant du noir au vert, d'une grande douceur et singulièrement pénétrants malgré une visible myopie. » Elle se faisait appeler Sonja, diminutif de Sophie, qu'elle inscrivait sur ses cartes de visite, dans les derniers temps.

Sophie Kowalevski inspirait l'amitié et la confiance. Elle était restée très femme, par son besoin d'être chọece, admirée, aimée.

Jugements. - L’Académie des Sciences de Paris a loué non 
seulement le savoir varié et profond, mais surtout le grand esprit d'invention de Madame Kowalevski. D'autre part, Kronecker déclare que « l’histoire des mathématiques parlerü d'elle comme d'une des plus rares investigatrices. „) Un de nos livres classiques de hautes mathématiques débute par une démonstration d'elle. Certaines thèses récentes de doctorat français commentent et poursuivent ses recherches.

Trop tòt enlevée, Sophie Kowalerski laisse des travaux peu nombreux, mais excellents et de première importance. Sa puissance de calcul était étonnante ! Elle est certainement supéricure à toutes les mathématiciennes qui l’ont précédée.

Sa première notice biographique est due à E. de Kerbetz, que nous croyons être une femme. M. Mittag-Leftler nous a donné dans les Acta malhematica une note sobre et d'une émotion contenue. Une amie, Madame Leffler-Cajanello, qui vient de mourir, a écrit une biographie assez étendue, dont on voudrait effacer quelques détails réalistes. Enfin Melle Pereraslawzewa, connue par ses travaux en zoologie, se propose à son tour de nous parler de la morte regrettée. On ne saurait trop connaître Sophie Kowalevski.

\section{Bibliograpilie.}

\section{OEuvres de S. Konvalevski.}

Zur Theorie der partiallen Differentialgleichungen. C'est la thèse de doctorat. Götting, 1874 (Journ. für Mathem. pp. de 1 ì 32. - Aussi Berlin, 1892, dans un livre de Mansion de même titre.)

Uber die Reduction einer bestimmtem Klasse Abel'scher integrale 3. ranges auf elliptische Integrale, 1884 (Acta Mathem., pp. 313 à 414 )

Sur lit propagation de la lumière dans un milieu cristallisé. Paris, 1984. (Compte rendus de l'Ac. des Sc., pp. 356-357; mème année, publié par l'Ac. suéd.).

Uber die Brechung des Lichtes in cristallinischen mitteln. 1885. (Acta math., pp. 249 à 304 ).

Zusitze und Bemerkungen zu Laplace's Untersuchung über die Gestalt der Saturnringe, 1885. (Astron. Nachr. pp. 37 à 48.)

Sur le problème de la rotation d'un corps solide autour d'un point flve, 18s9. (Acta math. pp. 177 it 232.)

Mémoire sur un cas particulier du probleme de la rotation d'un corps pesant, autour d'un point five, oì l'intégration s'effectue à l'aide de fonctions ultraelliptiques du temps, 1890. (Paris, Mémoires présentés à 
l'Ac. des Sc. par les savants étrangers. Il y a un tirage à part de ce mémoire qui a remporté le prix Bordin.)

Sur une propriété dı système d'équations différentielles qui définit la rotation d'un corps solide antour d'un point fixe, 1890-1. (Acta math. pp. 81 à 93.)

Sur un théorème de M. Burns, 1\$91. (Acta math., pp. 45 à 52.) Aussi un tirage à part.

\section{Sources pour S. Kowalevski.}

Kronecker. S. Kowalerski; 1891, Journ. für Mathem.

De Kerbetz. id. 1891, Rendiconti circolo matem. Il y a un tirage à part.

A Ch. Leffler. Sonja K. ; $1891-2$ (An. di matem.)

Souvenirs d'enfance de $\mathrm{S}$. K. écrits par elle-mème et suivis de sa biogr. par A - Ch. Leffler, 1895 (Traduction française.)

Mlittag-Leffler, S. K., 1893. (Acta math., pp. 385 à 392.)

Société mathem. de Hoscou; séance du 19 arril 1891. Trois discours prononcés (russe).

Svensk Tidskrift. Janvier 1893. Article de Mme Ellen Key.

L'Intermédiaire des mathématiciens, 1894, nos 1 et 3 ; Appell et Poincaré.

Méray. Leçons nouvelles de Calc. infin. ; préface.

E. Picard. Cours d'analyse, t. ll, p. 318 .

E. Goursat. Equations aux dér. part. du 1or ordre; au commenceinent.

Kœtter. Sur le cas traité par S. K., etc., 1893. (Acta mathem.)

F. Tisserand. Traité de mécanique céleste. (Le mém. de S. K. est analysé dans le t. Il.)

Revue de famille du 1 or aoùt 1893. Les femmes du Nord.

Arvède Barine. Revue des Deux-Mondes.

Birkeland. Comptes rendus, Ac. des Sc., t CXX, p. 1046.

The century illustr. monthly (américain) d'août 1895. Isabel F. Hapgood, sur S. K.

Bulletin Darboux ; a vril 1896.

Journal Les Débats du 20 avril 1895 ; feuilleton par Heurteau.

Rerue La Société nouvelle d'avril-mai 1896; traduction d'une étude de Laura Marholm.

$\mathrm{M}^{\mathrm{mo}}$ ron Adelung. Souvenirs inédits. (Revue des Revues du 15 décembre 1896.)

Darboux. Leçons sur la théorie générale des surfaces. (Art. 245.)

Journal L'anquité russe, décembre 1890. (Souvenirs du professeur Malievitch.)

J. Bois. L'Éve nouvelle, pp. 201 à 205.

Autographes. Fac-similés suédois. (Nous en donnons un à la page suivante.)

Portrait. Belle héliogravure insérée dans les Acta mathem. 
KOWALEVSKI

- $168-$

Haic Herr Sitz,

Ni har aukillit zgai att fai ve raipre of ucent ungdons frecticica utovivningar. Igair grall har jag firmat alt ateretalla.

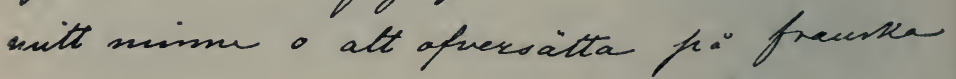

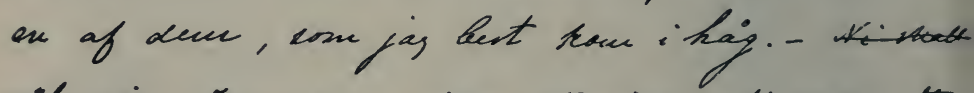

Jag ruel ine forrina att acke ott det ligier nayst personligt ufflefradt a decurabit. Det ere nupenet eabift ane Ni ville ofversitto nsoming.

Socer Lill sifu a

Oonfa 


\section{KREMPE}

Abel, le grand et infortuné géomètre, voulut avant de mourir revoir Mlıe Krempe, sa fiancée, qui habitait aux fonderies de Froland (Norvège).

\section{DE KRUDNER (JULIE DE WIETENGHOFF, BARONNE)}

176't-182't. - Mystique russe, auteur du roman mélancolique Valérie, prèche en 1807 aux foules allemandes la régénération du christianisme et meurt en Crimée où elle essayait de fonder une maison de refuge pour les criminels.

P. Lacroix (bibliophile Jacob). - SAmte-Becve. Portraits de femmes.

\section{LADD-FRANKLIN (CHRISTINE)}

L'américaine Christine Ladd est née le Ier décembre 18't7, à Windsor, Connecticut. Elle a étudié à l'Université John Hopkins, Baltimore, y est devenue agrégée, s’y est mariée au professeur Fabian Franklin et yest maintenant titulaire aussi d'une chaire de mathématiques supérieures.

Mrs Ladd-Franklin est une savante très distinguée, qui s'est occupée non seulement de mathématiques, mais aussi de logique et de psycho-physiologie.

Malheureusement ses nombreuses études sont dispersées dans les journaux spéciaux. Quelques tirés à part ne suffisent pas, il faudrait coordonner les divers travaux dans des livres.

Bibliographie.

OEuvres de $M^{\mathrm{me}}$ Ladd-Franklin.

Dans l'Educational times, divers problèmes qui avaient attiré l'attention de Sylrester (depuis 1871).

bans l'Analyst, articles et problèmes (Quaternions, 18:8: Polyonomial theorem, 1878; Four Circles inscribed in on and circumscribed about another, 1878).

Dans le American journ. of math. : Hexagone de Pascal, 1879; de Morgan's extension of the algebraic processes, 1880; Segments made on lines by curres, 1881 .

Dans le Mess. of math. : d'Alembert-Carnot geometrical paradox 1885-6.

Dans American journal of psychology : Une méthode pour la déter- 
mination expérimentale du Horopter, 1887; Quelques caractéristiques de la logique symbolique, 1889; Sur les livres d'optique physiologique depuis 1887.

Dans Mind : Some reforms in Common logic, 1890; comptes rendus des livies de E.E.C. Jones et de E. Schrœder. 1890 et 1892; Ebbinghan's theory of color vision, 1 $\$ 4$.

Dans les mémoires de Johns Hopkins Luiversity: Sur l'algèbre de lit logique, 1883.

Dans Zeitschrift für Psychologie : la théorie de la vision de Hering au Congrès de Londres, 1892; nouvelle théorie de la question précédente, 1893.

Dans psychological review : Définition normale de la vision dans le fovea, 1895; Jonction des bàtonnets de la rétine, 1896 .

Divers articles dans Nation, Science, etc...

En collaboration arec Fab. Franklin : On natural kinds (Yind 1888).

\section{LALANDE}

Marie-Jeanne-Amélie Harlay (1760-1832), devint par son mariage la nièce du grand Lalande. Gauss connaissait et appréciait cette dame (Voir Sophie Germain).

“ Ma nièce, dit Jéròme Lalande, Lefrançais de Lalande, aide son mari pour ses observations et en tire des conclusions par le calcul; elle a réduit dix mille étoiles, elle a donné trois cents pages de tables horaires, trarail immense pour son âge et pour son sexe : elles sont dans mon Abrégé de navigation. )

“ Une des rares femmes avant écrit des livres scientifiques. Elle publia des tables pour trouver l'heure en mer, par la hauteur du soleil et des étoiles. Ces tables furent imprimées en 1791 par ordre de l'Assemblée nationale. La mème année, elle faisait faire à Cassini sa première observation au Collige de France. En 1799, elle publiait le catalogue de dix mille étoiles réduites et calculées. »)

\section{Mme v'Alo. Anthologie féminine.}

Madame Lefrangais de Lalande eut une fille dont parle ainsi le grand oncle :

«Cet enfant de l'astronomie naquit le 20 jamvier 1790 . jour où nous vimes à Paris pour la première fois la comète que miss Caroline Herschel venait de décourrir; on donna 


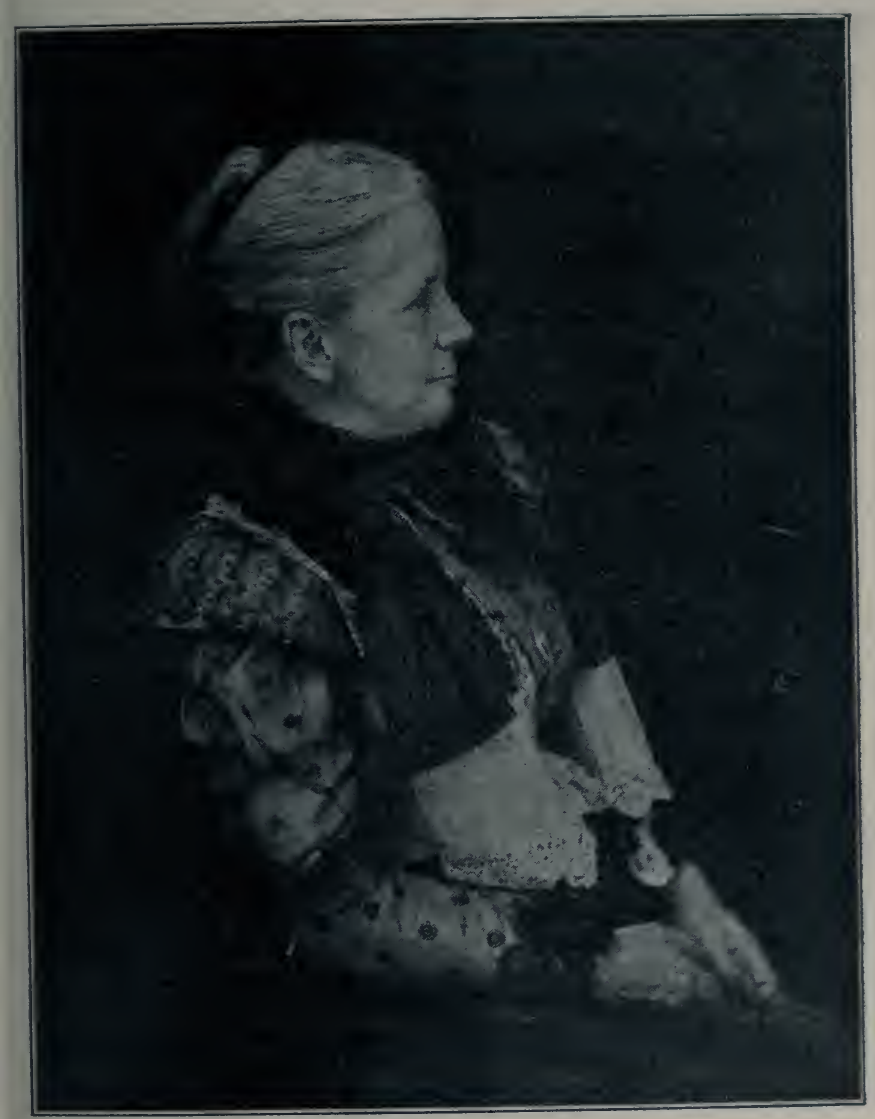

CIIISTINE LADD-FRANKLIN 

lonc à l'enfant le nom de Caroline; son parrain fut Deambre. "

1. Jarrin. Lalande et la Bresse au xvme siècle. Bourg, 869. in-8 (100 exempl.).

\section{LAMARCK (CORNÉLIE)}

La fille du grand naturaliste a travaillé longtemps au Huséum d'histoire naturelle.

"Lamarck vécut longtemps paurre, aveugle et délaissé, $10 n$ de moi, je l'aimai et le vénérai toujours. Sa fille, nouclle Antigone, vouée aux soins les plus généreux de la cndresse filiale, soutenait son courage et consolait sa misère all ces seuls mots : La postérité vous honorera! vous venrera! 》

Étievne Geoffroy SaINT-Hilaire. Fragments biographiques; 1). 81 .

\section{LAMB (ALICE)}

Astronome à l'Observatoire de Waschburn (U. S. A.), fait un service régulier d’observations méridiennes, étudie spécialement le mouvement des étoiles polaires.

\section{DE LAMBERT}

La marquise de Lambert (16'17-1733) est morte à Paris dans sa 86 e année.

Sies principaux ouvrages sont:

1" Avis d'une mère à son fils; $2^{0}$ Avis d'une mère à sa fille; 3. Traité de l'amitié; '40 Traité de la vieillesse.

Fontenelle a écrit son éloge.

1. ne Lescure. - Sainte-Beune. Lundis, t. 3 et '́.

OH ne sait presque rien de ses soixante premières années. Sun salon était présidé par Fontenelle. "Il est certain, écrit d’Argenson, qu’elle a bien fait la moitié de nos académiciens actuels. )

" Je ne blàmerais pas même un peu de philosophie; surtout de la nouvelle, si on en est capable; elle vous met de la 
précision dans l'esprit, démèle vos idcées et vous apprend à penser juste. )

Mme de Lambert. Avis d'une mère à sa fille.

\section{LAMME (BERTHE)}

Cette jeune fille de Sprinfield a conquis, à l'Université de l’Ohio, le brevet d’ingénieur électricien.

\section{LAPLACE}

Le 28 mars 1836, Arago recevait la lettre suivante:

"Monsieur, j'ai l'honneur de vous demander de vouloir bien soumettre à l'acceptation de l'Académie des Sciences un prix que j'ai l'intention de fonder à perpétuité.

Ce prix consisterait dans les OEuvres complètes de M. de Laplace; il serait donné tous les ans par les mains du Président de l'Académie au premier élève sortant de l'École Polytechnique.

Si, comme je dois l'espérer, l'Ac. des Sc. agrée l'offre que je lui soumets, je lui transmettrai aussitôt une inscription sur l'État de 210 fr., montant du prix des volumes convenablement reliés.

$\mathrm{N}^{\mathrm{mo}}$ de Laplace espère de l'affection des confrères et amis de $\mathrm{II}$. de Laplace qu'ils verront dans sa proposition un hommage qu'elle est heureuse de rendre aux Sciences, dont l'Académie est le Sanctuaire.

Agréez, etc. Marquise de Laplace."

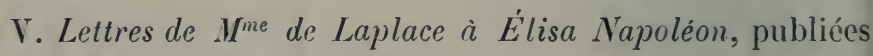
par P. Marmotan. 1897, in-8, portrait.

\section{LASTHÉNIE}

Lasthénie de Mantinée, en Arcadie, déguisée en homme suivit, avec Axiothée, les lecons de Platon.

\section{DE LAUTIER (ANNE)}

D'après Riballier, cette femme du $\mathrm{xvi}^{\mathrm{e}}$ siècle excella dans les mathématiques. Feugère la cite dans ses Femmes poètes. 


\section{DE LAUTRÉ}

Mad. de Genlis dit, dans ses Mémoires, que Mad. de Lautré multipliait de tête, dans les salons, des nombres de huit chiffres.

Cartésienne.

$$
\text { DE LAVIGNE }
$$

Dans le Recueil de vers du P. Bouhours, il y a une pièce où l'ombre de Descartes remercie $\mathbf{y}^{\text {lle }}$ de La Vigne de son zèle pour sa philosophie.

\section{LAVOISIER}

La femme et la collaboratrice du grand chimiste, mort sur l'échafaud.

1758-1836. - M. Paulze d'Ivoy, fermier général des finances, maria en 1771 sa fille âgée seulement de 1'́ ans à son collègue Lavoisier, qui en avait 28. La très jeune femme, vive et intelligente, se met au travail pour aider le grand chimiste. Elle apprend l'anglais, traduit les mémoires de Priestley, de Cavendish, ete., publie les traductions de deux ourrages de Kirwan, l'un sur la force des acides (s. d.) et l'autre sur le phlogistique (1788), qu'elle réfute. C'est elle qui prend des notes au laboratoire et qui grave les planches du Traité de chimie (1789).

Dans le portrait de Lavoisier par David, elle figure, appuyée d'une main sur l'épaule de son mari. Nous reproduisons ce beau tableau, qui appartient à H. de Chazelles, arrière petitneveu de Madame Lavoisier.

En 179't, son père et son mari meurent, le même jour, sur l'échafaud révolutionnaire.

Onze ans après, Mad. Lavoisier put à elle seule réunir et publier, avee une préface, les mémoires scientifiques du grand chimiste. Elle recevait, dans son salon d'Auteuil, Lagrange, Laplace, Berthollet, Cuvier, de Humboldt, Arago, etc. Elle se remaria, en 180马, avec le physicien philanthrope, Rumford, à la condition de s'appeler Madame Lavoisier de Rumford. 
L'union ne fut pas heureuse et aboutit au bout de quatre ans à une séparation à l'amiable. $\mathrm{M}^{\mathrm{me}} \mathrm{L}$. conserva son salon, mais elle dut regretter le temps où, suivant M. Guizot, « elle virait dans le laboratoire de M. Lavoisier, l'aidait dans ses expériences, écrivait ses observations sous sa dictée, traduisait et dessinait pour lui. »

V. Guizor. Mme de Rumford, 1841 (Notice reproduite dans le t. Il des Mémoires pour servir à l'histoire de mon temps).

Grimaux. Lavoisier, 1888 (Plusieurs portraits de M. et de M $^{\text {me }}$ Lavoisier. Presque tout le second chap. est consacré à $\mathrm{I}^{\mathrm{me}} \mathrm{L}$.).

Berthelot. La révolution chimique: Lavoisier, 1887 (Dessin représentant le chimiste dans son laboratoire dictant à sa femme. 11 est souvent question dans le livre de $\mathrm{II}^{\mathrm{me}} \mathrm{L}$.).

Portrait par David de $\mathbf{M}^{\mathrm{me}}$ Lav. et de Lav:

Elle est debout, coiffée d'une vaste perruque doublée et frisée d'où s'échappent de longues mèches de cheveux blonds, vêtue d'une robe de linon blanc à ceinture et à nœuds gris bleu. Elle pose la main droite sur la table où écrit son mari. La jambe droite de celui-ci se développe sur le velours qui tombe de la table. Un ballon de verre et un instrument de cuivre sont à terre dans le coin à droite. Un lambris divisé par des pilastres cannelés forme le fond du tableau. Au second plan, à gauche, un fauteuil en bois doré sur lequel on a posé un vêtement noir et un carton contenant des gravures.

\section{LEBLOIS (LOUISE-AMÉLIE)}

Fille d'un honorable pasteur de Strasbourg, cette demoiselle est le premier docteur ès sciences féminin fait par la Faculté des Sciences de Paris (31 mai 1888). Sa thèse portait sur cette question de botani(jue : "Recherches sur l'origine et le développement des canaux sécréteurs el des poches sécrétrices. ) Paris, Masson, in-8.

\section{LEBOEUF (LUCIE)}

On trouve signée de ce pseudonyme (sous lequel se cachait un étudiant) une démonstration d'un théorème de Ed. Lucas. dans la Nouvelle Correspondance de Catalan (1876, p. 15:3). - Voir aussi Nouvelles Annales de math. (1876, pp. 232-3.) 


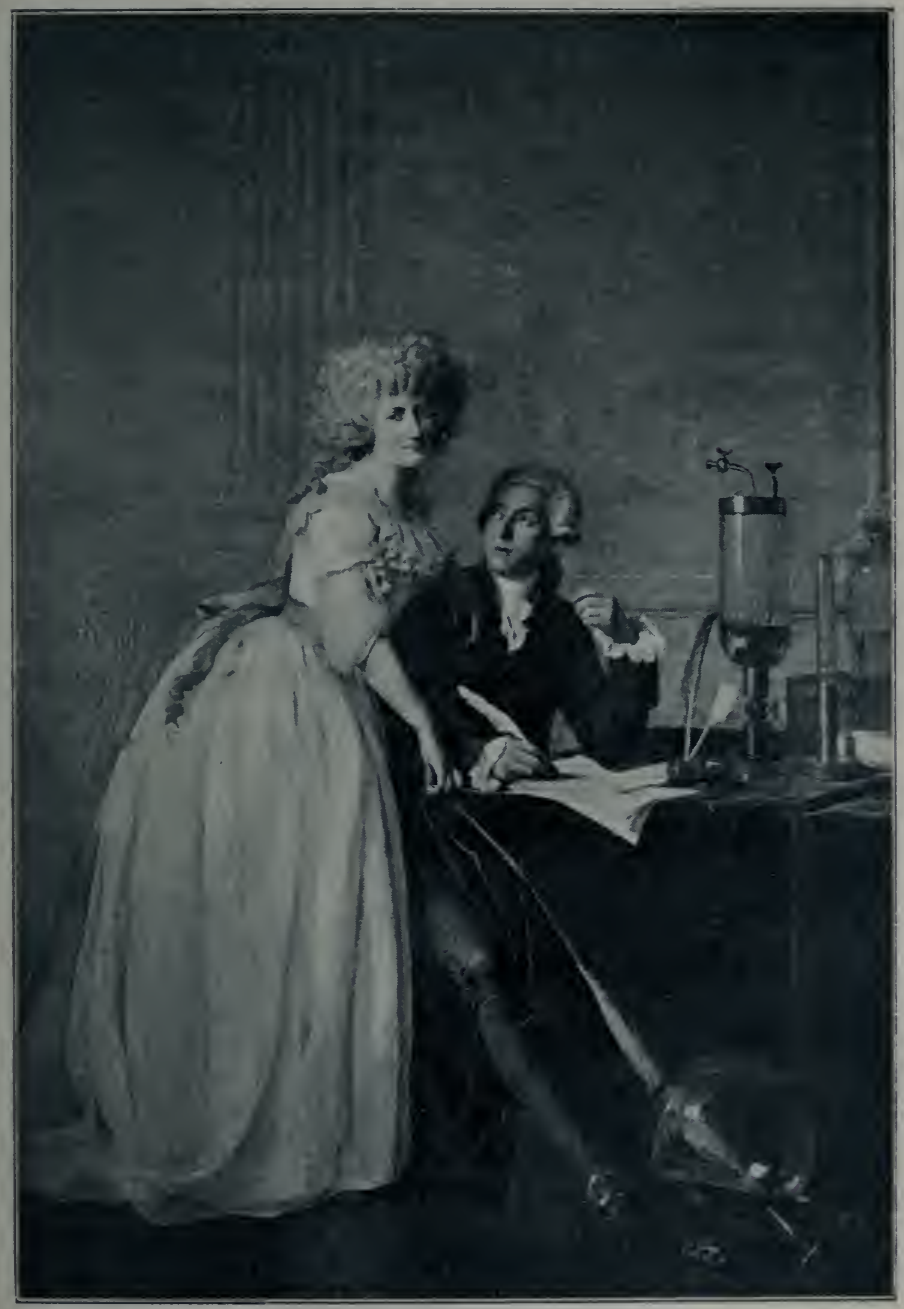

LAVOISIER ET MADAME LAVOISIER 



\section{LE BRETON (J.)}

Cette dame a publié : Histoire et applications de l'électricité, 188', in-8. - A traver's champs (botanique pour tous), in-8.

\section{LECHAUCEY (LÉONIDE)}

Si P, Q, A, B, C, D sont sur une conique, les points PA.QB, PB.QA, PC.QD, PD.QC, P et Q sont sur une même conique. Nouv. Ann. de math.; 186̈̈, 372-373.

\section{LÉE}

"Mistress Lée m’a dit que dans les parages de l'Afrique où elle a séjourné, les Termites ne mettent qu'un temps fort court pour dévorer totalement une habitation. Un escalier d'assez bonne dimension est dévoré en une quinzaine de jours. Des tables, des fauteuils et des chaises en beaucoup moins. L'illustre voyageuse m'a raconté qu’à Sierra-Leone, souvent, en rentrant chez soi, après une courte absence, on ne retrouve plus que l'ombre de son mobilier. L'extérieur possède encore toute sa fraicheur, mais le cœur manque, et chaque pièce creusée se pulvérise sous la main qui la touche. )

\section{F.-A. Poсchet. L'Univers, p. 115.}

Madame Lée a écrit une étude sur Cuvier.

\section{LEGENDRE}

Legendre avait épousé en 1793 une jeune fille qui l’avait eaché pendant la Terreur et qui fut pour lui une admirable compagne, aussi dérouée qu'intelligente. On doit retenir son nom, parce que Mlle Coulim continua, après la mort de Legendre, à aider de sa bourse les jeunes gens que les difficultés matérielles arrètaient dans leur carrière scientifique, qu'elle laissa à l'École polỵtechnique à sa mort en $18 \ddot{6} 6$ un fonds annuel pour la création de bourses, et qu'elle légua à la Commune d'Auteuil la maison de son mari, payée des droits 
d'auteur des Éléments de géométrie, pour en faire un presbytère et une école.

Les 72 savants de la Tour Eiffel.

I. Élie de Beaumont. Éloge de Legendre; 1861.

\section{LELAND}

Astronome adjointe à l'Observatoire de Harvard, U. S. A.

\section{LEMASSON LE GOLFT}

Née au Havre le 20̈ octobre 1750, Mlle Lemasson a publié La Balance de la Nature, 178', in-12 et divers mémoires sur l'iris, les anneaux colorés, les mouches communes, etc.

\section{LENNEBACKER (ELEN)}

Étudie les algues de Californie.

\section{LÉONCE OU LÉONTIUM}

Athénienne, amie et disciple d'Épicure, écrivit contre Théophraste. Cicéron en parle dans son traité de la nalure des dieux (livre I). Musicienne, poète et philosophe. Eut des disciples.

\section{LEPAUTE}

L'ardeur de $\mathrm{M}^{\mathrm{mc}}$ Lepaute est surprenante.

Clatraut.

Nous reproduisons la biographie due à Jéròme Lalande :

" Je terminerai la notice de 1788 par la vie de $\mathrm{M}^{\mathrm{mo}}$ Lepaute, que nous perdimes le 6 décembre. Cette perte était moins grande pour l'astronomie que pour moi : mais on pardonnera bien ce petit hors-d'œuvre à la sensibilité de l'auteur; ce sera une consolation pour moi, et un objet d'émulation pour un sexe que nous avons intérèt d'associer à nos travaux; témoin ceux de Miss Herschel, de $M^{\mathrm{me}}$ de la Lande, etc.

Non hoc procipuum amicorum mumus est prosequi defunctum ignaro questu. ТАсіт.

Le devoir d'un ami n’est pas d'honorer par de stériles litrmes la mémoire de celui qu'il a perdu. 
M ${ }^{\text {mo }}$ Lepaute mérite d'être citée parmi le petit nombre de femmes d'esprit qui donnent l'exemple à leur sexe par l'émulation et le goût des sciences exactes.

Nicole-Reine Etable de la Brière naquit, le ä janvier 1723, à Paris, dans le palais du Luxembourg, où demeurait son père, qui avait été attaché à la reine d'Espagne, Elisabeth d'Orléans, veuve de Louis qui fut roi d'Espagne en 1707, pendant sept mois. Cette princesse mourut au Luxembourg, le 16 juin 1742.

Im $\mathrm{m}^{*}$ Lepaute se distinguait, dès son enfance, par son esprit. Ine de ses sœurs, encore enfant, disait : Je suis la plus blanche; l'autre lui répondait: Et moi la plus d'esprit : elle l'avait entendu de ceux qui l'environnaient, même avant de savoir en quoi consistait cet avantage qui devait l'élever un jour, non au-dessus du reste de sa famille, mais au-dessus de la plupart des femmes.

Dès sa première jeunesse, elle dévorait les livres ; elle passait les nuits à des lectures, et se distinguait dans la société autant par son esprit que par sa vivacité et par ses gràces.

Elle fut raisonnable de très bonne heure; et quand il fut question de la marier, à l'âge de seize ans, son premier choix tomba sur un homme respectable, dont la disproportion d'àge était si grande, que, quoique sensible aux grâces et au mérite de cette jeune personne, il ne crut pas devoir accepter le présent qui lui était offert.

Elle épousa, le 27 août 1748, M. Lepaute l'ainé, qui commençait à se faire connaitre, et qui a été ensuite horloger du Roi, et qui a fait, avec son frère, les plus grandes et les plus belles horloges que nous ayons. Ce frère cadet a fait, en 1786, la superbe horloge de l'hòtel-de-ville de Paris, estimée près de cent mille francs.

En 17.53, j'avais pour observatoire la coupole qui est sur la porte principale du palais du Luxembourg, où de l'Isle avait observé avant son départ pour la Russie. M. Lepaute venait de faire, pour ce palais, la première horloge horizontale qu'on ait faite à Paris, avec une grande perfection; cela lui avait mérité un logement au Luxembourg. II avait fait aussi, en 17ว3, une pendule à une seule roue, et j'étais allé chez lui, comme commissaire de l'Académie pour l'examiner. Ces deux circonstances suffisaient pour établir des relations entre deux personnes dont les travaux avaient beaucoup d'analogie. Cette réunion a été utile à tous deux : j'ai contribué à la perfection des travaux de M. Lepaute en horlogerie, et M. Lepaute a été utile à l'astronomie; car il y a des pendules de ce célèbre horloger dans la plupart des 
observatoires de l'kurope, et elles sont de la plus grande perfection.

MIme Lepaute entra bientôt dans cette réunion de travaux; elle avait trop d'esprit pour n'avoir pas de la curiosité : elle observait, elle calculait, elle décrivait les ouvrages de son mari.

Nous entreprimes en commun un nouveau traité d'horlogerie, qui parut en 17335 , in-4, et où l'on trouve plusieurs objets nouveaux de $\mathrm{M}$. Lepaute ; entre autre des pendules d'équation, ou le cadran du temps vrai change par une courbe d'équation, en sorte qu'une seule aiguille marque le temps moyen et le temps vrai; une autre qui suit le temps vrai par le changement du pendule; méthodes que l'on emploie souvent avec succès. II Le Lepaute calcula pour ce livre une table du nombre des oscillations pour des pendules de différentes longueurs, ou des longueurs pour chaque nombre donné de vibrations, depuis celui de 18 lignes, qui ferait 18000 vibrations par heure, jusqu'à celui de 3000 lieues.

$\mathrm{Au}$ mois de juin 17399 , j'engageai Clairaut à appliquer sa solution du problème des trois corps à la comète qu'on attendait, et à calculer l'attraction de Jupiter et de Saturne sur la comète, pour avoir exactement son retour. MI ${ }^{\mathrm{me}}$ Lepaute nous fut d'un si grand secours, que nous n'aurions point osé, sans elle, entreprendre cet énorme travail, où il fallait calculer pour tous les degrés, et pour 1 ว 0 ans, les distances et les forces de chacune des planètes par rapport à la comète. Je lui ai rendu justice, à cet égard, dans ma Théorie des Comètes, p. 110.

En 1739, Clairaut avait également cité $M^{\text {me }}$ Lepaute dans son livre sur la Comète, où il profitait de cet immense travail ; mais il supprima cet article par complaisance pour une femme jalouse du mérite de $M^{\text {me }}$ Lepaute, et qui avait des prétentions sans aucune espèce de connaissance. Elle parvint à faire commettre cette injustice à un savant judicieux, mais faible, qu'elle avait subjugué. (On sait qu'il n'est pas rare de voir les femmes ordinaires déprécier celles qui ont des connaissances, les taxer de pédanterie, et contester leur mérite, pour se venger de leur supériorité : celles-ci sont en si petit nombre, que les autres sont presque parvenues à leur faire cacher ce qu'elles savent.

Clairaut m'écrivait : " L'ardeur de $M^{\text {me }}$ Lepaute est surprenante. "Dans une autre lettre, il l'appelle la savante calculatrice. On comprendrait difficilement le courage qu'exigeait cette entreprise, si l'on ne savait que pendant plus de six mois nous calculámes du matin jusqu'au soir, quelquefois même à table, et 


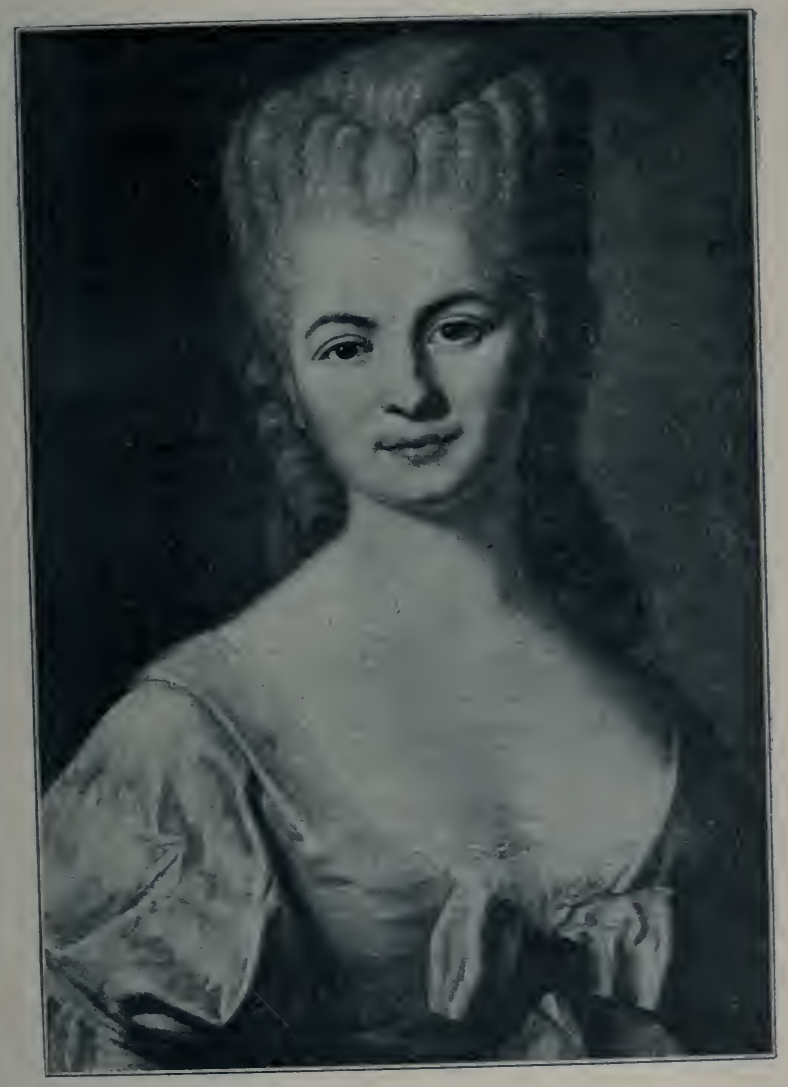

HORTENSE LEPAUTE 
qu’à la suite de ce travail forcé, j'eus une maladie qui changea mon tempérament pour le reste de ma vie; mais il était important que le résultat fùt donné avant l'arrivée de la comète, pour que personne ne pût douter de l'accord entre l'observation et les calculs qui serviraient de fondement à la prédiction. C'est ce qui arriva effectivement : la comète fut retardée de 600 jours par l'action de Jupiter et de Saturne ; et ce retardement fut annoncé à la rentrée publique de l'Académie des Sciences, au mois de novembre 1758 . On ne vit la comète à Paris que le 21 janvier 1739 et en Allemagne que le 20 décembre 1758. (Histoire de '.Acalémie, 1759, p. 142. Elle fut observée à Béziers, comme on le voit $p .1306)$.

La comète de 1762 occupa aussi $\mathrm{N}^{\mathrm{me}}$ Lepaute, quand il fut question d'en calculer les éléments par le moyen des observations.

L'éclipse annulaire de soleil, prédite pour 1764, était un phénomène curieux pour la France, où l'on n'en avait jamais observé. IIm* Lepaute la calcula pour toute l'étendue de l'Europe, et publia une carte où l'on voyait de quart d'heure en quart d'heure, la marche de l'éclipse, et une autre carte pour Paris, où l'on voỵait les différentes phases. Si un article inconsidéré de la $G a-$ sette de $\overrightarrow{F r a n c e ~ f i t ~ c r o i r e ~ q u e ~ l ' e ́ c l i p s e ~ s e r a i t ~ t o t a l e, ~ e t ~ q u ' i l ~ f a l-~}$ lait avancer l'office du matin, il suffisait pour être détrompé, de jeter les yeux sur les cartes de $\mathbf{I}^{\text {me }}$ Lepaute, dont on avait distrihué plusieurs milliers.

A l'occasion des différentes éclipses qu'elle avait calculées, elle sentit l'avantage d'une table des angles parallactiques, et elle en fit une très étendue, qui est dans la Connaissance des temps de 1:63, et dans le livre intitulé Exposition du calcul astronomique.

Ylme Lepaute fit aussi plusieurs mémoires pour l'Académie de Béziers dont elle était associée, entre autres le calcul de toutes les observations qu'on y avait faites lors du passage de Vénus sur le Soleil en 1761. Nais parmi les services qu'elle a rendus à notre science, on doit citer principalement le soin qu'elle eut, en 1768, de faire venir de Montmédi un neveu de son mari, alors àcé de quinze ans, pour l'attacher uniquement à l'astronomie : c'est Lepaute d'Agelet, reçu à l'Académie des Sciences en 178ว, et dont le voyage aux terres Australes en 1773, et le voyage autour du monde, qu'il entreprit avec La Pérouse, prouvent d'une manière bien importante, que $\mathbf{I}^{\mathrm{m}} \mathrm{L}$ Lepaute a été utile à l'Astronomie. 
Ce n'est pas la seule obligation que lui ait la famille de sor mari : N. Lepaute le jeune, qui fut horloger du roi, et ensuite te chef de la famille, eut des enfants; l'ainé fut élevé par $\mathrm{M}$ mo Le paute avec un soin extrême. Une intelligence peu commune tous les agréments et les talents qu'on peut espérer d'un enfant celui-ci les possédait. A l'âge de six ans, il faisait déjà des cal culs astronomiques; et comme il a maintenant trente-sept an (en 1802), il serait connu dans les sciences, comme d'Agelet sor cousin, si on lui eût fait embrasser cette carrière; mais on pré féra le mettre chez un notaire et ensuite dans les emplois. $O_{1}$ est surpris que ses parents ne l'aient point fait profiter des cir constances heureuses de sa première éducation pour lui donne un état pius flatteur pour l'esprit et pour la gloire; mais, quoiqui déjà riches, ils n'ont pu résister à l'appât d'une carrière plu: lucrative : on croit toujours faire mieux pour ses enfants quanc on leur procure le moyen de gagner plus d'argent.

En 1759, je fus chargé de la Connaissance des temps, ouvrage que l'Académie des Sciences publiait chaque année pour l'usage des astronomes et des navigateurs, mais dont les calculs pour raient occuper plusicurs personnes. J'eus le bonheur de trouve dans I $^{\text {me }}$ Lepaute un secours sans lequel je n'aurais pu entre prendre ce travail; et elle continua jusqu'en 1774, temps où ur autre académicien se chargea de ce pénible emploi : mais alor elle commença de s'occuper du travail des Éphémérides, dont le septième volume in- $4^{\circ}$, qui parut en 1774 , va jusqu'en 1784 , e dont le huitième, publié en 1783, s'étend jusqu'à l'année 1792 Dans celui-ci, elle fit seule les calculs du Soleil, de la Lune et d toutes les planètes, comme on le voit dans la préface, où j'avai: soin de rendre justice à mes coopérateurs.

Cette longue suite de calculs affaiblit sa vue, qui avait été excellente; elle fut obligée de discontinuer dans les dernière: années de sa vie.

Mais combien les qualités du cœur ajoutent à la gloire des talents de l'esprit! Hâtons-nous de dire que, pendant sept ans II $^{\text {me }}$ Lepaute fit voir l'héroïsme de la vertu dans les soins qu'elle prit d'un mari malade, perclus et séparé de la société. Elle eu le courage de s'enfermer avec lui dans la maison où il fallut le placer dans les premiers temps de son délire; elle quitta Paris et se retira à Saint-Cloud avec son malade, pour lui procurer ur meilleur air, et pour être moins détournée dans les soins qu'elle voulait prendre de lui sans relâche et sans partage, et auxquel: elle sacrifia son temps, ses occupations, ses plaisirs, et mème sa 
santé, avec une assiduité et un courage dont il y a peu d'exemples. C'est au milieu de ces fonctions respectables qu'une fièvre putride l'enlova, le 6 décembre, à sa famille, à ses amis et aux sciences. L'infortuné malade ne sentit pas la perte qu'il faisait : il ne survécut pas longtemps à sa bienfaitrice, étant mort le 11 avril 1789 .

M ${ }^{\text {me }}$ Lepaute avait des parents dont plusieurs ont aussi éprouvé sa bienfaisance lorsqu'ils ont eu besoin de son secours, et elle se privait des agréments que son aisance pouvait lui procurer, pour augmenter la leur. Les parents mêmes de son mari ont éprouré son désintéressement : elle institua son héritier $M$. Lepaute le jeune, son beau-frère, en le mariant avec $M^{110}$ Chardon.

Quand il s'agit d'une femme, on ne se défend point de parler de sa figure et l'on demande toujours si elle était jolie. Nous devons donc répondre à cette question, en disant que, sans être remarquable par sa figure, $\|^{\mathrm{m}}$ Lepaute avait une grande partie des agréments de son sexe; une taille élégante, un pied mignon, et une si belle main, que M. Voiriot, peintre du roi, ayant fait son portrait, lui demanda la permission de la copier, pour conserver un modèle de la plus belle nature; il s'en servit depuis dans ses tableaux. Le portrail de Mmo Lepaute a été placé dans mon cabinet, à côté d'un portrait rare de Copernic, dont la notice a été donnée dans le Journal de Paris du 24 mai 1785, et qui a été gravé. Dans son portrait, $\mathrm{II}^{\mathrm{m} e}$ Lepaute est représentẻe traçant la figure de l'éclipse de 176 ' , qu'e'le venait de calculer, et ayant une sphère à côté d'elle. Ce portrait ressemble un peu

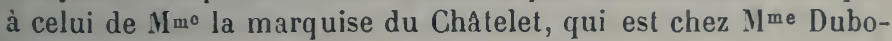
cage, à Paris.

I'mo Lepaute ne laisse aucun enfant, mais une sœur, une nièce et deux frères, dont l'un était $M$. de la Brière, architecte connu par ses talents distingués, auteur d'un beau portail gravé et projeté pour Saint-Germain-l’Auxerrois.

I. de la Louptière adressa à $\mathrm{II}^{\mathrm{mo}}$ Lepaute ce quatrain, qui parut dans le Mercure, vers l'année 1776 :

$$
\begin{aligned}
& \text { Par vos attraits et ros talens } \\
& \text { Vous charmerez toujours un sage; } \\
& \text { Vos mains ont mesuré le temps, } \\
& \text { Vos yeux en décident l'usage. }
\end{aligned}
$$

Dans des vers qu'on lui adressait lorsqu'elle commençait à faire usage des tables de sinus, on lui disait :

Des tables de sinus toujours environnée.

Vous suivez arec nous Hipparque et Ptolénı́e; 
Mais ce serait trop peu que de suivre leurs traces, Et d'ètre au rang de ceux que nous comblons d'honneurs, Reine, si vous n'étiez et le sinus des Grảces,

Et la tangente de nos cœurs.

Commerson donna le nom de Pautia, que le $C^{\text {on }}$ de Jussieu. changea en celui d'Hortensia, à une belle plante, appelée aussi Rose du Japon, que l'on voit sur les papiers de Chine.

$\mathrm{M}^{\mathrm{m}}$. Lepaute est la seule femme en France qui ait acquis de véritables connaissances dans l'astronomie, et elle n'est remplacée actuellement que par $\mathrm{I}^{\mathrm{me}}$ du Pierry, qui a publié divers calculs astronomiques et qui a mérité qu'on lui dédiât l'Astronomie des Dames, qui parut en 1786.

Ses calculs ne l'empèchaient point de s'occuper des affaires de la maison; les livres de commerce étaient à côté des tables astronomiques; le goût et l'élégance étaient dans ses ajustements, sans nuire à ses études. Les étrangers que son mérite attirait auprès d'elle, ont contribué à la réputation de MII. Lepaute, et leur ont été utiles. Son mari avait pour elle cette considération qui tient du respect, mais qu'un mérite rare inspire à ceux qui savent le sentir. Elle était cependant remplie de prévenances pour lui; elle le servait avec empressement et dans des détails qu'une autre aurait trouvés au-dessous de l'élévation de son caractère et de son esprit.

Sa société me fut utile et chère; elle m'éloigna de liaisons dangereuses; elle me procura les agréments d'une vie commode avec des gens aimables et instruits; elle supporta mes défauts, et contribua à les diminuer. Elle avait assez de caractère pour ètre impérieuse, quand cela pouvait être utile; mais elle avait assez de prudence pour céder, dans les occasions où la résistance eût été dangereuse. Enfin elle me fut si chère, que le jour où j'assistai à son convoi fut le plus triste que j'eusse jamais passé depuis celui où j'appris la mort de mon père, le plus respectable et le plus tendre de tous les pères.

Cette femme intéressante est souvent présente à ma pensée, toujours chère à mon cœur : les moments que j'ai passés auprès d'elle et dans le sein de sa famille, sont ceux que j'aime le plus à me rappeler, et dont le souvenir, mêlé d'amertume et de peine, répand quelque douceur sur les dernières années de ma vie, comme son amitié fit le charme de ma jeunesse. Son portrait, que j'ai toujours sous les yeur, est ma consolation, quand je pense qu'un philosophe ne doit pas se plaindre des lois impérieuses de 
la nécessité, et des pertes qui sont une suite nécessaire de l'ordre de la nature."

J. La Lande. Histoire abrégée de l'Astronomie.

Nous navons pas pu retrouver le portrait de Mme Lepaute, par Voiriot, mais il nous a été permis de reproduire le portrait à l'huile, sans nom d'auteur, conservé par M. HenriLepaute, au Belloy, près Saint-Germain-en-Laye.

Nous remercions aussi $\mathrm{M}^{\mathrm{me}}$ Alvar Lepaute de nous avoir montré la très belle pendule dédićo à Hortense Lepaute, œurre artistique et symbolique que devrait acquérir un de nos inusées français.

Table des longueurs des pendules. (Dans le Traité d'horlogerie du mari J.-A. Lepaute. 1755.)

Observations (Dans Connaissance des temps, 1759-77).

Carte du passage de l'ombre de la lune au travers de l'Europe dans l'éclipse annulaire du soleil qui doil arriver le $1^{\mathrm{er}}$ avril 1764. Paris, 1762.

Angles parallactiques. Paris, 1763.

Tables du soleil, de la lune et des autres planètes (Dans les Éphémérides du mouvement céleste de LaLande, t. VIl et VIII, 1774).

Mémoires d'astronomie (dans le Mercure).

\section{LEPORINE (DOROTHÉE-CHRISTINE)}

Auteur de : Quelques considérations sur les études scientifiques du beau sexe. Leipzig, 1749.

\section{LERMONTOF}

Cette compagne de S. Kowalevski a étudié lā chimie à Heidelberg.

\section{DE LESCLACHE}

Versée dans la philosophie, cette dame a composé plusieurs livres que, par modestie, elle a publiés sous le nom de son mari. Elle est morte le 22 décembre $\mathbf{1 6 6 9 .}$

Les avantages que les femmes peuvent recevoir de la philosophie..., par Louis DE Lesclache, 1667, pet. in-16.

A la fin du livre précédent, il est question d'un traité de philosophie en dix petits volumes, par la même. 


\section{LETELLIER}

Le prix Savigny, que l'Académie des Sciences décerne aux

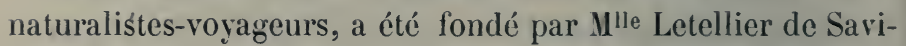
gny. Son père, membre des Instituts de France et d'Égypte, avait étudié les animaux invertébrés de l'Égypte et de la Syrie.

\section{DE LÉZARDIÈre (MARIE-CHARLOTTE-PAuLINE)}

Théorie des lous politiques de la monarchie française. Nouvelle édition publiée sous les auspices des ministres des affaires étrangères et de l'instruction publique. 4 forts vol. in-8, 18't'.

L'auteur est une jeune vendéenne (175ั'-1833̈). La premii re édition de ce livre philosophique et érudit fut brûlée pendant la Révolution, et la deuxième édition a été louée par MM. Guizot et Augustin Thiéry, pour son explication de la France d'aujourd'hui par le passé.

\section{LIBERT (MARIE-ANNE)}

Botaniste belge (1782-1863̈). Au pensionnat de Prüm, elle s'appliqua aux mathématiques, mais le goût des chiffres fit bientót place à celui des fleurs. Encouragée par Lejeune et de Candolle. De la végétation phanérogamique, elle passa aux cryptogames, découvrit une foule d'espèces, et publia Plantie cryptogamice quas in Arduena collegit M.-A. Libert. Elle avait publié auparavant :

Sur un nouveau genre d'hépatique. 1820 ;

Illustration du genre Inoconia de la famille des algues. 1826;

Observations sur le genre Asteroma... 1827;

Description d'un nouveau genre de champignon nommé Desmazierella. 1829;

Etc., etc.

Réputation comme cryptogamiste. Deux genres lui ont été dédiés : Libertia et Libertella. 
Son herbier et ses notes ont été acquis par le Jardin botanique de Bruxelles.

V. Notice par Dumortier(Bulletin de la Société de botanique de Bruxelles, 1865, pp. 403-411).

Prologue à la mémoire de Marie-Anne Libert, par Morren (Belgique horticole, 1868, pp. r-xv, avec portrait).

\section{LIET (SOPHIE)}

La philosophie absolue du Dr Mure.

\section{LILIVATI}

L'hindou Bhàscara (xII ${ }^{\mathrm{e}}$ siècle) a donné ce nom, qui est celui d'une femme, à un recueil mathématique en vers.

Débos.

D'un essaim de mouches à miel

Prends la moitié, plus la racine, Uans un champ de jasmins, celte troupe butine. Huit neuvièmes du tout voltigent dans le ciel.

Une abeille solitaire

Entend dans un lotus, son mari bourdonner : Attiré par le miel, pendant la nuit dernière, Il s'était fait emprisonner. De combien est l'essaim, le saurais-tu, ma chère?

(Traduit par M. L. Rodet.)

\section{LIND}

Mme Lind a découvert, le '4 mai 1783, chez W. Herschel, les volcans de la lune. (Voir Hévélús. De la distribution de la face de la lune.)

\section{LINNÉ}

On doit à la fille du célèbre botaniste, à Mlle Linné, la découverte d'un des phénomènes les plus extraordinaires de la végétation. Elle remarqua que pendant le crépuscule, ou vers le lever de l'aurore, les fleurs de la Capucine produisent des lueurs passagères d'instant en instant. Elle communiqua ses observations à son père, et à plusieur's physiciens, et l'on 
attribua généralement ces espèces d'éclairs à un dégagemen d'électricité. (Mémoires de la Société de Suède, 1762.)

Pultnex. Coup d'œil sur la vie et les ouvrages de Linné.

\section{LITWINOW-IWASCHKIN (ÉLISABETH)}

Une représentation mathématique (en russe); Saint-Péters bourg, 1879.

Notice biographique sur Lobatchefsky; id., id., 189'.

\section{LOCHE}

Madame veuve Loche a été directrice du Musée d'histoir naturelle d'Alger. Nous trouvons une note d'elle dans le Bulletin des sciences physiques et naturelles d'Alger (187't. p. 347); A propos des animaux destructeurs des sauterelles.

\section{LOCKYER (JOSEPH-NORMAN)}

Cette vulgarisatrice a traduit en anglais plusieurs ouvrages de A. Guillemin et de Flammarion.

\section{LOEVRY}

Juive, femme d'un graveur, possédait une riche collection de minéraux et a donné des leçons à Mary Somerville.

\section{LOMBAY}

"La de Lombay confunde al filosofo Espinosa. "

Qunones. De la education moral de la muyer. p. xiIr.

Nous ne connaissons que cette citation espagnole sur li dame en question.

\section{LOMBROSO (PAOLA)}

Fille et collaboratrice du savant italien, César Lombroso. Elle a étudié la psychologie de l'enfant (Turin-Rome, 189'), la cérébration inconsciente (Revue des Revues, 1: juillet 189' ), l'instinct de conservation chez les enfants (Revue philosophique, octobre 1896), etc. 
LORTET (Clémence Richard, dame)

Botaniste française (1772-1830̈).

"Le père de Madame Lortet (la femme du célèbre médecin), Richard, ouvrier de Lyon, et qui ne fut rien autre chose, s'avisa au régiment d'apprendre les mathématiques, et bientôt en donna des leçons à ses officiers et à tous. Rentré à Lyon et marié, il donna à sa fille cette éducation. Elle commença justement comme les bainbins de Frœbel par une étude qui charme les enfants, la géométrie (l'arithmétique au contraire, les fatigue extrêmement.) "

Mrchelet. La femme; page $3 \nmid 9$.

V. Roffavien. Notice sur $/ /^{\text {me }}$ Lortet, membre de la Société linéenne de Lyon. Lyon, 1833 .

\section{LOSA (ISABELLE)}

Sivante espagnole, née à Cordoue, mérita le bonnet de docteur à cette Université; clle fut surtout théologienne. Elle royagea en Italie et y fonda l'hòpital de Lorette. Morte en 10ั46, à 73 ans.

\section{LOSERIA (MARGUERITE-SYBILLE)}

Qualifiée de théologienne, jurisconsulte, chimiste et philosophe.

\section{LOVELACE (ADA), NÉE BYRON}

"Celte description (de la machine à calculer de Babbage) a été donnée par le général Menabrea, alors capitaine du génie dans l'armée piémontaise, en 1842, dans la Bibliothèque Universelle de Genève (t. XLI, p. 3ə22). Il y a lieu, à ce propos, de mentionner un fait curieux que le général Menabrea porta à la connaissance de l'Académie des Sciences de Paris, lorsqu'en 1884 il entretint la docte compagnie de la machine de Babbage. Son mémoire avait été traduit en anglais par un anonyme qui y avait ajouté des notes indiquant une remarquable pénétration d'esprit en même temps qu'une pleine intelligence du sujet.

Intrigué par cet anonymat, le capitaine Menabrea pria Babbage de lui en dévoiler le secret. Quelle ne fut pas sa surprise lorsque celui-ci lui livra le nom de lady Ada Lovelace, la fille unique de lord Byron? 
On ne saurait guère imaginer de plus singulier contraste que celui offert par cette fille de poète s'appliquant à l'étude si exacte et si ardue des machines à calculer. "

M. D'OCagne. Le Calcul simplifié par les procédés mécaniques et grapliques, note de la p. 36.

On lit dans les mémoires de Mary Somerville qu'elle a donné des leçons de mathématiques à Ada Byron.

\section{LOVI}

"In the Encyclopedia Britannica, XII, 536 , mention is made that Mrs Lovi improved (a perfectionné) the hydrometer. I do not know any thing further about her. ")

Lettre de David E. Smith, du 13 janvier 189.\%.

\section{LUNELLI-SPINOLA (BENEDICTE-CLODILDE)}

Outre divers ouvrages littéraires, des thèses soutenues à l'église Saint-Thomas : Conclusioni filosofiche; Turin, 17'1't, in-4.

\section{LYLE (E.-S.)}

Wat are the stars or a treatise on astronomy for the young. Londres, 1870, vi et 136 pp.; 1872, 162 pp.

\section{LYON (MARY)}

Institutrice et savante américaine (1797-18'9).

V. livre de Richemoxi) New-York, 1891, in-8.

\section{MACE (HANNAH)}

Aide du professeur Newcomb, à l'Observatoire naral des États-Unis, à Washington.

\section{MACKINON (ANNIE-L.)}

Docteur ès sciences.

Concomitant forms in terins of the roots (Annales de mathématiques, 189\%, pp. 9̋̈ et 10̈7). 


\section{MADDISON (ISABEL)}

A Bryn Mawr College.

The arithmetizing of mathematics, by Felix Klein. 'Translated; New-York.

Sur certains facteurs dans les discriminants en $c$ et $p$ et leurs relations avec les points fixes de la famille des courbes. (The quarterly Journal of mathematics, 1893.)

V. Nature (de Londres) du 2 juillet 1896, et Bulletin Darboux de mars 189 .

\section{DE LA MALARDIÈRE}

Cette dame, qui a vécu au xrire siècle, a publié un Abrégé de mathématiques à l'usage des jeunes gens. Paris, 1799 , in-12.

\section{MALATESTA (BATTISTA)}

Une des plus savantes femmes du xive siècle en philosophie et en théologie. Morte en 1416. - Sa sœur, sa fille et ses petites-filles furent aussi des femmes distinguées.

\section{MALTBY}

Américaine. Docteur en philosophie de l'Université de Gœttingue, avec une thèse de physico-chimie.

\section{MALWOVSKA}

D’après M[lle Malwovska, Copernic, jeune encore, aurait donné les preuves d'un grand courage en défendant une princesse dont la vie était en danger. Cette noble action changea la reconnaissance de la princesse en amour, mais une trop grande distance séparait le fils d'un bourgeois de la noble châtelaine. Copernic embrassa l'état ecclésiastique.

\section{MANFREDI (THÉRĖSE ET MADELEINE)}

Manfredi, directeur de l'Observatoire de Bologne, a publié en 1703 une Astronomie des dames. Ses deux sœurs l'aidè- 
rent à composer les Éphémérides de Bologne. (Consulter RAYET ; Les observatoires en Italie, p. 69.)

V. aussi MäDlen (t. I, p. 390.)

\section{MANIN (ÉMILIE)}

« La jeune Émilia, fille de Manin, subit l'exil et la pauvreté. Elle fut atteinte d'une cruelle maladie nerveuse. Mais à travers toutes ces épreuves, elle garda sa pensée haute et libre, aimant le pur entre le pur, l'algèbre et la géométrie. ")

Michelet. La femme, p. 106.

" Cette forte et pénétrante intelligence, visant toujours à la raison de toutes choses, à l'absolu, au parfait, singulièrement portée aux formes métaphysiques et mathématiques, s'associait à un naturel charmant et à toutes les nuances, à toutes les délicatesses de la sensibilité féminine. »)

H. Martis. Daniel Manin, p. 168-9.

Norte à 20 ans, d'une maladie nerveuse, en janvier 18วั'.

\section{MANOVA}

L'observaloire de Manova. - Ce nouvel observatoire, qui appartient à Madame Manova. ... est situé à Lussin Piccolo, dans l'île de Lussin (Istrie)..... L'atmosphère, qui est toujour's d'une transparence extraordinaire, permet les observations les plus délicates.

Revue scientifique, $20 \%$ mai $189: 3$.

\section{MANZOLINI (ANNA), NÉE MORANDI}

Naturaliste italienne de la fin du xrure siècle; elle enseignait l'anatomie à Bologne et observait très bien, dit-on. Les modèles qu'elle a confectionnés furent une des curiosités du musée bolonais. Sa science, ses découvertes, lui firent offrir une chaire à Milan, et lui valurent en 1769 une visite de l'empereur Joseph II qui la combla de distinctions honorifiques.

Y. Cavazza. Le Scuole dell antico studio bolognese, Milan, 1896, p. 290. 


\section{MARCET}

"Mariée avec un médecin éminent, chimiste habile, M" Marcet, douée elle-même d'un rare mérite, avait écrit, sous le titre de: Conversations sur la chimie, un petit traité populaire, justifiant sinon par son éclat extérieur, du moins par son langage simple et naturel, l'insigne honneur qui lui a été accordé d'ouvrir au jeune Faraday la route de la science et de lui inspirer l'amour profond de la vérité ; genre de succès qu'on souhaite, sans l'espérer. à ces traités modernes plus brillants et qui n'ont parfois de populaire que le nom.

Faraday ne se montra point ingrat; il attribua loujours son goùt pour les connaissances chimiques au soin qu'il avait mis à constater, par de petites expériences, chacune des assertions du livre de celle qu'il nommait avec bonne humeur sa première institutrice, et quand les relations du monde les rapprochèrent, loin de rougir de son humble enfance, ses pensées se reportant en arrière, il aimait, disait-il, à contempler en elle le présent et le passé. "

J.-B. Dusas. Éloge historique de Michel Faraday.

Voir d'autres détails dans l'éloge de Faraday, par de la Rive.

Il est aussi question plusieurs fois de Mrs Marcet dans les mémoires de Marie Somerville. Née Haldimand, à Genève, vers 178\%, clle était fille d'un riche négociant suisse établi à Londres.

Voici ses principaux ouvrages :

Conversations sur la chimie, traduits de l'anglais, Genève, 1809, 3 vol. in-12. Souvent réimprimé. Deux autres traductions, l'une par M. Payen : la chimie en XXYI leçons, Paris, 1820 ; l'autre : Entretiens sur la chimie, Paris, 1826, Ibे planches.

Conversations on natural philosophy, Londres, 1820 ; traduction française sous le même titre et, en 182\%, une contrefaçon : La phỵsique des gens du monde.

Conversations on vegetal physiology. Londres, 1830, 2 vol. in-8; une traduction française.

Conversations sur l'économie politique. (Traduit par Prérost 
de Genève, 1817.) «C’est la seule femme, disait J.-B. Say, qui ait écrit sur l'économie politique et elle s'y est montrée supérieure à beaucoup d'hommes. »

\section{MARCHAIS}

Un autre portique de l'Encyclopédie était le salon de Mme Marchais, le salon qu'elle tenait aux Tuileries dans le pavillon de Flore.... il était avant tout le salon du produit net. Sur la cheminée, sur les tables, on ne royait que brochures et questions économiques..... Mme Marchais avait été convertie par Mme de Pompadour à la science de son fameux ami Quesnay.

\section{MARCHINA (MARTHE)}

Une pauvre Napolitaine qui avait reçu du ciel, à défaut de la richesse, l'intelligence et la beauté.....

Elle fit tant de progrès dans la philosophie et dans la théologie qu'on lui offrit à l'Université de Rome une chaire qu'elle refusa. Martha mourut au milieu du xvi ${ }^{\mathrm{e}}$ siècle.

Ime Dora d'Istria. Des femmes, t. I, p. 262.

\section{MARGUERITE DE NAVARE}

( La sœur de François Jer, avait un maitre de géométrie. » E. Krantz.

\section{MARIE, DITE LA JUIVE}

Aurait vécu à l'époque du pseudo Demetrius. On lui attribue plusieurs traités d'alchimie (Berthelot); elle aurait inventé des instruments et des fourneaux ainsi que le bain-marie (du Cange).

Il y a aussi une Marie, dite la copte, dont on cite un écrit :

Le livre de Marie la copte avec les Sages, quand ceux-ci se réunirent auprès d'elle.

Ne pas confondre avec Marie l’Égyptienne (35̈'-131), une religieuse solitaire qui a été canonisée. 


\section{MARKS (SAHRA)}

Marks' London table-book of arithmetic, werghts and measures, the mariner's compass, etc. London, 1876.

The use of a line-divider, London, Pys. soc. Proceed 7, 188.̈1886, 1-6.

Problèmes dans « Educational times ».

\section{MARSHALL (DoROTHÉE)}

Communications à l'Académie des Sciences de Paris.

M. Ramsay et Miss Marshall «Sur une méthode de vaporisation des différents liquides à leurs points d'ébullition. 》 (8 novembre 1893.)

M. Griffiths et Miss Marshall, "La chaleur latente de vaporisation de l'eau. ") (Même date.)

Miss. Marshall seule, «Sur la chaleur de vaporisation de lacide formique ».

\section{MARTINEAU (HARRIET)}

1802-1876. - Niss Martineau, née à Norwich (Angleterre), s'est rendue populaire par' ses études sociologiques. Elle a traduit, en anglais, en l'abrégeant, le cours de philosophie positive de Comte.

Auguste Comte, La philosophie positive, condensée par Miss II. Nartineau. Trad. française par Avezac Laviơne, qe éd. 189', 2 vol. in-8.

"Gràce à vous, écrit Auguste Comte à Miss M., la pénible étude de mon traité fondamental ne reste indispensable qu'au petit nombre de ceux qui veulent devenir théoriciens. Maisl'immense majorité où la culture théorique est seulement destinée à préparer la raison pratique peut désormais et doit préférer la lecture habituelle de votre admirable condensation, qui vient pleinement réaliser un vœu que j’avais formé depuis dix ans. »

Le mème parle encore ainsi du manuel de Miss M.: «Un travail sans exemple où la conscience et le talent sont tou- 
jours en harmonie, vient de procurer une vie nouvelle à mon ouvrage fondamental qui devra désormais chez la plupart des lecteurs être étudié de préférence d'après cette traduction exceptionnelle. ")

L'abrégé de Miss M. date d'un demi-siècle; voir l'étude de ce travail par L. Dugas, dans la Revue philosophique de mai 1896.

De la même: Contes sur l'économie politique, trad. de l'anglais par Maurice. 1833-9, 8 vol. in-8. Portrait.

\section{MASETTI (MARIANNE)}

Savante italienne, morte en 18 '1 et dont Zobi a écrit la biographie (Florence, 18'2).

\section{MASHAM}

Lady Masham, fille du philosophe Cudworth, a soigné le vieux Locke, comme une fille. Elle a correspondu avec Leibniz.

V. Leibniz et les deu: Sophies, par Foucher de Careil. pp. 127 et suiv.

\section{MASSARINI (IGINIA)}

Docteur en mathématiques de Rome.

Tooria delle congruenze di Tschebicheef. Traduzione con aggiunte et note. Roma, 1898 .

\section{DE MASSASSEINE (MARIE)}

Femme d'un professeur de l'Université de Saint-Pétersbourg, s'occupe de sciences naturelles et fait des conférences scientifiques.

Le surmenage mental dans la civilisation moderne.

Le sommeil tiers de notre vie, pathologie, physiologie, hygriène, psychologie. (Trad. Jaubert, 1896, in-12).

Hallucinations prémoniioires (Annales des sciences pṣchiques, mai-juin 1896). 


\section{MASSEBIAU}

L'Océan et ses phénomènes, in-18.

\section{MASSON (ROSINE)}

de Lausanne; étudie la flore suisse.

\section{MASTRAMI (CLAIRE)}

A Lucques, au xvi siècle. Instruite dans la philosophie de Platon et versée dans la théologie.

\section{MATÉ}

Le télescope marin a été inventé par Mme illaté et perfectionné par sa fille. Cet instrument permet d'examiner les avaries d'un vaisseau sans le faire entrer dans le dock; il en résulte un grand progrès dans la tactique navale.

\section{MATHILDE DE TOSCANE}

La grande comtesse (10'6-1115), dans sa vie guerrière et dérouée aux papes, protégea les lettres et les sciences. Elle a créć les premières universités italiennes.

\section{MATT (BARONNE)}

1) après Mädler, elle avait à Vienne un observatoire particulier.

\section{MAURY (A.-C.)}

"C'est en Amérique, à l'observatoire de Harvard College, Cambridge (Massachusetts), que ce phénomène singulier du dédoublement périodique de certaines lignes stellaires a été constaté pour la première fois, au commencement de l'année 1890, par Miss Maury, sur les photographies des spectres des deux étoiles du ciel boréal, $\zeta$ de la Grande-Ourse et $\beta$ du Cocher. La première est une étoile double; l'étoile principale de $2^{\circ}$ grandeur est associée à un satellite de $4^{\circ}$ grandeur, de même couleur blanc verdàtre, très éloignée et tournant autour d'elle avec une extrême lenteur. L'observation de Miss Maury nous apprend que l'étoile principale elle-même est formée de deux étoiles 
extrêmement rapprochées, de même constitution chimique, probablement de même grandeur, qui tournent l'une autour de l'autre en un temps très court, 104 jours à peu près. "

C. Wolf. L'astronomie de l'Invisible. (Revue pédagogique de février 1891.)

V. Gelion Town. Astronomie astrophysique; 1896, in-12, t. II, p. 9't.

\section{MAYOUX}

Cette demoiselle a publié dans les Annales de l'Université de Lyon, puis en tirés à part :

Recherches sur les valeurs morphologiques des appendices superstaminaux de la fleur des Aristoloches; 1892.

Recherches sur la production et la localisation du tanin chez les fruits comestibles fournis par la famille des Pomacées; 189'.

\section{MÉCHAIN}

"Méchain était soutenu, protégé de loin par une femme admirable qui ne se lassait jamais de solliciter pour son mari les secours dont il avait besoin, qui poussait à un tel degré l'abnégation qu'elle faillit devenir victime de son dévouement lorsqu'il fut accusé d'émigration, et qui était la première à l'engager à se séparer d'elle lorsqu'il s'agissait de la gloire de son nom et du bien de la France.

Rien n'est plus touchant que de voir dans les archives de l'Lcadémie des Sciences les reçus signés de I $^{\text {me }}$ Méchain et prouvant que c'était par acomptes misérables, par remises de cinq cents francs, qu'elle arrachait à Lucas, agent général de l'Institut, l'argent dont son mari avait besoin pour la soutenir, pour travailler et pour ne pas mourir de faim lui-même.

Que d'amour, de noble ténacité et de vrai courage, la graphologie, si elle n'était pas un mensonge, devrait lire dans cette élégante et féminine signature que l'archiviste nous a montrée! "

W. de Foxvielle. La mesure du mètre, p. 138.

\section{MÉLISSA}

Pythagoricienne; a écrit sur les couleurs. 


\section{MENU-BENOIST}

Herbier élémentaire; 1811, in-8 (Il n'a paru qu'une livraison).

\section{MÉRIAN (MARIE-SIBYLLE)}

Les fleurs et les insectes lui ont dit tous leurs secrets.

" En terminant le xvı० siècle, nous ne devons pas oublier de mentionner une femıne, qui s'est particulièrement distinguée à la fois comme peintre et comme entomologiste, Maric-Sybille Mérian, née à Francfort en 1647, morte à Amsterdam en 1717. Habile à peindre les fleurs et les insectes, elle poussa si loin l'amour de la science que, non contente d'avoir examiné les collections des principaux cabinets d'histoire naturelle de l'Europe, elle visita le Nouveau-Monde. Pendant un séjour de deux ans à Surinam (de 1698 à 1700), elle dessina tout ce qu'elle y vit d'insectes, ainsi que les plantes sur lesquelles ils se tiennent. Ses observations parurent à Nuremberg (en 1679) et à Frankfort (en 1683); elles furent plus tard complétées, d'après les papiers laissés par l'intrépide naturaliste et publiées en français par Buchoz sous le titre de : Histoire générale des insectes de Surinam et de toute l'Europe; Paris, 1771; 3 parties; grand infolio avec figures. "

IloefFer. Histoire de la Zoologie.

Le président de Brosses dit que le Cabinet d'histoire naturelle de Mlle de Mérian a été transporté à l'Académie des Sciences de Bologne.

Alfred Maury. L'Ancienne Académie des Sciences, p. 118.

L'exemplaire du Muséum porte cette note à la main : "Cet exemplaire est un de ceux qui sont sortis des mains de Ille Mérian et qui ont été peints par elle-même ou du moins sous ses yeux. Aussi est-il pour l'exactitude fort supérieur à ceux qui ont paru en Hollande depuis sa mort. Pour le rendre complet, on y a ajouté les planches qui ont été données sous forme de supplément dans l'édition de 1719. J’ai eu cet exemplaire à la mort de M. Morin, le médecin. »

MariotTE. 
Voici un extrait de la préface de Mademoiselle Mérian :

“ Dès ma jeunesse, je me suis appliquée à l'examen des insectes, j'ai commencé à Francfort-sur-le-Mein ma patrie, par les vers à soie; ayant ensuite remarqué que les plus beaux papillons, tant ceux qui volent le jour que ceux qui ne volent que la nuit, sortoient des chenilles, je ramassai toutes celles que je trouvai, pour en étudier les transformations.

Pour faire mes observations avec plus d'exactitude, j'abandonnai toute sorte de compagnie el je m'appliquai au dessin afin de pouvoir peindre ces insectes au naturel.... Je publiai la première partie in-quarto en 1679 et la seconde en 1683, après les avoir gravés moi-même....

Je passai la mer dans le mois de juin 1699 et je restai dans ce pays-là (Surinam) jusqu'au mois de juin 1701 .... J'ai résolu, si le ciel m'accorde la vie et la santé, d'ajouter aux observations que j'ai faites en Allemagne, celles que j'ai recueillies en Frise et en Hollande et de les publier en latin et en hollandais. "

- La célèbre famille des Mérian, les imprimeurs de Francfort, a compté un artiste de grand talent, Marie-Sybille, qui épousa

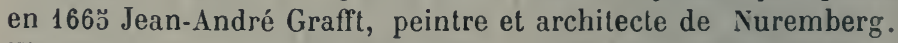
Elle peignait les fleurs, les papillons et les insectes, Pour trouver de nouveaux modèles, elle n'hésita pas à faire le voỵage de l'Amérique méridionale, en compagnie d'une de ses filles; elle en rapporta 60 miniatures sur vélin, qu'elle grava et publia à Amsterdam, en un album devenu rapidement fort précieux. Marie Mérian mourut à Amsterdam à l'âge de cinquante ans." VAcuoy. La femme dans l'art, p. 537.

La Fulgore porte-lanterne peut suppléer une lampe, par lit vive lumière dont resplendit sa monstrueuse tête. Sỵbille de Mérian rapporte qu’à Surinam, à l'aide d'un seul de ces hémiptères elle lisait les gazettes.

V. Michelet. L'insecte, pp. 39̋̈-7.

HéRISSAx. Biblioth. physique de la France, 1771, p. 362.

\section{DE MÉRIGNAC}

Nous devons à Mme de Mérignac, hardie " pyrrhonienue », le portrait de Bayle qu'elle fit graver el la grande édition dr ses œurres dont elle prépara les matériaux. 


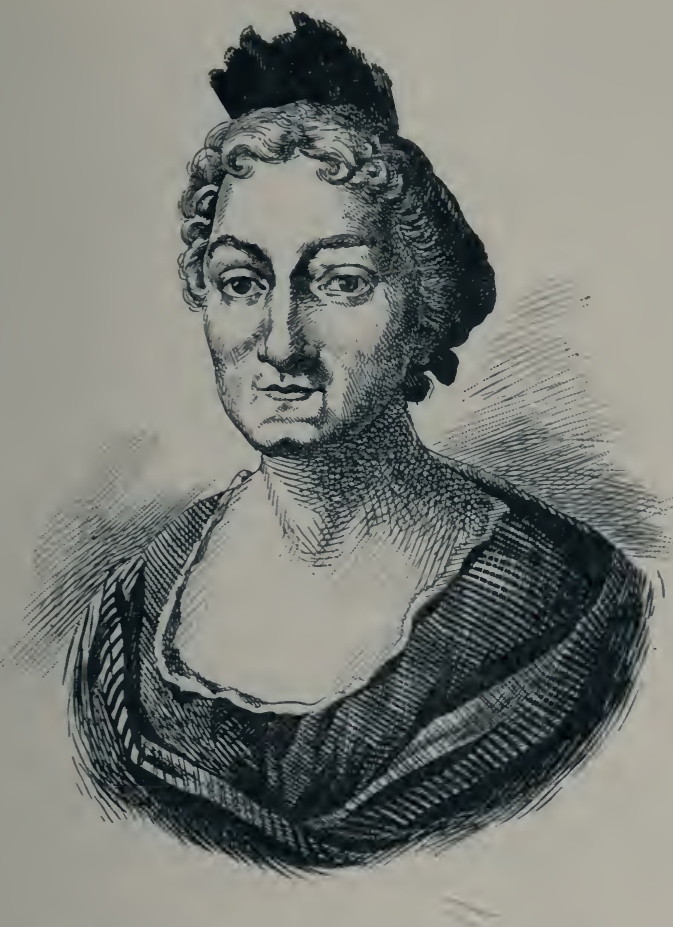

\section{Maria Sybilla Derian}

Blumen = Mablerin, Todter bes ditern \$athåus Netian, gebohren zu Grantfurt am Nain 1647, geftorben 1717, Sdúlerin ibres Stiefpaters

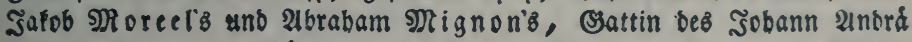
Eraf, Mablers zu Núrnberg. Shon war fie in Darftellung ber \$ofan=

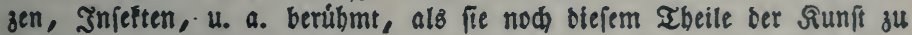

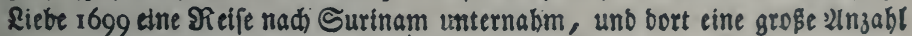

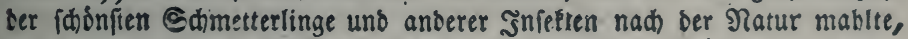

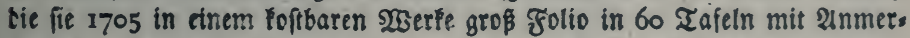
fungen zu 2mfrertam berausgab, too fie im 7often sabre ibreb 2llterz fiarb. Eie binterließ 2 Iodter: Dorotbea Maria, unb Soh. Jelena, welde leştere ibre Reifegefábrtin nad Surinam war. 
.

$=$

+

(2)

1

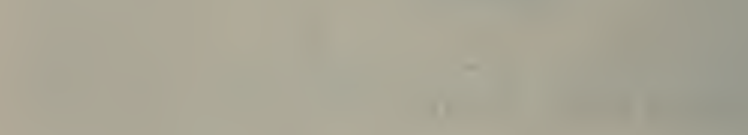

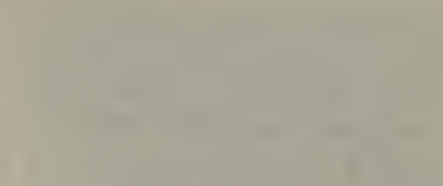

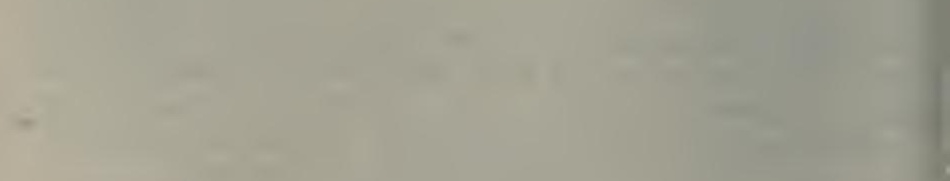


DE LA MÉSANGÈRE

La marquise, mise en scène dans La Pluralité des mondes de Fontenelle, est Madame de la Mésangère de Rouen. C'était une très belle femme mais, comme elle ne roulait pas être reconnue, l'auteur de blonde qu'elle était la fit brune.

On recomnaît très bien le parc de la Mésangère, à la deseription qui en est faite.

Trublet. Mémoires pour servir à l'histoire de la vie et des ouvrages de $\mathbf{M}$. de Fontenelle.

Madame de la Mésangère était fille de Madame de la Sablière. La Fontaine lui a dédié la fable Daphnis et Alcimandre.

V. Arsène Houssaye. Galerie du xwiI siècle; t. I, p. 47.

\section{METCHNIKOFF}

Contribution à l'étude de la vaccination charbonneuse. (Annales de l'Institut Pasteur, 1891.)

\section{MEULIEN (TULIA)}

Mad. Meulien a traduit, en 1837, sous les auspices d'Arago. La connexion des forces physiques de Mary Somerville. (Voir ce nom.)

Sous les mêmes auspices, elle a traduit aussi : Éléments de géologie, de Ch. Lyell, 1839, in-12.

\section{MEUNIER (STANISLAS)}

E. Levallois, née à Metz et mariée à S. Meunier, le naturaliste, a publié, entre autres ouvrages : L'Écorce terrestre (1880) ; le Monde végétal (1880); le Monde minéral (1883); les Sources (1886); Misère et grandeur de l'Humanité primitive; la Planète que nous habitons, etc. En collaboration avec son mari : Au hasard du chemin, voyages de jeunes natulistes.

\section{MEYER (MAUD)}

A été reçue, le 13 décembre 1888, membre de la Société anglaise de matlématiques. 


\section{MICHELET}

Mlle Nialaret, qui a eu l'honneur de devenir $\mathrm{M}^{\text {me }}$ Michelet, a collaboré avec l'illustre historien, lorsqu'il a publié ses livres : L'Oiseau ; l'Insecte ; la Mer ; la Montagne, où l'histoire naturelle devient poétique et philosophique.

\section{MILL (JOHN-STUART) OU TAYLOR}

On lit en tête de Liberty, du philosophe anglais :

- Je dédie ce volume à la mémoire chérie et pleurée de celle qui fut l'inspiratrice, et en partie l'auteur, de ce qu'il y a de mieux dans mes ouvrages : à la mémoire de l'amie et de l'épouse dont le sens exalté du vrai et du juste fut mon plus vif encouragement et dont l'approbation fut ma principale récompense.

Comme tout ce que j'ai écrit depuis bien des années, c'est autant son œuvre que la mienne ; mais le livre, tel qu'il est, n'a eu qu'à un degré très insuffisant l'inestimable avantage d'être revu par elle, quelques-unes des parties les plus importantes ayant été réservées pour un second et plus soigneux examen, qu'elles sont destinées maintenant à ne jamais recevoir. Si j'étais capable d'interpréter la moitié seulement des grandes pensées, des nobles sentiments qui sont ensevelis avec elle, Je monde en recueillerait plus de fruit que de tout ce que je puis écrire, sans l'inspiration et l'assistance de sa sagesse presque sans rivale."

\section{J. Stuart Mill.}

\section{MILLET-ROBINET ( $\left.\mathrm{M}^{\mathrm{me}}\right)$}

Agronome contemporaine, morte presque centenaire, auteur de La Maison rustique des dames; 18599, 2 vol. in-12. - La Líaison rustique des enfants. - La Routine vaincue par le progrès.

\section{MITCHELL (MARIA)}

Elle suivait le mouvement des astres, dans le merveilleux symbolisine de la formule mathématique.

Cette épigraphe est due à Mary W. Whithney, élive et successeur de Maria Mitchell, à Vassar, qui a publié une notice en son honneur. De ce travail, traduit et abrégé, nous dégageons les indications suivantes. 


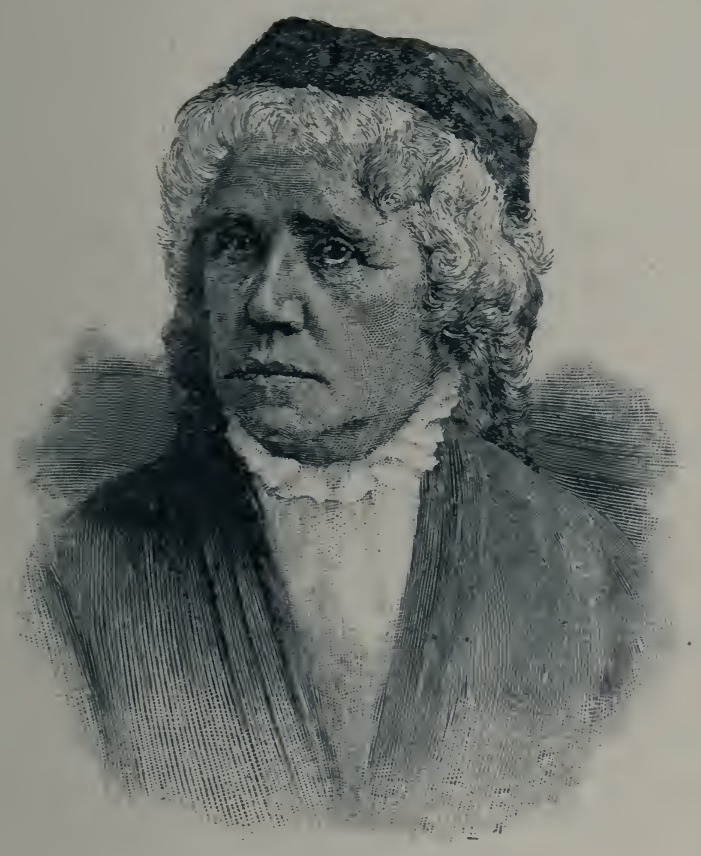

MARIA MITCHELL 
Pêcheurs de baleine ét euakers. - Maria Mitchell est née dans l'ile de Nantucket, où les femmes étaient aussi énergiques que les hommes, parce que ces derniers partaient pour de longs voyages de pêche et que les quakers dominaient. Lat légende rapporte qu'un des trois premiers blanes qui abordèrent dans l'ile était un ancêtre de l'astronome. Les femmes pouvaient parler et voter à l'église, mais la plus grande simplicité leur était imposée; elles se livraient au travail intellectuel.

Les Mitchell étaient de purs quakers, n'étaient pas marins et ils étaient parents de Benjamin Franklin. Le père de Maria, àgé de plus de 70 ans, aidait encore sa fille; il maniait bien le sextant et avait déterminé la latitude du lieu; il tenait les registres météorologiques.

PÈne ET FILle PENdant L’éclipse. - Maria Mitchell née dans l'ile, le $1^{\text {er }}$ août 1818, était la troisième de neuf enfants. La famille n'était pas riche. Le père dirigeait une école, était employé à l’inspection des còtes et se délassait en étudiant les étoiles. Il y avait dans le ménage un globe céleste et un petit télescope. Une éclipse annoncée mettait tous ces Mitchell en éveil.

Maria devint vite l'aide de son père dans ses observations astronomiques et dans ses calculs. Dès onze ans, elle mesurait le temps au chronomètre, pendant une éclipse lunaire, et, au retour de l'éclipse, ร̌ł ans plus tard, elle laissa ses élèves observer au télescope, et voulut se borner encore à mesurer le temps comme autrefois.

Laborieux comancement. - Pìre Pierce, l'instituteur, remarqua vite l'enfant et la poussa vers les sciences. A 18 ans, elle devint bibliothécaire à l'Athenceum Library, ragna quelque argent, étudia le latin et dévora Laplace et Gauss. Elle déclarait, dans son enthousiasme, qu'une formule mathématique est un hymne de l'univers (mot à commenter).

Premère comète. - Maria menait de front la pratique et la théorie. Pendant la nuit du fer octolore 1817, elle observa 
au ciel une petite tache nouvelle. Était-ce une simple nébuleuse ou une comète? Lorsque le lendemain, le verre fut de nouveau dirigé vers la tache, le petit nuage avait changé de place. Il s'agissait donc d'une comète et la jeune astronome de Nantucket l'avait découverte la première. Le P. Vico l'observa ensuite à Rome.

On donna le nom de Maria Mitchell à l'astre nouveau et le roi de Danemark envoya, en récompense, une belle médaille d'or.

Départ pour l'Europe. - La célébrité renait peu à peu. Aux instruments portatifs, succéda un grand télescope offert à Maria par ses admirateurs. Elle fut nommée calculatrice du Nautic Almanach et fit la connaissance des savants américains.

Ses économies étaient insuffisantes pour faire un voyage en Europe, ce voyage qu’elle désirait tant, lorsqu'un négociant lui demanda d'accompagner sa fille. En Angleterre, Mary visita John Herschel et Airy. Elle dut rendre sa fille au marchand qui avait fait de mauvaises affaires et elle continua seule le voyage, avec son fonds de réserve.

A Paris, Leverrier donna à l'Observatoire une fète en l'honneur de l'américaine. Le pape lui permit de visiter à Rome l'observatoire des jésuites où ancune femme n'était encore entrée .

Directrice d’observatoire. - De retour en Amérique, Miss Mitchell trouva sa mère malade et isolée, les autres filles s'étant marićes. Elle devint sa garde-malade et dut reprendre le poste de bibliothécaire. Après la mort de Mrs Mitchell, le père et la fille se retirèrent à Lymm, Massachusetts, achetèrent une maisonnette, $\mathrm{y}$ installèrent leurs instruments et reprirent leurs observations.

En 186:\%, on proposa à Maria, qui avait 47 ans, la chaire d'astronomie à Vassar College qu'on venait d'ourrir. Elle accepta non sans inquiétude. Il s'agrissait d'un collège de femmes, pour les hautes sciences. Quinze élèves purent seules suivre le cours. 
Le professeur savait stimuler les disciples et elle les traitait cordialement. Attendait-on une ondée de météores? Les détachements d'observatrices se succédaient sur le toit, et, dans l'intervalle, on allait boire une tasse de café chaud et se reposer au salon.

Miss Mitchell était devenue directrice de l'Observatoire, en même temps que professeur au Collège.

Juriter ex Sitcrie. - Malgré ses lecons, Maria trouvait le temps de faire des travaux personnels et de contribuer à l'avancement de la science. Jupiter et Saturne étaient ses planètes favorites.

En 187't, dès cưon commença à appliquer la photographie à l'astronomic, la directrice fit établir un appareil à ses frais et étudia, avec ses élèves, la face du Soleil.

Nous avons déjà dit combien Maria Mitchell était bonne. Elle réunissait sous la coupole, en un diner d'adieu, les jeunes filles qui allaient quitter définitivement l’Observatoire. Le gaz remplaşait la douce lueur des étoiles, on remisait les instruments, on s'amusait, on disait des vers.....

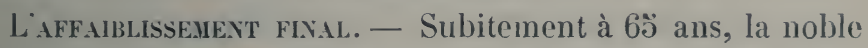
femme sentit une grande fatigue l'envahir et elle offrit sa démission. On la nomma professeur honoraire, avec un appartement dans l'Observatoire et le droit d'observer librement aux instruments.

Elle préféra se retirer à Linn et fit installer le télescope dans la maison de famille, mais, pendant le printemps de 1889 , le corps et l'intelligence s'affaiblirent définitivement et Maria Mitchell mourut le 28 juin.

Elle nous a donné un grand exemple de simplicité et de dévouement à la vérité, en proclamant avec joie les lois du monde physique et du monde moral.

BibliograpiIIE.

OEuvres de M. Mitchell.

On Jupiter and his satelliles (American Journal of science, 18i1, pp. 393 à 393 ; $187 \%$, pp. 454 à $456 ; 1878$, pp. 38 à 411.

Totes of the satellites of Saturn (Idem, 1879, pp. 430 à 432). 
Observations and elements of Miss Mitchell's comet. Londres (Astron. soc. Monthly not., 1847-8, pp. 9 à 11, 130 à 131).

Minima of Algol. (The astron. journ. Cambridge, U.S.A, 1858, p. 7.)

Observations on some doubles stars (Americ. journ. of Science, 1863, pp. 38 à 40 .)

Mädler. t. I, p. 398.

Sources pour M. Mitchell.

Appleton. American biography, 1888.

Annual cyclopedia, 1889.

The sideral messenger, t. IX, p. 49.

Chataugnan, t. X, p. 181.

Portrait. (V. notice par Niss Withney.)

\section{MOGNIZ}

Christophe Colomb épousa, en Portugal, une demoiselle Mogniz, dont le père arait été marin.

Libri. Histoire des mathématiques en Italie; t. III, note de p. 71 .

\section{MOLSA (TARQUINA)}

de Modène; avait étudié l'astronomie arec Antoine Guarino et la philosophie platonicienne avec François Patrizzi.

\section{MONGE}

En 1777, Monge s'était marié d'une façon originale. Aỵant rencontré chez des amis de Rocroy une personne de vingt ans. Ime veure Horbon, il en devint fortement épris. Il lui demanda sa main directement, sans prendre la peine de recourir, suivant l'usage, à l'entremise d'un tiers.

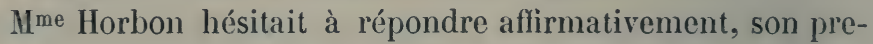
mier mari, maitre de forge, lui ayant laissé les ennuis d'une liquidation compliquée.

“ Ne vous arrêtez pas, Madame, à de pareils rétilles, dit Monge. J'ai résolu dans ma vie des problèmes bien autrement difficiles. Ne vous préoccupez pas non plus de mon peu de fortune, les sciences y pourvoiront. ") Le mariage eut lieu et cette union fut toujours sans nuage.

D’après Arago. Biographie de Monge.

Une descendante du grand Monge, Mme Marey-Monge assistait au centenaire de l'École Polỵtechnique. 


\section{MONIQUE}

332-386. - Sainte Monique, la mère de Saint-Augustin, s'adonnait à la philosophie, se préoccupait du temps et de l'éternité, de la création et des rapports avec l'Être infini. (Voir SaInt-Augustix; de beatâ vitâ, en particulier le colloque au port d'Ostie).

Abbé Bougaud. Histoire de Sainte Monique.

\section{MONTAGUE}

"L'inoculation serait restée dans la classe de ces usages des peuples barbares qui excitent une stérile curiosité, si en 1716 Mary Wortley Montague, agée alors de 26 ans, n'eût accompagné son mari dans son ambassade auprès de la Porte ottomane. Cette femme, d'un esprit fin et observateur, ne tarda pas à remarquer en Turquie les effets de la petite vérole artificielle. Dans sa lettre du $1^{\text {er }}$ avril 1717 , elle décrivit avec beaucoup d'agrément la manière dont se fait l'insertion du venin variolique et dès lors elle forma le projet de la tenter sur ses enfants, et de la propager à son retour dans la Grande-Bretagne.

Les hommages de ses compatriotes l'environnèrent toute sa vie et la suivirent jusqu'à Venise, où elle s'était retirée dans sa vieillesse. "

LéMoxtex. Histoire de la régence, t. II, p. 46 ò et suivantes.

V. Lettres de Milady Montague, trad. par Anson, 180ä, 2 rol. in 12. t. I. p. 227 et t. II, p. 330.

\section{MORE (HANNAH)}

Il a été publié en $18^{\prime} 10$ : Correspondance de. Newton et de miss Hannah More.

\section{MORELLE (JULIENNE)}

“Née à Barcelone en 1592, elle était à 17 ans si ferme sur les principes de la dialectique, qu'elle vint à Lyon soutenir des thèses de logique, de mathématiques et de morale : elle savait quatorze langues et possédait également bien la théologie, la jurisprudence, la musique. Elle parcourait le monde savant en habit de cordelier et allait défier les plus habiles juristes in 
utroque. Dégoûtée des vanités du siècle, elle se retira au monastère de Sainte-Praxède d'Avignon et y récut jusqu'à l'age de 62 ans. "

V. Barjatel. Biographie du Vaucluse.

\section{MORGAN (SOPHIE-ÉLIZABETH)}

Memoirs of Augustus de Morgan; Londres 1882, in-8.

Un ouvrage posthume de A. Morgan (Newton and his niece) a été publié par la femme de l'auteur, avec l'assistance de Ranyard.

\section{MORIA}

En 1783, Lady Moria se rendit utile à ses concitoyens en leur enseignant à faire de la toile avec des objets dont pour l'ordinaire on ne tire aucun parti.

Mme Briquet. Dictionnaire historique de français, p. 29.

\section{MULFORD (ISABELLE)}

"Le septième rapport annuel du Missouri Botanical Garden, publié en mai dernier, renferme un mémoire de Imo $^{\text {Mulford, }}$ sur les agavés des Etats-Unis, dont nous avons sous les yeux un tirage à part. Ciette étude de systématique descriptive, consacrée principalement à l'énumération des espèces, à la discussion de leurs caractères et de leur légitimité, à la coordination des renseignements épars fournis de droite et de gauche, renferme pourtant quelques considérations générales qui ne sont point sans intérềt.

L'article d'une page et demie se termine ainsi :

" $\mathrm{H}^{\mathrm{me}}$ Isabelle Mulford donne une longue liste des espèces américaines connues, arec description des caractères essentiels, s!̣nonymies, etc., et son œurre intéressera certainement les botanistes.

Revue scientifique (rose) du 18 juillet 1896 : Les agavés aux États-Unis.

\section{MYA}

Fille de Pỵthagore et de Théano, Mya a adressé à Phỵllis une étude sur la nourriture des enfants. 
MYRO

suidas dit que la rhodienne Mrro était philosophe.

\section{NANTES SABUCCO (OLIVIA)}

Naturaliste, née à Alcara (Espagne) sous Philippe II, soutint que ce n'est pas le sang, mais le suc blanc, qui nourrit le corps; elle reconnut aussi que le cerveau est le siège de l'intelligence et s'éleva avec force contre la physique et la médecine des anciens; on lui doit un traité estimé d’anatomie et de physiologie.

\section{NARDO CIBELE (ANGELA)}

La zoologica popolare veneta. Palerme, 1877.

\section{NETTY D...}

"J'ai connu, il y a quelques années, une demoiselle d'un grand mérite qui n’avait point peut-être pour les mathématiques une aptitude extraordinaire, mais qui pourtant les entendait fort bien. Son directeur spirituel, M. l'abbé Hetsch, vicaire-général d'Orléans, avait, durant de longues anníes, préparé les matériaux d'une philosophie de l'unité: il mourut arant de l'avoir écrite. Mlle Netty D... recueillit ces notes éparses, les ordonna et en fit un livre sous ce titre : L'abbé Hetsch par Mlle N... Paris, 1885, un vol in-12 (650 pages). C'est peut-être le livre le plus sérieux, le plus philosophique qu'une femme ait écrit au xixe siècle : il a eu deux éditions. »)

\section{NICARÈTE}

de Mégare; amie et disciple du philosophe Stilpon. Athénée dit qu’elle fut stoïcienne et mathématicienne.

\section{NICOLA (Clara ET JULIA)}

Lutivi. Tables of logarithmes, etc. The logarithmic differences calculated together with an index by Julia and Clara Nicola]. Londres, 1866. 


\section{NOGAROLE (ISOTA)}

de Vérone ( $x^{\mathrm{e}}$ siècle), que le cardinal Bessarion nomme " une vierge plus divine qu'humaine ", ne craignait pas de prendre la défense d'Ève contre la théologie catholique qui la rend responsable de la révolte d'Adam. Cette théologienne avait prononcé des harangues devant les papes Nicolas $V$ et Pie II.

Dora d'Istria. Des femmes, t. I, p. 26'.

\section{NOPS (MARIANNE)}

Class-Lessons on Euclid, etc. Londres, 1882.

\section{NORTH (MARIANNE)}

Botaniste et voyageuse, 1830-1890 (Voir Annual Register de 1890 , p. 180).

Recollections of an happy life par Mirs J.-A. Srmoxis: sœur de M. North, Londres, 1892 (2 portr.).

\section{OCCELO}

Disciple de Pỵthagore. Il reste d'elle un Traité sur la nature de l'Univers, attribué aussi à son père.

\section{OGILVIE (MARIE)}

Traite dans Nature (Londres) de la Géologie populaire.

\section{O'GRADY (MARCELLE)}

Ce professeur de Vassar, U.S.A., étudie les vésicules de Kupfer.

\section{ÖHBERG (MARIE)}

Om lineära differensekvationers integration Solfläckarnus. inflytande pandet vid Kronstadt.

Deux mémoires publiés à Helsingfors (Finlande), en 189'. 


\section{OLYMPIODORE}

La fille du philosophe péripatéticien de ce nom professa les mêmes doctrines. Elle épousa le philosophe Proclus.

\section{D'ORLĖANS (LOUISE-ADÉLÄIDE)}

Seconde fille de Philippe d'Orléans, devint abbesse de Chesles (1719); musicienne, chirurgienne, théologienne, e'est elle qui disait plaisamment : " Je suis carrée comme un cube. »

\section{ORMEROD (E.-A.)}

Cette entomologiste attire l'attention sur l'influence qu'ont les hérons sur le succès des cressonnières.

Cosmos, 23 mai 1896, p. $22 \%$.

\section{DE OSORIO (ANNA)}

De Burgos; célèbre dans l'étude de la théologie, d'après Hispan. Illustr., t. II, p. 282.

\section{PALMER (MARGUERITE)}

Miss Palmer, qui a complété l'orbite définitive de la comète de Maria Mitchell, a publié des mémoires dáns les «Transactions ») de l'Observatoire de Yale.

\section{PALOMBINO}

A Naples, le Président de Brosses parle de ses entretiens, sur les Sciences, avec la princesse de Palombino, qui excellait en géométrie. (Voir Lettres sur l'Italie, t. I, pp. 222. 223, 2'11, 2'12.)

\section{PAMPHILE}

Egyptienne vivant trois siècles avant Hypatie ; surnomméc par Suidas la Savante d'Épidaure; fille et femme de philosophes; a écrit huit livres de Mélanges. Pline lui attribue le tissage des étoffes de soie.

Revue britannique (janvier 1833). Étude sur Pamphila. 
M. Milhaud, dans ses Leçons sur les origines de la science grecque (p. 289), dit que Pamphila n'était pas une femme.

\section{PANYPERBASTE}

Nicéphore Grégoras déclare que l’éloquence de cette femme aurait fait honneur à Platon et à Pythagore.

\section{PAPE-CARPENTIER (MARIE)}

1815̆-1878. Célèbre institutrice française, auteur de $L_{e}$ secret des grains de sable, dont le titre fait penser à l'Arénaire d'Archimède et où elle a voulu, suivant Jean Macé " poétiser la géométrie, faire de ses figures autant de signes représentatifs du monde moral et poursuivre à travers les trois règnes la progression des formes depuis le tétraèdre jusquà la sphère, en assignant à chacune un sens symbolique ». Mme Maurice Sand a traduit en italien les grains de sable.

Pascal a dit : "Qui aurait le mot d'un grain de sable, aurait le mot de l'univers. »)

Gossot. Mad. Pape-Carpentier, sa vie et ses ceurres. 2e édition, in-16, avec portrait.

\section{DE PARTHENAY (CATHERINE)}

Cette célèbre calviniste (10ั3̈'t-1631), a traduit Socrate et publié : Apologie pour le roi Henri IV. Nous reproduisons plusieurs passages la concernant, dans la notice de Frévérir RitTER sur François Viète, inventeur de l'algèbre moderne. Paris, 189 .̈.

"Au parc de Soubise, Viète s'attacha à Ciatherine de Parthenay, enfant d'une rare intelligence et douée d'une aptitude toute particulière pour les sciences exactes ; éloignée de toutes ressources pour l'instruction de sa fille, Antoinette d'Aubeterre, femme très docte au dire de ses contemporains, s'en occupait elle-même; elle trouva dans le jeune secrétaire un précieux auxiliaire, et c'est ainsi que se forma, sous leur direction, une des femmes les plus remarquables du $\mathbf{x v i}^{\circ}$ siècle.

A cette époque, l'instruction des femmes était, dans les hautes 
classes de la société, souvent plus étendue que celle de la plupart des hommes; aussi, d'après les mémoires du temps, voit-on figurer dans les programmes des études de certaines femmes distinguées l'astronomie, le plus souvent sous le nom d'astrologie.

Viète, en initiant son élève aux principes de celte science, se passionna pour ces études et résolut de composer un grand ouvrage, l'Harmonicum cœleste, sur le plan de l'almageste de Ptolémée.

\section{V. aussi Ier vol. Bulletin de Boncompagni (juillet 1868).}

Pour l'instruction de son élève, il rédigea, sous forme de cahiers, les leçons qu'il lui donnait; mais ces petits traités, conservés sans doute daus le chartrier de la maison Rohan-Soubise au château de Blain, ont péri, en 1793. dans le stupide autodafé de ces précieuses archives.

Un seul de ces opuscules nous est parvenu par une traduction

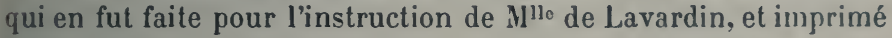
sous ce titre: Principes de cosmographie, tirés d'un manuscrit de Viète et traduits en français. Paris, Courbé, 163\%.

Viète... encouragé dans son œuvre par Catherine de Parthenay, devenue princesse de Rohan, à laquelle il communiquait ses belles inventions.

C'est à cette chère élève, sa bienfaitrice, qu'il dédia son " In Artem Anaiyticen lzagoge ou Introduction à l'Art de l'Analyse ". On lit dans cette dédicace latine :

"C'est à vous surtout, Auguste fille de Mélusine, que je dois mes études mathématiques auxquelles m'ont poussé et votre amour pour cette science et la très grande connaissance que vous en possédez et même ce savoir en toutes sciences que l'on ne saurait trop admirer dans une personne de si noble. race."

I. aussi Allegret. Éloge de Viète; Poitiers, 1867, in-8.

\section{PASCAL (VoIR PÉRIER)}

La vie du grand Pascal a été écrite par sa soeur Mad. Périer, née Gilberte Pascal. M. Cousin a publié un livre sur l'autre sırur, Jacqueline, il dit que cette théologienne janséniste " spirituelle: passionnée et obstinée comme son frère, est morte de chagrin à trente-six ans, pour aroir signé le formulaire, contre sa conscience ». 


\section{PASTEUR}

“ $M^{\text {me }}$ Pasteur fut non seulement la compagne dévouée, l'amie fidèle de l'illustre savant, mais souvent aussi sa collaboratrice intelligente aux heures de recherches et de travail.

Fille de M. Laurent, recteur de l'Académie de Strasbourg, elle se maria à l'époque où Pasteur était professeur suppléant à la Faculté de la capitale de l'Alsace.

Aucun des travaux de son mari ne la laissa indifférente et, sans abandonner son ròle de mère de famille et de femme d'intérieur, elle sut en maintes occasions aider son mari dans ses recherches.

C'est surtout au moment où Pasteur étudiait la maladie des vers à soie que $\mathbf{M}^{\mathrm{me}}$ Pasteur sut se rendre utile.

Au Pont-Gisquet, dans le Midi, où la famille s'était installée, Mmo Pasteur et sa fille devinrent de véritables magnanarelles, et pendant des mois on les vit passer une bonne partie de leur temps à trier les chenilles sur les claies et à renouveler leur litière de mûrier.

Ce travail se continua à Paris, une petite magnanerie fut établie dans l'antichambre de l'École normale et Nme Pasteur en prit la haute direction. )

V. Dessin représentant M. Pasteur dictant un rapport à sit femme (Revue encyclopédique du 15̆ janvier 1893̈).

\section{PECKHAM (ELISABETH)}

M. et Mad. Peckham ont étudié les sélections sexuelles et les ressemblances protectrices chez les araignées. La société d'histoire naturelle de Wisconsin a publié leurs travaux.

\section{PELCOT}

$M^{11 \text { le }}$ Pelcot et $\mathrm{M}^{\text {me }}$ veuve Vimont ont fondé une bourse au Collège de France pour les étudiants en mathématiques. Mlle Bortnicker a été titulaire de cette bourse. 


\section{PENLEBURY}

Mrs Penlebury et Mrs Seward ont étudié, le 13 décembre 1888, un cas de substitution chimique graduelle. (A la Société anglaise de mathématiques.)

\section{PEPOLI}

Cette duchesse, qui échappa avec peine au dernier supplice, lor's de la Restauration à Naples (1799-1801), a traduit les auvres de Mme Somerville.

On citait déjà au xve siècle, à Bologne, Anna et Catherine Pepoli, et au xvie, Ginevra Pepoli.

\section{PEREYASLAWZEWA (SOPHIE)}

Fille d'un colonel russe, a suivi les cours de l'université de Zurich où elle fut reçue docteur ès sciences. Pendant douze ans, a été directrice de la station biologique de Sébastopol, où elle a fait le plus grand nombre de ses travaux. Elle a exploré ensuite le golfe de Naples et les còtes de la France.

Voici les titres de ses principaux ouvrages, publiés en russe, en allemand ou en français :

Sur la reproduction des infusoires par division. - Quelques observation sur le nez des poissons. - Quelques mots sur la digestion des Tubellariés. - Le développement embryonnaire des Rotateurs. - Protozoa de la Mer noire. - Le développement du Gammarus poccilarus. - Le développement de la Caprella ferox. - Monographie des Tubellariés de la Mer noire (Ouvrage honoré d'un prix par le congrès des Naturalistes en 1893). - Mémoire sur l'organisation de la Nerilla antennata.

Le portrait de Mlle Pereyaslawzewa que nous publions p. $22{ }^{\circ}$ est dù au crayon de M. G. Lépine, qui a été un de ses voisins de laboratoire au Muséum d’histoire naturelle de Paris.

\section{PERICTIONE}

Mère de Platon. Pythagoricienne. Stobée dit qu’elle a com- 
posé deux traités de philosophie, l'un sur la sagesse, l'autre sur la constitution de la femme.

\section{PÉRIER}

1620-1687. - Gilberte Pascal, derenue Mad. Périer, est la sœur ainée du grand Pascal. Voici ce que dit d'elle sa fille Marguerite: « Ma mère était belle et bien faite, elle avait beaucoup d'esprit. Elle avait été élevée par mon grand-père, qui, dès sa plus tendre jeunesse, avait pris plaisir à lui apprendre les mathématiques, la philosophie et l'histoire. ») Monsieur Cousin, dans sa vie de Jacqueline Pascal, dit de Mad. Périer :

“ Ce qui la recommande à la postérité est la Vie si connue de son frère Pascal. Cette vie est admirable, elle fait aimer Pascal, et c'est sa sœur qui lui a rendu ce précieux office. Elle s'efface le plus qu'elle peut, ne laisse paraittre que son frère. Elle l'aimait tendrement, et s'affligeait, sans oser le dire, de ses froideurs apparentes. »

$\mathrm{M}^{\mathrm{me}}$ Périer est enterrée à Saint-Étienne-du-Mont, à còté de son frère Blaise Pascal.

Lettres, opuscules et mémoires de Madame Périer et de Jacqueline, sceurs de Pascal, et de Marguerite Périer, sa nièce, publiées sur les manuscrits originaux par M. P. FAcGère, 18 '5, in-8.

\section{PÉRIER (REYNÉE)}

Auteur d'un livre intitulé: Entretiens sur la physique et la cosmographie.

$$
\text { PERRIN (EMILY) }
$$

Problèmes dans Educational times.

\section{PETTRACINI (MARIA)}

Auteur de plusieurs ourrages sur l'éducation physique des enfants, a enseigné lanatomie à Ferrare, à la fin du xvü siècle.

Sa fille Zaffira Peretti a suivi ses traces. 


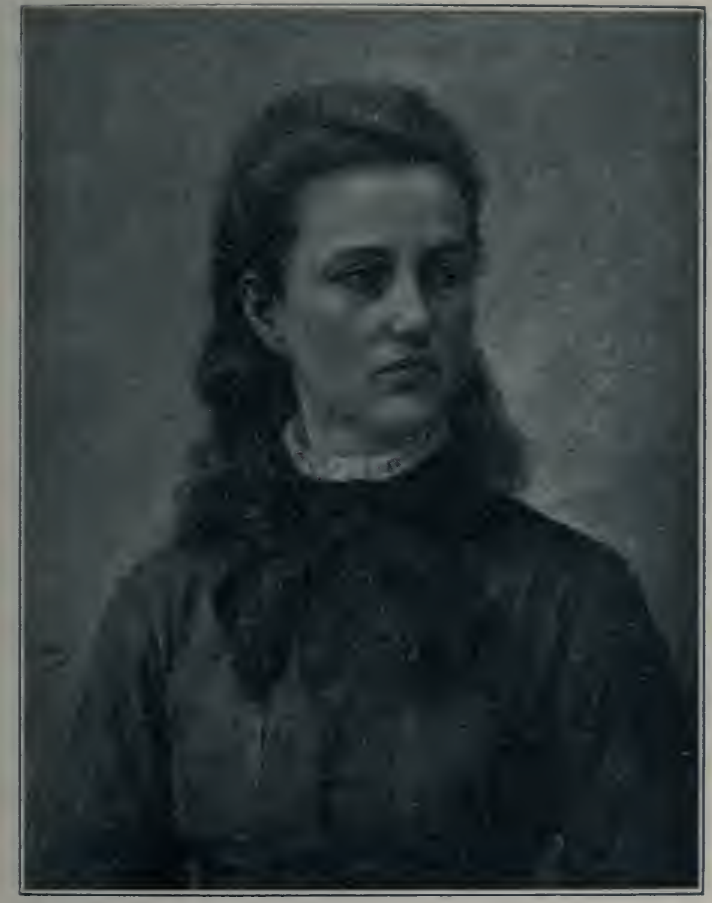

SOPIIE PEREYASLAWZEWA 

PFEIFFER (IDA)

Célèbre voyageuse, Vienne (179̋̈-18'18). Elle a publié : Voyage à Madagascar et Voyage d'une femme autour du monde.

\section{PHILÉNIS}

De la secte d'Épicure; savante en physique; eut des disciples.

\section{PHILTATIS}

Classée parmi les pythagoriciennes.

\section{PHINTIS}

Aussi pythagoricienne, a écrit un Traité de la tempérance des femmes.

\section{PIAZZI-SMITH}

M. Perrotin parle ainsi dans ses Notes de voyage de la femme du Directeur de l’Observatoire d'Édimbourg: " Elle fait des observations météorologiques suivies, et à heure fixe, qu' elle complète par des observations spectroscopiques sur les raies telluriques, le nombre et l'intensité de ces raies et leur rapport avec le temps. Le registre des observations est tenu par Mad. Piazzi-Smith avec un ordre parfait.... »

\section{PILATI (MARGUerite)}

Einfürung der Kinder in das Verständniss der Zinsrechnung.

Eine Rechenstunde in der einklassigen Volksschule. Rechencatechese für das sechste Schuljahr.

\section{PILLARD (HÉLOISE)}

Mémoires sur Georges Cuvier, publiés en anglais (traduction française par Théodore Lacordaire). Paris, Fournier, 1833, in-8.

\section{PITHIAS}

Cette fille d'Aristote fut aussi une philosophe. 
PLATT

Naturaliste; a étudié " the brain of the shark ». Morphologie animale.

\section{POGSON}

D'après Flammarion (Revue L'Astronomie, 188'), cette demoiselle serait directrice de l'observatoire de Madras. Elle a décrit, le 10 octobre 1883, une illumination crépusculaire.

\section{POMPILIANU (C.)}

Mlle Pompilianu a démontré dans la Nouvelle correspondance de Catalan un théorème de Laisant sur une parabole cubique.

Aussi Solutions de problèmes, dans le Journal de Vuibert et dans Mathesis, 1891-2.

\section{PONCELET}

La veuve du général Poncelet, le célèbre géomètre, avait un salon mathématique. Elle a offert, le $20 ̈$ janvier 1868, à l'Académie des Sciences, le capital dont les $\mathbf{2 . 0 0 0 ~ f r a n c s ~ d e ~ r e n t e ~}$ forment un prix annuel de mathématiques, dit Prix Poncelet. Le 12 juin 1876, Mme Delalande-Guérineau a augmenté le capital précédent, de façon à donner au mathématicien couronné une médaille représentant le général et ses aurres complètes.

\section{PORÈTE (MARGUERITE)}

Brûlée à Paris en 1310 pour avoir composé un livre mystique, jugé hérétique.

Ch. V. Laxglors. Revue historique; mars-avril 189'.

POUCHET

La femme du physiologiste de Rouen a contribué à ses travaux sur l'orologie.

\section{POWER (JEANNETTE)}

Cette dame, née de Villepreux, à Juillac (Corrèze), est l'auteur de Observations et expériences physiques sur plusieurs 
animaux marins et terrestres. Paris, Mourgues, 1860, in-8. (La couverture porte l'indication d'autres ouvrages.)

\section{PREDELLA (LIA)}

Docteur en mathématiques, professeur à l'école normale de Cagliari.

Sulle soluzioni singolari delle equazioni ordinarie di $1^{\circ}$ ordine; $189 \ddot{3}$.

\section{de PRÉmontVAl (AnNe-Victoire), née PIGEON}

Diderot a composé cinq mémoires sur différents sujets de mathématiques et il les a dédiés à $\mathrm{M}^{\mathrm{m}} \mathrm{de} \mathrm{P}$... Il ne s'agit pas de $I^{\text {me }}$ de Puisieux, comme on l'a cru, mais bien de II $^{\text {me }}$ de Prémontral. "Puissiez-vous les agréer et voir avec indulgence votre nom en tête d'un ouvrage, triste à la vérité, mais où l'on traite des sujets qui vous sont familiers... ») Mlle Pigeon, fille d'un professeur de mathématiques qui est l'auteur d'un Discours sur l'utilité des mathématiques et sur la nature du nombre, a épousé un membre de l'Académie de Berlin et elle est devenue lectrice de la princesse de Prusse (femme du Prince Henri). Elle a publié, d'après les idées de son père un ouvrage assez obscur : Le Méchaniste Philosophe (1750). Née à Paris en 172', elle est morte à Berlin en 1767.

\section{PRESTON-LOWEL}

De quelques orchidées indigènes. (The american naturalist, du 1er janvier 1891.)

\section{PRESTWICH}

La veuve du géologue de ce nom (Shoreham, Comté de Kent, Angleterre), préparant une biographie, demande communication des lettres de son mari.

\section{PRIDEAUX}

En 1881, miss Prideaux a obtenu à l'Université de Londres, la médaille d'or pour l'anatomie.

\section{PTOLÉMAÏS}

Contemporaine de l’impératrice Julie Domna, elle a traité 
de la théorie pythagoricienne de l'harmonie et de la musique. Hypsicle et Porphỵre renvoient à ses travaux.

\section{PUYZINIA}

La comtesse de ce nom avait fait bàtir un observatoire en Pologne.

\section{QUINET}

“ L'étude des mathématiques, de la géométrie surtout, peut être d'un grand secours à l'écrivain. La précision de l'esprit et la précision morale c'est-à-dire la justice ont certainement une base mathématique. »)

Ime Edgar Qunet. Le vrai dans l'Éducation, p. 43.

Du même livre, p. 44 :

" Envisagées à leur point de vue le plus élevé, les mathématiques n’ont pas seulement un caractère scientifique ; elles fortifient le caractère, elles ourrent des perspectives infinies à l'intelligence. »)

\section{RAFFALOWICH (SOPHIE)}

Cette demoiselle a publić dans les Revues d'économic politique :

John Bright et Henri Fawcett. - Vie de Richard Cobden, 188ว. - Lord Shaftesbury. Sa vie et ses travaux.

\section{RANDOLPH}

Mademoiselle H. Randolph a décrit, dans le Zoologischer Anzeiger du 4 mai 1891, la régénération de la queue chez le Lumbriculus. Elle a étudié aussi l'embryologie du Spirobis.

\section{REINHART (ANNA-BARBARA)}

De Winterthur, canton de Zurich. Mathématiques.

Voir Wolf. Biographien zur Kulturgeschichte. I, 3'1-33̈0.

\section{REMINGTON-HEMUP (MARIA)}

Auteur d'une étude intitulée Loi de la chaleur. 


\section{RENAN (HENRIETTE)}

La sœur et la première -inspiratrice d'Ernest Renan. Voir la Dédicace de la Vie de Jésus. Voir aussi Ma søur Henriette, $189 \%$, in-16.

Aurait laissé une Histoire de la Navigation.

\section{RENÉE de FRANCE (Duchesse de FERrare)}

Blois, 13̈10. Château de Montargis, 13̈7̈. - L'amour pour l'étude fit apprendre à cette seconde fille de Louis XII, l'histoire, les langues et même l'astrologie, dont Gauric lui apprit les secrets. La philosophie, la géométrie et l'astronomic furent ses occupations favorites.

Braxtorie. Vie des Femmes illustres, t. VIII, p. 108.

H.A(i. La France protestante, t. VIII, p. '110.

Citteau-Callenlle. Vie de Renée de France, Berlin; 1781. Robocanachi. Une protectrice de la Réforme.

\section{RENOOZ (CÉLINE)}

Madame Renooz est l'auteur de La Nouvelle Science, synthèse scientifique en 6 volumes. La force ; Le principe générateur de la vie; L'évolution organique de l'homme et des animaux ; L'évolution sexuelle ; L'évolution psychique ; Les àcres de l'humanité.

Nadame Renooz a aussi publié La Revue scientifique des femmes, qui a cessé de paraitre. Elle a fait des cours libres de psychologie, des conférences à la Salle des Capucines, etc.

L'origine des animaux; Histoire de leur développement primitif, nouvelle théorie de l'évolution réfutant par l'anatomie celle de M. Darwin, 1883, gr. in-8. Tome I (seul paru).

\section{DE RETZ (DUCHESSE)}

Claude Catherine de Clermont-Tonnerre, duchesse de Retz, dame d'honneur de Catherine de Médecis et gouvernante des enfants de France, est née en 15̆'43 et morte en 1603. D’après La Croix du Maine « elle mérite d’ètre mise au rang des plus 
doctes et des mieux versées tant en la poésie et art oratoire qu'en philosophie, mathématiques, histoire et autres sciences. »)

\section{REY (ARISTIDE)}

Madame Aristide Rey doit être rangée parmi les naturalistes. Elle a contribué à répandre les doctrines de Pasteur en publiant Le Monde des microbes.

Simples entretiens de physique et de cosmographie, 1878.

\section{REYNAUD (JEAN)}

Madame veuve Jean Rernaud a, par acte du 23 décembre 1878, fait donation à l'Institut d'une rente sur l'État de la somme de dix mille franes, pour un prix annuel « au travail le plus méritant relevant de chaque classe de l'Institut $)$.

\section{REYNOLDS (MARY)}

Collectionne et étudie les plantes de la Floride.

\section{RHODOPE}

Pythagoricienne.

\section{DE RICHELIEU}

“Madame de Richelieu, dont le mari était toujours à l'armée, arrive à la Cour de Lunéville, où elle dut être reçue en parente, car elle était de la maison de Lorraine. Nous avons dit qu'elle fréquentait fort Maupertuis et qu'elle avait mordu. elle aussi, à sa philosophie newtonienne; l'écolière, à ce qu'il paraîtrait, n'avait pas tardé à passer maitresse. Elle se mit, à Lunéville, à prendre des leçons de phỵsique de Varinge. Le père Dallemant, un jésuite grand prédicateur, s'avisa d'assister à une de ces séances et d'entreprendre la jeune femme sur l'attraction et sur le vide dont il ne savait pas le moindre mot. Elle le confondit complètement devant quelques Anglais, auxquels cette exécution inattendue inspira beaucoup d'estime pour le savoir des dames francaises. ")

De Nornestennes. Vollaire au château de Cirey, p. ̈̈8. 


\section{DE RIGNY}

Cette demoiselle a préparé elle-même son frère l'amiral à l'École polỵtechnique. Elle était versée dans les mathématiques. Mary Somerville en parle dans ses mémoires.

Sarrut et Saint-Edue. Biographie des hommes du jour; t. IV, qe partie.

RaBbe. Biographie universelle et portative des contemporains.

Hexwequn. Annales maritimes, 1832.

\section{ROBERT (MARIANNE)}

Voyage de milord Céton dans les sept planètes ou le nouveau mentor, traduits par $\mathrm{M}^{\mathrm{me}}$ de R. R.; 4 vol. in-2't (7 parties); La Haye et Paris, 176 כ.

L'avis du libraire dit que l'auteur est déjà connu par des ourrages, la Paysanne philosophe, la Voix de la nature, etc. Il sagit de Marianne Robert (1707-1771), amie de Fontenelle.

Dans la préface : «Peut-être trouvera-t-on que les matières sérieuses qui sont répandues dans cet ouvrage n’auraient pas dù être traitées avec autant d'enjouement. ")

\section{DE ROCHECHOUART-MORTEMART (MARIE-MADELEINE-GABRIELLE)}

Elle commanda saintementaux femmes et aux hommes.

Née en $\mathbf{1 6} 15$ et morte en 170', sœur de Mmes de Thianges et de Montespan, de la beauté desquelles elle avait quelque chose. Le cloitre la sauva du monde. Elle fit profession en $166 \ddot{3}$, à l'Abbaye-au-Bois, et devint, le 18 août 1670 , abbesse et générale de l’ordre de Fontevrault. Elle donna un grand exemple de vertu unie à la science. Elle savait le latin et le grec et elle traduisit partiellement Le Banquet de Platon. Jean Racine a complété «la chaste traduction de la docte abbesse (Cousin) ), 1732, in-12. Elle est citée par Ménage dans ses Femmes philosophes; en effet, la philosophie, soit an- 
cienne, soit moderne, n'avait point de système qu'elle ne connût. Les catégories d'Aristote, les universaux de Scot ne l'étonnèrent point.

La noble demoiselle était aussi une théologienne. Voici ce que dit, dans son oraison funèbre, le P. Anselme : "Quel spectacle plus surprenant et plus édifiant tout ensemble, que de voir une fille aussi humble qu'éclairée, assister, de son parloir, aux thèses que soutenaient ses Religieux ! Attentive à la dispute, capable de décider les questions les plus difficiles, elle s'en taisait néanmoins par modestie et se contentait de juger en secret des maitres et des disciples, pour les employer selon leurs talens. )

V. Conte de Rochechouant. Histoire de la maison de Rochechouart, 18599, 2 vol. in-'t. - Cousiv. I/ ${ }^{\mathrm{mo}}$ de Sablé. - CuéMENT F. Une abbesse de Fontevrault. - Avseune. Oraison funèbre. - Salnt-Anand. Portraits de grandes dames.

\section{RODRIGUE (ALICE)}

A remporté à l'Université de Genève le prix de botanique sur les étudiants.

Feuilles mobiles des légumineuses et des oxalidées.

\section{ROEBLING}

Quand on construisit le pont de Brooklyn, cet ouvrage gigantesque qu'on appelle la merveille du xixe siècle, ce fut use femme-ingénieur, Mme W. A. Rabling, qui présida à une partie des travaux pendant une maladie de son mari, lequel avait été chargé de cette merveilleuse construction. Aussi lui fit-on l'honneur de lui faire inaugurer le monument et traverser le pont la première.

\section{ROJEKI}

Travaille au Muséum de Paris. 


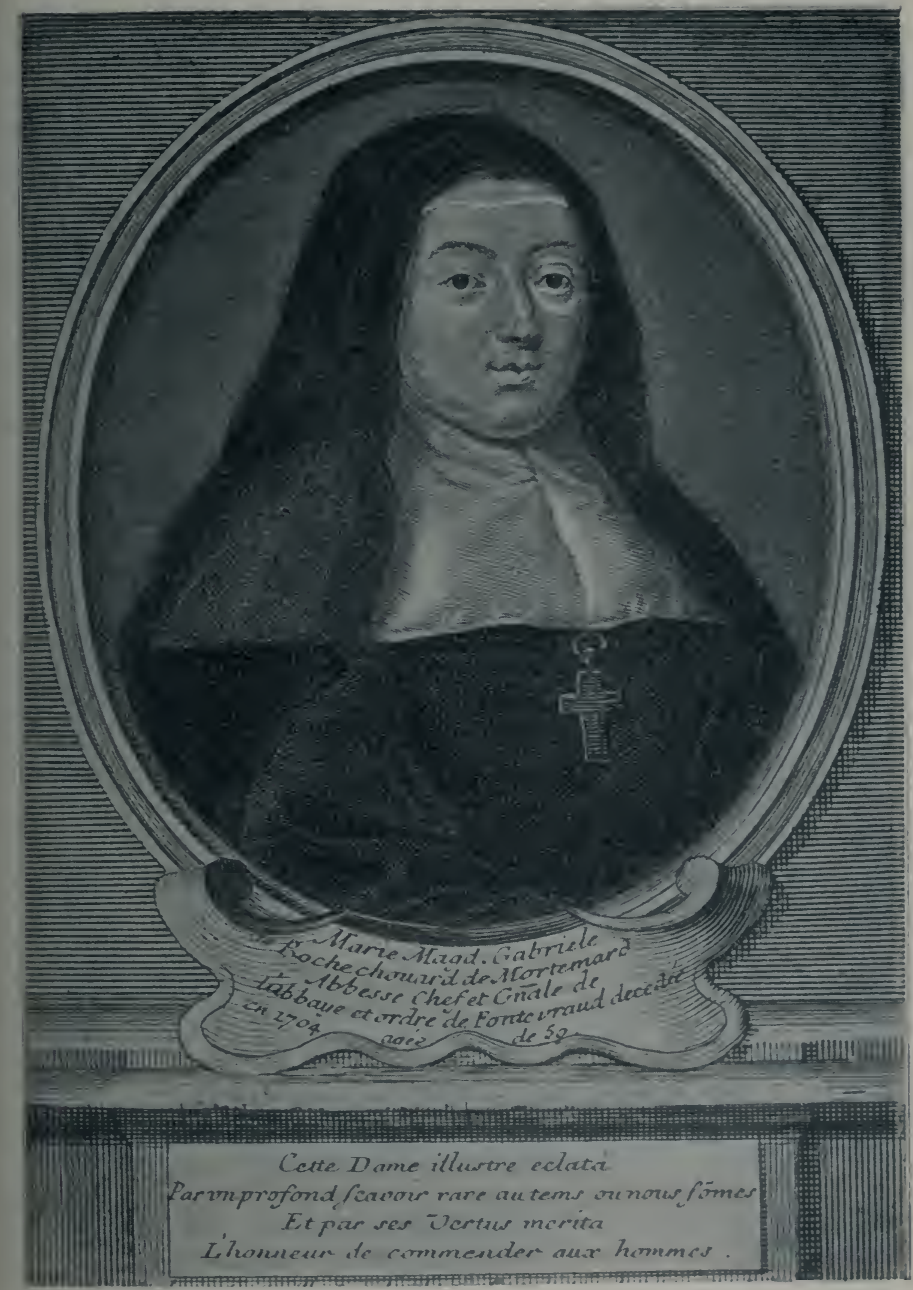





\section{ROLAND (MARIE-JEANNE)}

Madame Roland, demoiselle Philipon, est née à Paris en 17306 et y a été guillotinée le 8 novembre 1793.

L'Encyclopédie avait inspiré à Mad. Roland un vif amour des mathématiques, elle réussit en géométrie, mais l'algèbre la rebuta assez vite.

" J'envoyai par delà les ponts, dit-elle dans ses Mémoires, la multiplicité des fractions (sic) et je trouvai qu'il valait mieux lire de beaux vers que de me dessécher sur des radicaux. En vain, quelques années plus tard, M. Roland, me faisant la cour, tenta de rappeler cet ancien goût ; nous fimes beaucoup de chiffres; mais la raison par $x$ ne me parut jamais assez aimable pour me fixer longtemps. ”

Autres extraits des Mémoires publiés par le voyageur-naturaliste Bosc d'Antic :

“Durant deux mois, lisant Descartes et Malebranche, j'avais regardé mon chat quand il miaulait, comme une mécanique qui faisait son jeu; mais en détachant ainsi le sentiment de ses signes, il me sembloit que je disséquois le monde et je n'y voyois plus rien d'attachant; je trouvois bien plus doux de prêter à tout une âme, et j'aurois adopté celle de Spinosa plutôt que de m'en passer. Helvétius me fit du mal....."

"Je suivis un cours d'histoire naturelle et un cours de botanique, c'était l'unique et laborieuse récréation de mes occupations de secrétaire et de ménagère... jefis un herbier des plantes de la Picardie."

"L'anatomie nous convainc de l'immortalité de l'âme : en disséquant un corps, il est impossible de croire que ce soit là tout l'homme."

Le docteur Missa la gronde de relire, pendant une convalescence, La recherche de la vérité par Malebranche.

\section{ROMANES}

Une biographie du naturaliste J.-G. Romanes est en préparation. I $^{\mathrm{me}}$ J.-G. Romanes, Saint Aldates, Oxford, demande communication de celles des lettres de son mari qui ont un intérèt scientifique.

Revue scientifique (rose), du 7 juillet 189'. 


\section{RÖNSTRÖM (ANNA)}

Om läsningen of Euklides, andra bok; 1889.

Geometrien sůsom läroü $i$ folkskolan; 1893.

\section{ROOM (MRS)}

Elementary astronomy, with questions and problems of the globes. Lincoln, 186ə, in-12, 120 pp.

\section{DE ROQUE MONTROUSSE}

La philosophie et la géométrie n'étaient pas étrangères à cette femme distinguée du xur $^{\mathrm{e}}$ siècle, née à Carpentras.

\section{ROSALĖS DE ORDIGNY (ISABELLE)}

Cette espagnole a soutenu au $\mathrm{xvI}^{\mathrm{e}}$ siècle des thèses philosophiques, où elle commentait Jean Scot, en présence du pape Paul III et du sacré collège. Elle convertissait, dit-on, les juifs, par son éloquence.

\section{ROSSANDER-TSCHUDI (JENNY)}

Suédoise (1837-1887).

Om mathematik såsom undervisningsämne för fliclior; 186: .

Om malhematiken och dess studium vid vâra flicksiolor. Stokholm, 1871.

\section{ROSSÜSKAYA}

Mlle Rossüskaya, membre de la Société des naturalistes de Moscou, étudie l'embryologie des amphibies.

\section{ROUSSEAU}

Cette dame a publié en 188'́ un ouvrage remarquable sur la flore mycologique des environs de Bruxelles 


\section{ROYER (Clémence)}

Elle est presque un homme de génie.

E. Renan.

Clémence-Augustine Roỵer est née à Nantes, le 21 avril 1830, d'une famille légitimiste et religieuse, dont elle derait abandonner les croyances.

Elle a habité Lausanne où elle a débuté par un cours de logique pour les dames, pendant les deux hivers $18 \% 9$ et 1860. L'été suivant, l'importante question de l'Impòt étant mise au concours par le canton de Vaud, la petite demoiselle au chapeau de paille remonte à sa montagne pour étudier les économistes et elle partage le prix avec le fameux Proudhon.

Clémence Royer a accusé depuis sa forte personnalité, dans plusieurs directions. Savante universelle, vivante encyclopédie, elle s'est montrée presque simultanément philosophe, économiste, phỹsicienne et naturaliste. Peu disposée à se ranger dans les cadres consacrés, elle a des négations radicales, sans être ni socialiste ni positiviste. “ Je ne me laisserai jamais mettre en bouteille, je ferais sauter le bouchon $₫$, dit-elle.

Elle jouit peut-être en Amérique de plus de réputation qu'en France, où nous n'admettons pas au même degré la liberté des idées. De petite taille, avec son front large, $\mathbf{I}^{\text {me }}$ Royer laisse la complexité des choses agir sur l'esprit, mais elle applique ensuite une déduction rigoureuse. Elle attaque de vicilles opinions, retourne les hypothèses et en particulier celle de Laplace. Elle trouve qu'on n'a pas besoin de courage pour dire la vérité et qu'il ne faut pas abuser des mathématiques, dont la terminologie nouvelle l'effraie.

On a parlé à diverses reprises de Clémence Royer pour l'Institut, auquel elle ne songe guère, connaissant les préjugés. C'est certainement un cerveau puissant. Le corps est fatigué, mais la pensée reste libre et fière.

Au moment où nous mettons sous presse, on prépare un banfquet en l'honneur de $\mathrm{M}^{\mathrm{me}}$ Rover. 


$$
\begin{gathered}
-240- \\
\text { Biblographie } \\
\text { Euvres de } M^{\mathrm{mo}} \text { Clém. Royer. }
\end{gathered}
$$

Introduction à la philosophie. Leçon d'ouverture seule publiée ; 18399.

Conférence de la rue de la Paix. Les femmes dans l'antiquité. (Revue l'Illustration du 15 juin 1861.)

Théorie de l'impôt ou la dime sociale ; 1862, 2 vol. (Prix partagé avec Proudhon.)

Collaboration au Nouvel Économiste de Pascal Duprat.

Ce que doit être une église nationale dans une république.

Traduction de L'Origine des espèces de Darwin; 1862. (Avec une préface de la traductrice, qui a fait beaucoup de bruit.)

De l'étendue et de la formation des groupes nationaux.

Origine de l'homme et des sociétés; 1870, in-8 (où les théories de Lamarck sont reprises avant Darwin.)

Dans la Revue de philosophie positiviste : Lamarck et son système, 1869 ; Les ages préhistoriques, 1876 ; Le lac de Paris en géographie quaternaire, 1877 (explications géologiques fondées sur le déplacement des pôles géogr.); De la nature du beau, 1879 ; Attraction, d'après Newton.

Théorie de l'unité de la force et de la matière, 1873. (Congrès scientifique de Lyon.)

Zoroastre et sa doctrine, 1878. (L'auteur attaque la théorie des migrations d'Asie en Europe.)

Dans le Journal des économistes, nombreuses études de 1869 à 1879 .

Dans la Revue d'anthropologie : Le feu chez les peuplades primitives, 1876 ; Deux hypothèses de l'hérédité, 1877 ; A propos d’un lézard bipède.

Le bien et la loi morale, 1881. (A concouru pour le prix Jean Reynaud.)

De l'origine des mondes, contre l'hypothèse de Laplace, 1883. (Société pour l'avancement des sciences, Rouen.)

Les notions de force, de matière et d'esprit selon la science moderne, 1888.

Essai sur la justice et les inégalités sociales.

Collaboration au nouveau Dictionnaire d'économie politique et au Dictionnaire des sciences médicales.

Les jumeaux d'Aellas, 1864. (Roman philosophique.)

Recherches d'optique physiologique et de physique ; Bruxelles, 1892. 


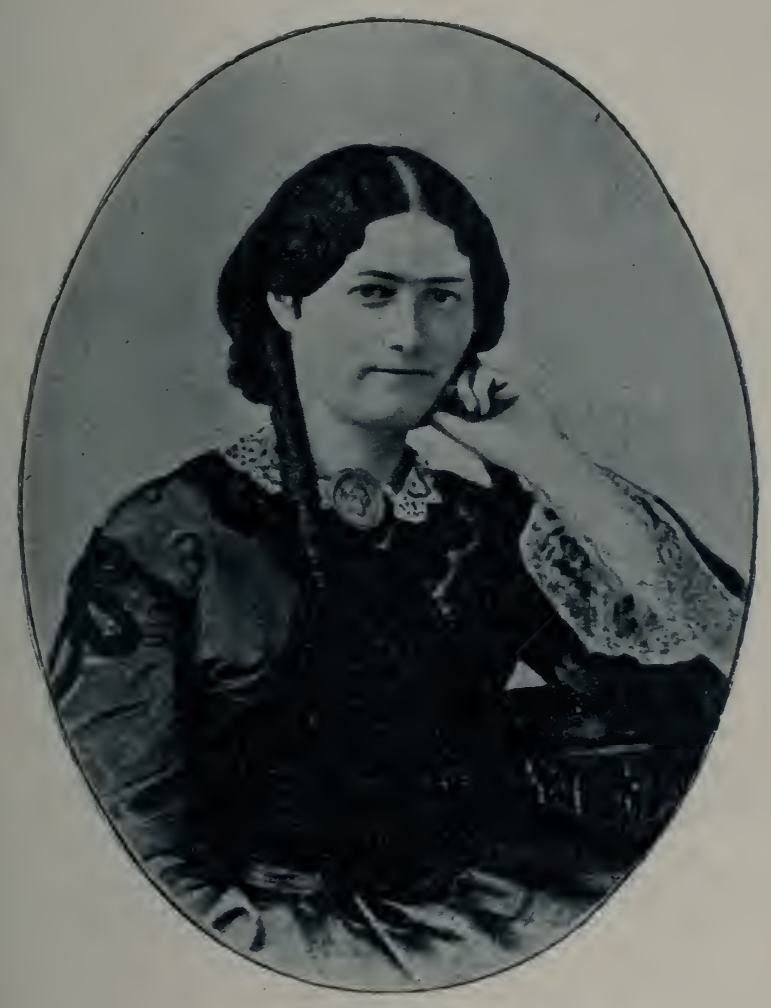

CLÉ.ENCE ROYER 

L'étoffe du monde, 1889, dans la Revue britannique. (Travail de haute valeur.)

La molécule de l'eau, 1889.

L'extinction des rentes perpétuelles, 1 ŏ décembre 189ّ̋. (Revue des Revues.)

La matière, 1895.

L'inconnaissable, 189 ว̈.

Discours au banquet des Bretons de Paris, 3 avril 1895 .

\section{RÜMKER}

Femme de l'ancien directeur de l'observatoire de Hambourg. Elle fut l'aide permanente de son mari et découvrit une comète le 11 octobre 1847 : plus d'un demi-siècle s'était écoulé depuis la dernière découverte par Caroline Herschel.

\section{SABINE}

$U^{\mathrm{me}}$ Sabine a étudié arec son mari, physicien, le magnétisme terrestre et fait des calculs pour lui. Elle a aussi traduit en anglais le Cosmos de de Humboldt.

\section{DE SABLÉ}

II ${ }^{\text {me }}$ de Sablé, moraliste étudiée par M. Cousin, s’intéresse à Socrate, à Épictète, etc. Elle a publié des Maximes.

Yoir la lettre de M. de la Brosse à cette dame sur la logique de Port-Royal.

\section{DE LA SABLIÈRE}

Une aimable femme qui préférait déjà les sciences à la rhétorique.

Madeleine-Henriette Hesselin, devenue Madame de La Sablì̀re (1636-169'1), aima et cultiva passionnément les sciences, protégea La Fontaine et fut attaquée par Boileau.

On croit que le caractère de la Scavante Ridicule a été fait pour une dame qui n'est plus et dont le mérite extraordinaire ne devait lui attirer que des louanges. Cette dame se plaisait aux heures de son loisir à entendre parler d'astronomie et de phṛ- 
sique et elle avait même une grande réputation pour ces sciences, de même que pour plusieurs autres que la beauté et la facilité de son esprit lui avaient rendues très familières. Il est encore vray qu'elle n'en faisait aucune ostentation et qu'on n'estimait guère moins en elle le soin de cacher ses dons, que l'avantage de les posséder..... L'autheur de la Satyre ayant mis dans un de ses ouvrages, il y a environ vingt ans, les deux vers qui suivent :

Que, l'astrolabe en main, une autre aille chercher

Si le soleil est fixe ou tourne sur son axe,

cette dame eut la bonté de lui dire que quand on se meslait de faire des satyres il fallait connaitre les matières dont on parloit, que ceux qui tiennent que le soleil est fixe et immuable, sont les mesmes qui soutiennent qu'il tourne sur son axe, et que ce ne sont point deux opinions différentes, comme il paraissait le dire dans ses vers. Elle ajouta qu'un astrolabe n'était d'aucune utilité pour découvrir si le soleil est fixe, ou s'il tourne sur son axe.

Perault. Apologie des femmes, 1684.

Perault aurait pu, à la suite des deux vers qu'il cite, ajouter ce troisième assez dròle:

Si Saturne à ses yeux peut faire un parallaxe.

Nous donnons plus loin un extrait de la satire sur les femmes où Boileau essaye encore dẹ ridiculiser Mad. de La Sablière.

Lire dans le journal Le Temps du 20 septembre 1891 un curieux article d'Anatole France.

"Pendant que M. de la Sablière, qui était aimáble, faisait de petits vers aux dames, sa femme se jela avec ardeur dans la philosophie et dans les sciences. Le vieux mathématicien Roberval lui donnait des leçons. Saint-Evremond était en correspondance avec elle. Bernier logeait chez elle. Bernier, qu'on nommait le joli philosophe, qui avait parcouru la Syrie, l'Égypte, l'Inde, la Perse, et servi de médecin à Aureng-Zeb, et qui, étant allé partout, revenu de tout, avait beaucoup à dire, étudiait sans cesse et ne croyait guère. Il fit pour $\mathrm{II}^{\mathrm{mo}}$ de la Sablière un abrégé du système de Gassendi, son maltre.

Et c'est un abrégé qui n'a pas moins de huit volumes.

La maison de $\mathbf{M}^{\mathrm{mo}}$ de la Sablière était l'hòtellerie des savants. Elle y recueillit même un géomètre, le jeune Sauveur, qui devint par la suite un des plus grands mathématiciens français. 


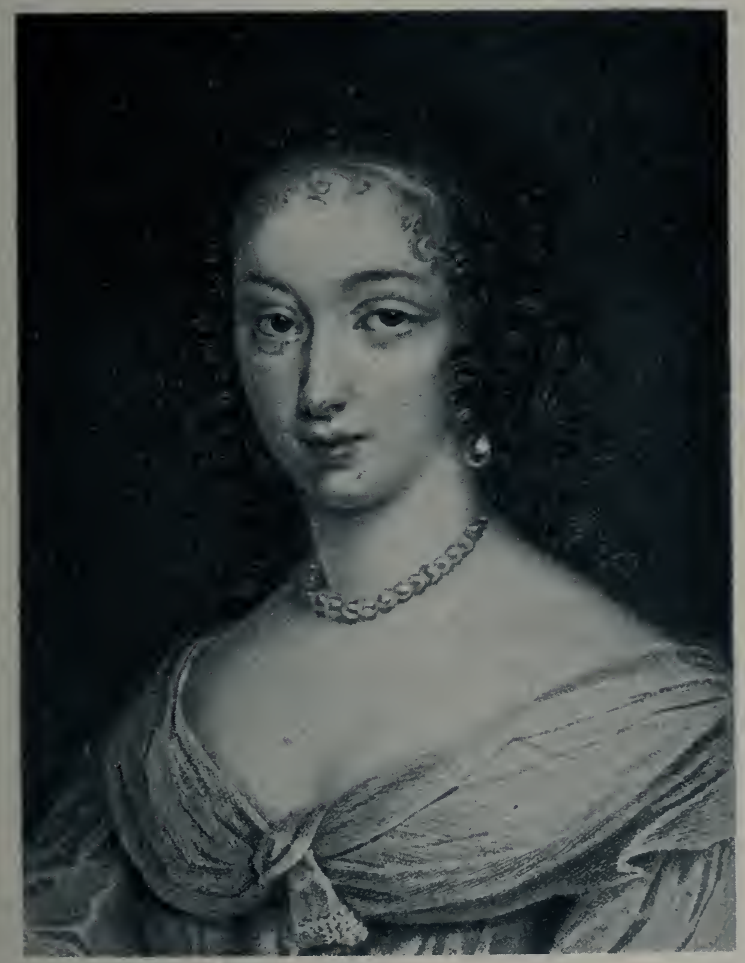

Mme DE LA SABLIERE 

Passant Armande en zèle pour les belles connaissances, elle allait le matin chez Dalancé faire des expériences au microscope et le soir assistait chez le médecin Verney à une dissection.

A trente ans, elle était illustre. Le roi Sobieski, de passage à P'aris, l'alla voir. Pour tout dire, c'était Vénus Uranie sur la terre. Encorc, elle s'était jetée dans la science avec une curiosité dévorante, et toute l'ardeur d'une âme qui ne quittait les choses qu'après les avoir épuisées. Point gracieuse, pédante moins encore, quoi qu'en ait pensé Boileau après qu'elle eut blessé son amour-propre de rimeur.

Boileau était un bon humaniste, d'un esprit judicieux, sans grande curiosité. Il s'enferma toute sa vie dans le cercle des belles-lettres et resta toujours étranger aux sciences physiques et naturelles. Aussi lui arrivait-il parfois d'employer dans ses vers des termes savants dont il ignorait le sens.

Quand $\mathrm{M}^{\mathrm{m}}$ de la Sablière lut les Épitres, elle s'arrêta, dans la cinquième, à ces vers :

Que, l'astrolabe en main, un autre aille chercher

Si le soleil est fixe ou tourne sur son axe,

Si Saturne à ses yeux peut faire un parallaxe...

Elle marqua de l'ongle cet endroit du livre et se moqua du poète qui parlait de l'astrolabe sans savoir ce que c'était, qui disait un parallaxe quand il fallait dire avec tous les savants une parallaxe et qui semblait enfin ne pas se faire une idée bien exacte du cours des planètes. Le régent du Parnasse, pris en faute comme un écolier et corrigé par une femme, en eut du dépit. Elle le jugeait trop ignorant; il la jugea trop savante et lui garda rancune. Son jugement était droit et son cœur honnête ; mais, cultivant la satire, il était vindicatif par profession. Méditant une poétique vengeance, il polit et repolit dans sa tête quelques vers destinés à prendre place dans sa satire des femmes. Je ne saurais dire au coin de quel bois, selon son usage, il en attrapa les rimes; contentons-nous d'affirmer que l'ombre du bonhomme Chrysale, lui tenant lieu de muse, en fournit l'inspiration. Le poète y désignait, sans la nommer

Cette savante,

Qu'estime Roberral et que Saureur fréquente.

Et, dans son envie de piquer la savante à l'endroit sensible, il s'avisa de dire que l'astronomie lui fatiguait les yeux et lui gâtait 
le teint. D'où vient, s'écriait-il dans un mouvement d'enthousiasme calculé,

D'où vient qu'elle a l'œil trouble et le teint si terni ?

C'est que, sur le calcul, dit-on, de Cassini, Un astrolabe en main, elle a, dans sa gouttière, A suivre Jupiter passé la nuit entière.

On voit que l'astrolabe lui tenait au cœur et qu'il était assez content de faire voir qu'il en connaissait enfin le véritable usage. On ne sait si le trait eût porté et si $\mathrm{M}^{\mathrm{m}} \mathrm{e}$ de la Sablière en eût été blessée. L'irréprochable Boileau, satisfait d'avoir pu se venger ne se vengea pas. Satis est potuisse videri. Il garda ses vers en manuscrit. "

La Fontaine dit dans la fable $\mathrm{I}$ du livre $\mathbf{X}$ (Discours à $M^{\text {mo }}$ de la Sablière) qu'elle a «'beauté d'homme avec grâce de femme ». Consulter aussi le Discours à Madame de la Sablière "Désormais que ma muse... »

V. D’Olnet. Histoire de l'A cadémie. - Fontenelle. Éloge de Sauveur. - Walkenaer. Vie de La Fontaine. - Mercure galant, 1678. - E. DE LERNE. Reines, etc.; 1867, in-8.

\section{DE SABRAN}

Le testament de Mignot de Montigny daté de Paris, le 13 mars 1782, contient cette clause :

"Ce que j’ai en histoire naturelle appartiendra à Madame la comtesse de Sabran. Je la prie d'envoyer à l'Académie des Sciences ceux de mes livres de physique, géométrie et astronomie qui ne lui conviendraient pas, ni pour son usage, ni pour celui de son fils. ")

\section{SADLER}

Créatrice de chaires de mathématiques. L'une de ces chaires Sadlériennes a été occupée par le célèbre Cayley, à Cambridge.

V. Fonsigut. Obituary.

\section{DE SAINT-CHAMOND (CLAIRE-MARIE)}

La marquise de Saint-Chamond, née à Paris, en 1731, est 
l'auteur d'un Éloge de René Descartes, 1760̈, in-8, avec des Notes critiques.

D’après Barbier (Dictionnaire des Anonymes), Mademoiselle Mazarelli est devenue la marquise de La Vieuville de SaintChamond.

\section{DE SAINT-QUENTIN}

Cette demoiselle, cartésienne, a çomposé un livre qui fit beaucoup de bruit Sur la possibilité de l'immortalité corporelle. Voici un quatrain de l'époque :

Qui cherche en tout la vérité, Qui raisonne si bien et des corps et des âmes, D'un commun jugement des hommes et des femmes Mérite l'immortalité.

\section{SALTON}

On ignorait en Angleterre l'art de fabriquer et de blanchir les toiles, lorsque Mrs Salton royagea chez les Flamands et les Hollandais pour découvrir leurs méthodes; elle sacrifia sa fortune dans ce but qu'elle atteignit. Morte le 12 septembre 15094 .

SAND (GEORGE)

Madame George Sand (180'4-1876), qu'on s'étonnera peutètre de voir citée ici, aimait la minéralogie et la botanique. Laura ; Jean de la Roche; Lettres d'un voyageur; Histoire de mavie, etc., etc.)

Elle a eu aussi des velléités philosophiques.

\section{SARA}

Une des filles de Pythagore.

\section{SAVORATA (DANIA)}

Auteur d'un livre sur les Femmes savantes scandinaves.

\section{SCARLATTI (MARIA)}

Trattato di Algebra ridotta in aritmetica, etc. Rome, 1781, Corso analitico d'Algebra ridotta in aritmetica, Rome, 1808. 


\section{SCARPELLINI (CATHERINE)}

" Catherine Scarpellini naquit à Folligno le 29 octobre 1808, et fut tenue sur les fonts baptismaux par son oncle, l'astronome Félicien Scarpellini, fondateur de l'Observatoire du Capitole, restaurateur de l'Académie des Lyncées et professeur aux deux universités de Rome. Ce patronage, pouvons-nous dire, la prédestinait à la science : dès ses plus jeunes années son amour des études sérieuses se révéla, et cette vocation ne fit que s'affirmer; rappelons brièvement ses principaux titres de gloire; elle organisa la station météorologico-ozonométrique du Capitole, appliquée à la prévision du temps, et en rédigea le Bulletin mensuel ; la Cor. respondance scientifique de Rome eut en elle un de ses plus actifs collaborateurs, et enfin, comme Caroline Herschel, comme $\mathrm{M}^{\mathrm{m}} \mathrm{R}$ Rümker, elle eut le bonheur de découvrir une comète dans la nuit du $1^{\text {or }}$ avril 1854. La grande question des étoiles filantes agitait vers cette époque le monde savant: on doit à $\mathrm{II}^{\mathrm{me}}$ Scarpellinile premier catalogue de ces météores observés en Italie, et elle fut la seule à observer à Rome la célèbre pluie d'étoiles de 1866. Elle a laissé en outre des études de valeur sur les influences probables de la Lune sur les tremblements de terre, études qui lui valurent des distinctions de la part de la Société des naturalistes de Moscou, de l'Institut géologique de Vienne, etc... Un grand nombre de sociétés savantes la nommèrent membre honoraire, et enfin en 1872 le gouvernement italien lui décerna la médaille d'or pour ses travaux statistiques. Nous pourrions ajouter que si tous ces témoignages attestent sa valeur scientifique, tous ceux qui l'ont connue nous la peignent comme réunissant ces dons particuliers à ceux qui font une bonne mère et une vraie femme, et ce n'est pas là le moindre des éloges qu'on puisse lui donner."

E. Lagranis. Les Femmes astronomes. (Ciel et Terre, du

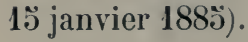

\section{SCAWINSKA (WANDA)}

Une polonaise, docteur ès sciences de Genève, collaboratrice de l'Année psychologique de Beaunis et Binet.

Comptes rendus de l'Ac. des Sc. du 17 aoùt 1896.

Anatomie générale: Sur la structure des cellules centrales 
nerveuses (Travaux du laboratoire de Roscoff et de la Sorbonne).

V. Lacaze-Duthiens. (Revue bleue du :j mars 189'1).

\section{SCHATUCK (LYDIA W.)}

Morte jeune, s'oceupait des fougères. C'était la méilleure botaniste de Mt Holyoke, U. S. A.

\section{SCHEPILOFF (CATHERINE)}

A communiqué, le 17 norembre 1892, à la Société de physique et d'histoire naturelle de Genève un filtre économique où l'eau est épurée par le permanganate de potasse et le charbon.

\section{SCHIFF (W.-J.)}

Professeur à l'école supérieure des femmes à Saint-Pétersbourg.

Sur les axes de symétrie des courbes centrales du $4^{e}$ ordre. (En russe.) 1891.

Méthodes pour résoudre des questions de gẻométrie élémentaire. (En russe.) 189'.

\section{SCHLOZER (DOROTHÉE)}

Allemande; docteur en philosophie en 1787 à Goettingue, Elle a épousé M. Rodde et a vécu de 1770 à 1820̈. - Quelques-uns la disent Suisse.

BéGx. Biographie de D. S. Metz, 18 '10.

\section{SCHUMOW-SIMANOVSKY (E.-O.)}

Cette dame a publié dans les Archives des Sciences biologrques (Saint-Pétersbourg; t. II, no 3 ) : Le suc stomacal et la pepsine che les chiens, ct aussi, dans le mème recueil (novemhre 1892), Recherches sur le streptoceccus pathogène. 


\section{DE SCHURMAN (ANNE-MARIE)}

Elle réunissait toute la science de son temps.

Une hollandaise qui a vécu de 1607 à 1678 . Elle est célèbre par ses connaissances étendues : latin, grec, langues orientales et modernes; broderie, peinture et gravure; rhétorique, philosophie et mathématiques. Jacquette Guillaume a écrit son Éloge; de même, L. Jacob en latin qui a été traduit, 16'16, in-8.

"Comme Gassendi passoit avec raison pour un des plus sçavans " hommes....., c'étoit la mode parmi les gens de lettres du " premier ordre de briguer son amitié et de lui faire part de leurs " ouvrages..... ce fut ce qui obligea l'illustre Anne-Marie "Schurman d'Utrecht de lui faire remettre un exemplaire de la " dissertation qu'elle avoit composée pour prouver qu'on ne " devoit point interdire l'étude aux femmes. Gassendi ne se con" tente pas de la remercier de son présent, il fait encore son " panégyrique dans la lettre qu'il lui écrivit; il nous apprend que " cette sçavante et admirable demoiselle surpassoit avec le pin" ceau et l'aiguille les plus habiles peintres et ouvriers; qu'outre " les langues vulgaires, elle sçavoit la latine, la grecque, l'hé" braïque, l'arabe; qu'elle avoit fait une étude singulière des " sciences divines et humaines; enfin qu'il n'y avoit rien de si " abstrait que la subtilité de son esprit ne pénétrát, rien que sa " langue n'exprimat éloquemment; aucun ouvrage fait à la main " qu'elle n'imitát avec une adresse merveilleuse; que c'étoit le " prodige de son siècle : il donne ensuite à son ouvrage les " louanges qu'il mérite, et finit par les témoignages les plus " sincères de son estime. La réponse qu'elle lui fit, ne démentit " point l'idée que Gassendi en donne. "

Le P. Bugerel. Vie de Gassendi, 1732, in-12, pì. 262-3.

\section{SCOT (CharLotTE-Angas)}

Née à Lincoln (Angleterre) le 8 juin 18388.

Une des plus fortes mathématiciemnes vivantes, docteur ìs sciences de Londres, professeur au Bryn Mawr College, Pensylvanie, U. S. A., depuis 1888. (Voir le portrait p. 2:37.) 


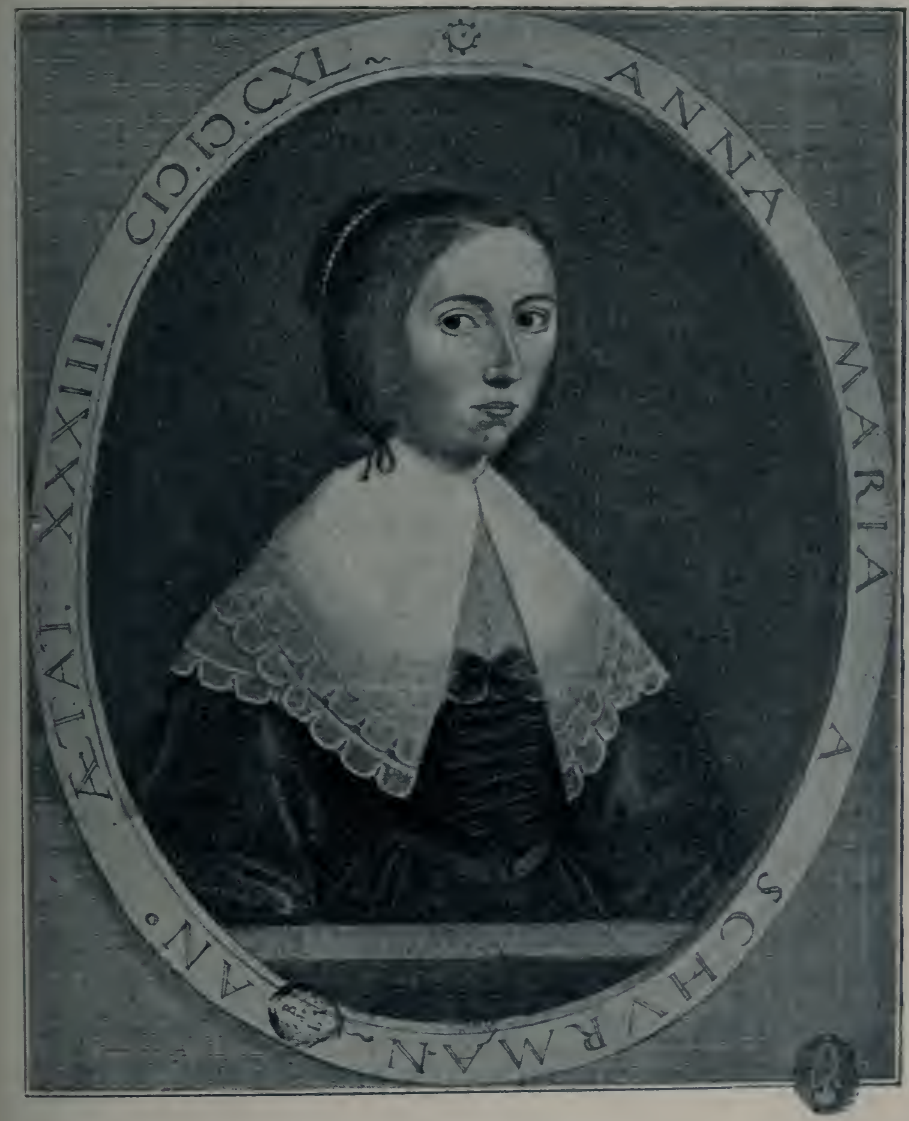

(jenitis sic picta nosties in imagine outhus:

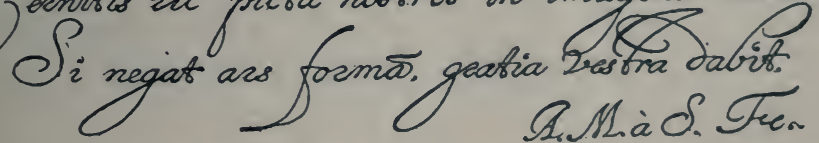





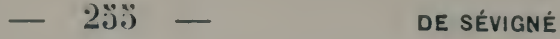

The binomial equation $x^{p}-1$; 1886, pp. 261-4 (Americ. journ. of math.).

On the numerical characteristic of a cubic curve; 1890.

On the higher singularities of plane algebraic curves, 1892, pp. 301-25 (idem).

The nature and effect of singularities of plane algebraic curves. 1893, pp. $221-43$ (idem;.

On plane cubics. 1894, pp. 247.77 (Royal soc., Philos. transact).

An introductury account of cerlain modern ideas and methods in plane geometry. New-York, 1894, in-8, pp. xiI, puis 288.

Arthur Cayley. New-York, 1895, pp. 190-5. (Americ. math. soc.)

Note on equianharmonic cubics. 1895, pp. 180-5. (Messenger of math.).

The three great problems of antiquity considered in the light of moder'n mathematical research. New-York, 1896, pp. 15ัi-6ł. (Americ. math. soc.).

Collaboratrice de Educational times, leçtrice, conférencière, etc.

\section{SECCA-SUARDO (PAULINE)}

Cette comtesse italienne a mérité par son goût pour l'histoire naturelle l'Invito a Lesbia Cidona que lui a adressé Mascheroni (17'46-1801).

Éloge, Bergame, 1839, in-4.

\section{SEIDOBINSKI}

Une russe qui a écrit sur les Intégrales d'Éuler.

$$
\text { SENGERIA (JUSTITIA) }
$$

Areugle. Théologienne.

Son livre sur Le psaume 599 de la passion du Christ a été imprimé à Hambourg en 15093.

\section{SERMENT (LOUISE-ANASTASIE)}

Grenoble, 16'12-1692; surnommée « la philosophe » par ses contemporains.

V. de Vigineul-Marville. Mélanges d'histoire, p. 1̋̈'t.

\section{DE SÉVIGNÉ}

Les lettres de ${ }^{1 \mathrm{~m}} \mathrm{c}$ de Sévigné nous montrent l'agitation produite par le cartésianisme dans les salons et parmi tous les beaux esprits. $M^{\mathrm{me}}$ de Sévigné se mèle peu de métaphysique, elle 
n'est pas cartésienne pour son propre compte, mais elle l'est un peu pour celui de sa fille, qu'elle veut pouvoir entretenir de tout. Elle n'a d'autre ambition que d'en savoir ce qui est nécessaire, non pas pour jouer, mais pour voir jouer. "Corbinelli et Lamousse parlent assez souvent de votre Père Descartes! Ils ont entrepris de me rendre capable d'entendre ce qu'ils disent, j'en suis ravie afin de n'être point comme une sotte bête quand ils vous tiendront ici. Je leur dis que je veux apprendre cetle science comme l'hombre, non pas pour jouer, mais pour voir jouer. " $M^{m o}$ de Grignan n'était pas seulement une spirituelle et charmante, mais encore une fort habile cartésienne, au témoignage de Corbinelli, qui dit qu'elle sait à miracle la philosophie de Descartes et en parle divinement. C'est Corbinelli, gentilhomme originaire d'Italie, ami et quelquefois secrétaire de $\mathrm{M}^{\text {mo }}$ de Sévigné, qui avait introduit dans sa maison et dans sa famille la philosophie nouvelle. Plein de vivacité, d'esprit et de verve, partout il défend Descartes de la parole et de la plume, mais $M^{\mathrm{m} e}$ de Sévigné et ses amis se plaignent qu'il n'achève et ne publie rien.

$M^{\text {me }}$ de Sévigné écrit donc à sa fille tout ce qu'elle a vu ou entendu autour d'elle qui puisse intéresser une cartésienne, sans toutefois s'abstenir de quelques légères plaisanteries sur son attachement filial pour Descartes, et sur certains dogmes cartésiens qui choquent son bon sens. Non seulement pour l'amour de sa fille, $\mathrm{M}^{\mathrm{me}}$ de Sévigné aime un peu Descartes, mais elle étend cette sympathie jusque sur les neveux et nièces du grand philosophe qu'elle rencontre dans le fond de la Bretagne : «Je ris quelquefois de l'amitié que j'ai pour N"le $^{11 \mathrm{D}}$ Descartes, je me tourne naturellement de son côté, j'ai toujours des affaires à elle, il me semble qu'elle vous est quelque chose du côté paternel de M. Descartes, et dès là, je tiens un petit morceau de ma fille. " Ailleurs elle raconte qu'elle a assisté à un diner de beaux esprits, "qui discoururent après dıner fort agréablement sur la philosophie de votre Père Descartes. Cela me divertissait et me faisait souvenir grossièrement de ma chère petite cartésienne que j'étais si aise d'entendre, quoique indigne. " Ses lettres sont parsemées d'al lusions badines ou ironiques aux doctrines de Descartes.

Boviluier. La Philosophie carlésienne.

“ Mme de Sévigné écrit parfois à sa fille " votre pìre Descartes, votre père Malebranche ». Sa correspondance est pleine d'allusions philosophiques. La table de ses a'urres 


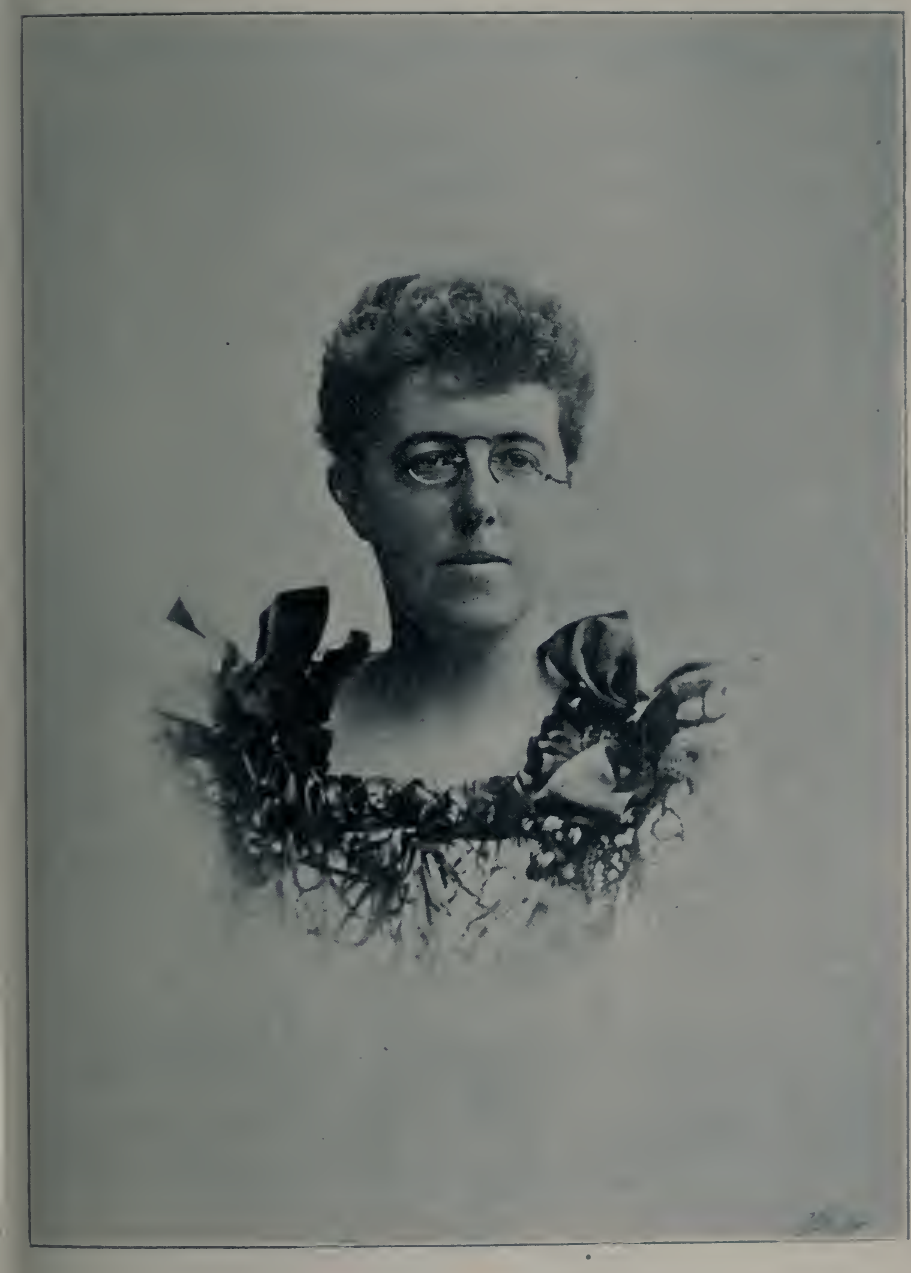

CIIARLOTTE ANGAS SCOT 

complètes (MovmerQué. Les grands écrivains de la France.) comprend au nom de Descartes une soixantaine de renvois.

Une amusante réflexion de la célèbre épistolière :

« Je ne jette jamais les yeux sur des pages d'algèbre, sans craindre de voir aussitòt apparaitre le diable. »)

V. Mme A. Conte. Éloge de $M^{\mathrm{me}}$ Sévigné, 18ł0, $32 \mathrm{pp}$. Portrait.

\section{SFORZA}

Auteur d'un traité philosophique Sur la vraie tranquillité de l'âme. Venise, 15’'t'.

\section{SIDWICK}

Mrs Sidwick, directrice du College Newnham, U. S. A., a travaillé avec Lord Rayleigh sur les unités électriques (Voir Conférences de W. Thompson, traduites par M. Brillouin). Elle a, au congrès de psychologie de Munich, du 4 au 7 août 1896, dirigé une enquête sur les hallucinations.

\section{SINARD (B.)}

Mademoiselle Sinard, à Avignon. Sur la présence du pentacrinus dans le myocène des Angles (Gard). (Association pour l'avancement des sciences. Congrès de Marseille, 1891.)

\section{SKORZEWSKA}

Consulter sur cette dame : J.-A. Grunent. La comtesse polonaise Skorzewska et les deux mathématiciens J.-H. Lambert et de Holland, sur le problème du cercle tangent à trois cercles donnés. (Arch. de math. et de phỵs. 1857, 35̈'1-359.)

\section{SLACK}

Mrs Slack a écrit sous le nom de George Fischer.

E. Cocker's Arithmetick, 43e édition corrigée par George Fischer. 172:, puis six éditions à la suite.

Arithmetic in the plainest and most concise method, etc. Londres, 10e édition, 17508, et 12e, 1768. 


\section{SMITH (E.-A.)}

Indiana. Mousses et fougères.

\section{SÖDERYJELM (FANNY)}

Licenciée ès sciences, née à Helsingfors, en 1866.

Ur den elementära matematikens historia. 1892, 26 pp.

Det hintorska elementel ' $i$ matematikundervisningen. 189', 3 pp.

Ett blad ur ekvationlärans. 189气, pp. I-xv.

\section{MARY SOMERVILLE}

Dans les mathématiques pures, Mrs Somerville est tout à fait supérieure.

A. DE Humboldt.

UNE FILLE D'AMIRAL. - L'amiral écossais Fairfax, prisonnier des Français, puis échangé, venait de reprendre la mer, lorsque sa fille Mary vint au monde, en 1780. Toute la jeunesse de l'enfant s'est écoulée à Burnisland. C'est un petit port tranquille, à l'opposé d'Édimbourg, les mœurs y étaient primitives, les huîtres y coûtaient un sou la douzaine.

Le père revenait de temps en temps : il soignait son jardin de tulipes et de roses; il réconfortait sa femme les soirs d'orage : “ Peg, prends ce grog, tu vas entendre rat-tat-too »; il disait que Dieu nous donne les aliments, mais que le diable envoie les cuisinières pour les préparer.

Mary Fairfax fait des collections, observe les astres et a un petit laboratoire dont l'unique cornue éclate. Elle porte un corset terrible, elle a un maître à danser et elle fait quatre heures de piano par jour. Ce qui vaut mieux, elle confectionne ses habits elle-même et elle apprend la cuisine chez un pàtissier.

Pendant une visite chez une amie de sa mère, elle voit à la 

fin d'un journal de modes une espèce de problème avec des $x$ et des $y$, entremèlés de petits traits diversement orientés; elle interroge et on lui répond : cela s'appelle de l'algèbre, ne m'en demandez pas plus long! D'autre part, son maitre de dessin ne cesse de lui répéter : “ Étudiez Euclide, base de la perspective, de la mécanique et de l'astronomic. » Le précepteur de ses frères lui procure enfin ce fameux Euclide et l'algèbre de Bonyeastle. Mary était sauvée, elle dévorait les deux livres, surtoutla nuit; on lui supprima la chandelle, elle lut travailler de tête. " $\mathrm{Peg}$, dit un jour le père, il faut couper court à ce travers, si nous ne voulons pas que Mary devienne folle, comme ce malheureux X... dont la longitude a troublé la cervelle. 》)

Heurecx mariage. - Mary Fairfax dut épouser un certain Greig, qui n'avait pas bonne opinion de l'intelligence des femmes. Le pauvre trousseau contenait un schal d'hiver qu'elle vendit pour acheter le portrait de son père l'amiral. Elle continua à étudier quand même, à Londres, dans une chambre mal ventilée. Elle nourrissait son second garçon, lorsque Greig mourut.

La veuve retourna en Écosse et le Journal de mathématiques de Wallace lui décerna bientòt un prix de problèmes. Nous avons des journaux qui proposent ainsi des questions à leurs abonnés et on remarque que des jeunes filles les résolrent souvent. Wallace conseilla à la lauréate d'acheter des traités français, c'est ce qu'elle fit et chacun la trouva de plus en plus ridicule; ces livres sont conservés au Collège de filles de Girton, à Cambridge.

Le second mariage de Mary avec son cousin Somerville, ancien médecin de marine, fut des plus heureux. Le nouveau mari encourageait, aidait et admirait sa femme. Il fut le modèle des préparateurs.

Madame Somerville avait toujours aimé les choses de la mer. Lorsque Parry partit pour les mers polaires, elle lui offrit plusieurs caisses de marmelade d'oranges de sa compo- 
sition. Le marin appela île Somerville une île glacée qu’il découvrit : Un bienfait n’est jamais perdu.

Vorageuns. - En bons anglais, les époux Somerville voyagèrent beaucoup sur le continent. Ils parcoururent plusieurs fois la France, l'Allemagne, la Suisse et l'Italie où ils finirent par se fixer.

Autobiographe. - Madame Somerville a laissé des mémoires, Personal recollections, qui ont été complétés et publiés par sa fille Martha. Ce livre, fort intéressant, est épuisé. La Revue britannique avait commencé, dans le temps, à en publier des extraits qu'elle a brusquement suspendus.

J'emprunterai aux Mémoires seulement deux anecdotes et les noms de quelques dames qui se sont occupées de science.

Laplace donna à dîner à Arcueil à M. et à Madame Somerville. En causant avec sa voisine, il lui déclara que deux femmes seulement avaient étudié sa Mécanique céleste. "Elles étaient, chose singulière, toutes deux écossaises; l'une s'appelait mistress Greig et l'autre, c'est vous, Madame. »)

Certaines dames de Paris s'occupaient alors de politique et la coterie légitimiste était très rebelle. On l'avait surnommér robes de résistance (en français, dans le texte).

Mrs Sabine a traduit le Cosmos; elle a fait aussi des calculs de magnétisme pour son mari.

Mrs Marcet est l'auteur de ces Conversations de chimie qui ont révélé le jeune Faraday à lui-même.

$\mathrm{M}^{\mathrm{me}}$ Biot a traduit de l'allemand un livre scientifique. La traduction a paru sous le nom de M. Biot.

Caroline Herschel a été l'aide de son frère William, le grand astronome; elle est morte centenaire.

Adda Byron, devenue Lady Lovelace, a déerit la machine à calcul de Babbage.

Mme Lavoisier a gravé les dessins du Traité de chimie et. après la mort de Lavoisier sur l'échafaud, clle a réuni plusieurs de ses mémoires et a écrit la préface de leur collection. 
Sur le tard, la veuve de Lavoisier a épousé Rumford; cette nouvelle union n'a pas été heureuse.

Mlle de Rigny a préparé seule à l'École polyttechnique son frère, l’amiral.

Nous nous bornerons là, quoique la liste soit plus longue. Du reste, nous parlons ailleurs de ces dames.

La mécanique céleste. - Au livre de Newton a succédé la Mécanique céleste de Laplace où, en einq volumes, les mourements de tous les astres sont minutieusement détaillés, en tenant compte des perturbations. On peut calculer ainsi, à l'aide de séries dont on prend les premiers termes, les positions des planètes et de la lune, plusieurs siècles à l'avance. Le marin sait alors se guider sûrement à travers les mers.

Lord Brougham, en homme pratique, eut l’idée de faire publier en anglais une réduction populaire du livre de Laplace et il s'adressa à Mme Somerville. Celle-ci répondit : “ J'estime que l'ouvrage n'est pas susceptible d'être vulgarisé, puisque le lecteur doit connaitre le calcul infinitésimal et qu’en outre Laplace ne donne aucune figure. Cependant, puisque vous et mon mari le désirez, j'essaierai quand même, à la condition que la chose restera secrète et que, si j’échoue, ce que je crains fort, mon manuscrit sera jeté au feu. ) Le Mechanism of heavens (mécanisme des cieux) a paru en 1831. Herschel déclare “ qu’il a lu avec admiration ce livre écrit pour la postérité et qu’il regrette que Laplace soit mort. ) La mécanique céleste de $\mathrm{I}^{\mathrm{me}}$ de Somerville devint vite classique el on nous assure qu'elle sert encore de text-book à Cambridge. Ce livre a son originalité propre, puisqu'il donne, en un seul tome, l'esprit des méthodes de Laplace, les calculs fondamentaux et les figures nécessaires.

Ce qu'une française avait fait pour Newton, une anglaise l'a fait à son tour pour Laplace. C'est là un échange de bons procédés.

Les sciences phrsiQues. - Mme Somerville ne s'est pas seu- 
lement occupée d'astronomie, elle a approfondi les sciences physiques.

L'Étude chimique et magnétique du soleil, d'après les raies du spectre nous a valu, à diverses dates, plusieurs mémoires, dans les Transactions philosophiques.

De la connexion des forces physiques est le titre d'un livre où Nme Somerville s'attache à montrer la liaison des différentes sciences physiques. Il a été traduit en français par $\mathrm{M}^{\mathrm{me}}$ Meulien, avec des notes d'Arago.

La Géographie physique a eu de nombreuses éditions, dont l'une à Calcutta. Quand le Cosmos parut, le premier mourement de $M^{\text {me }}$ Somerville fut de jeter son travail au feu, elle eut raison de se retenir. En effet, de Humboldt lui écrivit : « Le sentiment de précision que vos habitudes de géomètre vous ont si profondément imprimé pénètre tous vos travaux..... Vous dominez dans ces régions comme en météorologie et en magnétisme. "

C'est en 1869 que Mme Somerville a publié sa dernière cuvre Science moléculaire et microscopique.

Optimisue religieux. - Tous les livres de Mary Somerville sont empreints d'optimisme religieux. Une de ses épigraphes est.empruntée à Saint-Augustin : (Deus magnus in magnis, maximus in minimis. " Elle dit ailleurs que " par les sciences, l'homme s'élevant dans ce monde au-dessus des choses basses et périssables, se prépare à sa haute destinée dans l'autre. ” Ailleurs encore : "Rien ne m'a donné une preuve aussi convaincante de l'unité de la Divinité que les conceptions mathématiques, qui, n'ayant été accordées à l'homme que par degrés, ont existé de tout temps dans l'esprit omniscient du Créateur. »)

Cette chrétienne était d'une tolérance aimable; ce n'était pas une prédicante. "Je n’ai jamais pu, assure-t-elle, supporter un sermon un peu long. »)

Uxe centexarne. - Mme Somerville est morte à Naples, en 1879, à 92 ans. Cette quasi centenaire a travaillé sans 
fatigue jusqu’à sa dernière heure. On peut répéter pour elle le vers dı poète :

Rien ne trouble sa fin, c'est le soir d'un beau jour.

La savante a eu tous les honneurs. La reine d'Angleterre lui a fait une pension sur sa liste civile. Victor-Emmanuel lui a offert une grande médaille d'or. Elle faisait partie de la plupart des académies. De Humboldt a affirmé que « Dans les mathématiques pures, Ime Somerville est tout à fait supérieure. ») Un navire a porté son nom, mais il n'est pas revenu des mers de l'Inde.

In buste de Chantrey et un portrait de Surton nous représentent Mary Somerville. Elle est restée belle longtemps, avec un front un peu bas, mais large, et une physionomie régulière, calme et douce.

Il y a à Oxford un collège Somerville-Hall pour les jeunes filles. Il y a aussi à Londres un club Somerville; c'est un cercle original où les dames se réunissent seules, mangent et boivent, lisent et font des conférences, loin des gentlemen. Les Françaises ne seraient pas assez cruelles pour éloigner ainsi leurs serviteurs.

\section{Bibliographie.}

OEuvres de Mary Somerville.

On the magnetizing power of the more refrangible solar rays. 1826; Philos. Trans., pp. 132 à 139.

Mechanism of the heavens. Londres, 1832. Philadelphie, 1832.

On the connexion of the physical sciences. Londres, 1834, neuf éd. anglaises; New-York, 1846; trad. allemande par K.-F. Klöden, Berlin, 1835 ; trad. française par Mmo T. Meulien; Paris, 1838.

Expériences sur la transmission des rayons chimiques à travers différents milieux. 1836, Paris, Comptes rendus de l'Ac. des Sc.

$0 \mathrm{n}$ the actions of the rays of spectrum upon regetables juices. 1845้-6, Trans. Phil.

Physical geography. Londres, 1848, cinq éd. anglaises (Portr.); Philadelphie, 1818; quatre éd. américaines; une édition indienne, Benarès, 1853 .

On the molecular and microscopical science. Londres, 1863, 2 rol.

\section{Sources pour M. S.}

Personal recollections from early life to old age of Mary Somerville. With selection from her correspondance, by her daughter Martha 
SOMERVILLE

$-268-$

The parrat 4 sell as great aket as ecer of gour brathens he newes bels tum be avet sp teer

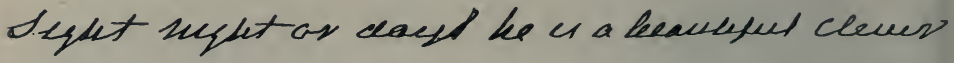
bind and insech aleased is kes juser an is sue bect the es nat ceng amserble 2 merthe asd hany, but they hawe bo suet bonely doy

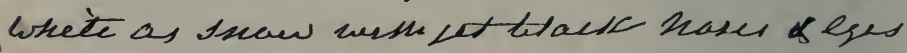
our old houre ceng is swle as dear a fillow

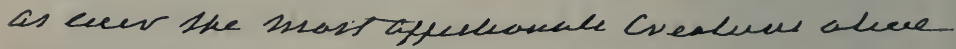
leet he daces nat conee up stans.

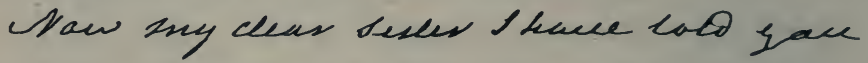
att ases leve newns, for ous bye es wang

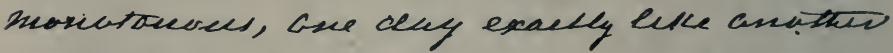
vared only by the newspaker, work and ang assursug. bovk we cass biers up - buth the.

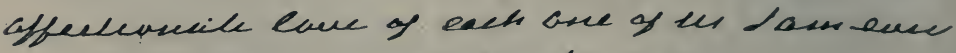

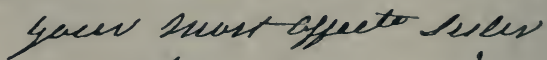

Mavy Soncervile

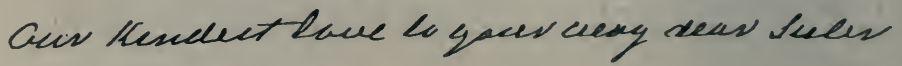
As werl as snisce 
Somerville. Londres, 1873 et 1883. (Portr. en buste, d'après le sculpteur Chantrey). Aussi une éd. américaine.

Astron. Soc. Month. 1873, pp. 190 à 7.

Notice nécrolog. Gotha, 1873.

Anonyme. Queens of litterature... Londres, 1887.

Irs Richemonds. The Wordl's women. New-York, 1894, in-8.

Alf. von Reumont. Histor. Taschenb. 1877 ; pp. 179 à 248.

Mrs H. Fawcett. Some eminent women... 189'; pp. 33 à 45 .

Daguin. Traité de physique. 1879; t. Iv, p. 35.

Mc Carthy. History of our times. t. II, pp. 376-7.

Journal des savants. 1832. Artic!e de Biot.

Portraits. - Buste par Chantrey. Portr. peint par Surinton que nous reproduisons. "Elle me parut dix ans plus jeune que son âge. Sa figure est agréable, son front un peu bas, mais large, son œil d'un bleu foncé. Ses traits sont fort réguliers et le buste de Chantrey donne l'idée d'une femme très belle. "(The atlantic monthly.)

Autographes. - Le colonel Ramsey-Fairfax, héritier de la famille, nous a gracieusement donné la lettre dont nous reproduisons un extrait. Le libraire Murray, de Londres, éditeur et ami de M. S., a dû conserver ses manuscrits.

\section{SOMERVILLE (MARTHA)}

Cette fille de Mary Somerville a publié les mémoires de sa célèbre mère, en les complétant.

\section{SOPHIES (LES DEUX)}

Sophie, électrice de Hanòvre (1630-1714) et sa fille SophieCharlotte, reine de Prusse et mère du grand Frédéric (16681705̈), ont été les correspondantes assidues de Leibniz.

La duchesse Sophie de Brunswick, très positive, comprenait peu la philosophie et accablait Leibniz d'objections, mais Sophie-Charlotte fut pour lui un disciple intelligent. La Théodicée a été composée pour cette reine de Prusse, qui épousa Frédéric Ier et fonda, en 1700, l'Académie des Sciences de Berlin.

V. Leibniz et les deux Sophies, par Foucher de CAreiL, in-8, 1876.

Revue des Deux-Mondes du $1^{\text {er }}$ novembre 1882, l'article de J. Bertrand sur Les deux Sophies. Dans la même Revue, ler mars mème année, un autre article de Mme Arvède Barine. 


\section{SOSIPATRA}

Femme philosophe du ve siècle, d'après Eunape. Elle avait épousé Eustathe, gouverneur de Cappadoce.

"Sosipatre et moi, n’arons-nous pas vaincu notre faiblesse et détruit le plus injuste préjugé? Ne sommes-nous pas comptées au rang des savants? N'avons-nous pas mérité ce titre? N'arons-nous pas des écoles, et la foule de nos disciples a-t-clle jamais dédaigné notre doctrine? Quelles Chaires sont plus suivies, quels Portiques plus fréquentés ?"

\section{STAEL}

Voici trois passages extraits de l'Allemagne de Madame de Stael :

" On a voulu tout démontrer, depuis que le goût des sciences exactes s'est emparé des esprits; et le calcul des probabilités permettant de soumettre l'incertain même à des règles, l'on s'est flatté de résoudre mathématiquement toutes les difficultés que présentaient les questions les plus délicates, et de faire ainsi régner l'algèbre sur l'univers. "

"Rien n'est moins applicable à la vie qu'un raisonnement mathématique. Une proposition, en fait de chiffres, est décidément fausse ou vraie ; sous tous les autres rapports, le vrai se mêle avec le faux, de telle manière, que souvent l'instinct peut seul nous décider entre des motifs divers, quelquefois aussi puissants d'un côté que de l'autre. L'étude des mathématiques, habituant à la certitude, irrite contre toutes les opinions opposées à la nôtre; tandis que ce qu'il y a de plus important pour la conduite de ce monde, c'est d'apprendre les autres, c'est-à-dire de concevoir tout ce qui les porte à penser et à sentir autrement que nous. Les mathématiques induisent à ne tenir compte que de ce qui est prouvé, tandis que les vérités primitives, celles que le sentiment et le génie saisissent, ne sont pas susceptibles de démonstration.

Enfin les mathématiques soumettant tout au calcul, inspirent trop de respect pour la force; et cette énergiẻ sublime qui ne compte pour rien les obstacles et se platt dans les sacrifices s'accorde difficilement avec le genre de raison que développent les combinaisons algébriques." 
"La politique est soumise au calcul, parce que s'appliquant toujours aux hommes réunis en masse, elle est fondée sur une combinaison générale, et par conséquent abstraite ; mais la morale ayant pour but la conservation particulière des droits et du bonheur de chaque homme, est nécessaire pour forcer la politique à respecter, dans ses combinaisons générales, le bonheur des individus. La morale doit diriger nos calculs; et nos calculs doivent diriger la politique."

\section{STEFANOSKA (MICHELINE)}

Polonaise, a étudié à Genève, élève de Vogt, docteur ès sciences naturelles, travaille maintenant à l'Institut Solvay, à Bruxelles.

La disposition histologique du pigment dans les yeux des artropodes, sous l'influence de la lumière directe et de l'obscurité complète (Recueil zoologique suisse, t. V, nº 2, 1890).

Traductions polonaises de plusieurs ouvrages de Flammarion et de Reclus.

\section{STEPHENS}

Une demoiselle Stephens avait imaginé contre la pierre un remède dont on vantait fort l'efficacité; le Parlement anglais en acheta le secret. Il ne s'agissait en réalité que d'un mélange de coquilles d'huitres et de savon d'Espagne. La nature a doté Vichy d'eaux minérales d'une composition analogue.

A. Macry. L'ancienne Académie des Sciences, p. 14.

Y. Histoire de l'Académie des Sciences. 1740-1 (Mémoires de Monand).

Cuftox. État de la médecine.... avec des expériences sur le remède de Mlle Stephens, faites par Hales et traduites par Cantwel. Paris, 1742, in-12.

Lagravge. OEuvres complèles, t. XIII, p. 196.

\section{SUCCA (MARIE DE)}

Naquità Liège en 1600. Excella dans la haute arithmétique et la musique. Finit par embrasser la vie religieuse. 


\section{SVALOW-RICHARDS (ELLEN)}

Américaine; chimiste et minéralogiste.

\section{SWETCHINE, NÉE SOYMONOF}

Née à Moscou (1782) cette grande dame passa de la communion grecque à la communion romaine :

“ Elle prit pour se rendre à Rome, le chemin le plus long, le plus difficile, le moins agréable, celui de l'érudition et du syllogisme. Ce fut à l'âge de trente-trois ans qu'elle se condamna pendant une retraite de six mois, à instruire le procès des églises grecque et latine, à compulser jour et nuit les infolios des docteurs, à feuilleter les actes des conciles, à confronter des dates, à examiner, à comparer, à vérifier des textes : marchant à pas comptés sur cette route embarrassée par les broussailles de la scolastique.... A la voir ainsi cloîtrée dans sa bibliothèque théologique, on dirait Descartes écrivant son Discours sur la méthode. ,

G. Merlet. Causeries sur les femmes et les liveres, p. 223.

Madame de Swetchine qui a essayé de concilier de Maistre et Lacordaire et qui " se plongeait dans la métaphysique comme dans un bain ", a vécu à Paris où elle est morte à 7 วั ans.

V. DE FAlloux. Madame Swetchine, sa vie et ses æuuvres, 1863, 2 vol. in-12. (Les œeuvres comprennent des lettres, des pensées, un écrit sur la vieillesse, etc.)

\section{TANNERY (PAUL)}

Le livre de M. Paul Tannery Pour l'histoire de la science hellène (1887) n'aurait pas paru, dit l'auteur, "si je n’avais été soutenu par l’appui dévoué, par les infatigables encouragements de celle qui est désormais la chère compagne de ma vie. Elle s'est sacrifiée à cette ouvre; c'est bien à elle que mon livre est dù, et je voudrais qu'il pût être plus complètement digne d'elle. " 


\section{TARNOWSKI}

s゙est occupée en Russie d’anthropologie criminelle.

\section{TAYLOR (JANET)}

Surnomméc la Somerville dı monde marin, cette dame, lont nous indiquons les principaux ouvragres, a méritć en 18:i!) uno pension de la Reine d'Angleterre.

Luni Solar and Horary Tables. London, 1833.

Lunar Tables, London, 1834.

Epitome of Navigation and nautical dstronomy. London, new edition, 1851 .

Diurnal Register for Barometer, Sympiesometer, Thermoneter and Ilygrometer, 2e édit., London, 1844.

Planispherium of the Fixed Stars, 1846.

Handbook of the Local Marine Board Examination.

liuide for the Use of Maury's Charts.

V. S. A. Alubox. Diction. of Engl. liter. London, $189 \%$.

\section{DE TENCIN}

Bornons-Hous à nommer cette manvaise mère qui a abanlonmé, à la porte d’une église, un fils nouvean-mé, qui devait levenir l'illustre d'Alembert. Le paure petit f'ut recueilli par une vitriere, Mme Rousseau, dont lo nom doit être retenu.

\section{TEUPKEN (WILHELMINE-FRÉDÉRIQUE-HENRIETTE}

Née en 186'r, actuaire de l’ "Alggemeene Maatschappij voor Levensverzedering ", assurance sur la vie, à Amsterdam.

I), Verwekeringen op, meer hoofden in de practijk. 1896. $8 \mathrm{pl})$

De invloed der selectie op de sterfteuitlomsten. $1896,6 \mathrm{pl}$.

\section{THÉANO}

Pythagore était déjà àgé lorsqu il épousa son disciple Théano, qui est devenue la plus célèbre des pythagoriciennes. Elle a, dit-on, beancoup écrit, mais ses ouvrages sont perdus. I la mort du grand philosophe, éest elle qui prit la direction de l'École. Raphä̈l l'a représentée dans son tableau l'École lithines. 


\section{THÈCLE (SAINTE)}

Dans son Banquet des Vierges, saint Méthoce dit que Thècle était fort versée dans la philosophie profane. Elle fut convertic au christianisme par saint Paul. On célèbre sa fète le 23 septembre.

\section{THÉMISTE}

De la secte d'Épicure. Cicéron, dans sa harangue contre Pison, dit : "Quoique vous soyez plus savant que Thémiste. ” Lactance vante aussi sa science.

\section{THÉODORA}

Péripatéticienne. Damascius lui a dédié sa Vie du philosophe Isidore, et Photius dit qu'clle s'était élevée jusqu'à l'arithmétique et la géométrie.

\section{THÉOPHILE}

Martial en parle dans une de ses épigrammes et dit que " le jardin de l'illustre vieillard d'Athènes (Épicure) et l'école stoïcienne se vantent également de l'avoir cue pour disciple ».

\section{THÉRÈSE (SAINTE)}

Espagnole, née à Avila (IB̈L:̈-82). Les papes l'ont appelée " docteur de l’Église », et Bossuet a qualifié sa doctrine de " céleste ". Sa psychologie est très fine, parfois subtile. Parmi ses écrits, nous citerons : P'ensées sur l'amour de llier et Le Château de l'àme.

Une traduction complète des weuvres de sainte Thérèse a été publiće par le P. Bonix, 1861, 3 vol. in-8. L'abbé Émery a écrit l'Esprit de sainte T'hérèse.

\section{THÉRÈSE DE BAVIÈRE}

Cette princesse, née en $18 \% 0$, a publié sous le nom de Théodore de Bayer, des ouvrages et des études de grécyraphie, de topographie et de géologie. Elle a été nommée membre honoraire de l'Acarlémie des ściences de Ilunich. 


\section{THOMPSON (ANNA)}

The unity of Fichte's doctrine of knowledye. Boston, Ginn and $\mathrm{C}^{\circ}, 18930,1$ vol. in-8, xx-213̈ pp. (n" 7 de la Collection des Radeliffe College Monography).

Compte rendu de G. Ronten, dans la Revue, de philosophie, d'avril 1896.

\section{THORNICROIT}

Le générateur de vapeur de du Temple a pris un nom anglais, parce que la sour d'un constructeur d'outre-Manche avait été admise à visiter les ateliers. On ne se méfiait pas du mécanicien en jupe. Elle comprit vite le sụstème et en fit le dessin de mémoire, à main levéc.

\section{TIKHOMIROV}

Ime 0. Tiкномпr. Sur l'histoire du développement de Chrysopa perla. (Congrès de Zoologie de Moscon: 1892.)

\section{TILLY STEVENSON}

Cette dame a fondé à Washington une Société d'anthropologie des femmes.

\section{TIMYCHA}

Lacédémonienne mise par Jamblique, dans sa Vie de P'ythagore, à la tête des quinze femmes qui furent pythagoriciennes. Il rapporte que Denỵs le Tyran voulant la soumettre à la torture pour' savoir les secrets de l'École, elle se coupa le bout de la langue avec les dents et le lui cracha au visage.

\section{DE TRACY}

Madame de Tracy est l'auteur du livre posthume Essais diver's, lettres et pensées, 18:2, 3 vol. in-12 (non mis dans le commerce). On y remarque une notice sur Destutt de Tratey, auteur de l'Idéologie, des études sur les l'ères de l'Éğlise l'auteur d'abord protestante s'était convertic all catholi('isme), un aperçu de la Flore du Bourhomais. ete. 
V. Cunllan-Fileury. Études historiques et littéraires. 183̈'1, 2 vol. in-18, t. I, p. 163.

\section{TRAUBE-MENGARINI}

IIme Traube-Mengarini a fait des recherches sur la perméabilité de la peau. Plusieurs expérimentateurs se sont occupés du mème sujet, soit en opérant sur la peau morte, soit en observant la pénétration dans la peau de quelques substances, pénétration que l'on provoquait en recourant aux frictions, aux bains, aux pulvérisations, et en cherchant dans les sécrétions les substances dont on avait fait usage. Mais les auteurs ne sont pas d'accord sur cette question. $\mathrm{I}^{\mathrm{me}}$ Traube-Mengarini a repris les expériences et pour éviter des modifications de la peau qui auraient altéré sa perméabilité, elle appliquait les substances sur la peau à l'aide d'un petit pinceau, trempé dans des solutions ayant la mèıne température que l'organisme. Les liquides qui servaient pour les expériences étaient des solutions de carmin boracique, de ferrocyanure de potassium, de la teinture d'iode. On appliquait ces solutions sur la peau du ventre du chien et sur les bouts des mamelles de cet animal. Les observations microscopiques ont permis de reconnattre que les solutions de carmin et de ferrocyanure traversent seulement la couche superficielle, la couche cornée, et qu'après elles s'opposent au passage de nouvelles quantités de solution. Au contraire l'iode, qui attaque la peau en se combinant avec les corps qu'elle contient, pénètre dans l'épiderme, et il est aisé, à cause de sa couleur, de suivre sa pénétration dans la peau.

Académie des Lincei, 1891.

IIme Traube-Mengarini décrit plusieurs expériences qui démontrent que la peau, immergée dans son milieu physiologique, est imperméable. Ayant exécuté des recherches en modifiant la composition du milieu liquide, et ayant vu que les protozoaires se comportent comme les métazoaires, Mme Traube-Mengarini arrive à la conclusion que la peau humaine doit obéir aux mèmes lois.

Mème académie, 1896.

\section{TREAT}

La Grande Encyclopédie cite de cette demoiselle: The Harvesting Ants of Florida, 1878. 


\section{TROTTER}

I été un disciple de Locke et une correspondante de Leibniz.

I. Loibniz et les deux Sophies, par Fouchen of C.unen, l. 10 '

\section{TROTULA}

On ne trouverait rien non plus d'hétérodoxe dans les écrits qui nous restent de Trotula (vers l'an 1059), femme médecin (magister Trota ou Trotula, comme s'exprime le Compendium salernitanum), issue de la noble famille de Roger. Toutes les pages sorties de sa main respirent le galénisme le plus irréprochable, aussi bien les chapitres qui nous ont été conservés dans le Codex salernitanus que l'abrégé de son ouvrage Sur les maladies des femmes, publié soit sous son nom, soit sous celui d'liros, médecin de l’impératrice Julie.

Grâce aux patientes investigations de M. Renzi, la personne de Trotula n'appartient plus à la légende, et son nom n'est plus un mythe. On sait maintenant qu'elle ne s'occupait pas seulement des maladies des femmes, mais encore de toutes les autres branches de l'art de guérir. Ainsi dans le Compendium salernitanum, il y a des chapitres empruntés à Trotula sur les maladies des yeux et des oreilles; sur les affections des gencives et des dents; sur le vomissement; sur les douleurs intestinales; sur les moyens de relacher ou de resserrer le ventre; enfin sur la pierre. - Dans le traité Des maladies des femmes que nous avons sous le nom de Trotula, et qui est un remaniement du traité original, je ne puis signaler ici que le conseil de prendre des bains de sable à l'ardeur du soleil, pour faire maigrir les femmes par l'excès de la transpiration; le chapitre sur le choix d'une nourrice, laquelle doit être fraiche, gracieuse, exempte de tout souci; enfin cet autre chapitre sur les soins à donner au nouveau-né, et dans lequel se trouve la recommandation encore trop suivie, de façonner par une sorte de pétrissage, la tête, le nez et les autres membres, qu'on doit strictement envelopper de langes. La dentition et l'apprentissage de la parole sont l'objet de sóins particuliers; il y a les petits hochets recouverts de sucre ou de miel pour adoucir les gencives, les images pour récréer la vue, le doux langage et les petites minauderies pour amuser l'enfant et lui donner une voix délicate. 
Trotula vivait à Salerne; cela est prouvé par les extraits du Compendium salernitanum, et par le traité Des maladies des femmes, oủ il n'est pas difticile de relever plusieurs passages qui prouvent qu'elle exerçait dans cette ville; elle y enseignait et pratiquait probablement vers 1039 ; c'est elle sans doute qu'Oderic Vital avait en vue lorsqu'il dit que liodolphe Mala-Corona ne trouva à Salerne, en 1050 , personne en état de disputer avec lui, sinon " une matrone fort savante " (Quamdam sapientem matronam). Le nom de Trotula, ou Trotta, ou Trocta, est assez fréquent à Salerne, au onzième et au douzième siècle ; c'est là encore un argument en faveur de l'année 105ั9, assignée par M. Renzi pour l'époque où florissait Trotula. Il n'est pas non plus hors de vraisemblance que Trotula ait été la femme de Jean Platearius, souche d'une illustre famille de médecins.

La médecine, histoire et doctrine, par Сн. Daremberg, pp. 139, 140 et 141.

\section{TSAVIÉTAIE VA}

Cette dame a pris part aux travaux du Congrès zoologinue de Moscou, en aont 18!) 2 .

\section{TSIKLINSKY}

Docteur ès sciences, attachée à l'Institut Pasteur.

La diphtérie, état actuel des connaissances bactériologiques. (Revue générale des sciences du 1 Ï̈ décombre 189:\%.)

\section{TUMARKIN (ANNA)}

Herder und Kant, Berner Studien zur philosophip und ilurer Geschichte.

" La lecture la plus attentive de cette étude sur Herder et Kant ne ferait deviner à personne que l'auteur de ce docte travail est une femme. Il en est ainsi pourtant, et cest bien une femmequi nous développe en une eentaine de pagesla lutte de lidéalisme transcendantal et de la théorio de l'évolution encore à l'état d'ébauche. A peine si l’on devinerait daus ce culte si déelaré pour Kant, daus eetenthousiasme froid pour la raison abstraite, daus cette condamnation perpétuclle du sentiment une défiance un peu voulue à l'égard de cette sensi- 
hilité dont le préjugé commun fait le lot ordinaire de la femme. )

J. S:cond. Revue philosophique de septembre 1896.

\section{TYNDALL}

Vous apprenons par Nature (Londres) que Mme Tyndall ayant l'intention de publier une biographie de son mari fait appel au public.

Adresse : Mme Tỵndall, à Hind Head House, à Haslemìre (Surrey).

\section{ULLIAC-TRÉMADEUR (SOPHIE)}

Vulgarisatrice scientificue.

Astronomie et météorologie, d'après Arago, Laplace et W. Herschel. 18't3-'t', in-8.

Le monde céleste. Bruxelles, 188', in-16.

Les jeunes naturalistes. Entretiens familiers sur les animaux, les végétaux et les minéraux.

Contes aux jeunes naturalistes sur les animaux domestiipues.

En plus des ouvrages moraux pour la jeunesse et Souvenirs d'une vicille femme, In-16.

\section{DE VAILLY}

Wlle de Vailly était une parente de Malebranche, chez laquelle se réunissaient les disciples du philosophe.

\section{VALLOT}

Annales de l'Observatoire du Puy-de-lôme, par M. et Madame J. Vallot, 1896.

\section{VALZ}

$M^{\text {me }}$ veuve Valz, par acte authentique. en date dn 17 juin 187'́, a fait don à l'Académie des Sciences d'une somme de dix mille francs, destince à la fondation d’un prix qui scra décerné tous les ans à des travaux sur l’astronomie. 


\section{de VAUX CLOTILDE)}

Inspiratrice de la vicillesse d'Auguste Comte, lors de son évolution religieuse (Religion de l'Humanité).

(Voir Testament d'Auguste Comte, où se trouve sa correspondance avec Mme de Vaux. - Voir aussi le livre allemand de Hugo Göring, intitulé : Sophie Germain et Clotilde de Vaux, leurs vies et leurs pensées.)

Mme de Vaux était la soeur de Maximilien Marie, auteur d'une Histoire des Mathématiques.

\section{VERNET}

Il faut lire, dans la biographie de Condorcet par Arago, le dévouement de cette amie du philosophe-mathématicien. Elle le cacha dans sa maison près de Saint-Sulpice. pentant les massacres de la Terreur.

\section{DE VERTILLAC (Comtesse)}

Le naturaliste et physicien Réaumur écrit à l’antiyuaire J.-F. Séguier :

a Mme la comtesse de Vertillac est bien fière de posséder un poisson pétrifié qu'elle doit à M. le marquis de Maffei, plus grand, mieux conservé et plus parfait en tout qu'aucun de ceux du Cabinet du Jardin du Roi et du mien. Elle s'en vante partout. Ne pourriez-vous point rabattre un peu de safierté?

" Si le hasard vous en procurait un pareil, je suis persuadé que vous me le sacrifieriez volontiers et. quoiqu'elle soit de ros amies comme elle est des miennes, que vous ne seriez pas fìché que je fusse en état de me venger de ses plaisanteries. "

Euràx: Noer. Une correspondance inédite de Réaumur. Rouen, broch. in-8, 1887.

\section{DE VIEUXBOURG}

- La maryuise de Vieuxbourg passait pour tris savante, ot Lister qui alla la visiter, quand il vint ì Paris, en 1698. en parle dans son roỵage. Son nom est encore cité dans une chanson satirique : 
A la scavante Vieuxbourg

Il ordonna pour lecture

De méditer chaque jour

In chapitre d'Épicure.

Les Femmes bibliographes de France, par Quextix BuLaIIIT; t. II. p. 422.

\section{VIGOUREUX (CLARISSE)}

Phalanstérienne militante, a fermé les yeux à Fourier et marié sa fille à Considérant.

V. Manane Comgiver. Victor Considérant.

\section{VINOT}

A aidé son père et donmé, en 1869). Le petit Astronome, in-18. 3e éd., 1872.

\section{DE VIRIEU (STÉPHANIE)}

Fille du comte de Virieu, député du Dauphiné aux États généraux de 1789.

" Nllle de Virieu était à la fois savante et artiste; elle causait mathématiques avec Ampère et étonnait Gérard par le srand style des compositions qu'elle jetait sur la toile, en écoutant la lecture de Platon. »

\section{WAEYWEL (AGNÈS)}

Traití ou considérations mathématiques et impartiales sur la démonstration de la quadruture du cercle de DAxiEa. W.arsWF.. La Haye, 1717, pp. x et 37, in-1. 2 pl.

\section{WALKER}

Astronome à l'Observatoire de Cambridge.

V. L'Astronomie, année 188̈̈, p. 232.

\section{WEINTRAUBEN (BARBARA)}

Allemande, auteur d'un manuel médical. 


\section{WELLS}

Deux nouvelles étoiles variables ont été découvertes par Miss Wells et une par Miss E. F. Leland (Ilarward College, U. S. A ; 189:̈).

\section{WELT (IDA)}

M. Friedel a présenté à l’Académie des sciences. le ỵ! octobre 189' laboratoire de chimie de l'Université de Genève : Sur les hydrocarlures saturés à radicaux amyliques actifs. Les pouvoirs rotatoires des termes de la sćrie sont déterminés et l'auteur annonce une publication plus étendue sur le sujet (рp. 7'43-7).

Dans C. R. du 12 novembre 189'1, 2 e note de Mlle Ida Welt: Sur l'acide amylacétique et quelques-uns de ses dérivés.

Doctenr is sciences phỵsiques en 189:3, avec une thèse sur les dérivés amỵliyues actifs.

\section{WENDSCHEID}

Cette demoiselle a été proclamée docteur en philosophie. à l’Université d'Heidelber'g (1893).

\section{WENTWORTH}

M"le F. G. Wentworth a publié dans The Astronomical Journal : $1^{\circ}$ Éphémérides de la conc̀te Swift (26 nov. 1892); 20 Sur la parallaxe de $\beta$ du Cygne (8 février 189)3).

\section{WHITNEY (MARY WATSON)}

A écrit une notice sur. Maria Mitchell qu’elle a remplacée. en 1893, comme Directrice de l'Observatoire de Vassar College.

En collaboration arec Caroline Furness. Observution de la comète Swift, 1896 (The astronomical Journal do Boston). 


\section{WIJTHOFF (GERTRUDE)}

Parmi les collahorateurs de la Revue semestrielle des pullications de mallématiques (Amsterdam), on trouve MIle Wijllioff.

Équations en coordonnées bipolaires du mouvement d'un point dans un plan sous l'influence de formes simples te forces. (Sujet de prix proposé par la Société.)

Nieuw Archiel' voor Wiskunde. 1893 (206-62).

Équations en coordonnées bipolaires et en coordomnées cllipticues. Cas de l'ellipse, de la lemniscate, des ovales de Paseal et de quelques autres trajectoires. Calcul du rayon de courbure en coordomnées bipolaires. Courbe tautochrone et courbe brachistochrone. Solution des problèmes 72, 73 et 7: de Tait et de Steele, Dynamics of a Particle.

Bulletin Darboux (octobre 1895).

\section{WILLARD (ChaRLotTe R.}

Astronome à l'Observatoire de Northfield, Minnesota, I. S.A.

\section{WINSTON (M.)}

Docteur de l'Université de Geettingue.

Eine Bemerking zur Theorie der hypergeometrischen Function. 189: (Mathem. Ann., pp. 15:9-60).

\section{WITTE (WILHELMINE), NÉE BÖTTCHER}

1777-18\%̆'t. Auteur de Cartes de la lune et de Sphères en relief des mondes.

\section{WITTENBACH}

Cette hollandaise, d'origine française, docteur de l'Eniversité de Marbourg, est l'auteur du Banquet de léentis.

\section{WOENA (ADÈLE)}

Nozioni elementari di sfera armillare e cosmografia. Modìne, 1867, in-8. 


\section{WOOD}

La Revue scientifque (rose), dans son numéro du 2 avril 1887, publie dans ses Inventions nouvelles un en trefilet commençant par ces mots : "Le Progrès industriel signale une substance nouvelle, la woodite, ainsi nommée à cause de son inventeur, M. Wood ». Or, cette substance n’a pas été inventéc par un M. Wood, mais par une IIme Wood. Il s'agit de l'emploi du caoutchouc pour protéger les navires et les vaisseaux de guerre contre les projectiles. La préparation rend le caoutchonc incombustible, imperméable à l'eau et peu altérable à l'air.

\section{WRONSKA (HOËNE)}

On signale dans le catalogue des auvres de lobseur Wronski :

10 Il se trouve aussi une copie de Mme Wronska intitulée : Instructions pour le Calculateur Universel, p.1 à 79 (complet). Dícembre 1823:

$2^{\circ}$ Ourrage entièrement inédit et achevé de la Mécanique céleste, 4 vol. in-4. Texte copié par $\|^{m e}$ Wronska;

$3^{\circ}$ Manuscrit secret des marées, texte écrit sous les yeux de Wronski par sa fille adoptive.

En outre, sans la participation de Wronski et aprìs sa mort :

Petit traitéde métaphysiqueélémentaire, traduit de Snell, par Mme IIö̈.x: Wrovskı, suivi de quelques considérations sur la philosophie absolur. Paris 1854, in-16.

Dédié à Mlle Veturie d'Espagne.

Sur le titre : "Ce petit traité est particulierement destiné aux femmes des classes élevées de la société, c'est-à-dire à celles qui, si elles en ont la tendance, peurent employer leurs loisirs a se dniner une haute culture intellectuelle. "

\section{WYCZOL-KOBSKA}

Thèse de philosophie en Suisse : La doctrine de Schopenhauer sur la liberté humaine.

Revue intern. de l'Enseignement, 1:i octobre 9:3.

\section{YVON-VILLARCEAU}

On lit en tète d’un des plus beiax mémoires de mathéma- 
tiques de M. Yron-Villarceau, membre de l'Académie des Siciences :

"Les formules sur lesquelles repose ina méthode ont été l'objet de plusieurs applications numériques, qui ont été exécutées par $1 l^{\mathrm{me}}$ Ivon-Villarceau, après qu'elle en avait elle-mème vérifié l'exactitude analỵtique; la plupart de nos confrères de France et de l'étranger ont pu apprécier le dévouement aux intérêts généraux, et à ceux de la science en 'particulier, dont elle n'a cessé de donner les preuves; ils comprendront le sentiment qui m'a dicté la préface placée en tête de ce mémoire. Il est utile d'augmenter la liste encore peu nombreuse des fernmes qui, par leur collaboration active et dévouée, ont contribué au progrès de la science. Aux noms de $\mathbf{M}^{\mathrm{m}}$ L Lepaute, de Caroline Herschel et de miss Mitchell, les astronomes ajouterunt celui de $M^{\mathrm{m}} \mathrm{O}$ Yvon-Villarceau. "

Voir l'Appendice de la Connaissance des Temps de 1877 : Cialcul des orbites des étoiles doubles.

La seule photographie de Mme Yron-Villarceau a été faite après sa mort et nous avons dû renoncer à la reproduire ici. 
$y$

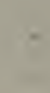




\section{NOTE I}

\section{SI LA FEMME}

\section{EST GAPABLE DE SCIENGE}

La raison du plus fort est toujours lit meilleure.

Belle tète, dit-il, mais de cervelle point.

Ce n'est rien, e'est une femme qui se noie.

Lis Foxtuse. 


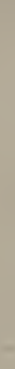

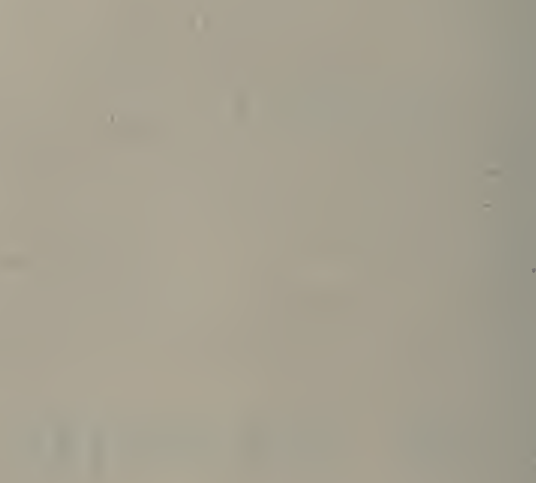

$=$ 
La femme est-elle capable de science? Les avis soni partagés. Molière, Boileau, Joseph de Maistre, Proudhon, Schopenhauer et beaucoup d'autres répondent énergiquement non. Les modérés distinguent et disent à la fois oui et non. Une minorité, qui va en croissant, réplique oui, avec Lalande, Michelet, Stuart Mill, Dupanloup, Anatole France, ete.

Il nous a paru piquant de réunir ici quelques spécimens des trois opinions, sans attacher d'importance à un débat théorique.

Bornons-nous à résumer les opinions extrêmes des anciens et des modernes.

Les adversaires argumentent ainsi :

$1^{\circ}$ Ce n'est plus une femme, c'est un homasse; elle néglige ses enfants et sa cuisine.

$2^{\circ}$ Ce n'est pas elle qui a travaillé, c'est lui, le souffleur dans la coulisse, le mari, l'ami, le professeur.

$3^{\circ}$ Elle n’a rien inventé, elle n’a pas de génie !

$4^{\circ}$ Quelle pédante ! mot terrible et décisif.

Voici les conclusions opposées :

$1^{\circ}$ Les femmes peuvent atteindre les plus hauts sommets de la science.

$2^{\circ}$ Elles le peuvent sans perdre les qualités de leur sexe.

$3^{\circ}$ Voyez le nombre croissant des femmes de sciences, dans toutes les directions !

$4^{\circ} \mathrm{La}$ science n'est pas exclusive, elle permet la culture des autres facultés.

$\check{\partial}^{\circ}$ Les études scientifiques se concilient avec les diverses religions, avec les diverses philosophies.

$6^{\circ}$ Nous avons assez de romancières. Pour l'œurre scientifique, jamais trop de travailleurs : là tout effort sérieux est 
utile. De quel droit barrer la route aux femmes ? Celles qui ne sont pas doućes seront vite découragées.

Écoutons maintenant les philosophes, les historiens les savants, etc., qui vont raisonner ou déraisonner sur la question.

Saint Justin (Apolog.) critique le mythe ancien qui avait fait sortir du cerveau de Jupiter, Ninerve, la déesse de la Sagesse et de la Science : " N'est-ce pas le comble dı ridicule d'avoir été prendre, pour en faire l'emblème de l'intelligence, la figure d'une femme? »

$$
\text { *** }
$$

A propos des femmes qui font de la médecine :

"C'est un sot animal qu'une femme qui se mesle de nostre mestier: cela n'appartient qu'ì ceux qui ont un haut de chausse et la teste bien faite.

..... Ce n'est pas à une femme de pratiquer la méthode de Gallien : Res est sublimioris intelligentio. Il faut avoir l'esprit plus fort. Mulier est animal dimidiati intellectus : il faut qu'elles filent leur quenouille, ou au moins, comme dit saint Paul, contineant se in silentio. "

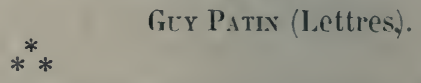

Quand je les vois (les femmes) attachées à la rhétorique, à la judiciaire, à la logique et semblables drogueries si vaines et inutiles à leurs besoins, j'entre en crainte....

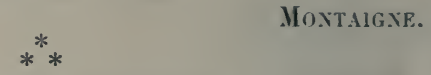

D'après Mad. de Maintenon, la connaissance des quatre règles était de luxe; une femme, même bien née, pouvait avouer sans: rougir qu'elle n'avait point " appris l'arithmétique ", qu’clle ne savait ni "faire un mémoire " ni " arrîter un compte ".

$$
*^{*} *
$$

Nulle science n'est pour elles trop profonde,

Et céans beaucoup plus qu'en aucun lieu du Monde.

Les secrets les plus hauts s'y laissent concevoir.

On y sait comme ront Lane, Etoile polaire,

Vénus, Saturne et Mars, dont je n'ai point affaire;

Et dans ce rain savoir, qu'on vil chereher si loin,

On ne sait comme vit mon Pot dont j'ai besoin. 
Vous deviez...

M'oster, pour faire bien, du grenier de céins,

Cette longue lunette à fitire peur aux frens,

Et cent brimborions dont l'aspect importune :

Ye point aller chercher ce qu'on fait dans la lune

Et vous mèler un peu de ce qu'on fait chez vous,

Où nous voyons aller tout sens-dessus-tlessous.

Il n'est pas bien honneste et pour beaucoup de causes

Qu'une femme étudie et sache tant de choses.

MoLì̀k. Les femmes savantes.

Dı mème Molière :

Et c'est assez pour elle, à vous bien parler,

De savoir prier Dieu, m'aimer, coudre et filer.

Prier Dieu, très bien; m’aimer, coudre et filer, quel egoïsme naif !

$$
\text { ** }
$$

Dien tire la femme de l'homme mème, et la forme d'une còte superflue qu'il lui avait mise exprès dans le cỏté... Les femmes r'ont qu'a se souvenir de leur origine, et, sans trop vanter leur délicatesse, songer, après tout, qu'elles viennent d'un os surnuméraire oì il n'y avait de heauté que celle que Dieu y voulut mettre.

Bossuet. Élévation sur les mystères (einquième semaine, leuxiène élévation).

$$
\text { *** }
$$

On a vu des femmes très savantes, comme il en fut de gnerrières, mais il n'y en eut jamais d'inventrices.

VOLTAiRe.

Issez rarement, soit; mais jamais, c'est trop dire.

$$
\text { *** }
$$

Pour l'ordinaire, les femmes sont incapables de pénétrer les vérités un peu difficiles à découvrir.

\section{MaLebraxche.}

$$
\text { ** }
$$

Pour les recherches laborieuses, pour la solidité du raisonnement, pour la force et la profondeur, il ne faut que dess hommes.

$$
\text { ** }
$$


Si elle (une belle dame, il y a vingt ans) m'avait dit, "qui m'empêche d'en savoir en astronomie autant que Newton? " je lui aurais répondu tout aussi sincèrement: "Rien dı tout, ma divine beauté. Prenez le télescope, les astres tiendront à grand honneur d'être lorgnés par vos beaux yeux, et ils s'empresseront de vous dire tous leurs secrets. "

"Dès qu'elle (la femme) reut émuler l'homme, ce n'est qu'un singe. "

"Le chef-d'œurre des femmes dans les sciences est de comprendre les hommes. "

“ On ne connaît presque pas de femme savante qui n'ait été malheureuse ou ridicule par la science. "

"La science en jupon. "

"On les appellerait donne barbute."

"Une coquette est bien plus facile à marier qu'une sarante. "

"Les femmes n'ont fait aucun chef-d'œurre dans aucun genre. Elles n'ont fait ni l'Illiade....., ni le livre des Principes.... Elles n'ont inventé ni l'algèbre, ni le télescope, ni les lunettes chromatiques, ni la pompe à feu, ni le métier à bas, etc., mais elles font quelque chose de plus grand que tout cela : c'est sur leurs genoux que se forme ce qu'il y a de plus excellent an monde : un homme et une femme."

Josepi de Maistre. (Lettres et opuscules inédits, t. I, passim.)

Dans ses lettres à sa tille Constance, de Maistre insiste sur ce qu'il appelle le taconnage des femmes, d'après un mot piémontais signifiant " ravaudage ".

$$
\text { ** }
$$

La'fluidité du sang et l'agilité des esprits animiques rendent les femmes incapables d'apporter une attention sérieuse à tout ce qui est un peu abstrait, et le dégoìt qu'elles sentent pour tout raisonnement suivi, proure la délicatesse de leur imagination, qui n'a pas la force de soutenir cet effort.

Du bel esprit; 169.3 ; Paris.

$$
* *
$$

11 faut abandonner les spéculations abstraites, les connaissances utiles mais sèches à l'esprit laborieux et solide de l'homme... Ainsi les femmes n'apprendront pas la géométrie.

$$
\text { Камт. }
$$

Elles l'apprennent un peu aujourd'hui et s'en portent mieux.

$$
*^{* * *}
$$


Dans l'éducation des femmes, il faut plus s'occuper du cour que de l'esprit. Il n'est pas nécessaire qu'elles soient savantes, qu'elles entendent Newton ou Leibniz, qu'elles péncitrent dans les profondeurs de la géométrie ou de la physique.... Que les femmes soient douces et fidiles, onctueuses (sic) et compatissantes; honnes mères, chastes épouses, qu'elles aient des eonnaissances ordinaires, quelques talents agréables, elles en sauront assez pour leur bonheur et pour le nôtre.

$$
\text { *** }
$$

Pétion.

La Rusox reut que les femmes n'apprennent point à lire aux astres : qu'elles comptent les œufs de la basse-cour, et non les étoiles du firmament.

La Russox veut que l'on interdise aux femmes la hotanique par principes; qu'elles se bornent à la connaissance des plantes potagères et de quelques simples.

La R.ısox n'approuve pas les femmes qui assistent aux leçons de la chimie : les cuisinières qui ne sarent pas lire sont celles qui font la meilleure soupe.

Projet d'une loi portant défense d'apprendre ì lire aux femmes par SrLtaix Mlaréchlal.

$$
\text { ** } *
$$

Les femmes n'ont rien inventé, pas même leur quenouille.

C'est Pamphila qui inventa le métier à filer la soie.

$$
\text { Procdilon. }
$$

PLiNe.

Elles n’ont pas mème inventé leur quenouille, s'éerie Proudhon qui sait sans doute qui a inventé la quenouille, mais qui par malheur est en désaccord ici avee toutes les traditions populaires, qui attrilucent a des femmes l'invention de filer et de tisser les étoffes.

E. L.aboulaye. Essai sur la condition des femmes, 1882, in-12.

Voici ec que dit encore le dédaigneux Proudhon :

"Pour mettre la femme au pair avec nous, il faudrait rendre en nous la force et lintelligence inutiles, arreter le progrès de la science, de l'industrie et du travail, empêcher l'humanité de développer virilement sa puissance, la mutiler dans son corps et đlans son âme, mentir a la destinée, refouler la nature, le tout pour la plus grande gloire de eette paure petite âme de femme, qui ne peut ni rivaliser avee son compagnon, ni le suive." 
Toujours du même Proudhon :

"Devant la nature et derant la justice, la femme ne pèse pas le tiers de l'homme."

C'est ainsi qu'on balance la femme.

$$
\text { ** } *
$$

Je n’ai jamais rencontré de femme qui füt en état de suive un raisonnement pendant un demi quart d'heure. Elles ont des qualités qui nous manquent, des qualités d'un charme particulier, inexprimable; mais, en fait de raison, de logique, de puissance de lier les idées, d'enchainer les principes et les connaissances et d'en apercevoir les rapports, la femme, même la plus supérieure, atteint rarement à la hauteur d'un homme de capacité médiocre.

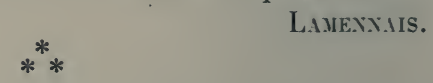

L'esprit féminin est primesautier. Il se plait aux idie's qu'on saisit vite, par une sorte d'intuition. Les méthodes lentes d'observation ou de calcul, par lesquelles on arrive surement à des rérités, ne penvent lui plaire. Les rérités elles-mêmes, abstraction faite de leur nature et de leurs conséquences possibles, sont peu de chose pour la plupart des femmes, surtout les vérités générales qui ne touchent i aucun individu en particulier. - Ajoutez une faible indépendance d'opinion, une faculté moins: intense que chez l'homme, et enfin l'horreur du doute par lequel toute recherche dans les sciences d'olservation doit commencer et sourent finir. En voici plus qu'il ne faut pour expliquer la position des femmes dans les affaires scientifiques.

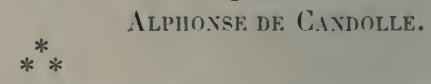

A plusieurs points de rne le caractire des hommes scientitiques est fortement anti-féminin. Ils s'occupent des faits et des théories abstraites, non des personnes et des intérêts humains.

\section{Fraxcis GaLtox.}

On dit : Un raisonnement de femme.

$$
* *
$$

"Il est remarquable que dans la longue liste des noms des inventeurs scientifiques, on ne rencontre pas un seul nom de femme. "

$\mathrm{D}^{\mathrm{r}} \mathrm{G}$. Gore. L'art de la découverte scientifique. Londres, 18is, p. 282 . 
Pas un seul nom! Votre liste n'est alors ni exacte ni complete. Qui veut trop prouver....

$$
\text { ** }
$$

Mathématiques, logique, dialectique, ne sont pas des ehoses féminines.

Lombroso. La femme criminelle.

$$
\text { ** }
$$

Ne sommes-nous pas menacés, à l'heure qu'il est, d'une invasion de bachelières parlant.... mathématiques, physique, philosophie, anatomic aussi bien que n'importe quel professeur de faculté? 0 Molière, lève-toi et fustige-moi tous ces bas hleus!

$$
*^{*} * \text { - }
$$

A (l'homme) et B (la femme) partent d'un point C, A avee une vitesse de 100, B avec une vitesse de 60 . Quand B rattraperat-il A? Solution : "Jamais! ”

Revue blanche; janvier 189:, p. 18.

StriNdBerg.

$A$ et $\mathbf{B}$ ne partent pas dı même point et n'ont pas de telles vitesses.

$$
*^{*} *
$$

Les femmes ne méditent guère. Elles se contentent d'en trevoir des idées sous la forme la plus flottante et la plus indécise. Rien ne s'accuse, rien ne se fixe dans les brumes dorées de leurs fantaisies. Ce ne sont qu'apparitions rapides, vagues figures, contours aussitòt effacés. On dirait qu'elles n'ont nul souci de la vérité des choses.

$$
\begin{aligned}
& \text { Daxiel Stenx (Comtesse d'Igoult). } \\
& *_{*}^{*}
\end{aligned}
$$

Les femmes sentent trop virement pour beaucoup raisonner el longtemps réfléchir.... L'étude des causes et des alsstractions les déconcerte et les ennuie.

C'est une remarque générale que les femmes sont d'autant plus instruites qu'elles ont des amis plus, savants.

\section{IsIDORE BOLRDON.}

Le mot de la fin est plus piquant qu'exact.

$$
\text { ** }
$$


La complexion de la femme lui défend tout ce qui exige une grande tension musculaire, aussi bien qu'une forte concentration intellectuelle. La nature ayant refusé à la femme cette double vigueur, elle ne pourra qu'exeeptionnellement atteindre les plus hauts sommets de la science.

La méditation lui répugne, et la poursuite désintéressée du Vrai, du Bien et du Beau n'est pas son fait. Elle manque d’idéal.

Généraliser, abstraire est impossible à la femme.

E. de Poniers.

Affirmez, affirmez sans preuve... il en restera toujours quelque chose.

$$
* *
$$

Les femmes savantes sont des exceptions, des espèces de monstres; - tout au moins des phénomènes, des êtres sans sexe, ni homme ni femme ou moitié homme et moitié femme, ad libitum.

\section{LÉox Rıcuer. La femme libre.}

De Goncourt a dit de son côté : "Il n'y a pas de femmes de génie; lorsqu'elles sont des génies elles sont des hommes. "

$$
*^{*} *
$$

Au cours, ces étudiantes sont un modèle d'attention ct d'application ; peut-être même s'appliquent-elles trop à porter à la maison, noir sur blane, ee qu'elles ont entendu... Seulement on peut remarquer ce fait que souvent elles ne jettent qu'un coup d'oxil superficiel sur les préparations que le professeur fait circuler. Quelquefois même, elles les passent au voisin sans les regarder: un examen plus prolongé les empêcherait de prendre leurs notes! Lors des examens, elles montrent les mêmes aptitudes que pendant les cours. Elles savent mieux que les étudiants; pour me servir d'une expression d'étudiant, elles ont énormément " bùché ", leur mémorisation est bonne, de sorte qu'elles savent parfaitement réciter la réponse à la quuestion qui vient d'être faite ; mais, généralenent, elies en restent lia. Une question indirecte leur fait perdre le fil. Dies que l'examinateur fait appel au raisonnement individuel, l'examen est fini, on ne lui répond plus. L'examinateur cherchera à rendre plus clair le sens de sit question, il lachera un mot se rattachant peut-itre à une partie du manuserit de l'étudiante, crac ! ça marche, c'est comme si nı 
avait pressé le bonton d'un phonographe. Si les examens consistaient uniquement en réponses écrites ou verbales sur des sujets qui ont été traités dans les cours, les étudiantes obtiendraient toujours de brillants suceis.

$$
*^{*} * \quad \text { C.ar Vogt. }
$$

- Ainsi, monsieur Maston, vous prétendez que jamais femme n'eut été capahle de faire progresser les sciences mathématiques ou expérimentales?

- $\Lambda$ mon extrême regret j'y suis obligé, répondit J.-T. Maston. Qu'il y ait en on qu'il y ait quelques remarquables mathématiriennes, et particulierement en Russie, j'en conviens tris volontiers. Mais étant donnée sa conformation cérébrale, il n'est pas de femme qui puisse devenir un Archinède et encore moins un Newton.

- Oh : Monsieur Maston, permettez-moi de protester au nom de notre sexe...

- Sexe d'autant plus charmant, mistress Scorbitt, qu'il n'est point fait pour s'adonner aux études transcendantes.

- Ainsi, selon vous, monsieur Maston, en voyant tomber une pomme, aucune femme n'eùt pu décourrir les lois de la gravitation universelle, ainsi que l'a fait l'illustre savant anglais à la tin du xirı sicele?

- En voyant tomber une pomme, mistress Scorbitt, une femme naurait pas eu d'autre idéc... que de la manger... à l'exemple de, notre mère Ėve.

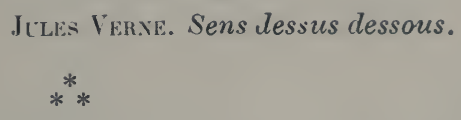

Jutis Ver.e. Sens dessus dessous.

$$
\text { ** }
$$

Une étude approfondic des lois scientificues ne parait pas d'accord avec la véritable vocation de la femme... Elle ne nous parait pas destinée à envisager les choses autrement qu'au point de vue 'sthétique, et, au besoin, à celui de l'utilité; les sciences proprement dites sont dn domaine de l'homme.

$$
\text { *** }
$$

WrGHGR.M.

La femme échappe à la logique, an raisonnement, ì la démonstration géométrique : rien de tout cela ne peut aroir de prise sur son petit cerveau. La femme est une impulsive, comme le sauvage. Eh! il n'y a pas de mal, car le plus sourent ses inpulsions sont bonnes; elles sont mème quelquefois sublimes. Là 
où commence le mal, c’est lorsqu'on veut la soumettre au régime intellectuel de l'homme et de l'homme supérieur... Alors on la détraque.

1) A.ial L.escher. (Jeanne Loiseau.) Névrosée.

cesos

En la philosophie, de la part qui sert à la vie, les femmes prendront les discours qui les dressent à juger de nos humeurs et conditions, à se défendre de nos trahisons, à régler la témérité de leurs propres désirs, à mesnager leur liberté, allonger les plaisirs de la vie, et à porter humainement l'inconstance d'un serviteur, la rudesse d'un mary, et l'importunité des ans et des rides, et choses semblables. Voilà, pour la pluspart, la part que je leur assignerois aux sciences.

Autres citations du même:

MoNtaliate.

"Et nous, et la théologie, ne requérons pas heaucoup de science aux femmes."

"La doctrine qui n'a pu leur arriver en l'àme, leur est demeurée en la langue."

"Madame, dit-il pourtant à Diane de Foix, e'est un grand ornement que la science et un util de merveilleux service. "

$$
*^{*} *
$$

Agrippa, dans son écrit L'excellence de la femme, assure au chapitre XVIII que les femmes savent toutes choses naturellement :

Quel est l'arithméticien assez tin pour tromper une femme par ses faux calculs, lorsqu'il lui paye ses dettes !...

Des femmes de la campagne ne surpassent-elles pas souvent, par leurs prédictions et leur's pressentiments, les philosophes et les mathématiciens? Lne femme de néant a souvent fait de plus belles cures que des mélecins célèbres.

(

$$
\text { *** }
$$

C'est la raison principale pour laquelle, si je ne me trompe, on exclut les femmes des sciences, parce que quand elles pourraient les acquérir, elles auraient trop de peine à les porter : de 
sorte que si on leur défend cette application, ce n'est pas tant, a mon avis, l'engager leur esprit à une entreprise trop haute, que dans celle d'exposer leur humilité à une entreprise trop dangereuse.

$$
\begin{gathered}
\text { Bossctet. Panégyrique de sainte Catherine. } \\
*^{*}
\end{gathered}
$$

Si vous arez une imagination raste, vive et agissante et une curiosité que rien ne puisse arrêter, il vaut mieux occuper ces dispositions aux sciences, que de hasarder qu'elles se tournent au profit des passions.

\section{FÉxตLก:}

$$
\text { *** }
$$

On regarde une femme savante comme on fait une belle arme ; elle est ciselée artistement, d'une polissure admirable et d'un travail fort recherché ; c'est une pièce de cabinet que l'on montre aux curieux, qui n'est pas d'usage, qui ne sert ni à la guerre ni à la chasse, non plus qu'un cheval de manège, quoique le mieux instruit du monde.

Mais à quelque cause que les hommes puissent devoir cette ignorance des femmes, ils sont heureux que les femmes qui les dominent par tant d'endroits, aient sur eux cet avantage de moins.

$$
\text { Li BruYère. }
$$

Lne femme peut aimer les sciences ; mais toutes les sciences ne lui conviennent pas, et l'entêtement de certaines sciences ne lui convient jamais, et est toujours faux.

L.i Rochefoccauld.

$$
\text { ** }
$$

L'ABbé de SAINT-Pierre désire qu'on apprenne aux jeunes filles " un peu d'astronomie, pour faire usage de l'almanach, pour savoir comment se font les éclipses, ce que ce peut être que les comètes, les impostures des diseurs et des diseuses de bonne aventure; un peu de connaissance de la machine du corps des animaux, de la nutrition et de l'économic de cette machine pour admirer la grande sagesse et la grande puissance de l'Être bienfinisant qui l'a composée ; quelque chose sur la cause de plusieurs effets naturels, comme de la pluie, de la grêle, de la neige, du 
tonnerre, des songes, des impostures des prétendus sorciers ou magiciens. "

$$
*^{*} *
$$

On peut enseigner aux élèves les plus âgées un peu de hotanique et leur faire un léger cours de physique et d'histoire naturelle, et encore tout cela peut-il avoir des inconvénients. Il faut se borner, en physique, à ce qui est nécessaire pour prévenir une crasse ignorance et une stupide superstition et s'en tenir aux faits, sans raisonnements qui tiennent, directement ou indirectement, aux causes premières.

Lettre de N.ıpóÉox an grand chancelier, à propos des écoles de la Légion d'honneur (13 mai 1809).

$$
\text { ** }
$$

Toutes les fois qu'il faudra agir arec la divination et arec l'instinct, les femmes seront supérieures aux hommes ; toutes les fois qu'il faudra agir arec le raisonnement, aree la science, les hommes auront sur elles une formidable supériorité..... Lne femme bien organisée, qu'une instruction malfaisante na pas encore dénaturée, possède tous les dons merveilleux des dormeurs lucides, tous les phénomènes intelligents des animaux privilégiés.

De la même:

$$
\text { MADAME E. DE GiR.IRINI. }
$$

L'homme ne demande pas à sa compagne de partager ses travaux, il lui demande de l'en distraire. La seience pour les femmes, e'est le luxe.... Elles sont un ornement, et la loi de tout ornement est de paraitre fin, léger, délicat et coquet.

$$
* *
$$

Lous Vivìs, Institution de la femme chrétienne, dit qu'on a tort de tenir les femmes savantes pour suspectes de mauraise conduite, parce qu'il y en a eu deux ou trois dont la ríputation n'était pas homne.

$$
\text { ** }
$$

La présence de quelques centaines de jeunes personnes dans les Iniversités de Suisse, d'Angleterre et des Etats-Lnis ne changera probablement pas ce qui existe.

Ces itudiantes apprennent volontiers; elles pourront enseigner ou appliquer leurs connaissances à la médecine, qui est 
leur étude favorite ; mais rien ne fait supposer qu'elles se voucront à l'avancement désintéressé des sciences et qu'elles y réussissent, du moins arec un certain degré de distinction.

Alphosse de Caxdolle.

\section{***}

Le zèle si pur, si désintéressé qu’ont tant d'hommes, pour lavancement de la Science, les femmes aussi sont suceptibles de le sentir ; et si, dans le dessein de se consacrer à l'éducation, elles s'étaient adonnées à l'étude des sciences naturelles, ce domaine jusqu'ici peu cultivé par elles, leur offrirait mille oceasions d'exercer leur sagacité. Il est plusieurs sciences d'un abord facile qui demandent à être enrichies de plus de faits, et le talent d'obsirration qu'ont beaucoup de femmes aurait là un emploi précieux. Dès lors, en travaillant à ce vaste édifice de la science qui s'élève avec les siècles pour la gloire de l'humanité, elles sentiraient la différence entre ces prétendues ressources auxquelles on se livre pour passer le temps et celles où l'on avance une œurre importante.

Madime Necker de Sausstre. L'éducation progressive. t. III, pp. 83-84. Voir aussi pp. 133-'́ et 372-7.

$$
\text { *** }
$$

Tous les observateurs s'accordent à dire que pour l'intelligence la femme a une véritable faculté d'intuition, c'est-à-dire cette vue rapide et exacte des faits. Elle voit mieux que l'homme ce qui est immédiatement derant elle. D'où résulte une aptitude spéciale dans l'appréciation des choses pratiques. A les prendre telles qu'elles sont aujourd'hui, les femmes paraissent inférieures à l'homme pour saisir les généralités, les principes et tout ce qui relève de la faculté spéculative. Mais il saute aux yeux quielles ont l'esprit plus vif et plus pénétrant.

$$
\text { *** }
$$

J'appelle esprit scientifique savoir suspendre son jugement jusqu'a ce qu'on ait vu des preures, et savoir chercher les faits avec une impartialité complète, sans se laisser détourner par des conséquences possibles. On nait ou on ne naît pas aver ces dispositions. On peut aussi les développer, mais ce n'est pas en restant passif. C'est par le travail, en mettant, comme on dit, " la main à la pâte. "Or, il se trouve que la moitié féminine et une grande 
proportion de la moitié masculine apportent en naissant des dispositions contraires.

Fraxids Gilltox.

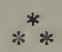

f)ans la philosophie, les sciences et les arts, nulle production digne du premier rang n’a été l'œurre d'une femme. Peut-on expliquer cette infériorité sans supposer que les fernmes sont naturellement incapables de produire ces chefs-d'œure?

Presque toutes les idées qu'on pouvait atteindre par la serule force des facultés natives sont depuis longtemps conquises, et l'originalité, dans le sens le plus élevé de ce mot, ne peut plus etre que le prix des intelligences qui ont subi une laboricuse préparation, et des esprits qui possèdent à fond les résultats olotenus par leurs devanciers.

Combien y a-t-il de femmes qui aient accompli cette tâche? Nladame Somerville seule connait peut-être tout ce qu'il faut savoir aujourd'hui en mathématiques pour y faire une décourerte considérable : dira-t-on qu'elle est une preuve de l'infériorité des femmes, si elle n'a pas le bonheur d'être une des deux ou trois personnes qui, pendant la durée de sa vie, associeront leur nom ì quelque progrès remarquable dans cette science?

Quand les femmes auront reçu la préparation dont tous les hommes ont besoin pour exceller arec originalité, il sera temps de juger par expérience si elles peuvent ou ne peuvent pas être originales?

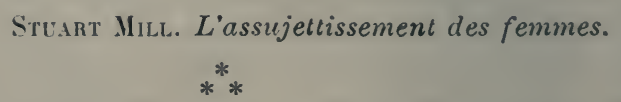

Que leur manque-t-il done (aux femmes), puisqu'elles possident, avec une intelligence égale à celle de l'homme, une scnsibilité plus délicate et plus vive? Lne seule chose, à notre avis du moins : l'attention dans le sens et au degré où Buffon l'égalait au génie, où Newton lui attribuait ses merveilleuses découvertes; l'attention forte, persévérante, capahle de découvrir entin l'unité vraie, l'ordre vrai sous la variété infinie des phénomènes à travers le voile épais des apparences trompeuses, lattention qui élève, surtont si le ceur l'accompagne, la raison à sa plus. haute puissance.

Cinnkir. De la pensée, p. 36it. 
II ne samrait etre question de laire pour les filles une science moins exacte, une science à leur usage, ad usum puellarum, mais seulement de leur rendre la science, la raie seience, plus accessible, plus assimilable, en la dégageant de tout ce qui n'est pas indispensable ì l'éducation de l'esprit.

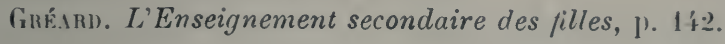

$$
\text { ** }
$$

Elle manque souvent d'esprit géométrique, mais elle a l'esprit de finesse. Elle ne sait pas découvrir ni démontrer méthodiquement la vérité, mais elle la devine et l'insinue.

$$
\text { ** Ilfred Croiset. }
$$

Elle (toujours la femme) s'assimile vite le concretet le détail, mais, comme les enfants, répugne à l'abstrait, généralise au hasard, ne pense que par cas particuliers. Quelques femmes pourtant ont excellé dans les mathématiques pures, preuve qu'aucune étude ne leur est nécessairement fermée.

\section{H. M.ırıx. Grande encyclopédie (article femme).}

$$
* * *
$$

La femme ne doit être ni médecin, ni architecte, ni général, ni chef de parti, mais elle le peut. Il est des hommes qui se font cuisiniers et tailleurs, tandis que de tout temps les hommes euxmêmes ont regardé la marmite et l'aiguille comme l'apanage de la femme; et cependant ces cuisiniers, ecs tailleurs conservent ou peuvent conserver les vertus de leur sexe. Pourquoi en serait-il autrement à l'égard de la femme?

Il y avait a Bologne une femme, Laure Bassi, professeur de philosophie et de physique, qui ne se rendait à ses cours qu'après avoir fait son ménage et soigné ses enfants.

Ine de C.IRLowitz.

$$
*^{*} *
$$

Chez certains insectes, comme les fourmis, les abeilles, etc., la supériorité de la femelle s'exerce aux dépens de sa sexualité. Il en est de même dans l'espèce humaine.

Poestion qui est arrivé à dresser les tableaux représentant la répartition des femınes savantes dans les écoles philosophiques de la Grèce, troure que, tandis qu'il y arait 39 élèves pour les écoles pythagoriciennes, il n'y en arait que 2 pour celles de So- 
crate, 5 pour Platon et 2 pour les écoles cyrénaï ques. En somme les 50 0/0 des femmes fréquentant les écoles pythagoriciennes prouvent que les femmes se laissaient attirer plutôt par les questions de sentiment que par celles de l'intelligence.

Comme propagatrices des grandes idées scientifiques ou sociales, les femmes sontsupérieures aux hommes. La marquise dı Châtelet a publié et vulgarisé les idées de Newton en France; Imc Clémence Royer en a fait de même pour Darwin; Ime de Stä̈l a fait connaître l'Allemagne à l'Europe; Sonia Kowalerski, tout en étant une grande mathématicienne, s'est appliquée à populariser les découvertes de Veierstrass, comme encore Mme Tarnowski a popularisé en Russie les données de l'anthropologic criminelle, etc.

J.ombroso. Le génie et le talent chez les femmes. (Revue des Revues d'aoùt 1893.)

$$
\text { *** }
$$

Je pense que les Sciences, loin d'être utiles aux f'emmes, leur nuiraient.... J'ai connu des physiciennes et des naturalistes; j’ai respecté leurs lumières, sans en être ébloui et sans en profiter.

Lezay Marnésia. Plun de lecture pour une femme, p. 9.

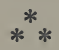

La femme peut donc, dans les idées complètement abstraites, s'élever par l'étude jusqu'à la raison qui comprend, rarement jusqu’a la raison qui crée. Aucune découverte mathématique, aucune théorie métaphysique n'est due à une femme. En Girèce, où les disciples féminins se pressaientsi ardemment autour des grandes écoles de philosophie; oì Pythagore rouptait tout un peuple de femmes parmi ses adeptes, pas un systeme philosophique n'est sorti de la tête d'une femme. Intelligentes comme interprètes, passionnées comme sectatrices, leur puissance s'arrêtait et s'est toujours arrêtíe là oì la críation commence.

LEgouvé. Histoire morale des femmes.

$$
\text { *** }
$$

La femme capable de donner de heaux enfants fait plus pour l'humanité que celle qui a subi les examens du bacealauréat is sciences. Avec la santé, c’est la moralité qui importe le plus à la 
race; l'intelligence et l'instruction, surtout seientifique, ne viennent qu’à la fin.

Alfifid Fotillée. L'Enseignement au point de vue national, p. 31 .

$$
\text { ** }
$$

Il y a deux ans qu'un matin deux dames entrèrent chez moi et exprimèrent le désir d’assister aux cours dans les écoles de Berlin. C'étaient des Américaines àgées de 20 ì 2 '́ ans... Je supposai qu'elles désiraient connaitre nos écoles supérieures de jeunes filles, et j'étais en train de leur noter le nom de quelques directeurs de pareilles écoles, quand elles me firent comprendre qu'il leur importait surtout de se rendre compte de l'enseignement des mathématiques et des langues anciennes dans les gymnases (lycées). Elles ne purent comprendre mon étonnement: étant elles-ınêmes professoresses en ces matiores, elles voulaient observer les méthodes allemandes dans les institutions mêmes. J'eus de la peine à les faire renoncer à leur projet. En disant : it is against our custom, je produisais quelqu'impression, mais passagère. Ce n'est qu'en observant que je ne répondais de rien si elles persistaient dans leur volonté; en leur demandant si elles voulaient risquer d'être reçues dans une classe de 50 joyeux secundans (élèves de seconde) arec une énorme hilarité, qu'elles y renoncèrent. - Quelques jours plus tard arriva un professeur américain d'école réale, à qui on accorda de bon gré l'assistance aux cours. Il me dit qu'on lui avait d'autant plus volontiers donné un congé d'un an, qu'il avait pu présenter une habile professoresse pour le remplacer. Le système américain a ses panégyristes en Angleterre, et même ses défenseurs en Allemagne; à ces derniers appartient le professeur Gneist à Berlin, qui dans une dissertation spéciale sur l'enseignement commun. a fait remarquer avec raison qu'on ne pourait parler de l'ouverture d'Universités pour les femmes, que si le systime d'instruction commune avait d'abord trouvé accès aux écoles savantes préparant aux études unirersitaires. Des Américains m'ont sourent répété, et mème Georges Bancroft : "Vous aurez tout cela; ce mouvement va de l'Ouest vers l'Est. „ En attendant, ecli nous produit encore l'impression d'une chose antiallemande, et de longtemps nous ne serons entrainés dans ce torrent de l'imitation américaine.

L. Wiese. Lettres sur l'éducation anglaise, t. II, p. 290. 
Estant le temps venu que les sévères lois des hommes n'empeschent plus les femmes de s'appliquer aux sciences et disciplines, il me semble que celles qui en ont la commodité doivent employer cette honneste liherté, que notre sexe a autrefois tant désirée, à icelles apprendre, et inontrer aux hommes te tort qu'ils nous faisoient en nous privant du bien et de l'honneur qui nous en pouroit venir.... Je prie les vertueuses dames d'eslever leurs espriti par dessus lours quenoilles et fuseaux..... Louse Labbé. (Lettre à Clémence de Bourges.)

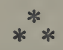

Je me merveille fort de l'opinion d'ancuns hommes, qui ne vouldroient point que leurs femmes, filles ou parentes, apprensissent sciences, et que leurs mœurs en empireroient.... Comme doneque est-il a penser que qui suit honnes leçons et doctrine, en doit empirer? Cette chose n'est à dire ni à soustenir.... N' N'stait pas de cette opinion Jehan Audry pour sa helle et honne fille qu'il tant aima, qui eut nom Novelle.... Et afin que la beanté d'icelle n'empechast la pensée des oyants, elle avait une petite courtine au devant d'elle.

Christine de Pisin. Le livre de la cité des dames.

$$
\text { ** }
$$

Encore que je sois l'ennemie déclarée de toutes les femmes qui font les savantes, je ne laisse pas... d'être souvent épourantée de voir tant de femmes de qualité avec une ignorance si grossière que, selon moi, elles déshonorent notre race.

$$
*^{*} \text { MIAD DE SCLDÉRY. }
$$

Jespere que vous ferez voir à vos frères que la seience peut être le partage des femmes comme des hommes... Je suis ravi de voir que vous savez patiner aussi bien qu'écrire... vous me permettrez cependant de préférer toujours les ouvrages de votre esprit à ceux de vos doights.

Le chancelier b'.lorkstent à sa fille.

$$
\text { ** }
$$

A l'égard des ourrages de grénie ot de sagarité, mille exemples nous prouvent que la faiblesse du corps n'y est pas un olstacle dans les hommes; pourquoi done une éducation plus solide et plus male ne mettrait-elle pas les femmes à portíe d'y réussir ? 
Descartes les jugeait plus propres que nous à la philosophie et une princesse malheureuse a été son plus illustre disciple.

$$
\text { *** }
$$

n'.'Lемiвект.

Coxdnikt (Mémoire sur l'éducation des femmes) dit que les femmes ne doir ent pas être exclues des professions scientifiques, parce quelles peuvent se rendre utiles à leur progrès, soit en faisant de's observations, soit en composant des livres. "Quant aux seiences, pourquoi leur seraient-elles interdites? Quand bien même elles ne pourraient contribuer à leur progrès par des décourertes (ce qui d'ailleurs ne peut être rrai que de ces découvertes du premier ordre qui exigent une longue méditation et une force de tête extraordinaire), pourquoi celles des femmes, dont la vie ne doit pas être remplie par l'exereice d'une profession lucrative, et ne peut l'ètre en entier par des occupations domestiques, ne travailleraient-elles pas utilement pour l'accroissement des lumières, en s'occupant de ces observations qui demandent une exactitude presque minutieuse, une grande patience, une vie sédentaire et réglée ?

$$
\text { *** }
$$

Poullain de la Barre, dans son livre De l'égalité des deux sexes (1635), dit que les femmes sont capables de mathématiques parce qu'elles aiment naturellement l'ordre et les proportions.

Le mème auteur original dit ailleurs :

Il n'est pas d'étude de raisonnement (la physique et la mathématique) qui ne demande moins d'esprit et de temps qu'il en faut pour apprendre le point et la tapisserie.

$$
* *
$$

Les véritables savantes sont fort rares, j'en conviens ; mais e'est un mal dont les hommes, par une secrète et vaine jalousie, sont la cause. Ils donnent aux femmes une espece d'lorreur pour le savoir. Que disent-ils d'une jeune savante, ou plutôt, que n'en disent-ils pas ? Je trouve qu'ils entendent bien mal leurs intérêts, et je crois aroir assez d'expérience pour décider que c'est à ce faux préjugé qu'on doit les plus grands maux des Républiques.

Continuation des Mémoires de Desmolets (t. V, p. 188).

$$
\text { ** }
$$


Quand les femmes ont du génie, je leur en crois l'empreinte. plus originale qu'en nous.

DIDEROT.

Je ne sais pour quelle destinée particulire il eut beaucoup de femmes pour disciples. La première de toutes qui s'aperçut hien vite qu'il avait quantité de façons de parler vicieuses, lui dit qu'en revanche de la philosophie qu'elle apprenait de lui, elle lui voulait apprendre le Français; il reconnaissait que sur re point il avait beaucoup profité avec elle. En général, il faisait cas de l'esprit des femmes même par rapport à la philosophie ; soit qu'il les trouvât plus dociles parce qu'elles n'étaient prévenes d'aucunes idées contraires, et qu'clles cherchaient à entendre et non à disputer ; soit qu'il fùt plus content de leur attachement pour ce qu'elles avaient une fois embrassé ; soit enfin que ce fond d'inclination qu'on a pour elles, agît en lui sans qu'il s'en aperçût, et les lui fît paraître pour philosophes, ce qui était la plus grande parure qu'elles puissent avoir à ses yeux.

Son commerce avec elles avait encore l'assaisonnement dı mystère ; car elles ne sont pas moins obligées à eacher les lumicres acquises de leur esprit, que les sentiments naturels de leur coeur, et leur plus grande science doit toujours être d'obserrer jusqu'au scrupule les hienséances extérieures de l'ignorance. Il ne nommait donc jamais celles qu'il instruisait, et il ne les voyait presque qu'avec les précautions usitées pour un sujet fort différent. Outre les femmes du monde, il avait gagné aussi des religieuses, encore plus dociles, plus appliquées, plus occupées de ce qui les touche. Enfin il se trouvait à la tête d'un petit empire inconnu, qui ne se soumettait qu'aux lumières, et qui n'obéissait qu'à des démonstrations.

Foxtexeluf. Eloge de Carré.

$$
* *
$$

Pourquoy (les femmes) ne seroient-clles pas aussi capables que nous de la contemplation et des sciences de la philosophic spéculative ? Leurs Ames sont-clles plus terrestres ot plus attichées à la matière que les nostres ? Sont-elles d'une trempe différente, ou d'une autre souree ? La Nature les a-t-clle charcesc: de quelque masse, les a-t-elle liées de quelque chaisne, yui les empesche de s'ólever? Sont-elles absolument incapalules de ces aisles que Platon a remarquées dans les Ames contemplatives ? Toutes choses done sont égales entre l es Hommes et le's Femme- 
Iu côté de l:Ime, qui est la partie intellignente, et qui fait les icanans et Ies Philosophes...

LE P. LenOrNe. Gallerie des femmes fortes, p. 't.3 ( $2^{\circ}$ partie).

Reconnaissons done que les femmes peuvent partager avee nous la possession des sciences. La Nature n'a pas eu le dessein de les en exclure, et les raisons mesmes qui sont alléguées contre leur droit, le confirment davantage et leur valent de noureaux titres. On scait aussi que depuis le temps des Muses, qui ont estí des Sçauantes érigées en Déesses, il n'a point esté de sièele qui n'ait eu un bon nombre de Femmes tries capables.

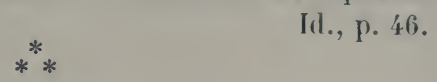

Les connaissances positives, l'instruetion exacte, l'étude approfondie des choses, convient aussi bien aux femmes qu'aux hommes.

$$
\text { ** Miss Engwortil. }
$$

Je crois qu'il ne manque aux femmes que les occasions de s'instruire et de prendre de l'émulation ; on en voit assez qui se distinguent, malgré les obstacles de l'éducation et du préjugé, pour croire qu'elles ont autant d'esprit que la plupart des hommes qui acquicrent de la célébrité dans les sciences.

Jérône L.alıxde. Astronomie des dames : préface.

$$
\text { ** }
$$

Admettons les femmes, comme on le faisait a Athines, dans les écoles de Rhétorique, de Philosophie, de Mathématiques et l'on verra parmi elles des femmes éloquentes, des philosophes iclairées, de profondes mathématiciennes.

Riballier. De l'éducation physique et morale des femmes, p. 90.

$$
* *
$$

Il faut longtemps oecuper l'esprit des jeunes filles de choses etrangères à leurs intérêts. Il faut obliger leur esprit à sortir de lat sphère des diseussions journalieres et des sujets constants de nos recommandations; l'étude de la nature morte, celle des lois éternelles de Dieu dans l'ordre intellectuel, sont les seules études qui exercent leur pensíe sans la troubler.... C'est là 
qu'elles apprendront à mettre du prix à la vérité, en oubliant elles-mêmes et les autres.

Mmo NeGker de Saussure. De l'éducation progressive, t. II, p. 333 et suiv.

$$
*^{*} *
$$

Thomas Buckee, auteur d'une Histoire de la civilisation, a fait à la Société royale de Londres, le 19 mars 1858, un discours célèbre : De l'influence des femmes sur les progrès de la science, reproduit dans l'édition des ouvres par Helen Taylor.

La femme a l'esprit déductif, or c'est la déduction qui fait et fera de plus en plus la science. L'homme est inductif, part des faits.....

$$
\text { ** }
$$

On a osé mettre en doute si les femmes sont capables d'une instruction complète dans les sciences les plus abstraites. Les uns ont soutenu que la faiblesse naturelle de leurs organes, P'inquiétude de leur caractère, la rariété de leurs sensations ne pouvaient permettre aux femmes cette attention constante qui peut seule réunir et comparer différentes idées; que leur impatience et leur propension au changement ne devaient pas leur permettre de suivre, durant l'espace de plusicurs années, le: même genre d'étude nécessaire pour acquérir des connaissances vastes et profondes; enfin que l'excès d'un travail uniforme, propre à accumuler les matériaux d'une grande érudition, devait amener facilement le dégoût chez les femmes.

Deseartes soutient le contraire, et malgré la rraisemblance des conjectures contre son opinion, l'expérience vient à son secours et nous démontre qu'en fait de sciences, les femmes sont capables de tous les ilans philosophiques dont les hommes se sont crus seuls susceptibles. Il suffit d'ouvrir l'histoire pour etre convaincu de cette proposition.

Nous avons en effet consulté l'histoire.

C.AThlixi.

$$
* *
$$

Ou la femme n'est pas faite pour ctre la compagne de l'homme. ou c'est une contradiction inique et absurde de lui interdire les connaissances qui lui permettent d'entrer en commerce spirituel avec celui dont elle doit partager la destinée, comprendre au moins les travaux, ressentir les luttes et les souffrances pour les soulager. Laissons-la done cultiver son esprit par toute sorte 
de belles connaissances et de nobles études, pourvu que soit inviolablement gardée la loi suprême de son sexe : la pudeur qui fait la grâce.

$$
\begin{aligned}
& \text { V. Cousin. Jacqueline Pascal, p. } 1 . \\
& *_{*}^{*}
\end{aligned}
$$

La femme portant dans la Philosophic et la Science sa finesse d'observation, son amour du concret, corrigera la tendance exagérée de l'homme à l'abstraction, et démontrera la fausseté des théories construites sur l'a priori, sur quelques faits seulement. C'est alors que disparaitra l'ontologie; que l'on reconnaîtra que l'hypothèse n'est qu'un point d'interrogation; que la vérité est toujours de nature intelligible, quelqu'inconnue qu'elle puisse être; on ne généralisera que des faits connus, et nous aurons ainsi une véritable philosophie, de vraies sciences humaines, parce qu'elles porteront l'empreinte des deux sexes. Jexiy D’Héricot'RT. La femme affranchie, t. II, p. 11 '

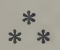

M. L.e Bon demande qu'on lui cite une seule femme qui ait réussi dans les sciences exigeant du raisonnement. Nous lui citerons Sophie Germain, Sophie Kowalevski et Narie Gaetana Ignesi, célèbre au xviri siècle par ses travaux mathématiques; - pour ne pas remonter anx temps des Diotime, Pamphila, Leontia, Pantaclea, Argia, Nicarette, Melissa, Ilypatie, etc., ni aux Italiennes, comme la philosophe Bassi, Isabelle Sforza, Claire Mastrami, ni aux femmes jurisconsultes de Bologne, Dotta, Bettina Buon Signori et Novella Audria.

A l'heure présente, c'est une femme de mérite, la doctoresse Catani, qui occupe à Bologne la chaire d'histologie.

A. FocilléE. Tempérament et caractère, p. 2't't.

$$
\text { *** }
$$

Peut-on parler de l'instruction supérieme en Amérique sans rappeler avec quelle ardeur les femmes s'empressent d'y participer? Le mouvement ne se ralentit pas, an contraire. Chaque jour voit augmenter le nombre de celles qui apprennent les mathématiques, la physique, le droit, la médecine, le latin ou mème le grec. Les programmes des études et des examens sont d'ailleurs identiques, en général, pour les deux sexes, soit dans 
le systeme de la coéducation, tris pratiqué, soit dans les cours spéciaux.

A vec le vif désir de s'instruire, les jeunes étudiantes apportent a cet enseignement élevé le ferme propos de conquérir l'égalití sociale, dont l'égalité scolaire est le prélude. Mais leur gràce native subsiste. Il s'y ajoute des qualités solides et un fonds de ronnaissances variées; anssi la conversation des femmes amériraines fait-elle le charme de la Société aux États-Lnis.

Jules Violle. L'exposition de Chicago et la science américaine.

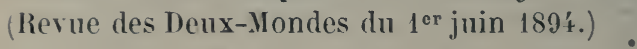

$$
*^{*} *
$$

Le collège d'Antioche (ville de l'ohio a donne un des résultats les plus étranges. Jusqualors on avait été persuadé qu'il y arait diversité d'esprit entre l'homme et la femme; que l'esprit de l'homme penchait plutôt vers les choses abstraites. L'expićrience acquise au Collège d'Antioche prouve que l'esprit n'a pas de sexe et qu'il n'y a pas d'études spéciales pour le jupon et pour l'habit. Si les femmes ont montré quelque part un peu plus d'aptitude que les hommes, c'est pour les études mathímatiques! Raisonnez après cela.

E. Labortuye. Horace Mann (Discours populaires).

$$
\text { *** }
$$

Les mathématiques sont du ressort de tous les sexes. Elles fortifient le jugement et le rectifient même jusqu'à un certain point; elles n'exigent aucune connaissance préliminaire; et elles devraient à ce titre être le commencement de l'éducation. Ce sont les mathématiques qui enseignent à calculer les richesses, ì mesurer les possessions et à tirer de l'argent le parti le plus avantageux. Le plaisir que l'on goùte en les cultivant fait nublier les maux et les chagrins; de toutes les sciences, elles seules ne demandent ni machines dispendieuses; ni grandes libliothèques.

Tous ces avantages réunis doirent intiresser les Dames en fareur des Mathématiques. Les fastes de cette science ont consacré à l'immortalité plusieurs d'entre elles qui les ont cultivées aree succès. L'Italic a vu dans ce siecle la sarante. I rnesi oceuper une chaire de Mathématiques. Paris a vu aussi avee étonnement $M^{\mathrm{mo}}$ Lepaute ealeuler le passage de V́mus sur le soleil et plusieurs volumes des Éphémérides. La lirillante réputation que s'acquit la marquise du Chatelet par son abrígé du svstime de 
Newton, dure encore. Il y a eu d'autres femmes qui ont étudie les Nathematiques aree suceis; mais je ne peux les nommer toutes dans cet abrígé. C'est assez d'aroir off'rt quelques exemples aux Dames courageuses qui roudront nous suive dans les détours du Calcul et de la lićométrie, sans itre rebutées par le petit nombre d'épines qui semblent en horder les arenues.

Bibliothèque universelle des Dames, 2't volumes, in-2't, chez Cuchet, rue et hotel serpente. - Commeneement du for vol. des mathématiques.

$$
\text { ** } *
$$

Les femmes aiment la philosophie, elles y réussissent; c'est-ìdire réussissent à la comprendre plutôt qu’i la juger. Eilles ont l'esprit plus subtil que nous. Tous les confesseurs (la théologir est de la philosophie) comprendront et approureront ce que je dis lì. Sainte Thérèse, Héloïse, madame Guygon, pour citer les plus glorieuses, sont des philosophes mystiques d'une grande et itrange habiletie.

J. Siмox. La femme au xix siècle.

$$
\text { ** }
$$

Il y a des hommes qui sont femmes par le coeur et la tète; des femmes qui sont hommes par la tête et le cœur; dans l'humanité, ils forment un huitième d'exception. Toute liberté et tout urnit leur sont reconnus.

Chaque membre du phalanstire suit sa rocation, obéit ì ses attractions, car les attractions sont proportionnelles aux destinées. Done le huitiime d'exceptions, dans les deux sexes, ayant attraction pour des travaux qui sont plus spécialement du ressort du sexe différent, est parfaitement libre de s'y livrer.

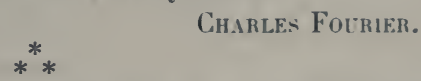

On fait naitre et on propage la futilité des femmes par rette rrainte de faire des savantes, de trop développer leur intelligence...

N'ohlige-t-on pas la femme qui a des goùts sérieux à les cacher ou à les faire excuser par tous les moyens qu'elle pourrait employer, s'il s'agissait d'une faute.

$$
\text { ** Depanlotr. }
$$

Si une fenme a la vocation de la science, de quel droit lui reprocherons-nous d'aroir suivi sa voie? Comment blâmer cette 
noble et douce Sophie Germain qui, aux soins du ménage et de la famille, préféra les méditations silencieuses de l'algèbre et de la métaphysique? La science ne peut-elle aroir, comme la religion, ses vierges et ses diaconesses? S'il est peu raisonnable de vouloir instruire toutes les femmes, l'est-il davantage de vouloir interdire à toutes les hautes spéculations de la pensée?

Axatole France. Le jardin d'Épicure, pp. 192-193.

$$
*^{*} *
$$

On sait aujourd'hui que la femme est capable d'exceller non seulement en littérature, en philosophie et dans l'art de gouverner les nations, mais dans les sciences naturelles et même dans les sciences exactes, mathématiques supérieures et astronomie.

Aug. Glandon. Deux femmes célèbres. (Bihliothèque universelle, mai 1894.)

$$
\text { ** }
$$

Voyez-les tous, acharnés à tuer, par le ridicule, l'essor encore incertain et timide de la pensée féminine.

$$
\begin{gathered}
\text { SÉNERINe. (Le Journal du } 15 \text { aoùt 1896.) } \\
*^{*} *
\end{gathered}
$$

Les mathématiques entrent également dans le bagage scientifique dont il faut munir de bonne heure la jeune fille; plus tard elle se trouvera tout arméc pour conquérir le vrai savoir, les hantes études.

IIme Edgar Quixet. Le vrai dans l'éducation, p. 5'ł.

$$
\text { ** }
$$

Il y a ígalité entre les sexes pour le développenent cérébral; on pourrait même soutenir, fait en rapport avec ce que l'anatomie comparée indique counme constituant le véritable progrès morphologique cérćbral, que la femme est plus avancée en évolutions que l'homme.

P. Topmaki Revue d'anthropologie du 13 juillet 1882).

$$
* *
$$

Pour déterminer la valeur intellecturle d'un cerveau, il faut tenir compte non seulement de sa grandeur, mais tout autant sinon plus, de sa texture intime, et de la delicatesse de chacune 
de ses parties. Il ne répugne donc pas de supposer que, sous ce rapport, le cerveau féminin l'emporte sur le cerveau masculin, autant qu'il est primé par lui en volume, et cela concorde avec. la finesse, la délicatesse plus grande du corps féminin.

$$
\text { ** } *
$$

Lours Bucuser.

Voir, a propos des deux citations précédentes, l'opinion du Dr Maneurrier, l'anthropologiste connu, sur la supériorité intellectuclle de la femme. (Issociation française pour l'avancement des sciences, 1882.)

$$
*^{*} *
$$

En supposant une capacité égale dans les deux sexes, il est plus ítonnant de trouver une femme savante que cent hommes savants, vu la différence de l'éducation.

f. Walsh. Discours sur les femmes, p. 119.

\section{***}

Ce n'est point arec les sciences que l'on risquera jamais de faire des pédantes ; an contraire, e'est par une instruction scientifique sérieuse et approfondie, qu'on arrivera à former des fernmes simples et modestes, car ces femmes sauront comprendre que ce qu'elles savent n'est rien en comparaison de re qu'elles ignorent.

$$
\text { * Mme J. Desparmet-Ruello. }
$$

Les sciences conviennent à merveille à l'esprit féminin et les sciences abstraites toutes les premières.

N'est-ce point un vrai chagrin de penser à tout le profit qu'a fait perdre à la science cet interdit jeté sur la moitié des forces intellectuelles de l'humanité.

Pall DupuY.

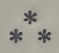

Pour développer chez la jeune fille ce pouroir de réflexion qui est la marque distinctive de la personne, et cet ordre de l'esprit qui procède par principes ct démonstrations, nous ríservons à la culture scientifique une place importante.....

On a répété que les femmes n'ont point de goùt pour les sciences abstraites, oubliant qu'on ne fait le plus souvent avec profit que ce qui coute de la peine. On ajoute qu'elles sont incapables de se livrer à des études scientifiques; l'expérience ne vient-elle 
pas, au contraire, de prouver, en France, "que les seiences al)straites ne sont pas plus interdites à un sexe qu'à l'autre, et que ce qu'il y a dans l'esprit des femmes de pratique et de subtil s'applique à merveille à l'intelligence des problèmes mathématiques. "Bien plus, sans prétendre les transformer en astronomes ou en géométres, il faut habituer les élèves à la théorie, régler leur intelligence au mourement de cette impeccable démonstration, leur donner l'esprit mathématiojue.

La sévère beauté du raisonnement pur les frappera bientôt et, en royant comment la raison a fait, de l'art de mesurer les terrains, la science de l'étendue, elles admireront ce pouvoir illimité de la pensée, souree inćpuisable du monde géométrique, ot la force de l'activité réfléchie déterminant avec une merveilleuse exactitude le détail infini des figures. Lótude des mathématiques pures donne à l'esprit confiance en lui-moime et prouve, mieux que toutes les exhortations, la nécessité et la puissance de la méthode: il n'y faut pas chercher tant un systeme qu'un merveilleux instrument de connaissance. Elles apprennent à réfléchir et par conséquent à apprendre : - c'est donc à ceux dont l'intelligence est mobile et l'imagination vive qu'il faut donner cette forte et calmante nourriture. La sulbtile harmonie du raisonnement, l'élégante économie des constructions, mises habilement en lumière par un professeur expérimenté, pourront bien vite aussi, quoi qu'en pensent les pédagogues allemands, éveiller le sens esthétique de la jeune fille. "On prétend, disait le profond auteur de la Métaphysique, que les mathématiques n'ont absolument rien de commun avec l'idée du heau. L’ordre, la proportion, la symétrie, ne sont-ce pas de très grandes formes de beauté ?"

E. Buty. L'enseignement secondaire des jeunes filles en Allemagne, p. 100 et suiv.

$$
\text { ** }
$$

J'ai enseigné les mathématiques ot aussi les scionces morales et philosophiques. Pour ces différentes branches d'ótudes, j’ai eu dans mes classes des jeunes filles aussi hien que des jeunes gens et je n’ai remarqué entre les uns et les autres aucune différence. I.es deux sexes ont une part égale parmi les forts et parmi les faibles.

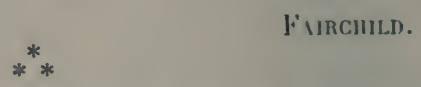

La femme qui sait, la femme qui pense, aimera-t-elle moins ? 
Il me semble qu'elle aimera davantage. Perdra-t-elle sat gráce parce qu'elle saura un peu d'histoire et d'algebre? Pas plus qu'elle ne perdra ses yeux, sil taille et ses cheveux.

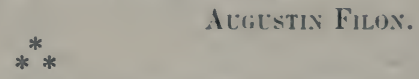

Quand peu à peu la science aura péuétré chez la femme, plus lentement et plus sùrement, elle reviendra a nous tamisce et scrutée, elle s'y reflétera pour rejaillir sur nous, le jour oì les masses affolées l'auront désertée.

$$
*^{*} \text { Felix Remo. }
$$

I la facilité de saisir et de retenir les faits, ajoutez le gout de la symétrie qui semble inné chez les femmes: vous comprendrez l'aptitude qu'elles montrent souvent pour l'étude de la tréométrie.

\section{P.acl Lafitte. Le paradoxe de l'égalité, p. 117.}

\section{***}

Dans l'intéressante étude de Cajori sur l'Enseignement des mathématiques aux États-Unis (1890), on remarque, parmi les réponses au questionnaire du gouvernement, celles relatives a la capacité comparée des deux sexes en mathématiques. Quarante-quatre concluent fermement à la supériorité des femmes, mais trente-six manifestent, avec quelques nuances, l'opinion opposée. Yous lisons ces observations :

Dans mes classes, les jeunes dames ont généralement excellé.

Les jeunes gens sont susceptibles d'efforts plus prolongés; les filles sont plus spontanées.

Les garçons sont supérieurs en moyenne, mais e'est souvent une demoiselle qui tient la tête.

Plusieurs de nos étudiants les plus distingués en mathématiques sont des femmes.

Les garçons paraissent plus inventif's. Nous l'expliquons parce que la fenme ayant été jugée a priori peu capable de science, n'a pas été exercée et il en est résulté un amoindrissement passager de la faculté.$$
*^{* * *}
$$

Les facultés d'entendement, jugement, raisonnement, sont très puissantes chez la femme. La plus jolie moitié du genre humain excelle à bien coordonner les faits, à bien raisonner, à bien juger. Ce sont là des découvertes qui ont hien leur importance. 
Beaucoup de personnes s'en doutaient bien, mais le fait n'était que probable et il parait démontré maintenant. Pouvoir remarquable de coordination, pouvoir de raisonnement. Mais ce sont là des qualités maîtresses; et, comme elles suffisent pour bien démontrer que le plus souvent, derrière l'homme, il faut chercher la femme! En tout cas, ces facultés nous expliquent de même les succès croissants que remportent les jeunes filles qui s'adonnent à l'étude des sciences. Longtemps on a cru que le cerveau de la femme n'était pas fait pour les spéculations abstraites.

Quelle erreur! Quand une jeune fille le veut, elle acquiert rapidement les connaissances scientifiques les plus ardues. L'expérience de ces dernieres années est hien la pour le prouver. La femme apprend le droit, la médecine, l'histoire naturelle, les mathématiques aussi bien sinon mieux que l'homme, et elle se montre souvent supérieure à l'homme dans ces travaux sévères.

De Pariale. (Journal des Débats dı 20 décembre 1893.)

$$
\text { ** }
$$

Il y a parmi les femmes, de beaux et de nobles cerveaux, parfaitement capables de s'élever à la compréhension des idées philosophiques et générales. Telle, pour ne parler que d'une morte, cette madame Ackermann, qui jeta sur sa robe le manteau de Lucrèce. En disant que cette égalité conquise dans le domaine de la pensée est une exception, qui sait si les hommes ne témoignent pas d'une certaine frayeur de la voir grandir et s'affirmer encore?

Hexry Focquier. Les Bas bleus. (Le Figaro du z̈ juillet 1896.)

$$
\text { ** }
$$

Le cerveau de la femme est, tout comme celui de l'homme, rapable de comprendre bien des choses, j'entends des plus hautes et des plus abstraites.

A вве́ Mellier. De l'éducation des femmes au $\mathrm{x}^{\prime} \mathrm{I}^{\circ}$ siècle, pp. 61 et 62 .

$$
\text { ** }
$$

On croit généralement en Allemagne qur les études mathématiques sont inabordables aux dames.....

.... Je me borne à nos observations ì Gettingue.

.... Durant ce trimestre, six dames ont suivi les cours et les 
exercices de mathématiques supérieures. Elles s'y sont constamment montrées, à tous points de vue, de mème valeur que leurs coneurrents maseulins.

$$
*^{*} \text { F. Kilfix. }
$$

Dans les temps anciens, comme dans les temps modernes, il y a eu d'éminentes mathématiciennes. En dehors de ces (exceptions, les femmes peurent étudier arec succès les mathématiques, comme le prouvent les expériences qui se font à Geettingue, à Zurich et aussi en Angleterre.

Malheureusement, en Allemagne, les femmes ne peuvent guère acquérir les connaissances préalables pour pouvoir étudier aux Universités, car on ne fait presque pas de mathématiques dans les écoles de filles.

$$
\text { * Wixgerix. }
$$

On me demande mon opinion d'astronome sur les hautes études des femmes. Je réponds qu'en astronomie, ainsi que dans les calculs et les mesures de précision, les femmes peurent réussir aussi bien que les hommes.... Des mesures demandant délicatesse et persévérance ont souvent été exécutées par des yeux et des inains de femme, avec la patience et l'habileté féminines.... Il y a aussi d'importants travaux faits par des femmes en mathématiques et en calculs numériques.

$$
\text { ** } \quad \text { Forster. }
$$

J'ai eu à trois reprises l'occasion de suivre les progrès de jeunes dames (en géologie et en paléontologie) et je me suis assuré qu'elles ne le eèdent aux meilleurs étudiants ni par la vivacité de l'intelligence ni par la pénétration dans l'observation; elles les dépassent par l'opiniâtreté dans le trarail. Quant à l'aptitude aux recherches scientifiques personnelles, je ne puis trouver aucune différence entre les étudiants des deux sexes.

$$
*^{*} \text { Vox Zittel. }
$$

Les quatre dernières citations sont extraites du live de hirscunorf, Die akademische Frau (189i), où sont réunies les opinions des professeurs des unirersités allemandes, sur l'admission des fenmes à l'enseignement supérieur. 

NOTE II

\section{MENUS PROPOS}

\section{SUR LES FEMMES ET LES SCIENCES}

Ne négligeons pas les petits faits et les petites observations : la poussière contient des germes. 
Nous réunissons à la suite quelques détails qu’on ne peut guère classer. Nous donnons successivement des Notules diverses, historiques, philosophiques, etc., des Pensées sur le sujet, des Anecdotes variées et enfin des Boutades et paradoxes. Il y a ici un peu de tout en désordre, du sérieux et du frivole, quelques grains d'or mêlés au sable. 


\section{NOTULES DIVERSES}

Fontenelle avait officieusement mis les sciences à la portíe du bean sexe, et son livre de la Pluratité des Mondes avait popularisé l'astronomie; il était du bel air de s’inquiéter de ce qui se passait dans Saturne et ditns Jupiter, et d'aller interroger ces mondes qui ouvraient le champ à toutes ces rèveries et à toutes ces chimères.

..... Toutes les temmes dévorèrent, en effet, son livre, et se firent astronomes comme auparavant elles avaient été cartésiennes, comme plus tard elles deraient se faire naturalistes arec les Époques de la Nature... un peu à l'areuglette, par genre, sans y entendre grand cliose.

Nous brouillons tout l'ordre des cieux :

Nous prenons Vénus pour Mercure,

Car vous saurez cqu'ici l'on n'a,

Pour examiner les planettes,

Au lieu de ros longues lunettes,

Que des lorgnettes d'opéra.

G. Desvoiresterres. La Jeunesse de Voltaire, p. 196.

$$
\text { *** }
$$

Le professeur Mason, du Mluséum de Washington, a prouvé que les femmes ont découvert la préparation des peaux et la fabrication de la poterie. Il a établi aussi qu'on doit aux femmes les premiers instruments de l'agriculture.

$$
* *
$$

Alphonse Renaud, Histoire nouvelle des arts et des sciences, Paris, G. Charpentier, in-18 jésus, 1878 .

P. 12. Diane dresse les chiens de chasse en Grèce (v. 2230). Arachné invente, en Lydie, les filets de pêche (v. 1440).

P. 13. Cybèle, en Phrygie, compose des remèdes purifiants pour les bestiaux (v. 1580).

P. 15. Cérès enseigne, en Grèce et en Sicile, la culture du blé ( - Sémiramis établit des canaux d'irrigation en Assyrie.

P. 18. L'art de filer fut enseigné aux chinois par la femme de l'empereur Yao (v. 2357), aux Hébreux par Nö̈ma (av. 1997), aux Lydiens par Arachné de Sardes (v. 1440), aux Grees parr Pallas (v. 1440), alux Péruviens par Mama 0ella, femme de Manco-Cajac (v. 1025)...

P. 30. Sémiramis construisit des chaussées diıns des terrains marécageux (av. 1874).

PP. 14 et 36. La culture du blé a été enseignée en Égypte par Isis. Isis, lasse de manier les lourdes rames de son vaisseau, défit le voile de sa tète, et s'étant aperçue que les vents le poussaient en le gonflant, 
imagina de faire mettre un màt au milieu du vaisseau et d'y appliquer une toile (Hyg. f. 274).

Pp. 34 et 38. Sémiramis fit établir un pont sous l'Euphrate en mème temps qu'un pont supérieur (av. 1874). (Diod. 2, p. 8 et 121). - Le char armé de faux fut inventé par Sémiramis (Clésias),.. le javelot par l'amazone Penthésilée (Pl. 7, 57).

P. 41. La charrue fut inrentée par Cérès, en Grèce.

P. 40. Les baïonnettes à douille pleine sont dues aux femmes de Bayonne (1523).

P. 45. Pénélope avait de grosses aiguilles de fer (0d, 22).

Pp. 49 et 50. Les télégraphes aériens sont l'invention de Adossa, temme de Ninus, et le levier celle de Cinyra (PI. 7, 57).

P. 50. La myrrhe fut introduite à Chypre par Myrrha, en Italie par Pompéa.

P. 85. Le corset armé de baleines et de lames d'acier, fut introduit en France par Catherine de Médicis (v. 1540).

P. 103. Une jeune fille de Sicyone, Callirrhoé, traça sur une muraille, avec un charbon, les contours de l'ombre de son fiancé, qui devait partir le lendemain pour un long voyage (PI. 35, 43) : ce serait l'origine du dessin.

P. 105. Minerve inventa l'architecture en Grèce.

P. 108. Junon décourrit la piroine et le lilas; Cérès le pavot; Diane la violette; Vénus la rose, le myrte, la marjolaine, l'anémone, le narcisse et la tubéreuse.

P. 116. Les poupées ont reçu leur nom d'une impératrice romaine (Poppée).

P. 133. Homère nous a, en quelque sorte, conservé l'herbier de Circé (v. 1300).

P. 138. La dorade (poisson rouge) a été introduite en France au $\mathrm{x}^{\mathrm{ruI}}{ }^{\circ}$ siècle, par la marquise de Pompadour.

P. 184. Les anciens attribuaient la logique à Inémosyne (v. 1440). (Diod. 5, 67.)

P. 185. Diodore prétend que les Amazones ont les premières entrepris une expédition lointaine $(3,70)$..... Sésostris, par ses conquêtes, flt connaître de nouveaux peuples et de nouvelles régions (v. 1400).

$$
\text { ** }
$$

D'après Jules Bors (L'Éve nouvelle, pp. 66 et suir. puis pp. 359 et suiv.) la femme aurait inventé le feu, l'arc, la roue, la charrue, le navire, etc.

$$
\text { ** } *
$$

Aux Ėtats-Unis c'est Ann Lee qui a fondé les Shakers. C'est Barbara Heck qui a réformé les Méthodistes. C'est Lucretia Mott qui a donné leur croyance aux Hicksites.

$$
\text { ** }
$$

Extrait d'un programme de cours de philosophie de l'université féminine de Wellesley, près de Boston :

"Types divers d'Ethique. Investigation psychologique sur les lois de 
l'esprit humain, comme base toute prète pour les théories qui se proposent d'établir une morale expérimentale. Etude de lit doctrine de l'érolution, en tant qu'elle rend compte des motifs de conduite individuelle et aussi l'histoire des institutions sociales et civiles. Types des différentes Ethiques vérifiées dans les phases de conduite morale, telles que les révèlent les littératures et les arts. »

$$
\text { *** }
$$

Sous la toge noire et le bonnet carré qu'elles portent dans l'enceinte de leur collège, les jeunes sarantes éroquent la Portia de Shakespeare. Vous les retrouvez au gymnase, lestes et agiles, en blouses, en pantalons bouffants et en bas de soie.

D'après Tı. Bextzon. Les Américaines chez elles.

$$
\text { *** }
$$

Ferguson a composé des Dialogues entre un jeune homme sortant du collège et sa sœur, à laquelle il enseigne en secret l'astronomie. $M^{\mathrm{m}}$ o de Genlis dit, dans la préface des Veillées du Château, que l'ourrage est d'une gande clarté.

$$
* *
$$

La Comtesse d'Egmont, fille du maréchal de Richelieu, a écrit sur les sciences politiques. Voir le t. 1 de Gustave III et la Cour de France par Gefrroy.

$$
\text { ** } *
$$

La reine d'Angleterre, épouse de Georges II, qui a servi de médiatrice entre les deux profonds métaphysiciens Clarke et Leibniz, n`a pas négligé pour cela un moment son travail de reine, de femme et de mère.

Fortuxée Briquet. Dictionnaire historique, etc., 1804; avant-propos.

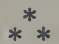

Dans le $2^{\text {e }}$ volume de l'Association française pour l'arancement des sciences (1894, Besançon), p. 303 et suivantes, on troure une note de M. J. S. Mackay sur le Journalisme mathématique en Angleterre. Nous y lisons que le Lady's Diary (Journal des Dames) est une des premières publications qui ait traité des sciences mathématiques. "L'amusement plutôt que les progrès de la science paraît aroir été, à l'origine, le but du journal. Avec le temps, les questions derinrent de plus en plus intéressantes et difficiles. "Les solutions de 1704 à 1818 ont été imprimées à part en quatre tomes.

On troure encore cité dans la mème notice le Lady's and Gentleman's Repository (1783-1784).

$$
* * *
$$

Voici quelques reférences, à propos des études féminines :

Women and learning. Atlantic Monthly, LXIV, 518.

- $\quad$ - medecine. Nation, LII, 131. 
Women as astronomers. Chantaugnan, XIV, 209, 340.

$$
\begin{aligned}
& \text { - - inventors - VII, 35ั5. } \\
& \text { - - scholars - XIII, } 77 .
\end{aligned}
$$

- in medicine. North American Reriew, CXXXIV, 52.

- - - Amer. Journ. of Social science, XIV, 178.

- in astronomy. Popular science monthly, XXVIIl, 534.

- - science. Public 0pinion, XIV, 305.

$$
\text { *** }
$$

Esquisse d'une histoire industrielle d'Angleterre (en anglais), par W. Cunningham et Miss Ellex Mc Antilur, chargée de conférences ì Girton College. Cambridge university press, $2 \approx 1 \mathrm{pp}$.

$$
\text { *** }
$$

Miss Gladstone, la fllle du grand ministre, a passé en 1878 les examens scientifiques de l'Université de Cambridge.

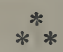

Une femme a été prise en 1890 pour pilote aux États-Lnis. C'est la première fois que ce fait s'est produit.

$$
\text { *** }
$$

Dans ce temps-là, sauf de rares exceptions, les sarants, les mathématiciens surtout, étaient regardés dans le monde cornme des ètres d'une nature à part. On aurait roulu leur interdire le concert, le bal, le spectacle, comme à des ecclésiastiqques. Un géomètre qui se mariait semblait enfreindre un principe de droit. Le célibat passait pour la condition obligée de quiconque s'adonnait aux sublimes théories de l'analyse. Le tort était-il tout entier du côté du public ? Les géomètres ne laraientils pas eux-mèmes excité à roir la question sous ce jour-là?...

D'Alembert reçoit indirectement de Berlin la nouvelle que Lagrange vient de donner son nom ì une de ses jeunes parentes. ll est quelque peu étonné qu'un ami arec lequel il entretient une correspondance suivie ne lui en ait rien dit. Cela mème ne le détourne pas d'en parler avec moquerie: " l'apprends, lui écrit-il, que rous arez fait ce qu'entre nous autres philosophes nous appelons le saut périlleux... I'n grand mathématicien doit, arant toutes choses, saroir caleuler son bonheur. Je ne doute pas qu'après aroir fait ce calcul, rous n'ayez trouré pour solution le mariage. "

Lagrange répond de cette étrange manière : "Je ne sais si j'ai bien ou mal calculé, ou, plutôt, je crois n'aroir pas calculé du tout; car j'aurais peut-être fait comme Leibniz qui, à force de réfléchir, ne put jamais se déterminer. Je vous avouerai que je n’ai jamais eu du goùt pour le mariage,... mais les circonstances m’ont décidé... à engager une de mes parentes... a a renir prendre soin de moi et de tout ce qui me regarde. Si je ne rous en ai pas fait part, c'est qu'il m'a paru que la chose était si indifférente en elle-mẻme, qu'elle ne valait pas la peine de vous en entretenir."

ARsio.

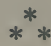


Ce père de l'Eglise (saint Jéròme) contribue plus qu'aucun autre ì compléter la transformation de la femme latine. Sur cent lettres théologiques, il en adresse cinquante à des femmes; dans quinze traités sur vingt, il traite de leur éducation; il leur alédie non seulement plusieurs livres de sit Vulgate et ses explications sur les psaumes, mais un traité contre les montinistes. Paula, Principia, Marcella deviennent des personnages agissant daus la société romaine, et la foule suivra les obsè(ues de Fabiola, comme elle ent suivi antrefois celles d'un imperator.

Les ennemis des femmes, par Arthú Desuandi. 1895̆, broch. in-8, p. 5.

$$
\text { ** } *
$$

Les propriétés des plantes qui servent encore aujourdhui dans la thérapeutique, ont été trourées au moyen àge par de savantes femmes, (fu'on flétrissait du nom de sorcières.

$$
\text { ** }
$$

Dans une Revue américaine, M. LÉox Maun signale :

Cne jeune fille de Lima (0hio), qui a imaginé un procédé pour extraire d'une tonne d'huile 10000 pieds cubes de gaz d'éclairage.

Mrs Harriett Plumb : In noureau ventilateur des voitures de chemin de fer.

Mrs Caterina Bloss, de New-York : Machine à coudre les fourrures.

Mrs Mary Burke, de Montpellier (ldaho): Une lavette en fils d'acier souples comme des fils de chanrre.

Mrs Batcheler : Instrument pour redresser les oreilles mal conformées et un autre pour rendre moins disgracieuses les physionomies asymétriques.

Dame anonyme : Horloge de cuisine contenant une étuve à gaz, un réservoir à vapeur, des easiers pour les plats, pour les utensiles de cuisine et une tablette pour écrire pendant qu'on surveille le pot-au-feu.

Mrs Lena Sittig, de Brooklyn : In noureau waterproof imperméable (le duck's buck).

Mrs Westover : Chariot pour le balayage des rues, le chargement de lit houille sur les navires et divers autres usages.

Mrs Louise Dyer : Une ardoise pourant se laver automatiquement, promptement et facilement.

Mrs Kate Eubauk, d'Oakland : Meuble servant à la fois de toilette et de bureau ì écrire et renfermant tout ce qui est nécessaire aux deux usiges.

Enfin l'auteur rappelle que sur la liste des employés d'Edison figurent plus de 200 temmes (l'inventeur les préférant aux hommes pour l'exécution des détails de ses appareils).

Revue encyclopédique du 1 er mai 1894.

$$
\text { *** }
$$

In riche anglais a acheté à Egham (comté de Surrey) la grande propriété de Mount-Leo pour y créer une Université spéciale, destinée aux femmes.

$$
\text { ** } *
$$


Nous avons le portrait de la Science, dans Joseph de Maistre : C'est une prophétesse sublime, sœur aînée de la Poésie dont elle inspire quelquefois et règle toujours les chants; ıne reine couronnée de la mitre orientale, vètue d'un manteau d'étoiles.

... Ce n'est pas du tout la personne que j’ai sous les yeux!

Celle-ci est petite, voutée, habillée de cotonnade, chaussée de caoutchouc, chauve sous un bonnet de soie, d'horribles bésicles de myope couvrent ses yeux chafouins. Elle traîne un attirail de compas, de cornues, de marmites; ses poches sont gonflíes de calepins qu'elle consulte sans cesse; elle prend le microscope pour regarder un bouf; elle parle, elle parle, elle parle! Et sa prétention est de tout savoir et de ne croire à rien.

Locis Veuillot : Les odeurs de Paris, p. 291.

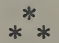

Beaucoup de sarants ont eu pour mère ou grand'mère des femmes remarquables. Nous pourons citer Buffon (il se plaisait à dire qu'il tenait de sa mère toutes ses qualités), Bacon (sa mère Anne Cooke était une humaniste distinguée), Condorcet (il parait aroir ressemblé à sa mère), Cuvier (sa mère, femme accomplie, s'était beaucoup occupée de son éducation), d'Alembert (fils de la célèbre Madame de Tencin), Watt (sa mère était Agnès Muirhead, qualifiće par les biographes de " ladylike "), etc., etc.

$$
\text { *** }
$$

Les femmes du xvıı siècle eurent des notions superficielles des sciences; elles coururent à des expériences de physique, de chimie, à des cours de mathématiques, d'astronomie, à des leçons d'histoire naturelle; il y en eut même qui voulurent ètre initiées à la médecine, à la chirurgie, qui l'eût pensé? à l'anatomie.

L'accessoire, l'inutile même prirent tant de place dans leur éducation, qu'il n'y resta plus de place pour l'essentiel.

A. Nettement. De la seconde éducation des filles, pp. 391-2.

$$
\text { *** }
$$

Dans Tiraqueau (De legibus connubialibus), 150 femmes sont citées pour leur instruction. Nous n'en arons retenu que quelques-unes.

$$
\text { *** }
$$

Le Popular Science Monthly publie dans son seul $n^{\circ}$ de janvier 1897 , deux articles de femmes :

Sur la psychologie des races, par .Ime A. T. Sinith.

Sur les araignées, par Mme V. Leigton.

$$
\text { *** }
$$

La fée Melior, héröne du roman de Parthenopus de Blois, type d'une parfaite dame du xı'॰ siècle, avait appris et savait dans la perfection les 7 arts libéraux. Elle était experte en toute médecine, et distinguait chaque plante et le parti qu'on pourait en tirer pour la guérison des plaies. Elle arait étudié la théologie, enfin l'astronomie qui se confondait alors avec l'astrologie judiciaire et la magie. 
Parthenopus de Blois, d'après un manuscrit de la Bibliothèque de l'Arsenal, publié par C.-A. Crapelet. Paris 1834, 2 vol. in-8.

$$
\text { ** } *
$$

Sylvain Marúchal, dit le berger athée, est l'auteur du curieux projet suivant :

Projet de loi

portant défense aux femmes d'apprendre

à lire et à écrire.

Considérant :

10 Que l'affection de famille, le mariage, la tendresse maternelle, la piété filiale, etc., sont antérieurs à l'alphabet, ont subsisté et se soutiennent sans l'étude; tandis que des inconvénients graves résultent pour les deux sexes, de ce que les femmes sarent lire.

$2^{\circ}$ Que l'intention de la nature a été que la femme fùt exclusivement occupée des soins domestiques; que, suivant La Rochefoueauld, l'esprit de la plupart des femmes sert plus à augmenter leur frivolité qu'à augmenter leur raison;

Etc., etc.

Maréchal, un assez triste sire, parle sérieusement et Madame Dufour Gacon prend la peine de le réfuter (1801).

$$
\text { ** } *
$$

Le stoïcien Apollonius avait fait un traité des femmes philosophes; Philochore un ourrage entier sur les pythagoriciennes; Juvénal cite de ses contemporaines qui cultiraient la philosophie. Aussi, sommes-nous surpris que Didyme dise que Théano est la seule femme qui ait écrit sur la philosophie et que Lactance n'accorde cet honneur qu'à Thémiste. Jai trouvé moi-mème, dit Ménage, soixante-cinq femmes philosophes dont il est parlé dans les écrits qui nous restent des anciens.

Voici la classification de Ménage :

On ne range sous aucune secte: Hippo, Cléobuline, Aspasie. Diotime, Béronice, Pamphila, Clea, Euridice, Julie Domna, Myro, Sosipatre, Anthuse, Agamie, Eudocie, Sainte Catherine, Anne Conıène, la seconde Eudocie, Panyperbaste, Norelle, Eloïse.

Platoniciennes : Lasthénie, Arria, Gemine, Amphichie, Hypatie.

Académicienne : Corelie.

Dialecticiennes: Diodore (Les filles de).

Cyrénaïque : Arète.

Mégarienne : Nicarète.

Cynique : Hipparchie.

Péripatéticiennes : Fille d'Olympiodore, Théodora.

Épicuriennes: Thémisto, Leonce, Théophile.

Stoïciennes : Porcia, Arria, Théophile.

Pythagoriciennes : Thémistoclée, Theano, Arignote, Damo, Sara, Timycha, Philtatis, Occelo, Eccelo, Chilonis, Mya, Lasthénie, Abrotelle, Echécratie, Tyrsène, Nesthéaduse, Byo, Babelyme, Cleoechma, Phintys, Perictione, Melisse, Rhodope, Ptolemaïs.

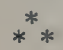


Je dis un jour à Madame de Longueville que je pouvais parier et démontrer qu'il y arait dans Paris au moins deux labitants qui avaient le mème nombre de cheveux, quoique je ne puisse pas marquer quels sont ces deux hommes. Voici ma démonstration, lui dis-je : je pose en fait que la tète la mieux garnie de cheveux n'en a pas deux cent mille, et que la tète la moins garnie est celle qui n’i qu'un chereu. Si maintenant vous supposez que deux cent mille tètes ont toutes un nombre de cheveux différent, il faut qu'elles aient chacune un des nombres de cheveux qui ront depuis un jusqu'à deux cent mille, car si l'on supposait qu'il (y) en avait deux parmi les deux cent mille qui eussent le mème nombre de cheveux, j'aurais gagné le pari. 0r, en supposant que ces deux cent mille hahitants ont tous un nombre différent de chereux, si j'y apporte un seul habitant de plus qui ait des cheveux et qui n'en ait pas plus de deux cent mille, il faut nécessairement que le nombre des chereux, quel qu'il soit, se troure depuis un jusqu'à deux cent mille et par conséquent soit égal au nombre de cheveux d'une des deux cent mille tètes.

or, comme au lieu d'un habitant en sus des deux cent mille, il y en a tout près de huit cent mille, rous vojez bien qu'il faut qu'il y ait beaucoup de tètes égales en nombre de chereux, quoique je ne les aie pas comptés.

Nicole.

Il parait que l'aimable marquise ne put jamais comprendre le copieux raisonnement précédent, plusieurs fois répété. Un moraliste indien a dit, avant Schopenhauer, que "les femmes ont les chereux longs et les idées courtes ".

$$
\text { ** } *
$$

D'après Taine (0rigines de la France contemporaine), rers 1782, les femmes du monde ont dans leur cabinet " un dictionnaire dhistoire naturelle, des traités de physique et de chimie. Elles se font peindre dans un laboratoire, assises parmi des équerres et des télescopes. Elles assistent aux expériences scientifiques, elles suirent des cours de sciences physiques et naturelles ".

$$
* *
$$

Rousselot. De l'éducation des fermmes, I, p. 24-25.

"Charlemagne n'était pas resté indifférent à l'instruction des fentmes, mais son zèle n'avait pas dépassé le cercle de sal famille et de son entourage. Gisèle, sa sour, une autre Gisèle et Richtrade, ses filles, Lieutgarde, sa femme, Théodrade et Gondrade, ses cousines, quelques autres encore, parentes des seigneurs de sa cour, étaient instruites non seulement dans les travaux de leur sexe, mais aussi " comme ses fils, dans les arts libéraux ". L'Ecole du Palais, sous la direction dillcuin, était une sorte d'Académie où elles flguraient, mais sous des noms d'emprunt... Alcuin a dédié à l'une son traité de la nature de l’àme ".

On leur enseignait en particulier la logique, larithmétique, la géométrie, l'astronomie, mais à un point de vue théologique.

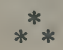


Prenons ce savant. C'est un inventeur; génie ardent, il tend toujours à l'ensemble des choses; son activité féconde, se portant à la fois sur tous les points de la science, y ourre, chaque fois, des percées inconnues. (?uelle gloire! direz-vous. Oui, mais partois aussi, quelle douleur! La médiocrité areugle le raille, la médiocrité clairvoyante l'attaque; los obtus, qui ne le comprennent jas, et les envieux qui le comprennent trop bien, s'accordent pour le relíguer parmi les fous; de li des moqueries, le désespoir, le doute de ses propres fores. Il va succomber... Rissurez-rous, il vivra, car il a près de lui une femme, sa femme, qui l'i deriné et qui lui montre l'avenir. C'est elle qui le rattache à ses puissants travaux : "Explique-moi tes pensées, tes projets, je ne suis qu’ignorance, mais Jésus lui-même ne dédaignait pas les paurres d'esprit qui sont riches de cour. Parle. "Il commence : ces idées qui ítaient comme mortes pour lui, découragé, se raniment à mesure qu’il les exprime; la nécessité de faire pénétrer ces sérieuses lícouvertes dans un esprit auquel elles sont étrangères encore, le force à un langage clair qui les lui éclaircit à lui-mème; il crée en racontant, et elle, elle grandit en l'écoutant. L'enthousiasme le saisit, il se jette dans $l_{i}$ lutte, il triomplie, et la plus vive joie de sa femme est de ne pas compter dans cette victoire cu'il n'en̂t peut-ètre pas remportée sans elle.

LEgouré. Histoire morale des femmes, p. 359.

$$
\text { *** }
$$

D'aprìs l'Almanach historico-physique des Dames, sur les quarantehuit cabinets d'histoire naturelle qui existaient à Paris vers le milieu de la seconile moitié du siècle dernier, sept appartenaient ì des femmes, parmi lesquelles Mlles Clairon et Ibis.

$$
\text { ** }
$$

Les romans disparaissent de la toilette des femmes, et l'on ne roit plus que des traités de physique et de chimie sur les chiffonnières. Le's plus grandes dames et les plus jeunes s'occupent des matières les plus abstraites et rivalisent avec $\mathbf{M}^{\mathrm{m}}$ de Chaulnes embarrassant les académiciens et les savants qui viennent chez son mari. Dies 1750, Maupertuis est déjà la "coqueluche " des femmes; il est déjì de ton pour les petites-maîtresses d'aller s'extasier aux séances de l'abbé Nollet, et de voir sortir du feu, un feu qui fait du bruit, du menton d'un grand laquais qu'on gratte. Dans les salons de la fin du siècle, on forme des sociétés de ringt, ringt-cing personnes, pour suivre un cours de physique, un cours de chimie appliquée aux arts ou de myologie. On rougirait de ne pas assister aux leçons de M. Sigault de la Fond ou de M. Mittouirt; ne nomme-t-on parmi celles qui s'y pressent $\|^{\text {mes }}$ d'Harville, de Jumilhac, de Chastenet, de Malette, d'Arcambal, de Meulan? Une femme ne se fait plus peindre sur un nuage d'Olympe, mais assise dans un laboratoire. Que Rouelle, le frère du fameux Rouelle, fasse des expériences sur lit fusion et la rolatilisation des diamants, il aura pour spectatrices la marquise de Nesles, la comtesse de Brancas, la marquise de Pons, la comtesse de Polignac, Mme Dupin, qui suivront d'un oil attentif et curieux le dimant brillant sous le feu de la moutle, étincelant une dernière fois, et suant la lumière. Un journal va paraitre réjondant aus besoins du temps, aux goûts de la femme, qui, mèlant les sciences aux 
arts agréables, donnera à côté de la poésie, ... les mémoires scientificues, les descriptions de machines, les observations d'astronomie, des lettres sur la physique, des morceaux sur la chimie, des recherches de botanique et de physiologie, les mathématiques.... Musćes et lycées ront remplir Paris de science aimable, d'érudition attrayante. Et quel spectacle plus charmant que toutes ces jolies têtes tournées vers le docteur qui trône sur sa chaise curule, au bout d'une longue table garnie de cristallisations, de globes, d'insectes et de minéraux ? Il grasseye, il nuance sa diction, au milieu d'un cercle de femmes formant la première enceinte de l'auditoire, les joues sans rouge et comme pâlies par les reilles, la tète appuyée négligemment sur trois doigts en équerre, immobiles dattention....

On est loin de la délicate maxime de Mme de Lambert: "Les femme doivent avoir sur les sciences une pudeur presque aussi tendre que sur les vices. "Nulle science ne répugne à la femme, et les sciences les plus viriles semblent exercer sur elle, une tentation, une fascination... Beaucoup se montrent jalouses de la petite-fille de Mmo Doublet, la comtesse de Voisenon, qui auprès des médecins reçus chez sa grand-mère a appris tant bien que mal l'art de guérîr et médicamente dans ses terres, parmi ses amis, tout ce qui tombe sous la main ; si bien que les plaisants, insérant un carton dans le Journal des Savants, lui font croire qu'elle est élue présidente du Collège de médecine. La marquise de Voyer raffole des leçons d'anatomie, et s'amuse à suivre le cours du chyle dans les viscères. Car l'anatomie est alors un des grands gouts de la femme: peu s'en faut que les femmes à la mode n'aient dans un coin du jardin de leur hôtel, ce petit boudoir, ces délices de Nile Bihéron la grande artiste en sujets anatomiques faits de cire et de chiffons, un cabinet vitré plein de cadavres! Et ne verra-t-on point une jeune femme de dix-huit ans, la jeune comtesse de Coigny, se passionner tellement pour cette horrible étude, qu'il ne lui arrivera point de voyager sans emporter dans le coffre de sa voiture un cadarre à disséquer, comme on emporte un livre à lire ?

E. Eт J. DE Goxcolnt. La Femme au dix-huitième siècle.

\section{$* *$}

Qui s'offrira d'abord ? Bon, c'est cette sarante

Qu'estime Roberval, et que Sauveur fréquente.

D'où vient qu'elle a l'ceil trouble et le teint si terni ?

C'est que sur le calcul, dit-on. de Cassini,

Un astrolabe en main, elle a dans sa gouttière

A suivre Jupiter passé la nuit entière.

Gardons de la troubler. Sa seience, je crois,

Aura pour s'occuper ce jour plus d'un emploi :

D'un nouveau microseope on doit, en sa présence,

Tantôt chez Dalancé faire l'expérience;

Puis d'une femme, morte, avant l'infection,

11 faut chez du Verney roir la dissection.

Rien n'échappe aux regards de notre curieuse.

Bonleat Despnéatx. Satire sur les Femmes.

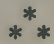


Mercure, pour tirer une déesse du plus grand embarras, joua aux échecs avec la lune, et lui gagna la soixante-douzieme partie du jour.

Pltanotw. Traité de Iside et Osiride.

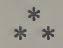

Recueil de receptes choisies, expérimentées et approuvées, contre quantité de maux fort conıus, tant internes qu'externes, invétérés, et difficiles à guérir (par Imo Focquet), à Villefranche, de l'imprimerie de Pierre Grandsaigne, MDCLXXV.

$$
* *
$$

Jenner pratique la première raccination, le 14 mai 1796, au moyen du pus recueilli sur les mains d'une jeune vachère, Sarah Nelwes.

$$
* *
$$

La lettre XXXYII du Recueil des lettres du pape Clément XIV contient l'éloge d'une dame rénitienne qui a traduit Locke.

$$
\text { ** }
$$

Des laboratoires de recherche ont été inaugurés en 1893, ì BedfordCollege, pour les femmes. La science actuelle une fois acquise, il faut aller en avant...

$$
\text { ** }
$$

Ils troureraient dans la seule école de Pythagore beaucoup de jeunes philosophes qui n'avaient pas encore subi le joug du Mary. Ils en trouveraient aussi dans celles des Stoïciens et des Aradémiciens, et il ne leur serait pas plus difficile de produire de jeunes Épicuriennes, puisqu'Epicure n'était pas moins curieux d'enseigner sa philosophie aux Filles que Zénon et Platon. On peut dire qu'ils seraient accablés de leur abondance, s'ils roulaient ramasser tout ce que les Auteurs ont dit des jeunes grecques qui ont excellé dès leur bas-ìge dans les autres connaissances, surtout dans les Arts libéraux et dans les Matlématiques, quand ils roudraient se renfermer dans la seule ville d'Athènes.

Les écoleschrétiennes n'ont pas éte moins fertiles en jeunes scavantes. On sait ce que l'histoire nous rapporte de celles d'Alexandrie sous Origène et les autres professeurs qui luy ont succédé. Les filles en sortaient si scavantes, aussi bien dans les Lettres humaines et la Philosophie, que dans les Saintes Écritures, qu'elles pouvaient tenir teste aux plus savants des gentils; et que, non contentes de confondre le Paganisme par la force de leur raisonnement, elles pratiquaient la véritable manière de mépriser la mort et allaient droit de l'École au martyre, en philosophes chrétiennes.

$$
* *
$$


Cambridge (Etats-Unis).

Observations astromomiques du collège Harward.

Caleulatrices : M110 S.-J. Bailey, M"le S.-C. Bond, M"le F. Cushman, IHe J.-W. Eddy, MHe M. Fleming, MHe E.-F. Gill, MHe L.-L. Hodgdon, MHo E.-F. Leland, MHe A.-C. Maury, MHe R.-F. Rogers, MHo J.-F. Rugg, M110 M.-C. Sterens, M110 N.-C. Storin, M110 L.-D. Wells, M110 A. Winlock, MHo L. Winlock.

En 1819, Mme Blanchard, dont le ballon avait pris feu, périt dans sa 67 escension, écrasée sur le pavé de Paris.

Rambatd. Histoire de la civilisation contemporaine, p. 479.

Élisa Garnerin opéra la première descente en parachute.

\section{$* *$}

En iconologie, la géométrie est représentée par une femme d’àge moyen, couverte d'un voile blanc et transparent. Un globe est à ses pieds et elle trace, avec un compas, un cercle sur un papier où sont déjà d’autres figures.

$$
* *
$$

Parmi les dames qui ont pris part à la manifestation en l'honneur de l'illustre géomètre Hermite, nous remarquons M"le Söderhjelm (Finland), MI10 Giliberti (Naples). Mme Kerbetz (Palerme), Mmo Schiff (Russie), Mmes Bouquet, Briot, Halphen, etc. (France).

$$
\text { ** } *
$$

Uranie, c'est-ì-dire la céleste, une des 9 muses selon la Fable, préside à l'astronomie. On la représente ordinairement avec une robe de collleur d'azur, couronnée d'étoiles, soutenant des deux mains un grand globe, et environnée d'instruments de mathématiques.

$$
\text { *** }
$$

La gloire de Lavoisier a passionné beaucoup de Parisiennes pour la chimie, à ce point qu'il y a deux ans de belles dames se plaisaient ì expliquer les impulsions de leur cœur par des réactions chimiques.

$$
\text { K.ıkımixe, voyageur russe. }
$$

$$
* *
$$

Roc Ssei.ot. L'éducation des femmes, t. I, p. 11 et 12.

Saint Jérôme, maitre de Marcella, de Paula, d'Eustochium, de Lota, d'Albine, met en scène Aspasie dans ses dialogues... Thémiste professe la philosophie parmi les plus savants de la Grèce. Des femmes gauloises le consultaient, en particulier Hédibie de Bayeux et Algasie de Cahors.

$$
* *
$$


Du temps de Gabriel Naudé (v. 1630), on comptait plus de 22000 femmes qui araient composé des livres, et le comte Ferri a laissé à Pardoue, en 18.7, une bibliothèque de près de 32000 volumes, exclusivement composée d'ouvrages écrits par des femmes, en toutes langues et en tous pays...

Alpu. Revacd. Histoire nouvelle des sciences et des arts, p. 358.

$$
* *
$$

Goethe fait part de ses travaux sur la composition vertébrale de la tète des mammifères, le 30 avril 1784 à $\mathbf{I I m e}^{\mathrm{m}}$ Kalb et le 4 mai suivant ì Imo Herder.

$$
\text { *** }
$$

Dans les Acta eruditorum de Leipzig, ann. 1724, p. 239, dissertation intitulée Bitisia Gozzadina, seu de Mulierum Doctoratu; on y relive les noms des femmes qui, depuis le treizième siècle, ont mérité le titre de docteur.

$$
* *
$$

Dans le calendrier positiviste, nous lisons les noms de Sainte Monique, Héloïse, Sainte Thérèse, Mathile de Toscane, Mmo de Stael, Mme Roland, Ime de Sévigné, Mme de Staal, Ime de Lambert, Sophie Germain, etc.

$$
* *
$$

Philippe de Maizières dans le songe du vieux Pélerin représente l'astrologie judiciaire comme une vieille femme portant lunette de cristal et s'exprimant en ces termes : "Les grants clercs, les grandes chappes et chapperons fourrez, les grands princes séculiers, n'oseraient rien entreprendre sans me consulter; ils n'oseraient fonder un chatean, bitir une église, commencer une guerre, livrer bataille, mettre une rolse neuve, faire un cadeau, entreprendre un voyage sans mon commandement. $)$

$$
\text { *** Abbé Lebetf. }
$$

A l'école de médecine pour les lemmes, ourerte ì Londres, en 1874. les professeurs suivants sont des doctoresses:

Sophie Yex-Blake, Garett-Anderson, Louise Atkins et Edith Pechey.

$$
* *
$$

Il est un objet capital oì le concours des femmes serait un réritulble bienfait, c'est la domestication des espèces animales. Le monde des créatures nous reste encore presque entier à conquérir; sur les milliards d'insectes différents qui peuplent l'univers, nous n'en arons utilisé qu'une espèce, le ver à soie; cinq ou six quadrupèdes, huit ou dix variétés de volatiles forment toutes nos richesses sur ce point: les femmes seules, par leur talent d'observation, leur esprit pratique, leur 
propreté, leur douceur patiente, leur instinct naturellement éluciteur, multiplieraient ces dominations pacifiques; et la fermiere, comme la femme riche, trouvant dans cette science, l'une un guide pour le mouvement de la ferme, l'autre une distraction pour son oisiveté, feraient de leur perfectionnement individuel un progrès pour l'humanité.

Erxest Legoví. Histoire morale des femmes, p. ว3.

$$
* *
$$

Théologie, philosophie, histoire, jurisprudence, mathématiques et médecine, ces femmes (du $\mathrm{xr}^{\mathrm{e}}$ et du $\mathrm{xur}^{\mathrm{e}}$ siecle), comme le docteur Faust, avaient tout parcouru, tout étudié.

H. Blaze de Bury. Dames de la Renaissance, p. 105.

$$
\text { ** } *
$$

dimé-Mantin. Lettres à Sophie sur la physique, la chimie et l'histoire naturelle.

C. Liskexwe. Lettres à Palmyre sur l'astronomie.

lsidone Bounon. Lettres à Camille sur la physiologie, 18 $\$ 3$, in-12. in-8.

E. Mulsaxt. Lettres a Julie sur l'entomologie. Lyon, 1830, 2 rol.

A ces lectures pour le beau sexe, on peut ajouter le dernier livre de JEAN MACÉ, 1895, in-12:

Voyages dans les mondes, Les soirées de ma tante Rosy. Dédié à MHc Bord, directrice du pensionnat du Petit-Chàteau. C'est une astronomie dialoguée et bon enfant.

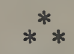

Dans le catalogue des tableaux de M. Blondel de Gagny par Remy, 1776, on signale le portrait par Charlier de MHe de Gontaut, représentée assise dans un laboratoire.

Dans Le $\mathrm{xix}^{\mathrm{e}}$ siècle de Grand-Carteret figure le cours de II. Caro à la Sorbonne, au milieu des dames (1885), d'après un dessin original de Loëvy.

$$
\text { *** }
$$

Nicarète, en jouant arec ses compagnes, donna le cinquième des noix qu'elle arait à Clito, à Sapho le quart, le cinquième à Aristodice, à Theano le vingtième et en sus le douzième, le vingt-quatrième à l'hilénis et il resta encore cinquante noix ì Nicarète. Combien en avait-elle d'abord?

$$
\text { ** } *
$$

Anthologie grecque.

D'après MHe Dugard, il y a aux Etats-Unis, en fait de femmes, 70 mídecins des hòpitaux et 95 professeurs dans les écoles de médecine.

$$
\text { *** }
$$

Quelques travaux des étudiantes de Saint-Pétersbourg, en 1895: Ines Horembourg (théorie du mélange des couleurs), Martchewski (raies 
spectrales), Parlow, Poper, Sourine, Tehernor (analyse des terrains de li Russie méridionale), Boujoukol (l’argon), Vera Popof (stéréochimie), ete.

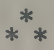

Sardi a dédié son commentaire de triplici philosophia à 0lỵmpe Fulvia Moratil.

N. Bellot, femme du Président des Meinières a publié : Réflexions d'une provinciale sur le discours de M. Rousseau touchant l'inégalité des conditions, 1756, in-8.

Actuellement, Mme Dickmay est secrétaire général du Collège libre des sciences politiques.

\section{PENSÉES}

De qui la science et la puissance de l'esprit? De qui, sinon de la mère dı genre humain? Et, quoique ses fils aient brillé d'àge en àge..., elle a communiqué ì ses filles un pouvoir supérieur.

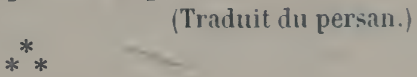

L'intelligence n'a pas de sexe.

Le P. Lemorne. Galerie des femmes fortes.

Mème idée dans J.-J. Rousseau.

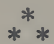

Il n'y aura de science définitive que lorsque la femme aura parlé.

Exfastix.

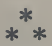

L'habitude de compter sourent fait le bonheur dans les maisons.

FÉxelon. Éducation des filles.

$$
* *
$$

Il est bon que les jeunes filles apprennent les quatre règles de l'arithmétique.

RoLlix. Études, fllles, p. 61. 
Des nombres combinés les quatre lois premieres Doirent à son esprit être encor familières.

Eulalie, par F. Poncho. (chant II, page 85), ou les 4 àges de la femmu.

$$
*^{*} *
$$

Une femme qui pense, fi donc! Autant vaut un homme qui met du rouge. La femme doit rire, toujours rire; cela suffit à sa noble mission sur la terre; cela suffit pour maintenir en joyeuse humeur l'auguste roi de la création.

LEssing. Émilie Galotti.

$$
* *
$$

Il y a des pédantes de lessive et de ménage ; il y a même, dans ma Gascogne, des pédantes de canards gras.

\section{**}

MII DE VIRIEC.

La science rend les hommes rarement aimables, les femmes jamiis.

BE.ıucuẾNk.

Une femme sarante n'est pas une femme qui sait, c'est une fe'mme qui fait parade de sa science.

Tout dépend des définitions.

\section{J. Simox.}

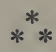

Précieuses pour précieuses, les scientifiques me semblent plus ridicules encore que les littéraires.

C. Rousset.

Ni pédantes ni poupées.

$$
*^{*} *
$$

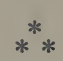

E. LEgoUté.

La science ne suffit pas au sarant : il lui faut des vertus sociales: sans elles, qu’il reste dans son cabinet.

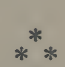

$$
\text { M.ID. DE P'UıSIEUX. }
$$

Tous les géomètres ont l'air sot.

$$
\text { ** }
$$

M.AD. DE: Pomp.ndoun.

La science n'a jamais rendu ridicule un bon esprit, dans quelque seve qu'elle se soit trouvée.

Govgr:T.

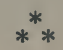


Pour donner aux femmes l'habitude du travail intellectuel, il fiudrit l'ithord mettre dans la tète des jeunes filles que leur éducation n'est pas finie à dix-huit ans et que lia première robe de bal n'a, pas plus que le diplòme de bachelier pour les jeunes gens, la vertu de donner à leur science son parfait développement.

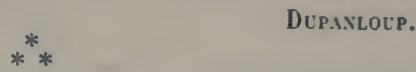

Il n'est aucun de rous qui ne préférera, pour passer la vie avec elle, une servante ì une femme savante.

Certains choisiraient une servante de la science.

DE STENDH.AL.

$$
* *
$$

Böhtling cite, dans ses Proverbes indiens, cette progression géométrique : Je donnerais dix brahmes pour un professeur, cent professeurs pour un père et mille pères pour une mère.

$$
\text { *** }
$$

On attribue ces mots, d'une fierté cruelle, a Cornélie, mère des Gracques : “ Moi, en vérité, je me glorifie bien plus de la science que j’ri acquise, que des fils que j'ai enfantés. "

Confucius a dit que la science est plus rare que la bonté et le courage.

$$
\text { *** }
$$

Un peu de science peut rendre une femme pédante, beaucoup de science la rend modeste.

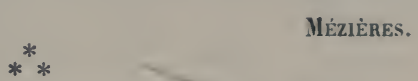

Le préjugé attaque la femme qui s’occupe d'études sérieuses.

N'est-il pas à craindre que la femme qui aura pris goût aux plaisir's intellectuels, n'y consacre une trop grande partie de son temps...?

Je répondrai que le même danger existe, bien plus grand, pour celle qui a contracté l'habitude des entretiens et des occupations frivoles.

Marie Sincére. Des Préjugés, pp. 197 et 198. (Pseudonyme de Marie Romieu.)

$$
\text { ** }
$$

Molière. en France, a fait le mème désordre par sa comédie des Femmes savantes. Depuis ce temps-lì, on a attaché presque autant de honte au saroir des femmes qu'aux vices qui leur sont le plus défendus. Lorsqu'elles se sont vues attaquées sur des amusements innocents, elles ont compris que, honte pour honte, il fallait choisir celle qui leur rendrait davantage et elles se sont livrées aux plaisirs.

Mad. de Lambert. Réflexions sur les femmes.

$$
\text { ** }
$$


Il faut que la femme comble les vides du passé, qu'elle répare ce que de longues années de servitude et de tutelle lui ont donné d'infériorité factice. Pour cela, l'instruction est indispersable; elle est aussi toute puissante.

$$
\text { * } \quad \text { L. Cosson. }
$$

Un savant disait à une femme, calme et judicieuse : "Vous êtes comme une montre bien réglée qui marche sans qu'on aperçoive le mouvement. ”

$$
* *
$$

A propos des deux sexes, M. Legouvé parle ingénieusement de l'égalité dans la différence. C'est ce que les mathématiciens appellent l'équiralence.

$$
* *
$$

Qui le croirait ? c'est par des lignes arides, c'est par l'austère géométrie que doit commencer l'étude de la parure. Cette jolie femme est emprisonnée à son insu dans un réseau de parallèles inexorables, comme le serait un oiseau dans sa cage; un invisible treillis de verticales ct d'horizontales emprisonne sa beauté mouvante et libre.

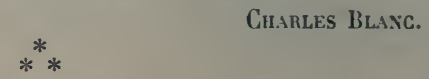

Je ne m'enfoncerai jamais dans le chaos des sciences : ma piété n’a pas hesoin de savoir, elle est toute dans mon cœur, elle est toute d'amour...

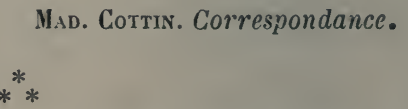

La plysicienne, la mécanicienne, la femme-médecin, etc. épouseront de préférence le physicien, le mécanicien, le médecin, et le trarail commun donnera des résultats supérieurs.

Jexxy d'Hénicourt. La femme affranchie, t. II, p. 213.

$$
* *
$$

Jamais femme ne fut si sarante, et jamais personne ne mérita mom qu'on dit d'elle : c'était une femme sarante.

$$
* *
$$

Voltaine.

Chez l'homme domine l'analyse réfléchie qui aboutit à la différentia tion; chez la femme, la synthèse spontanée à l'intígration.

\section{A. Foullée. Tempérament et caractère.}

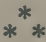


De ces sommets, on en apercerial d'autres. Les forees de l'humanité se toumeront vers les sciences et renverserout les olsstales qui s'opposent à la conquète de la nature.

Les sciences sont des émancipatrices patcifłques.

LUUISE: Micuel.

$$
* *
$$

Parmi les hommes les $\frac{2}{3}$ s'appliquent aux sciences et le $\frac{1}{3}$ aux arts; pour les femmes les $\frac{2}{3}$ aux arts et le $\frac{1}{3}$ aux sciences.

Сh. Fourrier. Le nouveau monde, p. 20.

$$
\text { *** }
$$

Lit Vénus des Hellènes est trop pâle. Et puis elle a le tort d'ètre géomètre et métaphysicienne. La pensée roule dans sa belle tète arec l'exactitude d'un astre lumineux parcourant son zodiaque. Elle médite sur la force qui crée le monde et en maintient l'harmonie.

Anatole Fra.jce (Le Temps du 16 mars 1891).

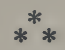

Comment done, pour les siècles écoulés, pourrait-on compirrer les actes des femmes à ceux des hommes, puisque les deux sexes ne se trouvaient point dans les mèmes conditions physiques ni mentales ? Ce serait procéder comme le mathématicien cuui voudrait comparer deux fractions non réduites au mème dénominateur.

\section{J. Lourbet. La temme devant la science.

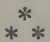

Le nueud gordien fut coupé par Alexandre impatient. Le souple fil d'Ariane servit de guide dans le Labyrinthe.

$$
* *
$$

Il n'y a plus que des techniciens, cherchant des inventions nouvelles et de nouveaux procédés mécaniques. Certes les progrìs de l'imlustrie ne sont pas ì dédiaigner; mais ces progrès mêmes s'arrèteront bientòt, dans la routine, si la curiosité théorique et le culte de la science pure ne sont pas entretenus.

Clémevce Royer. 


\section{ANECDOTES}

Il y avait, une fois, un paurre professeur appelé Meades chargé, ¿̀ récole des jeunes filles d'Oakland, de faire entrer dans la cerrelle de ses jeunes et belles compatriotes les lois électriques d'Ampère, de Faraday, d'Ohm et de leur apprendre le mystère des volts, des potentiels, etc., arec expériences à l'appui. Lì, sur la table, trônait un grand galvanomètre, instrument qui révèle le plus petit courant électrique et si moindre variation. Chaque élève après explication de M. Meades derait faire fonctionner l'instrument délicat. Mais, mystère, aussitôt que la première appelée s'approche, l'instrument est jris de rertige et l'aiguille s'affole. La seconde, à un mètre de distance, dévie l'aiguille qui danse une tarentelle effrénée. La troisième amène l'aiguille à une division inconnue. Le paurre M. Meades n'y comprenait rien.

Quelqu'un comprit pour lui. Malgré l'interdiction la plus sévère, le corset avait trouvé le moyen de se faufiler à l'école et son armature de fer avait troublé l'instrument de physique. Ce fut une grosse affaire; la direction décida qu'après appel nominal et essai an galranomètre toute jeune fille, qui " exercerait de l'influence ", serait immédiatement expulsée. L'instrument se montra galant et ne dénonça personne: depuis ce temps on a abandonné le corset à Oakland. C'est de bon augure pour la Californie. Mais ce que les galranomètres doirent ètre affolés en France!

Hexri de Parville (Les Débats du 15 octobre 1896).

$$
\text { ** }
$$

Les Poésies de Clotilde de Surville (1403̈-1494) ont étẻ publiées en 1803. Un des motifs faisant croire ì une supercherie littéraire, c'est qu'il est parlé, dans ces poésies, des satellites de Saturne, dont le premier ne fut découvert par. Huygens qu'en 1655.

Lourse D'Alq. Anthologie féminine, p. 22.

$$
\text { ** }
$$

L'impératrice-reine Marie-Thérèse ayant demandé ì Maupertuis s'il eonnajssait la reine de Suède, søur du roi de Prusse: "On dit, ajoutat-elle, que c'est la plus belle princesse du monde. " - "Madame, répondit Maupertuis, je l'avais cru jusqu'it ce jour. "

$$
* *
$$

A Berlin, M. de Treitschke, profésseur à l'Lniversité, apercevant une auditrice à sa leçon, lescendit de sa chaire pour lui offrir son bras... et la conduire dehors.

$$
* *
$$


Ion père, répondit-elle en se rassurant assez vite, comme toutes celles à qui l'on n'enseigne pas l'embarras, je viens te demander combien de distance nous devons mettre entre Saturne et Uranus. - Tu trouveras le calcul écrit dans mon cabinet, près de la sphère céleste. Va, mon enfant. " La jeune fille s'éloigna.

"Mon ami, dit le comte arec étonnement, pourquoi rotre fille estelle venue vous demander la distance de Saturne à Uranus?

Pour le saroir, mon ami.

$$
\text { L'Hote (riant). }
$$

Sans loute; mais ì quoi bon?

$$
\text { Le Conte. }
$$

\section{L'Hote.}

Pour établir sur notre terrasse arec des proportions exactes son petit système du monde.

$$
\text { LE Conte. }
$$

Comment, son système du monde?

\section{L'Hоте.}

Ye rous ai-je pas conté cette mienne inrention? J'en suis cependant très fier. Quand j'eus montré ì ma fille les premiers principes de l'astronomie..

$$
\text { LE Conte. }
$$

Votre fille sait l'astronomie !

\section{L'Hote.}

Non pas, non pas, elle l'apprend; nous n'en sommes encore qu'au premier cours, mais demain nous commençons le second. Lors done que les principes furent à peu près sus, j'imaginai, pour qu'elle ne les oubliait pas, de planter sur notre terrasse...

\section{Le Coyte.}

Voyons, vous raillez, n'est-ce pas? Que voudriez-rous que rotre fille fit de l'astionomie?

\section{L'Hote.}

Ce qu'on fait de toutes les sciences; ce qu'on fait de l'histoire, de lit physique, de la chimie.

\section{Le Comte.}

Vous lui apprendrez peut-ètre aussi la chimie ?

Pourquoi non ?

\section{L'Hote.}

Ersest Legoové, Histoire morale des femmes, pp. 16, 17, 18.

$$
\text { ** } *
$$

Madame Adélaïde (1), surtout, avait un désir immodéré d’apprendre; elle apprit ì jouer de tous les instruments de musique, depuis le cor (me croira-t-on!) (2) jusqu'à la guimbarde. L'italien, l'anglais, les hautes

(1) Fille de Louis XV.

(2) Ton, ton, tontaine, tonton : 
mathématiques, le tour, l'horlogerie, occupèrent successivement les loisir's de ces princesses (1).

Mmo Campan, Mémoires.

$$
* *
$$

Un professeur de chimie à I'Université de Genève déclarait doctement. il y a quelques années, que les femmes n'ont pas d'aptitude pour les sciences parce que dans les manipulations elles cassent plus d'éprouvettes que les hommes.

Est-ce là une réritable épreuve ? Non, ce n’est qu’une... éprourette.

$$
\text { ** }
$$

Une veure, mère de dix-neuf enfants, voulant se faìre exempter de l'impôt, écrivit au Roi qu'ayant donné dix-neuf sujets à l'Litat, elle roudrait bien ètre dispensée du vingtième.

$$
* *
$$

M. Léopold Hugo a adressé ì l'Académie des Sciences une note sur une jeune calculatrice et sur les questions qu'il lui a posées. (Renvọé à la Commission Inaudy. - 14 mars 1892.)

\section{***}

Un jour qu'il faisait nuit, comme dit la chanson, Pons, le coneierge de l'observatoire de Marseille, décourrit une comète importante. MarieLouise, qui régnait à Parme, le nomma son astronome.

$$
* *
$$

Au printemps de 1819, une petite fille d'environ onze ans parut it Royal Excliange (la Bourse de Londres) où elle fit des calculs rraiment extraordinaires. Quelques boursiers lui adressèrent des questions extrèmement difficiles à résoudre de tète, et elle donna sans avoir l'air de calculer les résultats exacts. On lui demanda de multiplier 225600 par 250 , et elle répondit, en moins d'une minute, 56400000 . On lui dit: Combien y a-t-il de minutes en quarante-deux ans? Réponse : 22075200. On lui énonça deux nombres, 5250000 à multiplier par 450. Elle répondit qu'en les multipliant l'un par l'autre on obtiendrait 236250000 . Elle résolut de la mème manière plusieurs autres questions encore plus difficiles.

Cette enfant ne savait ni lire ni écrire. Elle s'appelait Ileywood et était la fille d'un tisserand qui habitait Mile-End-New-Town.

Percy. Anecdotes (1822).

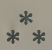

Deux fiancés, séparés par la vaste étendue des mers, étaient convenus de regarder la mème étoile à la mème heure. Comme ils ne saraient pas

(1) Craindre l'indigestion. 
l'astronomie, ils ignoraient que le jour de l'un était la nuit de l'autre et réciproquement.

$$
* *
$$

Litdy Joan arait reçu le matin mème une lettre d'Arago; clle en attenlait une le lendemain lu docteur Buckland; elle était cliarmée que l'un lui eùt écrit, étonnée que l'autre ne l'eût pas encore fitit. Enfin, avant de passer au silon, elle invita Egremont à venir avec lidy Marney à son observatoire, pour voir une comète qu'elle avait décourerte la première.

$$
\begin{aligned}
& * \\
& * *
\end{aligned}
$$

Thénard alla bravement trouver Vauquelin et lui proposa ses servires comme garçon de laboratoire. Il ne dut le succès qüälintervention d'une des socurs du célèbre chimiste qui, présente à l'entretien, dit à son frère : "Tu derrais le garder; il aiderait dans le laboratoire et surveillerait notre pot-au-feu, que tous les muscadins laissent trop bouillir. "

"Je n'ai jamais été assez ingrat, disait Thénard, pour oublier depuis qu'un pot-au-feu qui bout ne fait que de mauvaise soupe."

M. Marie. Histoire des mathématiques, t. XI, p. 139.

$$
\text { *** }
$$

En $1844, M^{\text {mo }}$ la princesse Galitzin offre à l'Académie des Sciences un prix de mille franes pour " étudier le derniel changement opéré dans les monnaies de la Russie " puis un autre de mille francs aussi, pour " montrer les inconvénients de la pomme de terre considérée comme" nourriture habituelle des peuples ".

L'Académie a refusé ces deur donations.

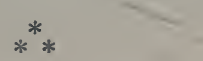

Dans Artamène ou le grand Cyrus (10 rol. in-8, t. X, 1) 560) Mademoiselle de Scudéry oppose à Sapho, la femme instruite, Damophile, lit pédante. Cette dernière " a chez elle cinq ou six savants en astrologie qui raisonnent en sil présence sur l'éclipse qu'on royait alors et ell passe toute la nuit a parler de l'interposition de la terre entre la lune et le soleil ".

$$
\text { *** }
$$

La première femme de M. Rohault, disciple de M. Descartes, dont il expliquait la philosophie dans des conférences publiques, se metlitit ces jours-là sur la porte de sa maison et en refusait l'entrée a tous ceus qui n'avaient pas l'air de qualité, persuadée qu'il fallait avoir cet air pour mériter d'écouter son mari. Le bon homme se tuait à lui dire que lit fortune ne donne pas toujours de riches habits aux philosophes: elle voulait roir du velours et n’en démordait pas.

Mélanges d'histoire et de littérature de du Vigneul-Marnilf, tome I, p. 20 .

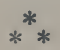


Je me suis enquis des remèdes contre la rudesse de la peau des bras. mais je n'en ai pas trouvé de particulier pour cela, mais seulement pour rendre douce la peau des mains, que l'on dit encore pouroir servir à ce que Mademoiselle Cabellino demande. Je rous en enroie la recette que m'a donnée une dame qui a les mains fortblanches et helles, et je souhaite que celles de la demoiselle susdite le deviennent autant pour votre satisfaction, car pour moi il y a peu d'apparence que je les touche jamais, et rous en devez estimer d'autant plus le soin que je prends.

(Extrait de la correspondance de Cumstisx Horgexs.)

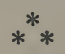

Descartes, le grand philosophe et le grand mathématicien, ne crut pas trop déroger en composant des vers à l'occasion d'un bal ; on i mème retrouvé dans ses papiers le manuscrit d'une pièce de théàtre dont il roulait faire hommage à la reine Christine de Suède.

$$
\text { ** } *
$$

Ln jour Arago annonce ì M. Ampère l'arricée d'une berlinoise dont les connaissances en astronomie sont véritablement fort étendues.

" J'ai eu, dit-il, occasion de m'entretenir arec elle, et son saroir m'a positivement surpris. Du reste, elle se propose de vous aller roir, car elle m'a demandé votre adresse. "

Effectivement, quelques jours après, M. Ampère voyait entrer chez lui une dame voilée dont la mise étrange et les allures cavalières sentaient de fort loin leur bas bleu. Après une heure de conversation transcendante, soutenue à grand renfort de germanisme, cette savante berlinoise (car c'était elle) se retire en laissant ì $\mathbf{1}$. Ampère la plus haute idée de ses capacités.

On se doute que la femme prodige n'était autre qu'Arago lui-mème grimé et costumé d'une façon méconnaissable, surtout pour un homme aussi distrait que son éminent confrère.

\section{Enmond Guḱrard. Dictionnaire d'anecdotes.}

$$
\text { *** }
$$

Leibniz était riche mais son trésor fut fatal à la femme de son seul héritier, fils de sa sœur, qui administrait une paroisse près de Leipzig. Cette femme, en voyant tant d'argent réuni qui lui appartenait, fut si transportée de joie qu'elle en mourut subitement.

$$
\text { *** }
$$

Hier, raconte l'astronome Képler, fatigué et l'esprit troulblé par les médilations sur les atomes, je fus appelé à diner, et ma femme Barbara apporta sur la table une salade. - Penses-tu, lui dis-je, que si, depuis la création, des plats d'étain, des feuilles de laitue, des grains de sel, des gouttes d'huile et de vinaigre, et des fragments d'mufs durs flottaient dans l'espace, le hasard put les rapprocher aujourd'hui pour former une salade? - Pas si bonne, à coup sûr, réponulit ma belle épouse, ni si bien faite que celle-ci.

$$
\text { ** } *
$$


Saunderson fut, quoique areugle, professeur de mathématiques et d'optique. Il dit un jour, dans un salon, qu'une dame qui rentit de sortir et qu'il n’avait jamais entendu parler, aviit de fort belles dents. Comme on se récriait, il répliqua : "Je n'at aucun motif pour supposer" cette dame insensée, or je l'ai entendu rire continuellement. J'ai supposé que c'était pour montrer ses dents. 》

$$
\text { *** }
$$

Lagrange aimait beaucoup la conversation des femmes, parce qu'elles sont généralement plus spirituelles que les hommes et qu'elles ne sont pas savantes. Il disait un jour arec finesse dans une société où on parlait de femmes àgées de soixante ans: Est-ce que vous avez vu des femmes de soixante ans? Pour moi, je n'en ai jamais rencontré.

Bıт. Mélanges scientifiques, t. III.

$$
\text { *** }
$$

Devenu areugle dans sa vieillesse, Mathieu Laensberg, le légendaire chanoine de Saint-Barthélemy de Liège avait pris pour secrétaire une jeune béguine, sa nièce, laquelle avait charge d'écrire sous sa dictée ses pronostics en regard de chacun des jours de l'année. L'àge et aussi les misères de la cécité n'avaient pas laissé d'assombrir outre mesure les visions du prophète: malheur's et sinistres lui pleuvaient des lèvres. De quoi la fillette se désolait, n'ayant pas les mèmes raisons de désespérer. lis en étaient arrivés au 23 août : " Orage, grèle, tonnerre, la foudre tombera sur un des plus beaux clochers de l'Europe ", grondait l'oracle impitoyable. Pour le coup le secrétaire se révolta : "Tant de calamités au 23 août, jour de Saint Nathieu, jour de votre fète ! Vous n'y pensez pas, mon oncle! " - " C'est pourtant vrai, murmura cette fois le rieillard, il faut changer cela, ne fût-ce qu'en l'honneur du bon Saint Mathieu, évangéliste. " Et à la place du premier texte il fit mettre "Temps clair et doux, soleil et joie, sérénité inaltérable, beau fixe..."

A. Le Braz. (Les Lébats du 20 novembre 189\%.)

$$
* * *
$$

La mère de Poisson lui écrivait avec une grande régularité, surtout après la mort de son père. L'humble femme ne se mettait guère en frais de rédaction dans ses réponses. Ses lettres étaient les copies de celles de son fils, avec un simple changement dans les pronoms. Si Poisson avit écrit: " Je prépare un mémoire d’astronomie ; je m’occuperai ensuite de la seconde édition de mon Traité de mécanique, etc. ", on était certain de trourer dans la réponse maternelle : "Tu prépares un mémoire d'astronomie, tu t'occuperas ensuite de la seconde édition de ton Tratité de mécanique, etc. "C'était là l'empreinte naïre de l'admiration profonde que la mère professait pour son fils adoré, admiré du monde savant.

$$
* *
$$

Je compte encore par 20 , disait $M^{m o}$ de Lafayette dans sa $3 C^{\circ}$ année, ne roulant ni déclarer, ni dissimuler son àge.

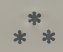


Maurice de Fleury raconte une visite féminine au college de France:

Retroussant joliment ses jupes parmi les appareils joncluant le sol, avec des piaulements aigus lorsque sa robe accrochitit, des effets de bouche béante devant les surprenantes mécaniques; furetant avec une moue parmi l'encombrement des tables, le foullis poussićreux des étagères; solennelle pour regarder à l'oculaire d'un microscope; prenant des allures tragiques en brandissant un bistouri ; à l'aspect d'un cobay: dépecé, mimant une attaque de neris ; claquant des dents, simulant des frissons de terreur devant la cage aux chiens inoculés de rage; saisie de compassion tendre ì l'aspect des bassins où, dans un clair courant d'eau vive, barbote, en attendant la mort, une légion de grenouilles, la jeune femme qui s’amusait beaucoup chanta victoire quand elle découvrit, au fond d'un placard, la robe herminée et la toque à torsade d'or du professeur.

$$
* *
$$

- Cependant, doù Jupiter tirerait-il une semblable chaleur ?. . pas du Soleil, assurément, puisqu'il en est cinq fois plus éloigné que li Terre... Ne m'avez-rous pas dit, mon père, que la surface du Soleil, vu de Jupiter, - étant vingt-sept fois plus petite - il s'en suit que la planète y est réduite au trente-six millième de l'intensité de la chaleur et de la lumière reçues par la Terre.

En écoutant parler sa fille, le visage du vieillard devint radieux.

- Ah! fillette, fillette, murmura-t-il d'une roix attendrie, tu es lit joie et l'orgueil de mes rieux jours.

Le Faure et Gr.sfig.ny. Aventures extraordinaires d'un savant russe, t. III, p. 151 .

$$
*^{*} *
$$

Messier, l'astronome que Louis . XV appelait le furet des comites, eut le malheur de perdre sa femme au moment où son colligue Montagne découvrit une nouvelle comète : "J'en avais encore une, fallait-il que ce Montagne me l'enlevât! "On lui fit remarquer qu'il sagissait de sa femme et non de la comète : "Ah ! oui, dit-il, cétitit unc bien bonne femme. » Au fond, c'était la comète qu'il pleurait.

$$
* * *
$$

Gisèle ! C'est M. Resal, l'éminent professeur de mécanique ì l'École polytechnique, qui, cette année, a présenté Gisèle à ses confrìres de l'Académie des Sciences. Qu'est-ce que Gisèle ? Il y a beaucoup de Gisèle, mais celle-là est une petite dinseuse d'opéra qui exécute à ravir des pas, des battements, des entrechats arec une gràce, une souplesse, une séduction qui lui ont valu les applaudissements de la savante compagnie. Gisèle est une blonde aux yeux bleus; M. liesal la met dans sa poche, non pas qu'il soit d'une taille bien extraordinaire, mais parce que la ballerine est lilliputienne, haute comme son doigt. Quand il reut la montrer, il li sort délicatement, étale ses jupes un peu fripées et la pose sur le dessus bien rerni d'une boîte en bois blane, à peine granile comme un in-18. L'n signe amical. I'n air de polka sort de lit boîte. Aussitôt, Gisile avance le pied, et la roilì gui pirouetle, valse et 
entreprend sans reprendre haleine les pas les plus complipués et les plus variés. M. Resal est tout joyeux et applaudit avec ses graves roufrires. C'est qu'il est parrain de Gisèle. Le père de Gisèle est M. Japy, de la maison si connue Japy frères. Je crois que le parrain est encore plus fier de sa pupille que l'auteur mème de Gisèle. Quand on le jousse un peu, il finit par avouer qu'au fond ce n'est qu'un jouet; mais quelle jolie application de la mécanique! Quoi, rien, l'inslillation d'une tige? rerticale suffit pour produire aree le frottement des pieds sur une surface lisse des effets de volte-face et d'entrechats si parfitits ! II est de fait que tout le secret de ce mécanisme est si simple qu'il devient intéressant par cela mẻme. Je ne dirai pas à M. Resal que j’ai vu, il y a quelques années déjì, au sommet du liki-Schedegg une ballerine qui ressemblait singulièrement à Gisile. Pour amuser les touristes, le dorteur Stierlin a placé à l'entrée de son établissement une miniature de " chevaux de bois mécaniques". Les chevaux tournent; un singe bat de la grosse caisse et fait marcher des cymbales; deux ballerines valsent au son le la musique. On met 10 centimes dans la tire-lire et la petite mécanique fait merveille. C'est très amusant par les jours de neige! Le mécanisme a été simplifié jar M. Japy et sa Gisèle en a bénéficié. lien en effet de plus gracieux et de plus étonnant.

La boite qui sert de support renferme un cylindre it musique et un mourement rudimentaire d'horlogerie qui actionne une tige verticale. Cette tige de quelques centimètres sort par un trou disposé au milieu de la face supérieure de la boite, va et vient avec une régularité chronométrique. On fixe la poupée sur l'extrémité de la tige; les pieils frôlent le parquet ciré qui constitue le dessus de la boìte. Or les frottements de chaque pied sur le parquet combinés aux mourements alternatifs d'élévation et d'abaissement déterminent comme par magie les: pirouettes et les évolutions étonnantes de la poupée. MI. Resal roudrait bien mettre ce problème de mícanique en équation; mais c'est si subtil qu'il y renoncera. En attendant, sa Gisèle continue ì valser avec un entrain diabolique. Cela devient de l'obsession, l'air le la boitte rous poursuit, les entrechats vous restent dans les yeux. Matin et soir, Gisèle danse, danse toujours. Nous la recommandons à MM. Bertrand et Gailhard... Car après l'Académie des Sciences, où pourrait-elle êtr" mieux qu'à l'Académie de Musique ou au foyer de lá danse?

Hexni de Parmille

(Les Débats, du 26 décembre 1894.)

$$
* * *
$$

Une fois seule, elle s'iccordait des récréations; elle interrogeait les instruments dont Guy tirait tant d'expériences, et dont le mystère lit tourmentait. Quand elle lui eut cassé deux ou trois fois son microscope, Guy, impatienté, lui apprit à le mettre au point.

Belle est instinctirement adroite. En très peu de temps, elle maniat l'instrument comme un vieux micrographe. Guy, enthousiasmé, lui mit d'autres mécanismes entre les mains. Bientòt, il n'eut plus dי réserves pour elle. Il l'initia à toutes ses manipulations, il lui ouvrit ses armoires et lui confia mème son fameux mierotome tout neuf, d'une délicatesse extrème, fragile, auquel il ne touchait lui-mìme qu’aver un 
luxe de précautions attendries... Jamais, quand je passais laprès-midi chez eux, il ne m'arait permis de toucher à ce microtome.

Belle était presque aussi farouche. Elle alléguait l'interdiction de Guy et, pour me consoler, traraillait devant moi, contente, au fond, de m'émerveiller par son habileté précoce. Elle arait vite épuisé les troublantes délices du grossissement et la joie inquiète de voir grouiller un monde au fond d'une goutte d'eau, entre les lamelles pàles du microscope. A quatorze ans, elle faisait déjà des coupes et iles préparations pour son frère qui utilisait sans vergogne la féminine souplesse de son doigté.

\section{Le cas de Georges d'Arell par Dis:K Max.}

$$
\text { ** }
$$

Caboche-Demerville (Les enfants célébres, 1842, in-8, p. 43). I.e duc de Bourgogne, âgé de six ans (1757), fit à Meudon ses premiers essais de géométrie pratique. Mad. la Dauphine prenait plaisir à le voir, lı règle, l'équerre, le compas à la main, comme un arpenteur consommé. Une image les représente tous les deux, l'enfint se servant derant sa mère du niveau d'eau et de la mire.

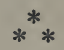

Le professeur Weyer se rappelle le cas d'un capitaine de vaisseau, qui amenait à Hambourg sa fille aux leçons d'astronomie nautique, parce qu'elle comprenait plus vite que lui, et pouvait ensuite lui expliquer les choses.

$$
\text { Kincunorf. Die akademische Frau, p. } 255 \text {. }
$$

$$
* *
$$

A cela, Pasteur pouvait répondre... Si rous me dites que le microscope vous fait peur, et que son maniement ne rous semble pas facile, ipprenez ceci, e'est qu'il y a chez moi une petite fille de lutit ans qui s'en tire trìs bien.

$$
\text { E. Duclaux. Pasteur, histoire d'un esprit, 1'. } 204 .
$$

\section{PARADOXES ET BOUTADES}

On doit la prune Reine Claude à Claude de France, flle de Louis XIII.

Poppora, femme de Néron et aussi méchante que lui, n’a pas dì inventer la poupée. Une honne grand'mère, la reine Victoria, les perfectionne.

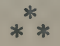


Après Julienne et son potage, on doit citer aussi par leurs seuls pré noms, deux autres cuisinières, Madeleine avec son gateau et Charlotte avec sa marmelade de pommes garnie.

$$
\text { ** }
$$

A Port-Roỵal la mère Thècle, tante de Racine, composa pour les paurres gens l'onguent de la mère qui ne s'est plus perdu.

E. Folriser. Le vieux et le neuf. t. II, p. 391.

$$
\text { *** }
$$

Parmi les nombreuses démonstrations du carré de l'hypoténuse, Bhascara cite la chaise de la petite mariée, dont la figure représente vaguement une chaise.

$$
\text { *** }
$$

Antrone. Moi, je ne roudrais certainement point d'une femme savante.

Magdalie. Et moi, je me félicite d'avoir reneontré un mari qui ne vous ressemble pas, car la seience nous rend plus chers, lui à moi et moi à lui.

L'abbe et la savante, par Erasme, pp. 23-24.

$$
\text { *** }
$$

Niss Positive ne sera ni jolie, ni mème propre: la science est exigeante. - Elle aura les ongles en deuil de nos collégiens et les chereux courts en broussailles. - Elle sera brouillée avec les brossés, les savons; les frais parfums, les romans et l'idéal!

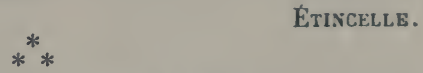

Les feuilles américaines rapportent que M. Mac-Kay, directeur de Central-Parke-Zoo, de New-York, apprend à ferire à un chimpanzé femelle, Johanna.

L'élève, dont le cerveau a un développement supérieur à celui de bien des humains, ferait des progrès sensihles.

$$
\text { ** } *
$$

Dars une chansonnette de Xanrof:

........ Sa nuque avait des tons rosés,

Elle marchait presque aussi vite que des intérèts composés.

Malheureusement, elle penchait à droite comme la tour de Pise.

$$
* *
$$

Les femmes ont assez généralement la coutume de retrancher un certain nombre d'années sur le chiffre de leur àge. Mais ces années ne: sont pas perdues, elles ajoutent à l'ìge de leurs amies tout ce quielles enlèvent au leur.

L'àge total du sexe n'est pas changé.

Comtesse Diase.

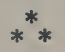


Tous trouvons dans un recueil du siècle dernier des vers d'une dame à une autre dame, en lui faisant présent d'un étuy de mathéınatiques.

Que la belle $\mathrm{A}^{* *}$ se pique

D'algèbre et de mathématique, Sciences qu'on connaît si peu dans notre cour, De son étude, hélas! pareils soins sont-ils dignes?

Fùt-ce pour calculer qu'elle reçut le jour?

Et ses mains faites comme au tour

Les fit-on pour tracer et mesurer des lignes?

Eviter l'aspic du premier vers.

$$
* * *
$$

J'admets avec vous, lui dis-je, que le gaz azote ait bien roulu prendre un corps palpable et devenir génie ou dénıon, comme vous voudrez : il ne serait pas un mauvais génie, car il n'a sur les fonctions vitales aucun effet nuisible. Nous l'aspirons et nous l'expirons en respirant, sans en éprouver aucun malaise. Il n'aide pas à la vie, mais il n'y est pas contraire; il est inerte. Done mademoiselle Azote est inoffensive..

\section{Maurice. Sand. Mademoiselle Azote.}

$$
* *
$$

On discourait sur la pihilosophie - le sujet ì la mode - chez Ime de Forgeville qui tenait bureau d'esprit dans le l'aris du dix-huitième siècle.

"Mais, mon Dieu! disait-elle, pourquoi toujours votre grand mot de philosophie? Quel bien ont-ils fait vos philosophes? L'humanité s'en trouve-t-elle plus heureuse?

- Quel bien ils ont fait, Madame ! s'écrie d'Alembert... Mais comptez-vous pour rien cette forêt de préjugés qu'ils ont abattue pour frayer un chemin à la vérité ?

- Ah ! c'est donc pour cela que vous nous débitez tant de fagots. "

Lonédax-LARCuEr. Les joueurs de mots, p. 5̌t.

$$
* *
$$

En Sorbonne... La scientifique: figure pauvre, cheveux paures. bras pauvres; trop grande; la déshéritée de la Pédagogio. Plus myope que les plus myopes, toute en nez et en pieds. Aggrave son anémie à suivre de très loin les démonstrations des savants MIN. P...d et $\mathrm{A}$....

La Vie Parisienne, du 22 décembre 1894.

$$
* *
$$

In quidam, bon mari mais meilleur citoyen,

Rêvant patriotisme et songeant all moyen

Que Necker a trouvé pour sauver la patrie,

Lui dit : "Voilà ma femme, elle est jeune et jolie,

Elle inspire à chacun une tendre amitié.

Vous demandez mon quart, je donne ma moitić. 
Le nombre des femmes remarquables par leur vigueur intellectuelle "roît en une progression dont la " raison" est la liberté.

Jacoces Lotrbet. La Femme devant la science contemporaine, p. 169.

$$
\text { ** } *
$$

Bernardin de Saint-Pierre prétend faire des femmes uniquement des ménagères et des amies. Ce n'est pas avee la science et la philosophie qu'on prend un homme: c'est par toutes les séductions féminines, et c'est par la cuisine qu'on le retient. In mari n'aime point à trouver un rival ni undocteur dans sa femme. "In mari aiıne la bonne patisserie quand ilse porte bien, la bonne tisane quand il est malade. Il aime le bon café au lait, les confitures dont le jus brille comme le feu des rubis."

$$
* *
$$

Kostner était mathématicien et poète. Voici un quatrain peu galant qu'il a rimé pour un virtuose :

Orphée eut le renom d'adoucir par ses chants

Les rochers les plus durs, les monstres rugissants,

Les barbares instincts des plus cruelles âmes ,

Mais toi, tu fais bien plus : tu fais taire les dames.

Traduit de l'allemand par Charles Berdellé.

$$
\text { ** }
$$

Le célibat était jadis imposé aux professeurs des universités. Le $M a$ riage des Sept Arts par Tainturier est un vieux conte du xul ${ }^{\circ}$ siècle où lon plaide la cause du mariage. Dans une prairie émaillée de fleurs, sept eunes filles, Grammaire, Mlusique, Logique, Rhétorique, Astronomie, Arithmétique et Géométrie s'entretiennent du désir qu'elles ont de se inarier. Surviennent Théologie et llédecine; lit première cherche à dissuader ses colligues en leur détaillant les avantiges de la solitude. Médecine réplique qu'il est des filles auxquelles le mariage est bon et elle leur tàte le pouls, à toutes les sept. Médecine conclut en riant: "Théologie, il faut les marier."

$$
* *
$$

Dans Neptune, chaque année dure plus d'un siècle et demi : 165 de nos rapides années. Si la biologie y est réglée dans les mèmes proportions, une jeune fille de dix-sept ans sur Neptune a réellement vécu 2800 de nos années : elle vivait déjà depuis près le mille ans quand J.-C. naquit en Judée; elle a été contemporaine de Romulus, de Jules César, de Constantin, de Clovis, de Charlemagne, de François Ier, de Louis . IIV, de Robespierre... et elle n`a encore que dix-sept ans ! Létlargique flancée, elle épousera dans trois ou quatre cents ans un jeune homme àgé luimême de plus de trois mille ans terrestres.

E. Flamminiox. Astronomie populaire.

$$
* *
$$


Loulou. - Répétiteur d'math....

Papa. - Hein?

Loulou, condescendante. - ... ématique... nous disons math... c'est plus court...

Papa. - En effet...

- Loulou. - C'est du reste pour toi que j’avais dit répétiteur d'math... car on doit dire : "le rép... d' math... ", c'est le vrai genre.

Papa. - Ah !... c'est le genre $! .$. et pourquoi as-tu un répétiteur d' math... puisque math... il y a ?...

Loulou. - Parc'que c'est ce qui me chante l' moins !... j' suis obligée d' les bûcher très dur, ces sales math...

$$
* * *
$$

Grp (Ime Martel).

Elle résout d'un mot, en plaçant sa fontange,

Ces grandes questions qui terrassent Lagrange.

On voit sur sa toilette un Euler, un Piscal,

Salis et barbouillés de rouge végétal.

Elle trouve en Yewton je ne sais quoi d'aimable

Et l'algèbre a pour elle un charme inexprimable.

Le soir, dans un donjon, d'un regard curieux,

$\mathrm{Au}$ bout d'une lunette interrogeant les cieux,

Son ceil observateur y poursuit la comète:

Lalande tous les ans lui role une planète.

Coliet. L'art de diner en ville.

$$
\text { *** }
$$

“ ... La psychologie, voyez-vous, ne sera constituíe à l'état de science exacte que si l'on s'habitue à parler de l'àme comme on parle des triangles et des carrés...

Posons done

$$
\mathrm{A}=a^{\prime}+b^{\prime}+c^{\prime}+d^{\prime} \ldots
$$

Cela signifie que la force que vous concentrez sur l'objet aimé doit et peut se décomposer en une série de forces moindres. Ce n'est qu'une addition, et ce mème problème de la guérison de l'àme se ramène à cet autre : détacher successivement $a^{\prime}, b^{\prime}, c^{\prime} d^{\prime} \ldots$ jusqừ̀ ce que nous ayons

$$
\mathrm{A}=0 .
$$

- "Les choses du cœur sont pourtint plus complexes que cela...." insinuai-je.

Paul Bounget. Physiologie de l'amour.

$$
* *
$$

La nuit, dans cet espace immense

Que Newton soumit ì sa loi, Je mesure, hélas, la distance

Qui me sípare de toi.

de Tressax.

$$
\text { ** }
$$


Plusieurs mémoires de mathématiques sont signés par Mme $\mathrm{V}^{\mathrm{vo}}$ Prime, de Bruxelles. Jexprime le soupçon que le mystérieus auteu est du sere laid et qu'il est mineur.

$$
* *
$$

DIALOGUE DES MORTES

Un groupe de femmes mathématiciennes et philosophes.

Hypatie, grecque d'Alexandrie, drapée dins le manteau des philosophes. - Aimons et contemplons les nombres et les figures. Platon rajeuni, de plus en plus subtil, suffit à notre vie morale.

Émilie du Châtelet, marquise de la Régence. - Newton nous a enfin décourert la mécanique et la géométrie de la Nature. Nous admettons aussi l'existence de Dieu, à condition qu'il ne gêne pas nos plaisirs.

Marie Agnesi, religieuse milanaise bleue. - Propageons le calcul infinitésimal, puisque le pape le permet. Surtout aimons Dieu et serrons les paurres : le reste est vanité.

Sophie Germain, bourgeoise de 1830. - La physique sera mathémattique ou elle ne sera pas. Cultirons la raison seule et découvrons l'ordre partout.

Mary Somerville, écossaise protestante. - On peut, sans négliger sil famille, propager Laplace et comparer les sciences physiques. Virons tranquillement et agréablement sous la loi du Seigneur.

Sophie Kowalerski, russe de Stockholm, un peu fin de siècle sous ses fourrures. - L'explication profonde dı mouvement réside dans les équations différentielles. Dégustons aussi la psychologie de Bourget et le socialisme de Tolstoï.

$$
\text { *** }
$$

... Cette petite, servant d'Égérie au vieux licencié, et plus trapue en $x$ que les candidats à Polytechnique et à Normale, cette petite est Césarine en personne...

... Vacquant lui-mème, dit-il, Vacquant c'est le professeur de Spéciales) n'est que de la gnognotte auprès d'elle.

... Certains ourrages qu'elle seule peut lire couramment... Elle est si étonnante, un génie mathématique. Son père était fort lui-même, seulement trop imbu de Wronski.

"Tout se résout en somme, dans la rie, mème les actes les plus extraordinaires, par des équations bien faites. "(Mot de Césarine)... De ces équations morales, je n’ai vu moi que les inconnues dégagées, je veux dire les faits... je ne puis ainsi que noter des points, en laissant à de plus perspicaces le soin de retrourer les coordonnées psychologiques.

Richepis.

$$
* *
$$

Vous ètes des zéros et nous sommes des chiffres.

Nous vous faisons valoir.

$$
\text { ** * }
$$


Je souffrirais plus volontiers une femme qui a de la barbe qu'une femme qui fait la sarante.

$$
\text { ** Balzac, le vieux. }
$$

“La parole est à NHe liı chéfesse du bureau des Calculs de l’Observiltoire."

A cette invitation, la jeune lauréate de l'Institut se dirigea rers lia tribune.

"Mes deux sarants collègues, fit-elle, sans exorde superflu, ont raison tous les deux, puisque d'une part il est incontestable que les agents météoriques, aidés par la pesinteur, nivellent insensiblement le globe terrestre, dont l'écorce s'épaissit et se solidifie de plus en plus, et que d'autre part la quantité d'eau diminue de siècle en siècle à la surface de notre planète. Ce sont lì deux points que la science peut considérer comme acquis. Mais, messieur's, il me semble pourtint que la fin du monde n'aura pour cause ni la submersion des continents ni le manque deau pour l'entretien de la vie des plantes et des animaux. ”

Cette nouvelle déclaration, cette annonce d'une troisième hypothèse, paraît frapper l'auditoire d'un étonnement roisin de la stupéfaction.

" Et je ne crois pas davantage, se hâta d'ajouter l'élégante oratrice, que ce soit la comète qui se charge de la catastrophe finale; car je pense arec mes deux éminents prédécesseurs à la tribune, que les mondes ne meurent pas d'accident, mais de vieillesse. "

Flammariox. La fin du monde.

Ce serait par le froid que l'Humanité périra.

$$
* * *
$$

Elle copiait une écquation qu'elle n'arait pas pu lire de sa place et qui restait sur le tableau. Tranquillement elle inscrivait les delta et les léta au-dessus des upsilon. Il s'agissait de laccroissement de sensation produit par une augmentation de lumière. Ainsi les plus rudes abstractions, en apparence, ne réussissaient pas ì la démonter.

Daniel Leseecu (Jeanne Loiseau). Névrosée.

$$
\text { ** }
$$

Un de mes amis Français, auquel on voulait fitire épouser une jeune fille (américaine) très riche, a rompu ce matriage, parce que sa demifiancée, très préoccupée de seience, lui arait exposé, toute une soirée durant, linvention d'une locomotive nourelle. "Je ne peux pas me marier arec un ingénieur... »fut sa seule réponse aux reproches de la personne qui l'avait présenté.

Paul Bounget. Outre-Mer, 1. 94.

$$
* *
$$

De la marquise de la Ferté-Imbault, ennemie les enc yclopédistes, sur une femme de la secte: 
Quel philosophe aimez-rous?

Elle les possède tous :

Locke, Aristote, Malbranchic,

Elle les a dans la manche.

Lampons, camarades, lampons.

Elle travaille, dit-on,

Sur le vide de Newton,

Avec d'iutant plus de zèle

Qu'elle l'a dans la cervelle,

Lampons, camarades, lampons.

$$
\text { *** }
$$

Ode triomphale en l'honneur du centenaire de 1789, poème et musique par Augusta Holmès. - Paris, 1889.

\section{LES Sciexces.}

Figures allégoriques, hommes et femmes. Lit Philosophie, l'Astronomie, la Géométric, l'Algèbre, l'Arithmétique, la Mécanique, la Médecine, la Zoologie, la Botanique, la Géologie, la Minéralogie, la Chimie, la Physique, etc. Chacune de ces figures doit porter le costume et les attributs voulus... Effet riche et sévère. Les tons d'acier, de feu, de nuit doivent dominer.

Nous avons déchiré les voiles du mystìre Dont se couvrait la Vérité :

Le feu dérorateur, l'onde, l'air et la terre Sont soumis à ta volonté.

$$
\text { *** }
$$

Les femmes ignorent les distances et ne savent pas mesurer le temps : leurs montres ne marchent jamais bien.

Par contre et pour plus de sûreté, quelques-unes mesurent chaque fois le diamètre du cercle et sa circonférence.

$$
\text { ** }
$$

La Physicienne, comédie en un acte et en vers, par M. de La Montagne, jouée au Théàtre-Français, le 16 mars 1786. On y a roulu fronder le ridicule d'une femme qui affiche la manie de la science physique, électrique, magnétique, etc.

Mesdames, malgré ros clameurs,

Votre savoir nous enchante.

Il s'embellit des sons flatteurs

De rotre voix touchante.

Vos talents doivent s'employer

Dans nos cours de physique :

Deux beaux yeux sont le vrai foyer

De la flamme électrique. 


$$
* *
$$

Une demoiselle n'augmentera point ses chances de remplir lit première loi de sa destinée et de se marier, si elle a remporté le prix de " physiologie animale ".

P. Stapfer. (Revue bleue du 5 octobre 1895.)

$$
\text { *** }
$$

0n organisera le mandarinat féminin à côté du mandarinat masculin. Ni hommes ni femmes : tous bacheliers !

Paul Lafite. Le paradoxe de l'égalité, p. 137.

$$
* * *
$$

Peut-il y avoir des académiciennes? Pas directement, sauf les disciples de Platon, les anciennes associées de l'Académie des Beaux-Irts et quelques femmes des Sociétés de province. Mais une femme en se mariant it un mem bre de l'Institut de Paris derient une académicienne.

$$
\text { *** }
$$

de ne me rappelle plus le nom de ce président de tribunal, demandant l'àge d'une dame et qui obtint cette réponse : "...ante ans, monsieur le président. " Ainsi avec les mots septante, octante, nonante, de trente à cent ans, on aurait toujours ....ante ans.

E. Lec.ss. Récréations mathématiques, t. $1 \mathrm{~T}, \mathrm{p} .22$.

$$
\text { *** }
$$

Le fantaisiste Anatole France prétend que le serpent tentateur était musicien et géomètre :

" ll intéressa nos premiers parents en formant devant eux arec son corps, des figures exactes, telles que le cercle, l'ellipse et la spirale, dont les propriétés ont été depuis reconnues par les Grecs. Mais quand le serpent, s'étant mis ì parler, enseigna les vérités plus hautes, celles qui ne se démontrent point, il reconnut qu’Adam, pétri de terre rouge, ćtait d'une nature trop épaisse pour percevoir ces subtiles connaissances." "

On sait qu'Ève comprit trop bien les sifflements du serpent.

$$
* *
$$

Le tétraèdre régulier est de tous les solides le plus paurre en faces, angles et arètes, et celui qui, sous un développenent donné de surface, contient le moins de substance.

Malgré cette paurreté, ou plutòt à cause de cette paurreté, il déconcerte l'œil, qui a peine à s'en rendre compte. Son aspect a quelque chose de menaçant. De quelque cùté qu'on l'aborde, on le trouve armé d'angles aigus et d'arètes tranchantes. Placé dans la position qui lui est propre, droit sur une arète, il ne peut s'y soutenir seul et il tombe. Sur quelque face qu'on le pose, la largeur de la base se 
trouvant toujours égale ì la hauteur du sommet, il s'établit largement, prend ses aises, pour ainsi dire; mais c'est un aplomb grossier et une aisance sans grìce.

Ses faces sont ígales et semblables; ses arètes égales et semblables; ses angles égaux et semblables. Et arec cela rien n'est d'arcord : tout se coupe, se heurte, se contre-carre. Faces et lignes ne se correspondent que dans leur mutuelle et réciproque hostilité. Le tétraèdre, pauvre de fond, tranchant de forme, exclusivement réduit à lui-mème, représente la plus exiguë, la plus étroite individualité.

D'une monotonie qui fatigue, d'une àjreté qui désole, c'est l'embryon le plus élémentaire, le plus borné de la stricte nature.

Mme Pape-Carpentier. 


\section{TABLE DES MATIÈRES}

Pages.

Dictionnaire des femmes dans la Science . . . . . . . . . . 1

Si la femme est capable de science . . . . . . . . . . . . 287

Menus propos sur les femmes et les sciences . . . . . . . . 321

Autographes : Agnesi : Lettre . . . . . . . . . . . 9

- Fac-simile des "Institutions analytiques" . . . 13

du Châtelet: Avant-propos des "Institutious de physique " et fac-simile du titre. . . . . . 62

Sophie Germain : Lettre à Gauss . . . . . . 118

Sophie Kowalevski : Lettre . . . . . . . . . 168

Mary Somerville : Lettre . . . . . . . . . . 268

Portraits : Agnesi . . . . . . . . . . . . . . . 5

Laure Bassi . . . . . . . . . . . . 29

Mrs Bryan et ses filles . . . . . . . . . . . 4 5

Imo du Chàtelet. . . . . . . . . . . . . 57

Christine de Suède et Descartes . . . . . . . . 71

Agnès-Yary Clerke . . . . . . . . . . . 7ว

Marguerite de Staal-Delaunay . . . . . . . . . 87

Elisabeth de Bohème, princesse palatine. . . . . . . 99

Sophie Germain . . . . . . . . . . . . 113

Caroline Herschel . . . . . . . . . . . 135

Sainte Hildegarde . . . . . . . . . . . . 139

Dorothée Klumpke . . . . . . . . . . . 155

Sophie Kowalevski . . . . . . . . . . . 161

Christine Ladd-Franklin. . . . . . . . . . . 171

Lavoisier et IIme Lavoisier. . . . . . . . . . 177

Hortense Lepaute . . . . . . . . . . 183

Marie-Sybille Mérian . . . . . . . . . . 205

Maria Nitchell . . . . . . . . . . . . . 209

Sophie Pereyaslawzewa. . . . . . . . . . . 22ว

Marie-Madeleine-Gabrielle de Rochechouart-Mortemart . . . 235

Clémence Royer . . . . . . . . . . . . 241

Mme de la Sablière . . . . . . . . . . . 245

Anne-IIarie de Schürman . . . . . . . . . 233

Charlotte Angas Scot . . . . . . . . . . . 257

Mary Somerville . . . . . . . . . . . . . 261

Bar-le-Duc. - Imp. Comte-Jacquet. Facdouel, Dir. 

$-$ 


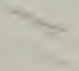





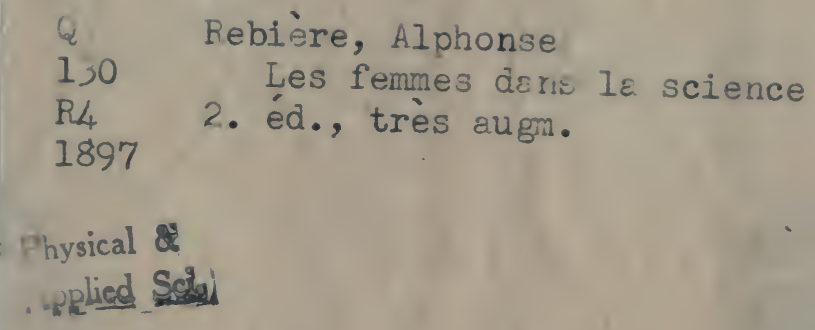


